University of Tennessee Health Science Center

UTHSC Digital Commons

\title{
Cost Burden of the 'Presenteeism' Health Outcome in a Diverse Nurse and Pharmacist Workforce: Practice Models and Health Policy Implications
}

Carol L. Warren

University of Tennessee Health Science Center

Follow this and additional works at: https://dc.uthsc.edu/dissertations

Part of the Health and Medical Administration Commons

\section{Recommended Citation}

Warren, Carol L. , "Cost Burden of the 'Presenteeism' Health Outcome in a Diverse Nurse and Pharmacist Workforce: Practice Models and Health Policy Implications" (2009). Theses and Dissertations (ETD). Paper 295. http://dx.doi.org/10.21007/etd.cghs.2009.0345. 


\title{
Cost Burden of the 'Presenteeism' Health Outcome in a Diverse Nurse and Pharmacist Workforce: Practice Models and Health Policy Implications
}

\begin{abstract}
The complex phenomenon of presenteeism is an undesirable health outcome that occurs when employees remain present on-the-job with lowered work productivity caused by personal health conditions. The cost burden of presenteeism in healthcare professionals has been under-explored and the cost burden of presenteeism across racial and ethnic minority employees has been un-explored. Aims of this research were to describe presenteeism and its cost burden among nurses and pharmacists and to determine distinctness of differences across racial/ethnic groups within these professions. In exploring presenteeism, the focus was on recognizing it, characterizing it, and measuring it. In monetizing presenteeism, its costs burden from the perspective of the employer was determined at the broader workforce level.

This analytical study entailed an on-line survey of a cross-sectional, convenience sample of 226 nurses and pharmacist stratified by race and ethnicity ( $23 \%$ minorities and $77 \%$ non-minorities). Wellness-atWork, a patient reported outcomes (PRO) tool that adopted presenteeism scales from two well established presenteeism surveys were administered. Contingency tables using Chi-square tests established association or differences by profession or race. Ordinal logistic regression modeled 12 predictors of presenteeism and the human capital approach determined cost burden.
\end{abstract}

Over half, $52.65 \%$, of the sample (226) reported experiencing presenteeism -- $47.06 \%$ nurses and $52.94 \%$ pharmacists. Mean rate of reported presenteeism was 13.2\%. Presenteeism was the driver of annual lost productivity valued at $\$ 12,700$ per nurse or pharmacist, a workforce value of $\$ 2.6$ million loss. The likelihood of presenteeism increased $22.4 \%$ if professionals suffered physical health symptoms, increased $22.5 \%$ if they suffered mental health conditions, decreased $34 \%$ if their physical and mental health conditions were never treated by pharmacotherapy, and decreased $29 \%$ if their mental or physical health conditions were previously treated by pharmacotherapy (but not currently treated). Both professions had significant self-reported mental health conditions and physical health symptoms. Physical health symptoms significantly associated with presenteeism were: feeling tired or no energy; back or neck pain; pain in arms, legs, joints; watery eyes, runny nose or stuffy head; trouble sleeping; headaches; muscle soreness; cough or sore throat; fever, chills, or other cold/flu; constipation, loose bowels, or diarrhea; and nausea, gas, or indigestion. Depression and anxiety were more prevalent conditions than the common cold or flu symptoms in these knowledge-based professions and mental health conditions were a significant predictor of presenteeism.

Rates of presenteeism between racial and ethnic non-minority and minority groups and rates between nurses and pharmacists were not found to be significantly different ( $p=.5774$ and $p=0.4282$ respectively). Of note is that rates of presenteeism for racial ethnic minorities were slightly lower than non-minorities, but not statistically significantly so. The imperative for individual health care employers was to address workforce cost burden by being the catalyst for developing creative practice models and changing health policies.

\section{Document Type}

Dissertation

Degree Name

Doctor of Philosophy (PhD) 


\section{Program}

Health Outcomes and Policy Research

Research Advisor

Shelley I. White-Means, PhD

\section{Keywords}

diverse workforce, health workforce, nurses, pharmacists, presenteeism, productivity

\section{Subject Categories}

Health and Medical Administration | Medicine and Health Sciences 


\title{
COST BURDEN OF THE 'PRESENTEEISM' HEALTH OUTCOME IN A DIVERSE NURSE AND PHARMACIST WORKFORCE: PRACTICE MODELS AND HEALTH POLICY IMPLICATIONS
}

\author{
A Dissertation \\ Presented for \\ The Graduate Studies Council \\ The University of Tennessee \\ Health Science Center
}

\author{
In Partial Fulfillment \\ Of the Requirements for the Degree \\ Doctor of Philosophy \\ From The University of Tennessee
}

By

Carol L. Warren

May 2009 
Copyright (C) 2009 by Carol L. Warren All rights reserved 


\section{DEDICATION}

This dissertation is dedicated to my mother, Carrie B. Lackland. Well into her $70^{\text {th }}$ decade, instead of full retirement, she chooses to remain a vibrant nurse working with needy children in the Memphis City School System. I am girded by her gifts of 'resilience to adversity' and 'strength of character.' I am molded by her fruits of prayers, discipline, and determination. Thank you Mama. 


\section{ACKNOWLEDGMENTS}

I express my deepest gratitude to my research advisor, Dr. Shelley I. WhiteMeans. She supplied wisdom, encouragement, and expertise that I will eternally be grateful to have received. The remaining members of my committee: Dr. Cyril Chang, Dr. Dick Gourley, Dr. Muriel Rice and Dr. Mona Wicks helped shape my work in major ways. I appreciate the extra efforts they extended and have no doubt that their pointed questions and challenges made this research a richer endeavor. Also, Dr. Davis Mirvis provided early advisement and a solid foundation in health policy for which I vow to always have part of my research career.

I am also thankful for the support of my family, close friends and support system. My children, Deah Brittny Warren and David Bernard Warren, Jr., are my proudest accomplishment. The vision of the smile on their faces as I leave them this legacy is what sustained my motivation. I acknowledge the fantastic sister friends of Ashante Literary Guild, church members, and my friend/pastor Denise Bell. My God son, Michael, and his sister mom, Patryce Steele and are on my permanent list of thanks for understanding my unavailability. I am blessed to have friends and family who support me and made all the difference in enduring this scholarly journey.

I would also like to acknowledge the help of Zhiyong Dong for SAS ${ }^{\circledR}$ consultations, time, and patience. Moreover, because I have always worked full-time while completing this dissertation, I want to express my gratitude to my past employer, the College of Nursing at the University of Tennessee Health Science Center, and to my current employer Clinical Neuroscience Solutions, Inc. (CNS Healthcare). CNS executives Dr. Scott West, Dan Kearney and Terrie Woods have been supportive of my scholarship and I am indebted to them for their understanding. The CNS Memphis Team and a host of other colleagues have made this journey lighter because of their willingness to get the job done. Also, many nurses in the College of Nursing, particularly Dr. Margaret Hartig, and Dr. Patricia Cunningham never hesitated share ideas and innovations. My gratitude to Dean Donna Hathaway for supplying my first article on presenteeism and sharing resources from the Institute of Health and Productivity Management (IHPM) conference that helped me formulate my conceptualizations around a dissertation on presenteeism.

It hardly seems it has been over half a decade ago that Dr. Belinda Fleming and I decided to embark on the PhD journey. Belinda was instrumental in my 'staying the course' and for that I will be eternally grateful. We keep asking each other, what's next!

Lastly, the following former or current doctoral students at the University of Tennessee Health Science Center have been fantastic in volunteering to help wherever they could, thank you for your support, encouragement, and sharing: Drs. Lois Bolden, Dr. Cheryl DeWood; Dr. Meghan Hufstader; Dr. Brandy Everett; Dr. LaMarcus Wingate; Dr. Joyce Addo-Atua, Dr.Varun Vaidya, Dr. Sarah Hurley, and Dr. Lawrence Brown. 


\begin{abstract}
The complex phenomenon of presenteeism is an undesirable health outcome that occurs when employees remain present on-the-job with lowered work productivity caused by personal health conditions. The cost burden of presenteeism in healthcare professionals has been under-explored and the cost burden of presenteeism across racial and ethnic minority employees has been un-explored. Aims of this research were to describe presenteeism and its cost burden among nurses and pharmacists and to determine distinctness of differences across racial/ethnic groups within these professions. In exploring presenteeism, the focus was on recognizing it, characterizing it, and measuring it. In monetizing presenteeism, its costs burden from the perspective of the employer was determined at the broader workforce level.
\end{abstract}

This analytical study entailed an on-line survey of a cross-sectional, convenience sample of 226 nurses and pharmacist stratified by race and ethnicity (23\% minorities and $77 \%$ non-minorities). Wellness-at-Work, a patient reported outcomes (PRO) tool that adopted presenteeism scales from two well established presenteeism surveys were administered. Contingency tables using Chi-square tests established association or differences by profession or race. Ordinal logistic regression modeled 12 predictors of presenteeism and the human capital approach determined cost burden.

Over half, 52.65\%, of the sample (226) reported experiencing presenteeism -$47.06 \%$ nurses and $52.94 \%$ pharmacists. Mean rate of reported presenteeism was $13.2 \%$. Presenteeism was the driver of annual lost productivity valued at $\$ 12,700$ per nurse or pharmacist, a workforce value of $\$ 2.6$ million loss. The likelihood of presenteeism increased $22.4 \%$ if professionals suffered physical health symptoms, increased $22.5 \%$ if they suffered mental health conditions, decreased $34 \%$ if their physical and mental health conditions were never treated by pharmacotherapy, and decreased $29 \%$ if their mental or physical health conditions were previously treated by pharmacotherapy (but not currently treated). Both professions had significant self-reported mental health conditions and physical health symptoms. Physical health symptoms significantly associated with presenteeism were: feeling tired or no energy; back or neck pain; pain in arms, legs, joints; watery eyes, runny nose or stuffy head; trouble sleeping; headaches; muscle soreness; cough or sore throat; fever, chills, or other cold/flu; constipation, loose bowels, or diarrhea; and nausea, gas, or indigestion. Depression and anxiety were more prevalent conditions than the common cold or flu symptoms in these knowledge-based professions and mental health conditions were a significant predictor of presenteeism.

Rates of presenteeism between racial and ethnic non-minority and minority groups and rates between nurses and pharmacists were not found to be significantly different ( $\mathrm{p}=.5774$ and $\mathrm{p}=0.4282$ respectively). Of note is that rates of presenteeism for racial ethnic minorities were slightly lower than non-minorities, but not statistically significantly so. The imperative for individual health care employers was to address workforce cost burden by being the catalyst for developing creative practice models and changing health policies. 


\section{TABLE OF CONTENTS}

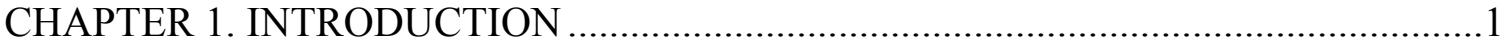

Description of the Problem ................................................................................ 1

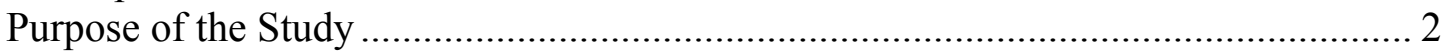

Specific Aims and Research Questions ………………............................................ 3

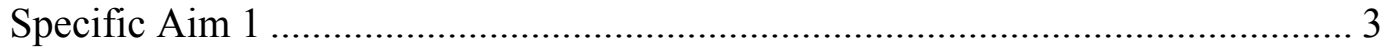

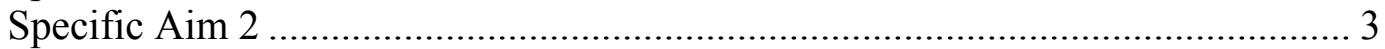

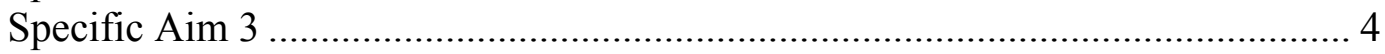

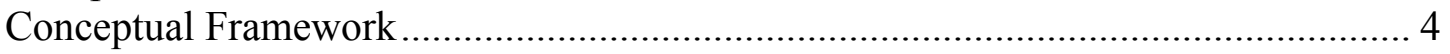

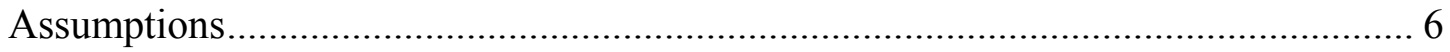

Concepts and Questions ................................................................................. 8

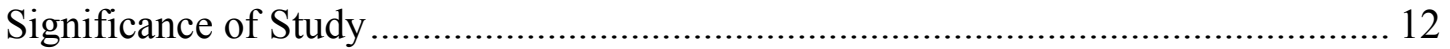

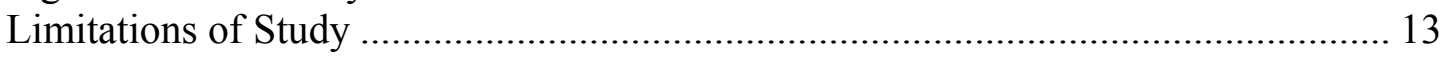

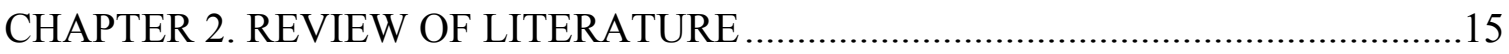

Historical Perspective of Presenteesism ................................................................ 15

Determinants of Presenteeism............................................................................. 17

Demographics and Prevalence.......................................................................... 17

Health Symptoms and Health Risks ……………............................................... 18

Physical Health Conditions ............................................................................ 20

Mental Health Conditions ........................................................................... 23

Pharmacotherapy and Presenteeism ............................................................... 24

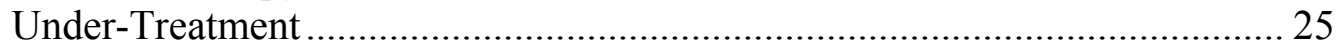

Presenteeism and Costs...................................................................................... 27

Contrast Medical, Pharmacy, Absenteeism and Presenteeism Costs ................... 27

Cost Burden of Highly Prevalent Conditions ..................................................... 30

Presenteeism and the Healthcare Workforce ……………......................................... 33

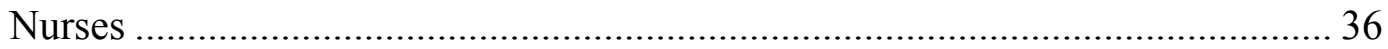

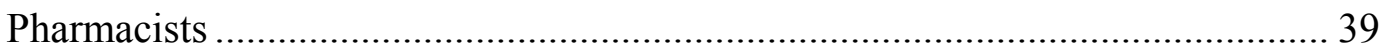

Presenteeism and a Diverse Workforce ………………….................................... 43

Summary of Literature Review............................................................................. 48

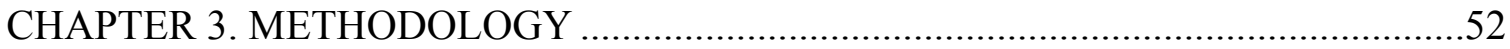

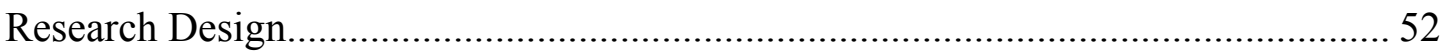

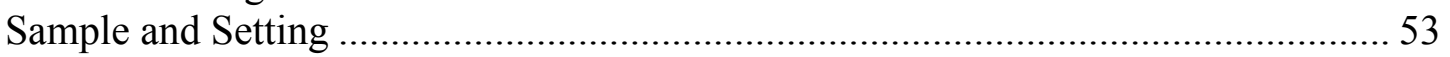

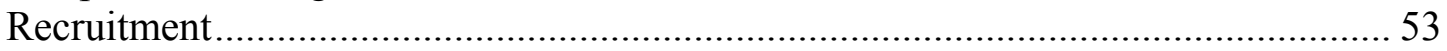

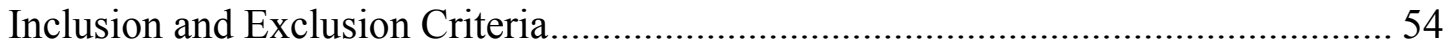

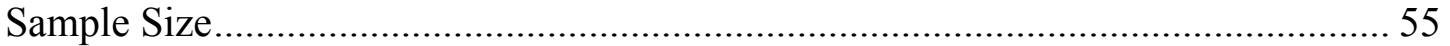

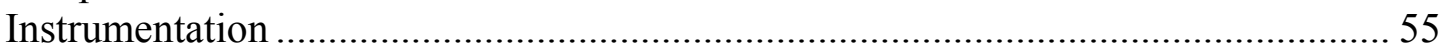

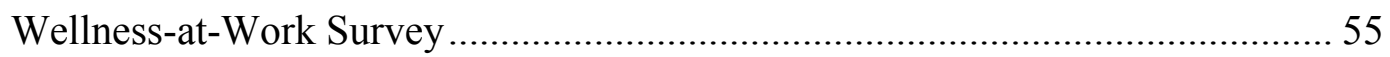

The Health and Productivity Questionnaire.......................................................... 56

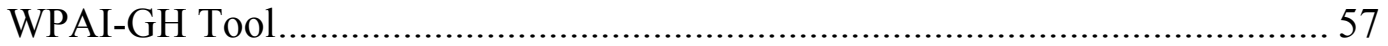

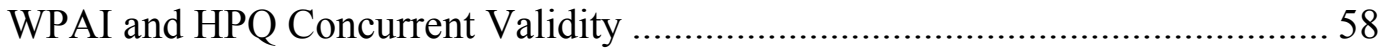

Data Collection Procedures............................................................................... 58

Consideration of Human Subjects .......................................................................... 59 


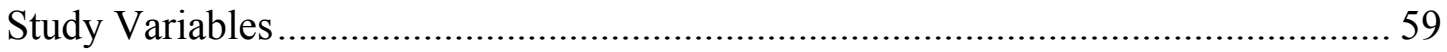

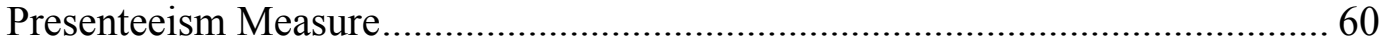

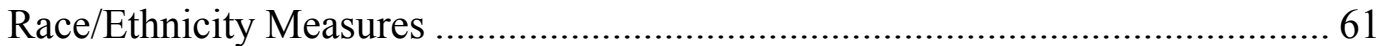

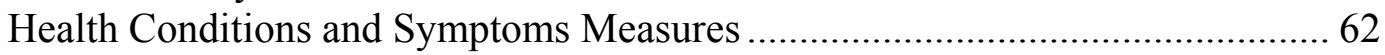

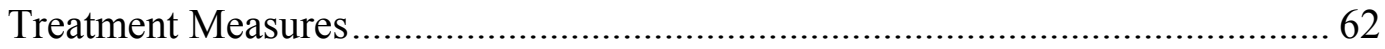

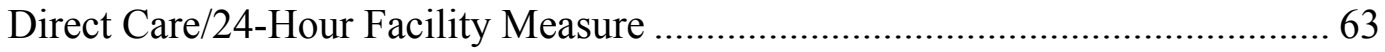

Monitizing Presenteeism and Calculating Cost Burden .............................................. 63

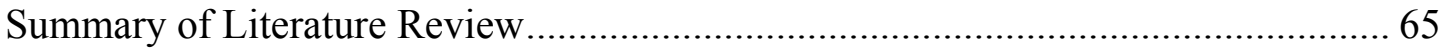

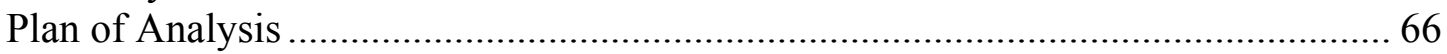

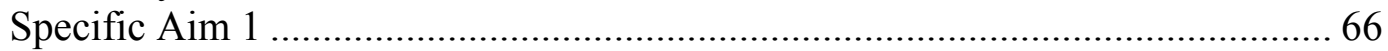

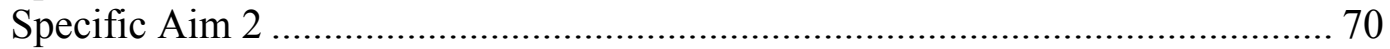

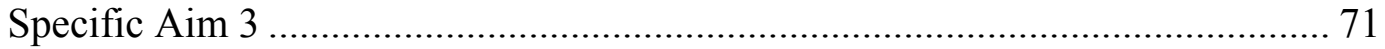

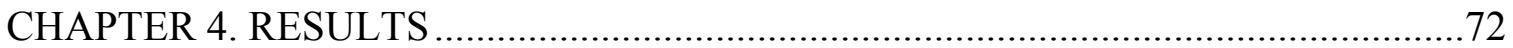

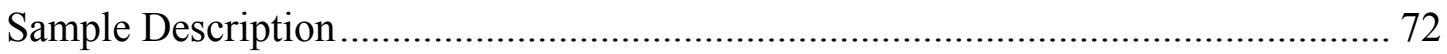

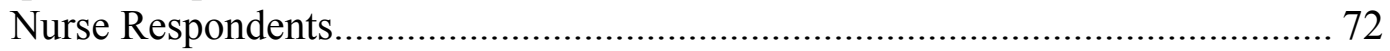

Pharmacist Respondents ……………………………................................. 74

Summary of Key Demographics..................................................................... 75

Health Conditions of Total Sample ................................................................... 77

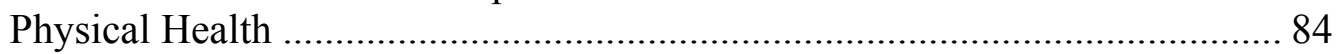

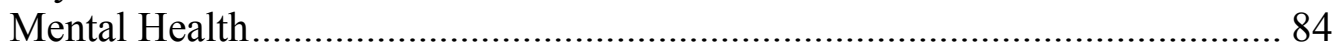

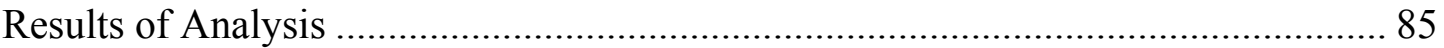

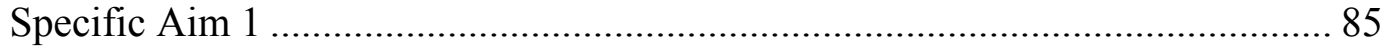

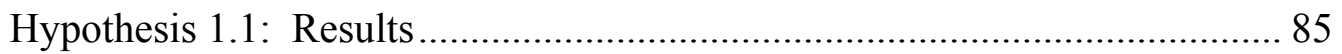

Hypothesis 1.1: Conclusions..................................................................... 90

Hypothesis 1.2: Results........................................................................... 90

Hypothesis 1.2: Conclusions.................................................................. 99

Hypothesis 1.3: Results......................................................................... 99

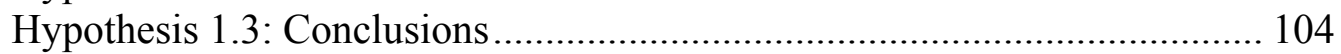

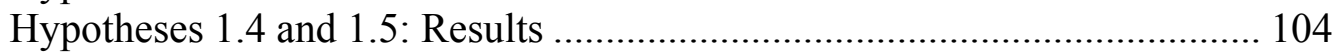

Hypotheses 1.4 and 1.5: Conclusions ....................................................... 106

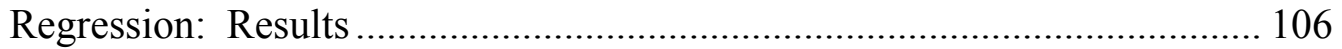

Regression: Conclusions .................................................................... 115

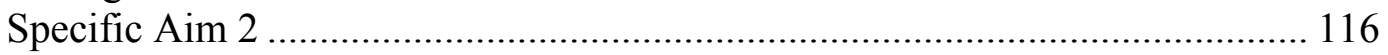

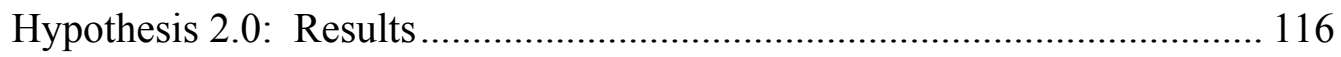

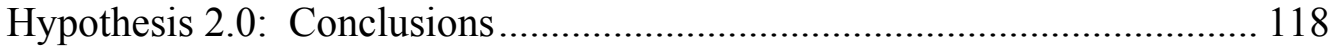

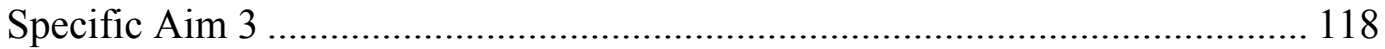

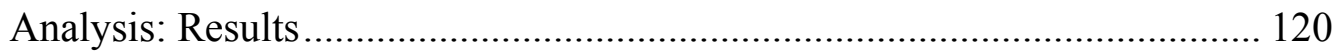

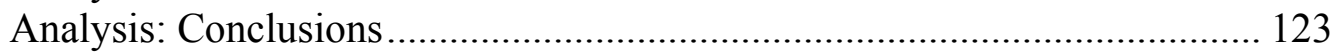

Conclusions and Implications .................................................................. 124

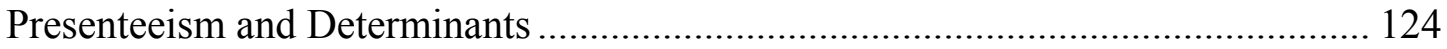

Distinctness of Presenteeism among Racial/Ethnic Groups .................................... 125

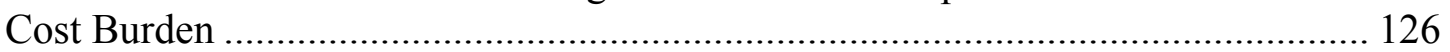

Unexpected Findings and Recommendaton for Future Research............................ 128

Practice Models and Policy Strategies to Address Key Determinants ..................... 130

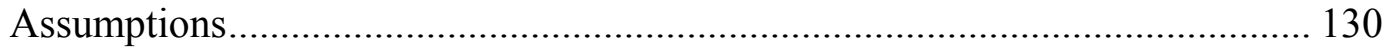

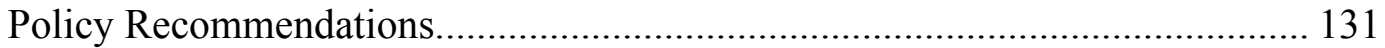


Transform Employee Assistance Programs (EAPs) .................................... 131

Revisit Benefits Financing Strategies .................................................... 131

Provide Worksite Based Ergonomics and Rehabilitative Services............... 131

Revise Worksite Time-Off Policies ........................................................... 132

Include Presenteeism Measures in Employee Wellness Assessments ........... 132

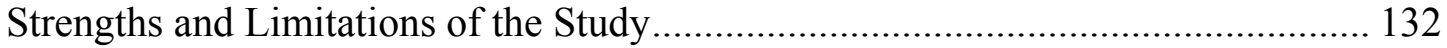

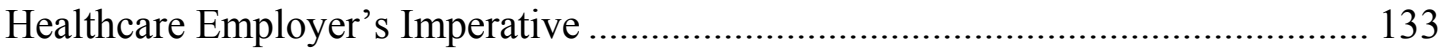

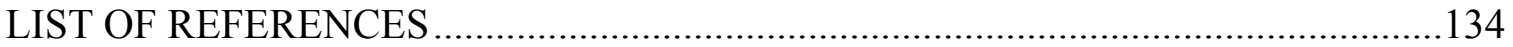

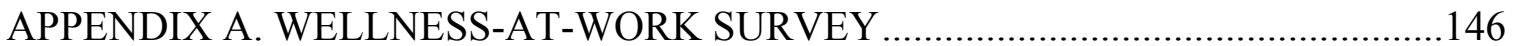

APPENDIX B. SURVEY TOOL LOGIC CROSSWALK ............................................. 162

APPENDIX C. INSTITUTIONAL REVIEW BOARD APPROVAL ...........................166

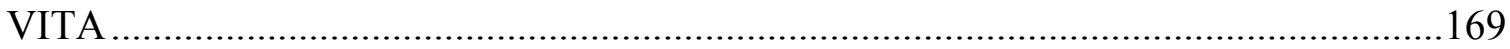




\section{LIST OF TABLES}

Table 2-1. Prevalence of Health Conditions Associated with Presenteeism from Multiple Sources and Occupations .......................................................22

Table 2-2. Summary of Key Presenteeism Studies: Determinants of Presenteeism .28

Table 2-3. Rank Order of Top Ten Cost Driving Health Conditions from Four Employers

Table 2-4. Summary of Key Presenteeism Studies: Presenteeism and Costs .34

Table 2-5. Summary of Key Presenteeism Related Studies: Presenteeism and Healthcare Workforce

Table 2-6. Summary of Key Presenteeism Related Studies: Presenteeism and Diverse Workforce.

Table 4-1. Income Categories by Profession and Race/Ethnicity ...............................76

Table 4-2. Demographics Entire Sample of Nurse and Pharmacist Respondents..........78

Table 4-3. Rank Order Physical Health Conditions by Profession and Race/Ethnicity Entire Sample....

Table 4-4. Rank Order Mental Health Conditions by Profession and Race/Ethnicity Total Sample

Table 4-5. WPAI B14 and HPQ B13 Presenteeism Scales Correlation........................86

Table 4-6. $\quad$ WPAI B14 Scale and HPQ B10 Priming Question Correlation ...................86

Table 4-7. Differences in Presenteeism by Profession across Race/Ethnicity ...............87

Table 4-8. Levels of Presenteeism by Profession and Race/Ethnicity .........................89

Table 4-9. $\quad$ Prevalence of Individual Physical Health Conditions in Nurses and Pharmacists with Presenteeism.

Table 4-10. Presenteeism and Physical Health Symptoms: Differences by Profession and Race/Ethnicity

Table 4-11. Grouped Physical Health Conditions and Symptoms Associated with Presenteeism by Profession and Race/Ethnicity

Table 4-12. Prevalence of Mental Health Conditions in Nurses and Pharmacists with Presenteeism 100 
Table 4-13. Presenteeism and Individual Mental Health Symptoms: Differences by Profession and Race/Ethnicity

Table 4-14. Grouped Mental Health Conditions and Symptoms Associated with Presenteeism by Profession and Race/Ethnicity

Table 4-15. Presenteeism Associated with Provision of Treatment of Health Conditions

Table 4-16. Ordered Logistic Regression: Response Profile ............................................108

Table 4-17. Ordered Logistic Regression: Model Fit Statistics ......................................108

Table 4-18. Ordered Logistic Regression: Testing Global Null Hypothesis: $\mathrm{BETA}=0$

Table 4-19. Logistic Model Predictive Probabilities \& Observed Responses

Table 4-20. Logistic Regression: Maximum Likelihood Estimates of Independent Variables Predicting Presenteeism.

Table 4-21. Health Factors Interacting with Race/Ethnicity.

Table 4-22. Health Factors Interacting with Specialty Profession

Table 4-23. Marginal Effects of Model for Predictor Variables on Presenteeism at Lower Levels.

Table 4-24. Marginal Effects of Model for Predictor Variables on Presenteeism at Higher Levels

Table 4-25. Workforce Presenteeism and Cost Burden for Nurse and Pharmacist Workforce

Table 4-26. Comparison of Cost Means across Professions and Race/Ethnicity......

Table 4-27. Top 10 Conditions Associated with Presenteeism: Previous Research Compared to Current Study 


\section{CHAPTER 1. INTRODUCTION}

\section{Description of the Problem}

The complex phenomenon of presenteeism is an undesirable health outcome that occurs when employees remain 'present' on-the-job with lowered work productivity caused by personal health conditions (Goetzel, et al., 2004; Kessler \& Stang, 2006; Stewart, Ricci, Chee, \& Morganstein, 2003a). The study of presenteeism is in its infancy, and while the cost burden of presenteeism in all employed populations has been underexplored; the occurrence and cost burden of presenteeism across racial and ethnic minority employees has been un-explored. Given current population projections, by 2050 it is likely that nearly $50 \%$ of the US labor force will be composed of racial and ethnic minorities (Bureau of Labor Statistics, 2007; Kaiser Family Foundation, 2007). This demographic trend, combined with the fact that racial and ethnic minorities have historically experienced unequal burdens in disease morbidity and mortality, suggests that differences in cost burden of health-related productivity among racial and ethnic employees should be explored (Agency for Healthcare Research and Quality, 2006; Kaiser Family Foundation, 2007; Smedley, Stitch, \& Nelson, 2003). A review of published literature indicates there is a void in health-related productivity research that describes whether there are differences in presenteeism across racial/ethnic groups. Such a void in empirical data leaves unanswered questions about whether such differences should be part of the discourse on presenteeism within the emerging field of health and work productivity research. Greater insight into these factors will have implications for productivity research as well as disparities research.

The U.S. Department of Labor projects that, between the years 2002 and 2012, nearly half of the twenty fastest growing occupations will be in health care (Bureau of Labor Statistics, 2007; Kessler \& Stang, 2006). In both 2000 and 2001, the World Health Organization emphasized that the health workforce was the most important of all health system inputs (World Health Organization, 2001). From a macro perspective, the phenomenon of presenteeism becomes visible, though not easily measured, in the form of reduced quantity and quality of work production (Stewart, et al., 2003a). Despite the obvious importance of healthy employees on an intuitive level, few employers (including healthcare employers) capture and document costs of and impact of health conditions that cause their employees to perform sub-optimally (Goetzel, et al., 2004; Stewart, et al., 2003a). This means that data on untreated health conditions that impact work productivity are often non-existent (Kessler \& Stang, 2006). Additionally, data on health conditions that may have been previously treated but continue to negatively impact work (called under-treated), are equally scarce (Kessler \& Stang, 2006). Therefore, in the absence of separate analyses to determine whether impairments in work productivity are associated with health conditions that are untreated or under-treated, it has proven challenging to determine whether low rates of treatment should be considered a problem from the perspective of the employer (Kessler, et al., 2003). In light of the current widely documented shortages in the nursing and pharmacy workforces and the underrepresentation of ethnic and racial minorities within these workforces (Agency for Healthcare Research and Quality, 2004), it is unknown whether personal health 
conditions experienced by nurses and pharmacists could be impacting the production by these workforces and the diversity among them. Moreover, since employees of these workforces are considered knowledge-based jobs, insight into the cost burden of presenteeism among diverse knowledge-based professionals is an important area in which a knowledge gap exists.

Since 1940 American businesses have played a major role in providing employee health benefits. This role peaked in the 1990's when businesses supplied approximately $90 \%$ of the workforce benefits. More recently, even with coverage dwindling to about $60 \%$ of the workforce, American businesses are concerned about the cost impact of employee health benefits on global economic positioning (Loeppke, et al., 2007). From an economic perspective, presenteeism is believed to be the missing component in the equation of workforce costs drivers. In this equation of costs drivers, both presenteeism and absenteeism are considered drivers of indirect medical costs; while medical claims, pharmacy claims, and health insurance are considered drivers of direct medical costs (Burton, Conti, Chen, Schultz, \& Edington, 1999). Costs of decreased productivity are expected to vary by occupation and industry in the US; however, population level research suggests that presenteeism can represent from $18 \%$ to $60 \%$ of a company's total health dollars (Goetzel, et al., 2004). Presenteeism was estimated to amount to $\$ 2$ to $\$ 3$ for every $\$ 1$ spent by employers on medical costs, surpassing both direct medical, pharmacy, and disability costs (Goetzel, et al., 2004; Stewart, et al., 2003a). Moreover, for every one day an employee in the US workforce was absent due to health conditions, it was estimated that 2.4 days were lost from reduced work performance (presenteeism) while on the job (Stewart, et al., 2003a).

\section{Purpose of the Study}

The purposes of this study are to describe and monetize presenteeism in a racially and ethnic diverse nurses and pharmacists and to identify implications for practice delivery systems and health policies. In exploring presenteeism, the focus will be on recognizing it, characterizing it, and measuring it. In monetizing presenteeism, its costs burden from the perspective of the employer/payer will be determined at the population level.

The premise of this research is that when employers/payers recognize, characterize, measure, and monetize additional business value from healthy workers through better productivity, it expands the value of all employees' health, including health of racial/ethnic minorities who have historically proven to be more at risk for negative health outcomes (Laviest, 2005). This anticipated increased appreciation for employees' business value, specifically the value of health care knowledge-based employees such as nurses and pharmacists, could potentially add to the business cases for addressing disparate health outcomes that can impact work productivity across racial and ethnic groups. Findings from the study are expected to have implications for policies affecting health cost, practice delivery systems and health policies that U.S. employers have considerable influence in shaping. 


\section{Specific Aims and Research Questions}

The following are the three specific aims of this research, the three research questions designed to address the aims, and for aims 1 and aims 2 , the hypotheses about the anticipated results.

\section{Specific Aim 1}

Specific aim 1 was to describe presenteeism, its prevalence, associated health conditions and treatment in employed nurses and pharmacists and indicate whether there are differences across racial/ethnic groups. The research question that was used to address this aim was 'what is the prevalence of presenteeism, its associated health conditions and extent of treatment among nurses and pharmacists; and, do these vary across racial/ethnic groups?' The following hypotheses predict the answers to this research question.

- $\quad$ Hypothesis 1.1 - There are no differences in presenteeism among nurses and pharmacists nor does it vary across racial/ethnic groups of both professions.

- Hypothesis 1.2- Health conditions characterized as physical health conditions are more associated with presenteeism among racial/ethnic minority groups versus non-minority groups of nurses and pharmacists.

- $\quad$ Hypothesis 1.3-Health conditions characterized as mental health conditions are more associated with presenteeism among non-minority versus minority racial/ethnic groups of nurses and pharmacists.

- $\quad$ Hypothesis 1.4-Under-treated health conditions are associated with presenteeism in both nurses and pharmacists and it varies across racial/ethnic groups.

- $\quad$ Hypothesis 1.5 - Health conditions treated by providers are more associated with presenteeism than conditions treated by pharmacotherapy and this does not vary across profession or racial/ethnic groups.

\section{Specific Aim 2}

Specific aim 2 was to quantify, from the employer's perspective, the indirect cost of presenteeism in nurses and pharmacists and determine whether the indirect costs vary across racial/ethnic groups. The research question that addressed this aim was 'what is the indirect cost burden of presenteeism among nurses and pharmacists and does it vary across racial/ethnic groups?' The hypothesis that was predicted to address this question was 'there are no differences in the indirect cost burden of presenteeism among nurses and pharmacists across racial/ethnic groups of both professions.' 


\section{Specific Aim 3}

Specific aim 3 was to examine the cost burden and policy implications of presenteeism in a diverse healthcare workforce of nurses and pharmacist. This aim was reflected in the research question 'what are cost and health policy implications that could address key determinants of presenteeism among a diverse workforce of nurses and pharmacist?'

\section{Conceptual Framework}

This investigator created a conceptual framework for this research in order to provide a clear view of the relationships and structure for the concepts of interest (Polit \& Beck, 2004). This framework is from the employer's perspective and is a synthesis of concepts from the disciplines of economics, business, health, behavioral health, and social science. The conceptual model for this research is called "Presenteeism as HealthDriven Economic Burden," shortened to the 'presenteeism model' throughout this study. It includes concepts from the Determinants of Health (McGinnis, Williams-Russo, \& Knickman, 2002), Health Capital Theory (Grossman \& Banaji, 1992), Salutogenesis Model (Antonovsky, 1990) and the Human Capital Theory (Santerre \& Neun, 2004). The presenteeism model is illustrated in Figure 1-1.

The conceptual model for this research embraced the Determinants of Health framework of McGinnis et al. (2002) that recognized individuals possess five domains or determinants of health: genetic predispositions, social circumstances, environmental conditions, behavioral patterns, and medical care. This research considers these domains inclusive of worker's ethnic and racial status. In the presenteeism model, this investigator proposed that individuals who possessed overall 'positive' determinants of health were recognized and hired by employers as 'good health commodities' (Berger, Howell, Nicholson, \& Shardra, 2003b; Grossman \& Banaji, 1992). These acquisitions of employees as 'good health commodities' across all racial ethnic groups were consistent with the Health Capital Theory in economics that indicated that good health was an attractive value that employers actively sought in employees (Berger, et al., 2003b; Grossman \& Banaji, 1992). However, as biologically functioning humans, employees would inevitably experience both naturally (e.g. aging) and non-naturally occurring (e.g. disease, disorders, and injuries) personal mental or physical health conditions. Realizing this, employers sought to maintain or recapture the value of their 'good health commodities' by investing in their employees (Berger, et al., 2003b). Such investments in employees are part of Human Capital economic theories that suggest that employers 'invest' in employees to maintain them as good health commodities (Berger, et al., 2003b; Santerre \& Neun, 2004). The major investment strategies employers have historically used to impact employee health were to provide employee medical/health benefits and to implement workplace health/safety policies and practices (Berger, et al., 2003b; Davies, 2007). The best of these investments were purported to be supplied by larger self-insured employers who could afford to provide 'value in healthcare' through more comprehensive services called 'integrated employee health benefits management(Integrated Benefits Institute, n.d.; Kessler \& Stang, 2006).Consistent with 


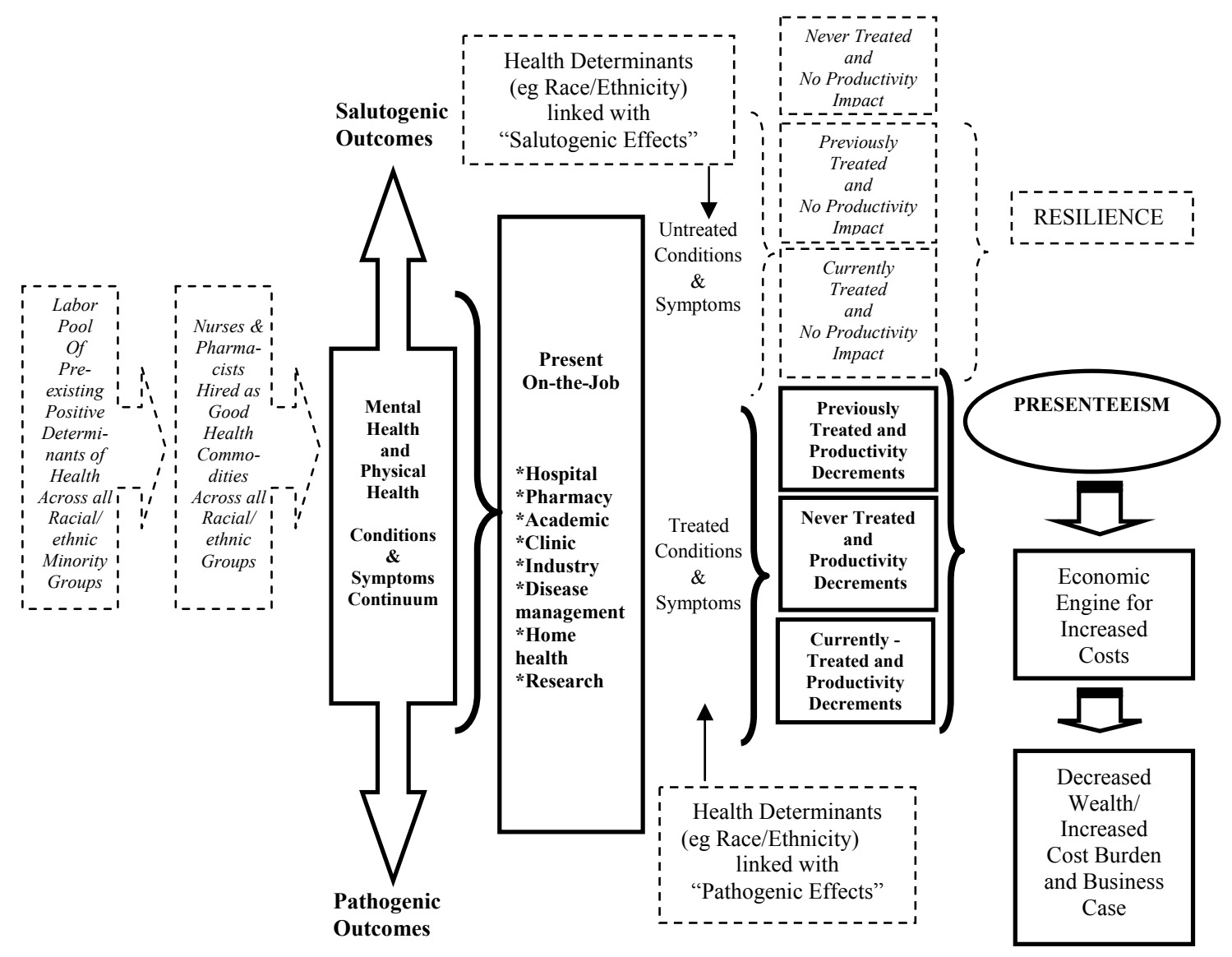

Figure 1-1. Conceptual Model: Presenteeism as Health Driven Economic Engine . . _ . Variables for contextual perspective in dotted line and are not part of current study

Study variables are in solid black 
Antonovsky's (1990) Salutogenic model, this researcher's conceptualization recognized that employees may not always experience negative health outcomes as a consequence of pathogenic health conditions. The model developed for this research by this investigator, as shown in Figure 1-2, allowed for the fact that employees may either have experienced what this investigator labeled 'pathogenic effects' that helped, or 'salutogenic effects' that hindered the occurrences of health/illnesses. When 'salutogenic effects' occurred in the presence of pathogenic conditions and the pathogenesis is mediated or eliminated; the result was labeled 'resilience.' The end points were considered to be positive health outcomes. Conversely, when 'pathogenic effects' occurred in the presence of pathogenic conditions, the pathogenic conditions were actualized; the result was illness or health conditions. The end points were considered to be negative health outcomes. In this model, the health outcomes progressed to impact work and facilitated the presenteeism health outcome that impacted health and wealth.

If the terms 'pathogenic effects' and 'salutogenic effects,' as defined in this framework, were applied consistent with historical characterizations of the relatively poor health outcomes for minority race/ethnicity groups; the label of minority race and ethnicity groups would equate to 'pathogenic effects.' This model shows that race/ethnicity can be on a continuum toward either 'salutogenic or pathogenic effects,' depending on the other health determinants impacting the employee as described by McGinnis et al. This was meant to illustrate that negative health outcomes were not assumed inherent to the category of race or ethnicity; but can be impacted by what occurs pathogenically or salutogenically.

Combining these constructs together, the model in Figure 1-2 sought to show that when presenteeism occurred, it was a negative health outcome driving the economic engine that led to decreased wealth. Although this study is from the employer's perspective, and the model focused on decreased employer wealth (business profits); presenteeism as a health driven economic engine can have broader wealth impact. For example, it can negatively impact wealth of employees (wages, promotions and career advancement), of the public (tax revenue base) and/or society (decreased industry and global competition) (Brach \& Fraser, 2002; Stewart, et al., 2003a). However, in the case of the influential employer market, the presenteeism model assumes negative health outcomes supply the economic business case to drive fair distribution of health policies and benefits. In this way, all employees benefit from broader health system changes and practices which are consistent with a goal of maintaining a stock of healthy human capital.

\section{Assumptions}

This study was conducted with the following four assumptions:

1. Employers invest in health expenditures for 'all employees;' including racial/ethnic minorities and they expect equal value in health care for 


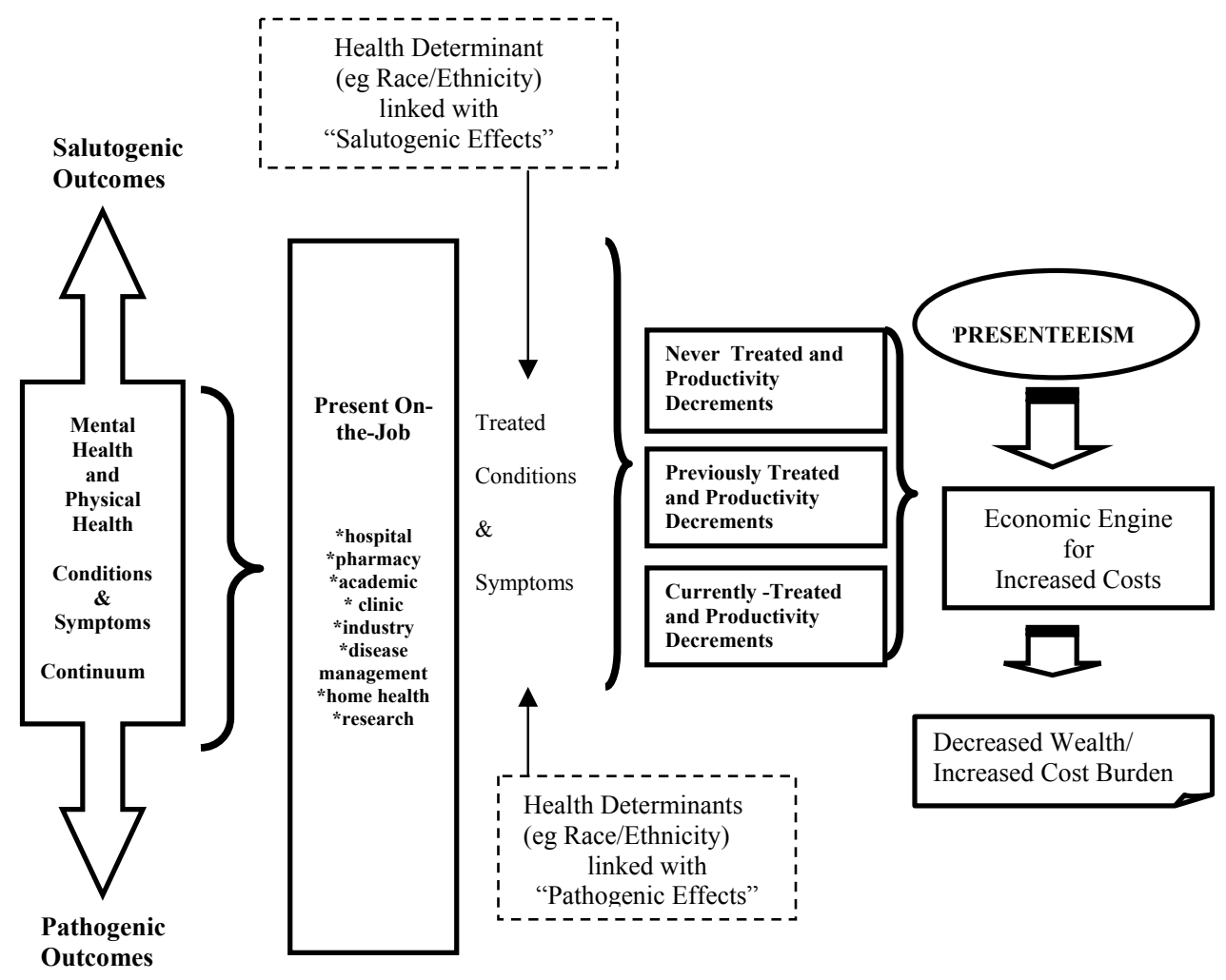

Figure 1-2. Conceptual Model of Study Variables: Presenteeism as Health Driven Economic Engine

Study variables in solid black 
equal dollars expended on each of their employees (Brach \& Fraser, 2002; National Business Group on Health, 2003).

2. Most employees do not take their jobs lightly and therefore, they want to continue working when they can (Hemp, 2004). This assumption is supported by many employee surveys conducted over time by the National Study of the Changing Workforce through the Family and Work Institute (Galinsky, et al., 2005).

3. Employees expect to share in profits and rewards that are experienced by their employers. Employees expect higher wages and job stability when their employers are able to provide it (Berger, et al., 2003b; National Business Group on Health, 2003).

4. Employers, as a matter of practicing sound and classic business management principles, choose to do business with certain suppliers and affiliates whom they expect provide services and products that are aligned with their (employer) business goals (Kerr, 1995). Kerr's contribution to the business world uses the phrase, "it's the reward system stupid" and is considered a 'business classic.' Using Kerr's logic and the application of this principle directly to healthcare of Berger et al.(2003b), employers desire vendors to provide health care services to employees that facilitate the employer meeting business goals. It is therefore reasoned to likely be an unintended consequence that employers often reward (pay for healthcare services) health service providers/vendors/suppliers who are not aligned to deliver positive health outcomes for all their employees (Berger, et al., 2003b; Kerr, 1995).

\section{Concepts and Questions}

The following concepts and definitions are used in this research.

- $\quad$ Productivity. From the field of economics, productivity is the numeric cost ratio of final product outputs to inputs (Crown, 2000; Moody, 2004). According to the Institute of Health and Productivity Management (IHPM), productivity in humans reflects a continuum of performance that extends beyond the absolute boundaries of incident-based definitions or mechanical performance (Institute for Health and Productivity Management., n.d.). IHPM (n.d.) sees that 'softer' factors like morale, autonomy, and team dynamics/processes have mental, motivational, emotional and social influences, which also affect productivity as much as physical and functional capacity.

- $\quad$ Presenteeism. A health outcome that occurs when employees remain 'present' on-the job with lowered work productivity caused by personal 
health conditions (Goetzel, et al., 2004; Kessler, et al., 2003; Stewart, et al., 2003a).

- Racial and ethnic minority groups. Hispanics (12.5\%), not including those living in Puerto Rico, are the largest growing minority group and are identified by the census as an ethnic and not a racial group. According to the 2000 Census, America is composed of the following minority groups African-Americans (12.9\%), Asians (4.2\%), Pacific Islanders/Hawaiian $(0.3 \%)$, and American Indian/Alaska Natives (0.7\%) (Agency for Healthcare Research and Quality, 2006; Kaiser Family Foundation, 2007).

- $\quad$ Race and ethnicity measures. In this study, race and ethnicity were viewed as concepts beyond the usual demographic factors that interact with other variables of concern on socioeconomic status variables, such as income, education or health insurance levels (Agency for Healthcare Research and Quality, 2004; White-Means, 1995). From this perspective, race is a 'holistic or composite' measure that included socioeconomic status, cultural interactions, psychological attitudes, as well as genetically influenced incidences of disease (White-Means, 1995). Therefore, in this study, race and ethnicity is one holistic measure or composite variable, conceptually included in the broad category of 'determinants of health' (McGinnis, et al., 2002).

- Health conditions. Health conditions referred to both acute and chronic illnesses and common health risks. It included both physical or mental signs and symptoms of ill health, or common health risks. The following health conditions were among the most commonly examined in healthrelated productivity research: arthritis, back or neck pain, musculoskeletal disorder, migraine, severe or frequent headache, chronic pain, hypertension, heart disease, high cholesterol, stomach or intestinal ulcer, gastrointestinal problem, allergies, asthma, respiratory or lung problem, urinary or bladder problem, diabetes, obesity, sleep problem, chronic fatigue/low energy, cancer, anxiety, depression, other emotional problem, or substance use problems (Kessler, et al., 2003).

- Treatment. A broad term used in this research to refer to a wide range of treatments that include pharmacotherapy, medical treatment, and other health services that address the alleviation of health conditions and health symptoms.

- Under-treatment. Previous treatment of health conditions that does not result in resolution of health conditions, such that such conditions continue to negatively impact work (Kessler \& Stang, 2006).

- Determinants of health. The concepts of 'determinants of health' are terms influenced by research of McGinnis, Williams-Russo and Knickman with the Robert Wood Johnson Foundation (McGinnis, et al., 2002). 
Their extensive insight provided five domains that composed determinants of health. Their research allowed them to attach an estimate of each domain's percentage of influence on total population health. The percentages were as follows: behavioral choices and patterns $(40 \%)$, genetic and gestational endowments (30\%), social circumstances $(15 \%)$, medical care $(10 \%)$ and environmental exposures $(5 \%)$ (McGinnis, et al., 2002).

- $\quad$ Health capital theory or 'good health' commodities. Consistent with Grossman's model, employees who enter the market starting with the commodity of 'good health' can be viewed as a durable capital stock that produces output of healthy work time (Grossman \& Banaji, 1992). According to Grossman, it is a commodity sought after by every individual and health can be maintained by investment in health-related activities such as preventive care, exercise, health care, etc. (Berger, Bingelors, Hedblom, Pashos, \& Torrance, 2003a; Grossman \& Banaji, 1992).

- Human capital approach (HCA). With the human capital approach, the economic value of life was equal to the market value of the output produced during a person's expected lifetime (Santerre \& Neun, 2004). Only assets that increased the worth of the person, e.g. education, skills, knowledge, investments, health, etc., contributed to the value of the human capital.

- $\quad$ Salutogenesis. Origin of health. Salutogenesis was coined by medical sociologist, Aaron Antonovsky in 1979 (Antonovsky, 1990; Davies, 2007; Rabin, Mataloni, Maoz, \& Shiben, 2005). Salutogenesis was identified in efforts to understand what moved people toward the health part of the health and illness continuum (Rabin, et al., 2005). Its health context regards the whole person in its social and biological context, a holistic view (Bahrs, Heim, Matthiessen, \& Müller, 2003). With salutogenic outcomes, healing resources were envisioned to facilitate active adaptation, resilience, risk reduction and development of resources (Ericksson \& Lindstrom, 2006, 2007). Resilience was considered a salutogenic outcome.

- $\quad$ Pathogenesis. Origin of disease. Pathogenesis was regarded as a dichotomy consistent with the medical model, where a disease was present or not. Uses of outside physical interventions, such as a medical provider or medical devices, were used to repair, cure, restore or correct pathogenesis or a problematic health condition (Bahrs, et al., 2003). Pathogenic outcomes occurred where disease or sickness prevailed over health promoting factors (Ericksson \& Lindstrom, 2007). In the use of both salutogenic and pathogenic model, it was possible for an employee to have a chronic condition, yet have their salutogenic potential activated by such things as diet, physical activities, etc. (Bahrs, et al., 2003). 
- Health conditions continuum/ salutogenic model. According to Bahrs et al. (2003), the pathogenic model's concept of health was a dichotomy of health or disease. It saw disease's origin as pathology in that an individual possessed certain risk factors and native stressors. This model saw intervention only in terms of healing either with devices or through human intervention. Conversely, the Salutogenic model of illness was holistic and on a continuum in that people could acquire healing resources and a sense of coherence. Intervention required active adaptation to reduce risk and develop resources. Aaron Antonovsky examined factors that allowed or facilitated staying healthy in the face of stressful situations, severe hardships and other adversities (Davies, 2007; Ericksson \& Lindstrom, 2007). His initial research was with women who survived the Holocaust. In the Salutogenic Model some health conditions or states of illness do not result in performance decrements consistent with presenteeism. The Salutogenic model allows for a view of health as salutogenesis and disease as pathogenesis but does not insist that only one state exists at any one time or that they are mutually exclusive (Ericksson \& Lindstrom, 2007). It is understood that even when healthy, the biological body has to react to genetics, and pathogenic factors in its external surrounding. Hence, being healthy is not a static condition but is fluid, in constant ebb and flow. The employee was seen as more or less healthy, or more or less ill. This view allowed for the fact that not all health conditions will cause performance limitations (Bahrs, et al., 2003). The salutogenic and pathogenic health outcome for an employee was not a health or illness either-or process.

- Racial/ethnic disparities. Disparities in health were considered unequal burdens in disease morbidity and mortality rates experienced by ethnic and racial minority groups when compared to majority groups (Baldwin, 2003; Laviest, 2005). Disparities in health care implied differences in health care quality and outcomes received by minorities in comparison to nonminorities that are evidence of inequality or unfairness within the fabric of the health care systems and the legal and regulatory climate (Agency for Healthcare Research and Quality, 2006; Baldwin, 2003; Laviest, 2005; Smedley, et al., 2003).

- Healthcare dissimilarities. Health care dissimilarities referred to the racial/ethnic differences that did not seem caused by underlying inequities, but were differences produced by cultural preferences or choice of a patient (Laviest, 2005).

- $\quad$ Pharmacotherapy or medication therapy management. Medication Therapy Management (MTM), also called pharmacotherapy, was a regime of medical treatment that included medications/drugs.

- $\quad$ Knowledge-based worker. Workers, particularly healthcare workers who used their intellectual capital or cognitive services as a sign of their productivity, were considered knowledge-based workers (Moody, 2004). 
Other terms used for knowledge-based workers include knowledge assets, cognitive services, intellectual capital and intellectual knowledge (Moody, 2004). According to Moody (2004) "cognitively thinking about, evaluating for, collaborating with, and actively serving and negotiating human health is intellectual capital and is an actual economic asset."

- Value in healthcare. Value refers to considerations of both quality factors plus cost factors, versus either factor alone. Value in health-related productivity field generally refers to the idea that the healthcare conversation needs to expand from one of mere cost containment to one of realizing the best clinical outcome for each healthcare dollar spent (Clark, 2006).

- Integrated employee health benefits management. Refers to health and benefits management systems whereby an employer has health insurance and wellness benefits plus the ideal combination of data and systems to capture and measure information about the relationship between employee health and productivity. Such a system has both absenteeism and work performance or presenteeism data on employees at the individual level and at the same time has measures of health change over time through annual physicals (Kessler \& Stang, 2006).

\section{Significance of Study}

While scholars and researchers were challenged to translate health-related productivity research to practical applications, they were also challenged to be prepared with a forwarding looking view of America's changing workforce composition. With rapid advancements in health care innovations and extended population lifespans, employees were predicted to stay in the labor-market longer, maintain their productivity, and not completely withdraw during common episodes of ill health (Greenberg, Birnbaum, Kessler, Morgan, \& Stang, 2001). Moreover, a more racially and ethnically diverse workforce in light of later retirements will make the oldest and most racially and ethnically diverse workforce in contemporary times (Greenberg, et al., 2001). The significance of this research was that it was expected to contribute to empirical knowledge in four specific areas as follows:

1. Whether or not racially and ethnically diverse workforces bring differing factors and outcomes to presenteeism research.

2. Description of unique issues that the nurse and pharmacist as knowledge based professions brings to presenteeism studies.

3. Whether treatment by providers or pharmacotherapy made for differences in 'current treatment,' 'no treatment,' or 'under-treatment' as factors in employees with presenteeism related productivity deficits. 
4. What the employer's cost of doing nothing is for the nursing and pharmacist workforce when less than 'good health' or 'full health' exists at work.

Contrary to traditional thinking, managing a single employee health benefit category can imply a need for health system or benefit changes which can ultimately result in unintended consequences, such as reducing direct medical and/or pharmacy costs at the expense of presenteeism or absenteeism costs (Loeppke, et al., 2007). The results of this analytical study are expected to give new perspectives and insight into policies and practices that will assist in reducing costs of presenteeism for healthcare employers.

\section{Limitations of Study}

The following are potential limitations of this research study:

- $\quad$ There may be selection bias in that the survey required respondents to be actively employed. Nurses and pharmacists whose work is likely to be most impaired for health reasons often are selected out (voluntarily or involuntarily) of active workforces, leading to an artificial reduction in the association between the predictors and the outcomes in the sub-sample of nurse or pharmacists who remain in the labor force.

- Health disorders reported by nurses and pharmacists may have been selfdiagnosed and self-treated and if they were, they were not captured separate from diagnoses and treatments presumed by an objective health provider.

- $\quad$ The results are of a convenience sample nurses and pharmacists in the state of Tennessee. The results of a study of these professionals may not be generalizable to other nurses and pharmacists in the Tennessee, had a random sample benchmarked to the Tennessee workforce been used.

- Depth of information obtained from any questionnaire is usually shallower versus a face-to-face interview that obtains more complex and richer responses.

- $\quad$ Objective performance-based assessment measures of work performance that includes questions tailored to the unique demands and domains of each occupation singularly was not available for this study.

- It is possible that bias is introduced into productivity estimates in that employees' productivity may be influenced by unmeasured factors such as seasonality (allergies, strains-sprains, and arthritis). 
- $\quad$ Selection bias is introduced because the number of employees whose productivity impairment due to severity of illness may appear to swamp untreated employees simply because the severity of conditions strongly predicts whether or not the employee will seek treatment. Such productivity outcomes may lead to a conservative bias in estimating treatment effects. Before and after comparisons or longitudinal survey to evaluate the effects of workplace health care interventions in experimental analyses can shed light on this problem.

- $\quad$ According to Aday (2004), there are limitations of internet based surveys. First, there may be selection bias when surveys are internet based because completion of the surveys requires internet savvy. The demographic groups that used the Internet most heavily in 2004 were the highly educated, high-income, and white males (Aday, et al., 2004). This study attempts to overcome this limitation by studying professions (nurses and pharmacists) whose jobs have been transformed by technology and cause them to be relatively technologically savvy. However, for some rural areas in Tennessee, this may still have presented a limitation. Also web based surveys traditionally have low response rates impacted by spam filters, inability of the researcher to detect non-delivery, or respondents weary of solicitation emails.

- The cross-sectional design limits the ability to discern the direction of observed associations. To overcome this, longitudinal study was recommended, however, as mentioned earlier cost and time made such a study design impractical.

- $\quad$ Even though this study is from the perspective of the employer, not all market labor costs are captured in the study. Costs such as the hiring and training of replacement workers, impact of team or coworker's productivity, and employee's potentially forfeited leisure time were excluded. These weaknesses were not overcome in this study and remain due to the cost and time required to overcome them.

- Ideally this study would have utilized a sample benchmarked to the US workforce because presenteeism is best studied from a population basis (Kessler \& Stang, 2006). A review of national data bases commonly utilized in population studies of health related factors revealed none that asks all questions that could be used to quantify presenteeism and its cost burden. 


\section{CHAPTER 2. REVIEW OF LITERATURE}

This chapter contains the review of literature and is divided into five sections: historical perspective of presenteeism, determinants of presenteeism, presenteeism and costs, presenteeism and the healthcare workforce, and presenteeism and a diverse workforce.

\section{Historical Perspective of Presenteesism}

Despite the novel term 'presenteeism,' theories that link productivity to other broader societal issues date back over two-hundred years to philosopher and economist Adam Smith, author of An Inquiry into the Nature and Causes of the Wealth of Nations, first edition written in 1776 (Brandt-Rauf, Burton, \& McCunney, 2001; Smith, 1904). In his book, Smith links national and global performance and proposes that healthy citizens lead to healthy economies. He also implies that there are both social and economic consequences of illnesses that can cause substantial societal, employer, as well as personal costs (Brandt-Rauf, et al., 2001; Greenberg \& Binbaum, 2006; Smith, 1904). Most noteworthy, because Smith's writing occurred over two hundred years ago, was that Smith had insights into the impact of both mental and physical health on human productivity. He wrote:

...that men in general should work better when they are ill fed than when they are well fed, when they are disheartened than when they are in good spirits, when they are frequently sick than when they are generally in good health, seems not very probable. Years of dearth, it is to be observed, are generally among the common people years of sickness and mortality which cannot fail to diminish the product of their industry (Smith, 1904, p. I.8.44).

The concept of 'human capital' was initially expressed by Smith in 1776 and was reintroduced in the 1960's by economists Theodore Schultz and Gary Becker. A multitude of scholarly writings analyzing the contribution of human capital to industry and economic growth has followed (Whiteford, 2006). More recently during the 1990's, a focus on valuing and linking health with human capital occurred. The term presenteeism is credited to Cary Cooper, a professor of organizational psychology and health at Manchester University in the United Kingdom (Lowe, 2002). Reportedly, Cooper used the term to describe overwork and feelings of job insecurity of workers in industry resulting from downsizing and restructuring (Lowe, 2002). In the US, the term began to appear in health and productivity literature during the last half of the 1990s. The definition of presenteeism in the US has more consistently referred to worker's on-thejob productivity loss that is caused by illness or health conditions (Brandt-Rauf, et al., 2001; Kessler, et al., 2003; Stewart, et al., 2003a). According to Shamansky (2002), R.W.Whitmer, president of the Health Enhancement Research Organization, is credited with coining the term's widespread use in the U.S. 
A review of published literature shows an increased number of empirical studies in the U.S. using the term presenteeism within the decade 1998 through 2008, with most scholarly research published on the subject in the Journal of Occupational Environmental Medicine. Some of the earliest efforts to mobilize interest in research and collect data about presenteeism occurred around 1995 and 1996 (Health Enhancement Research Organization (HERO), n.d.; Integrated Benefits Institute, n.d.). By 1997, three well recognized professional organizations and initiatives had been created to further this area of inquiry: Integrated Benefits Institute (IBI) in 1995; the Health Enhancement Research Organization (HERO) in 1996; and the Institute for Health and Productivity Management (IHPM) in 1997 (Holland \& Holland, 2001; Institute for Health and Productivity Management., n.d.; Wellness Councils of America, 2003).

The Integrated Benefits Institute (IBI), web sites www.benefitsintelligence.org and www.ibiweb.org, is a national private nonprofit organization whose purpose is to provide research and analysis of health, wellness, absence, disability and productivity issues beyond traditional workers' compensation, group health, and non-occupational lost-time benefits programs (Integrated Benefits Institute, n.d.).

Health Enhancement Research Organization, web site http://www.the-hero.org/, is a national coalition of business organizations partnering to create 'systems of synergy' to facilitate research that helps employers and dependents be healthier, control utilization of healthcare, moderate medical expenditures, and increase productivity (Health Enhancement Research Organization (HERO), n.d.).

The Institute for Health and Productivity Management, web site http://www.ihpm.org/index.php, and their educational arm, Academy for Health and Productivity Management, web site http://www.ahpm.org/, aim to help employers measure and increase the returns from investing in their human capital (Holland, 2001). The IHPM commissioned four Centers of Inquiry to investigate the interactions between health and productivity to conceptually account for connections or linkages among physical workplace environment, employee health, productivity, and overall business performance. More recently, the IHPM created a new professional journal entitled Health and Productivity Management (Kessler \& Stang, 2006).

In continued testament to the newness of the health-related productivity field, as recently as 2006 a new initiative called the Harvard Health and Work Performance Initiative was established for the basic purpose of bringing together interested researchers and policy stakeholders to build a consensus about the best ways to conceptualize and measure work performance (Kessler \& Stang, 2006). Since empirical research over the past decade had indicated an association between poor health and low work productivity, the members of this initiative believed that better health-related productivity information was needed from the employer's perspective as an end-user (Berger, et al., 2003b; Kessler \& Stang, 2006). Therefore, over the most recent years, most researchers have sought to establish a gold standard for measurement and determine economic value of averting presenteeism from the employer's perspective. 
Although various private organizations and initiatives have been developed to support research in the field of health and productivity, R.W.Whitmer indicated that the field will ultimately benefit when health and productivity research occurs in places where quality research occurs: in traditional university centers (Wellness Councils of America, 2003). Whitmer's impression is that this has not happened to date because of university funding challenges and the hope is that future public funding vehicles will show interest in the field as it matures (Wellness Councils of America, 2003).

\section{Determinants of Presenteeism}

\section{Demographics and Prevalence}

Walter Stewart et al. (2003a) of AdvancePCS Center for Work and Health with the Geisinger Health Systems analyzed a multi-national workforce, to establish a perspective on lost productive time. Stewart et al. (2003a) benchmarked their data to the US workforce. Their study used a telephone survey of a random sample of 28,902 employees. The tool used was the Work and Health Interview (WHI) portion of the American Productivity Audit (APA) to quantify the impact of health conditions on work productivity. They determined that the ratio of reduced performance or presenteeism lost productive time (LPT) to work absence LPT was 2.4 to 1. Presenteeism, on average, composed $71 \%$ of all health-related LPT. The following were the results when workers were asked for a 2 week recall of health-related productivity:

- $\quad$ An average of $10 \%$ were absent for a personal health reason.

- $\quad$ An average of $2 \%$ were absent for a family health reason.

- $\quad$ An average of $38.3 \%$ had unproductive time (presenteeism) as a result of a personal health reason.

The overall average for all work time-off for either a personal health or family health reasons was 2 hours. Of the 2 hours, $66 \%$ (1.32) were for personal health reasons. The total work absence for personal health was 0.54 hours per week and absences for family health or caregiver were 0.12 hours per week. Of note, was that of the $38.3 \%$ with presenteeism, $50 \%$ were for times fewer than 2 hours per week.

The demographic profile for presenteeism identified by Stewart et al. (2003a) indicated that total lost productivity time (LPT) was 30\% higher in females than men $(\mathrm{P}<0.001)$. They reasoned that this was influenced by a number of factors. First, women more commonly experience depression, anxiety, migraines, and gastrointestinal disorders than men (Stewart, et al., 2003a). Secondly, women were thought to have been disproportionately exposed to cold, flu, and other infections as they were presumed to be the primary caregiver. In support of this reasoning, Stewart et al. (2003a) found that women had significantly higher self-reports of cold, flu and other infections than men ages $18-45$ years $(19.4 \%$ vs. $16.5 \%$; $\mathrm{P}<0.001)$. Workers with more education (a college 
degree or higher) reported less lost productivity time than workers with less education $(\mathrm{P}<0.001)$. Workers earning less than $\$ 10,000$ or more than $\$ 50,000$ per year reported less lost productivity time than workers with intermediate incomes $(\mathrm{P}<0.001)$. Workers who resided in the Northeast or South reported significantly less lost productivity time than did workers in the Midwest or West $(\mathrm{P}<0.001)$. Older workers ages 50-65 reported two thirds of the lost productive time. Employees in high demand-low control occupations had the lowest LPT at 1.81 hours per week. Those in low demand-high control jobs reported significantly highest at 3.32 hours per week $(\mathrm{P}<0.001)$. On average, Asians reported a substantially lower lost productive time greater than or equal to two hours per week than all racial/ethnic groups 14.83\% $(\mathrm{P}<0.001)$ (Stewart et al., 2003a). Lost productive time (LPT) varied by occupation, with employees in the fields of architecture and engineering reporting the lowest mean LPT (1.35 hours per week). By comparison, employees in personal care or service, building grounds maintenance, and installations and repair reported $70 \%$ higher than those in the lowest reporting occupations. Healthcare occupations composed $6.61 \%$ of the workforce studied and were in the top third of all 24 occupations in amount of LPT and costs estimates (Stewart, et al., 2003a).

Even though published study by Stewart et al. (2003a) contained a table that showed that the study was performed across ethnic and racial groups, the published analyses of results were not such that distinct results across ethnic and racial groups could be considered. Data gleaned from the table indicated Native Americans had the largest percentage of LPT at $27.98 \%(2.42 \mathrm{hr} / \mathrm{wk}$, SE 0.26), Blacks were a close second at $27.73 \%$ (2.26 hr/wk, SE 0.09), Hispanics were third highest at 26.41\% (2.01 hr/wk, SE $0.11)$; second lowest were Whites at 22.77\% (1.83 hr/wk, SE 0.03), and lowest were Asians at 14.83\% (1.00 hr/wk, SE 0.20). Because scores noted by Stewart et al. (2003a) were for total LPT, There was no way to distinguish how the LPT varied for absenteeism versus presenteeism across racial and ethnic groups. However, such data clearly indicated a need for future research on differences in prevalence across racial and ethnic groups.

\section{Health Symptoms and Health Risks}

Burton, Chen, Conti, Schultz, Pransky, and Edington (2005) examined the association of employee health risk factors on presenteeism by examining 28,375 employees also using the Work Limitation Questionnaire (WLQ) incorporated into a national financial services company's Health Risk Appraisal. The studies by Burton et al. (2005) and Burton, Chen, Conti, Schultz, and Edington (2006) provided insight into employee health risks. Employees spanned 25 states and the headquarters for this estimated fourth largest US financial services firm is in the Midwest. Burton et al. (2005) found that in a one week period, employees reported an average of 3 hours 10 minutes total missed time due to personal health related presenteeism. For those respondents with presenteeism, the average age was 38.8 years, $73.1 \%$ were female, and they averaged 2.16 health risks per worker. The risk factors examined were divided into 3 broad categories of 12 health risks: 1) Life dissatisfaction risks - included job dissatisfaction, poor physical health, and high stress; 2) Lifestyle risks - included current smoker, physical inactivity, safety belt usage, alcohol use, and use of relaxation medication; 3) 
Biological risks - consisting of high blood pressure, high cholesterol and a BMI $\geq 30.0$. Ten of twelve risk factors examined were significantly associated with lost productivity time with the following most prevalent: high stress (35\%), physical inactivity $(30 \%)$, life dissatisfaction (29\%), and obesity-BMI $\geq 30(28 \%)$ (Burton, et al., 2005). Results indicated that overall, perception-related health risk factors, including life dissatisfaction, job dissatisfaction, self rated poor health, and stress, were most associated with presenteeism. Almost two-thirds of the 28,375 employees (63.2\%) were in the low risk category ( 0 to 2 health risks). Those with medium risk ( 3 to 4 health risk) factors composed $24.5 \%$ of the employees. Those with high risk ( 5 or more health risk) factors composed $12.2 \%$ of the workforce. There was a strong association between having more health risks and presenteeism, as the number of risk factors increased, so did scores of presenteeism (Burton, et al., 2005). Each additional risk factor was associated with an additional $2.4 \%$ productivity reduction.

In another study, Burton et al. (2006) sought to determine if changes in 12 specific health risks are associated with changes in presenteeism. They reviewed data for 7026 employees of national financial services company and compared results of their previous studies in both 2002 and 2004. They used a health risk assessment (HRA) tool and a modified version of the Work Limitation Questionnaire (WLQ). They confirmed that a change in health risk (positive or negative) produced the same directional change in presenteeism.

Myde Boles and associates (2004) performed a study that also occurred with a national employer. However, in this study, employees who were members of corporate fitness centers were compared with non-member employees. Significant health risk factors for presenteeism were identified. They surveyed 2264 employees to provide evidence for the relationship between health risks status and work productivity lost via presenteeism and absenteeism. A 20 question health risk assessment tool that contained questions from the Work Productivity and Activity Impairment Questionnaire-General Health (WPAI-GH) tool was used. Consistent with the findings of Burton et al. (2006; Burton, et al., 2005), as the number of health risk increased above one, the risk of lost work productivity also increased (Boles, et al., 2004). The total risks for the sample ranged 0 to 9 with a median of 3 . The study showed health risks as follows were most prevalent: high cholesterol, 47\%; physical inactivity, 45\%; high stress, 29\%; and lack of emotional fulfillment, 24\%. Employees with physical inactivity were significantly more likely to be both absent and impaired on the job compared with employees who did participate in physical activity (Boles, et al., 2004). Also in this study, consistent with other studies, females were significantly more likely to have any productivity loss than males. Individuals who reported high stress also reported an average 10\% impairment compared with $5 \%$ reported by individuals who did not report stress. The mean prevalence range was from $1.3 \%$ presenteeism for employees with zero risk to $25.9 \%$ presenteeism for individuals with eight risks. Absenteeism also increased as health risk accumulated, but the range was smaller ( $0.0 \%$ to $6.3 \%)$. Boles (2004) found that 4.2 days were the average lost per year for absenteeism and that 15.5 days were the average lost per year for presenteeism. Of note is that they found that absenteeism and presenteeism were associated with different health risks. Absenteeism was most associated with 
diabetes/high blood glucose $(2.285,95 \% \mathrm{CI}=1.167-4.474)$. Presenteeism was more associated with poor diet, physical inactivity, high stress and lack of emotional fulfillment $(\mathrm{P}<0.05)$. Among these factors, the productivity loss was highest for stress (2.085, 95\% confidence interval 1.650-2.444), and next highest for lack of emotional fulfillment (1.928, 95\% confidence interval 1.521-2.444).

Physical Health Conditions

Phillip Wang and associates (2003), Harvard Medical School, studied the associations between chronic conditions and absenteeism, presenteeism, and critical incidents. This study utilized archival data and provided calibration and validation data for the Health and Productivity Questionnaire (HPQ) lost productivity measurement tool. Wang et al. analyzed results of employees of 4 occupations: 441 reservation agents of a major airline, 505 customer service representatives for a telecommunications company, 554 executives of a major automobile manufacturer, and 850 railroad engineers. They used the interviewer version of the Health and Productivity Questionnaire and found that prevalence of health conditions associated with lost productivity varied by occupation. The most common health conditions across all occupations were, in order: seasonal allergies, chronic back/neck pain, chronic headaches, hypertension, arthritis, and depression (Wang, et al., 2003). Executives had the lowest prevalence of most conditions but the highest prevalence of hypertension. Customer service representatives had the highest prevalence of asthma, depression, and gastrointestinal ulcers. Reservation agents had the highest prevalence of chronic headaches. Railroad engineers had the highest prevalence of arthritis, chronic back/neck pain, diabetes and allergies (Wang, et al., 2003).

Ronald Goetzel and colleagues (2004) at Cornell University sought to establish the total cost of health, absence, disability, and presenteeism of 10 common health conditions (physical and mental) affecting US employers. This highly cited study also analyzed data from administrative records of medical treatment, administrative records of employee absence, and disability. These data were obtained from a 374,799 employee HPM (Medstat's MarketScan Health and Productivity Management) database that was used to generate metrics for health administrative claims for the period 1997 to 1999 . The HPM data quantified absences and presenteeism loss and was combined with the results of 5 multi-condition studies on absence and presenteeism losses using 5 different measurement instruments (Goetzel, et al., 2004). The findings were that absenteeism resulted in greater than 10 days lost per year and that presenteeism resulted in 30 days lost per year (Goetzel, et al., 2004). The top 10 chronic and acute conditions that produced the highest economic burden based on the "average impairment and prevalence estimates" for US employees were: hypertension, depression/sadness/mental illness, heart disease, arthritis, asthma, cancer, migraine/headache, allergies, and respiratory infections. Goetzel et al. (2004) found that presenteeism costs were higher than medical costs in most cases, and represented $18 \%$ to $60 \%$ of all costs for the top 10 conditions. 
Other studies found many of the same health conditions consistent with those found in Goetzel et al. (2004), however as expected, their prevalence varied. A key factor in identifying different health conditions by costs is whether claims data were considered, as was considered by Goetzel et al. (2004). The conditions that Stewart et al. (2003a) found most prevalent and costly in terms of lost productivity at work were considerably different from those found by Goetzel et al. (2004) because Stewart et al. (2003a) did not consider claims data. Stewart et al. (2003a) found more self-reported conditions such as: pain (e.g. from headache, low back pain, or arthritis), the flu or common cold, symptoms suggestive of a depressive disorder (e.g. sad and blue, fatigue), allergic rhinitis, and gastrointestinal complaints.

James Collins and associates (2005) from Dow Chemical Company, sought to determine the prevalence and total cost estimates for chronic health conditions in the US workforce for five locations of Dow Chemical Company. They measured presenteeism using the Stanford Presenteeism Scale and the SF-36 to identify global health of approximately 8000 employees. Much like Goetzel et al. (2004) and Wang et al. (2003), Collins obtained objective administrative archival data such as demographics, medical and pharmaceutical claims; however they also included health risks such as smoking status, biometric health risk factors, payroll records, and job type in order to merge relevant data from their productivity measurement scale. The findings were that absenteeism associated with chronic conditions resulted in 1.35 to 8.85 days lost per year and that presenteeism associated with chronic conditions resulted in 44.5 to 91 days lost per year (Collins, et al., 2005). They also found that employees who suffered from depression, anxiety, or emotional disorders experienced highest presenteeism at $36.4 \%$. Those who had breathing disorders such as bronchitis and emphysema were at $23.5 \%$ presenteeism. Consistent with other demographic findings, Collins (2005) found that predictors for presenteeism included female $(\mathrm{P}=0.012)$, plus increasing age $(\mathrm{P}=0.000)$, service workers or operative type jobs $(\mathrm{P}=0.000)$, the presence of a chronic condition, and an increased number of chronic conditions (both at $\mathrm{P}=0.000$ ). Consistent with other studies, health conditions that included migraines, back or neck pain, and breathing disorders were also predictors of presenteeism (Collins, et al., 2005). Quite different from Stewart et al. (2003a), Collins (2005) found that working less than 40 hours was more associated with presenteeism.

According to the Integrated Benefits Institute (n.d.), the severity of health problems that affect functioning in any workplace can vary widely among chronic and acute episodic conditions. Despite this knowledge, many employers and researchers initially focused only on high cost chronic illnesses whose impact were more easily accessible through claims data. The research of Stewart et al. (2003a) and others has now begun to demonstrate that, although the lost productivity cost resulting from acute episodic conditions at the individual-level are reportedly modest; population-level costs are more substantial because the prevalence of common episodic disorders are relatively high. Consistent with this impression are data in Table 2-1. It contains physical and mental health conditions most associated with presenteeism across multiple published studies. When available, standard errors were included. 
Table 2-1. Prevalence of Health Conditions Associated with Presenteeism from Multiple Sources and Occupations

\begin{tabular}{lccl}
\hline Health Condition & $\begin{array}{c}\text { Prevalence } \\
(\%)\end{array}$ & SE & \multicolumn{1}{c}{ Source } \\
\hline Arthritis & 15.2 & 1.8 & Goetzel, 2004 \\
Back or neck pain & 25.1 & 0.9 & Goetzel, 2004 \\
Other musculoskeletal disorder & 33.5 & 1.8 & Goetzel, 2004 \\
Migraines, severe/frequent headaches & 17.7 & 0.7 & Goetzel, 2004 \\
Chronic pain & 23.6 & NA* & Canadian, 2006 \\
Hypertension & 14.9 & 0.7 & Wang, 2003 \\
Heart disease & 11.9 & NA* & Collins, 2005 \\
High cholesterol & 20.0 & 0.5 & Kessler, 2008 \\
Stomach or intestinal ulcers & 1.9 & NA* & Collins, 2005 \\
Other gastrointestinal problems & 8.1 & 0.3 & Kessler, 2008 \\
Allergies & 31.2 & 1.8 & Goetzel, 2004 \\
Asthma & 10.2 & 0.5 & Goetzel, 2004 \\
Other respiratory or lung problem & 1.3 & NA* & Collins, 2005 \\
Diabetes & 3.8 & 0.4 & Collins, 2005 \\
Obesity & 5.9 & 0.3 & Kessler, 2008 \\
Sleep problem & 8.6 & 0.3 & Kessler, 2008 \\
Chronic fatigue/low energy & 6.4 & 0.3 & Kessler, 2008 \\
Cancer & 1.7 & 0.2 & Wang, 2003 \\
Anxiety & 5.6 & 0.3 & Kessler, 2008 \\
Depression & 9.4 & 0.6 & Goetzel, 2004 \\
Other emotional problem (stress) & 26.0 & NA* & Denelsbeck, 2006 \\
Substance use problem (drug / alcohol) & 4.7 & NA* & Musich, 2004 \\
\hline *NA N A & & &
\end{tabular}

$* \mathrm{NA}=$ Not Available 


\section{Mental Health Conditions}

In a cross national survey among adults in 14 countries conducted in 2001-2003, the US had the highest rate of any mental health disorder including substance abuse (Lerner \& Henke, 2008). The proportion of those with mental health disorders in the US was $26 \%$. Broken out by type of mental health illness, the 12 month prevalence of anxiety disorder in the US was $18 \%$, mood disorder 10\%, impulse control disorder $7 \%$ and substance abuse disorder 4\% (Agency for Healthcare Research and Quality, 2006). According to AHRQ, the lifetime prevalence of mental health disorders were as follows:

- $\quad$ Major depressive disorder 9.5\%

- $\quad$ Dysthymia 6.1\%

- $\quad$ Any mental disorder $18.7 \%$

- $\quad$ Mood disorder $9.7 \%$

- $\quad$ Impulse control 10.4

- $\quad$ Substance abuse disorder $7.2 \%$

Despite the fact that a majority of research on the topic presenteeism has thus far focused on lifestyle and biological health risks or chronic diseases; findings indicated that psychological variables are equally or more related to presenteeism than biological health risks and lifestyle risk factors (Boles, et al., 2004; Burton, Pransky, Conti, Chen, \& Edington, 2004; Lerner, et al., 2004). Boles et al. (2004) found the highest risk factor associated with presenteeism was the use of 'relaxation medication' by employees. Approximately $34.9 \%$ of their study population indicated that stress was a problem, the prevalence of employees taking such medication was $15.7 \%$, and the estimated presenteeism was $8.4 \%$. As mentioned earlier, Boles et al. also found that employees with high stress reported twice the occurrence of presenteeism at $10.2 \%$ compared with presenteeism at 5.0\% among employees who did not report stress $(\mathrm{P}<0.001)$ (Boles, et al., 2004).

Debra Lerner and associates (2004) took a different approach and sought to determine the specific occupational characteristics that contribute to productivity loss among employees with depression. Specifically, they wanted to describe the impact of depression's negative symptoms on multiple dimensions of varied types of job components. They administered the Work Limitations Questionnaire to patients recruited from primary care physician offices. They had a control group and a depressed group. When depressed employees were in occupations that required proficiency in exercising judgment and communication, results indicated that health problems resulted in more work limitations and more absences than for those employees who had health problems but were not depressed. Lerner et al. (2004) further determined that when employees' occupations required employees to have high client contact with the public, the result was 
that the employees' health problems were associated with larger losses in ability to handle mental and interpersonal demands as well as physical job demands. The study identified two groups of depression symptoms that increased employee productivity loss - difficulty concentrating and distractibility. Those employees having these two symptoms had poorer presenteeism scale scores and more presenteeism loss. Also, Lerner (2004) reported that employees reporting tiredness and sleep disturbance had more difficulty performing mental-interpersonal, time and output-related tasks and more days missed. Furthermore, employees with depression had two to three times increased likelihood to indicate that health problems interfered with their ability to meet job demands compared to the control sample (Lerner, et al., 2004).

In a later study, Lerner and Henke (2008) assessed the work impact of depression by reviewing research articles published since 2002 in an effort to up-date information on the topic of work and depression. Lerner and Henke's premise was that employment activity had become a surrogate marker for personal health and/or economic status in clinical and epidemiological research (Lerner \& Henke, 2008). Their article focused on the 3 aspects of employment status, absenteeism, and presenteeism. Through their reviews, they determined that depression limited performance of jobs requiring physical demands by an average of $20 \%$. For jobs requiring time management, mentalinterpersonal demands, and output demands, depression limited performance by $35 \%$ over a 2 week period of time. The degree of severity of depression mattered in that there was a corresponding directional relationship between higher depression and higher presenteeism (Lerner, 2008). Studies reviewed by them, with only one exception, were consistent in findings that absenteeism and presenteeism were impacted by depression and that presenteeism created the higher cost burden. According to Lerner et al. (2008), depression symptom severity has been shown repeatedly to account for some of the variation in work outcomes related to physical health conditions from various studies.

Pharmacotherapy and Presenteeism

Pharmaceutical researchers have been at the forefront of health-related productivity research aimed at demonstrating impact of pharmacotherapy on productivity for use in cost-effectiveness analyses and cost-of-illness studies (Evans, 2006). Burton, Morison, and Wetheimer (2003) published a summary and critical review of literature on the relationship between 12 pharmaceutical products and worker productivity loss. Studies of U.S. employees that were published between the years of 1990 and 2002 where productivity loss was an endpoint were the focus of their research. Burton et al. (2003) sought to link chronic illnesses with productivity losses, to calculate productivity costs, and to determine if pharmaceutical costs offset costs of treatment. Their reviews were to encompass studies that addressed both presenteeism and absenteeism. However, some studies reviewed did not conceptualize productivity loss from the employer's perspective and presenteeism was defined as diminished capacity due to ill health while at work or school. These definitions confound the issues of interest for this research that is from an employer's perspective. Additionally, some studies assessed costs of pharmaceutical treatment and costs of illness such as in the use of vaccines compared to 
placebo. In those cases, the costs savings were societal versus employer and were not comparable to costs in this investigator's research. Other studies, such as those by Burton et al. (2003), reported on pharmacological compounds where presenteeism was conceptualized consistent with current health-related productivity studies. Studies on pharmaceutical products such as benzodiazepines for treatment of panic disorder, antidepressants for treatment of depression, triptans for treatment of migraine, nonsedating antihistamines for the treatment of allergic rhinitis and allergies, were ones that demonstrated statistical significance for decreasing the loss of productivity such that the cost of the drugs were off-set.

Pharmaceutical products that influenced absenteeism differed from those that influenced presenteeism. Five studies reviewed by Burton et al. (2003) were statistically significant in decreasing absenteeism. These studies included use of non-steroidal antiinflammatory drugs (NSAIDs): naproxen for treatment of dysmenorrheal; sulfonylureas glipizide for treatment of diabetes; selective serotonin reuptake inhibitors (SSRIs) for treatment of depression; and beta-agonists for treatment of asthma. A few studies showed that while certain health conditions could decrease productivity, use of medications did not conversely show statistically significant impact on lessening the decrement when compared to placebo (for example the use of antacids and $\mathrm{H}_{2}$-receptor antagonists in treatment of dyspepsia and alpha (1)-adrenoceptor antagonists for irritating or obstructive urinary symptoms).

The conclusions of Burton et al. (2003) were that the evidence is 'very good' that approximately 12 drug classes of pharmaceuticals are helpful in reducing the loss of productivity such that treatments may be partially or completely offset when employees benefit from increased productivity. The following health conditions were examined: respiratory illnesses (includes asthma, allergic disorders, bronchitis influenza and upper respiratory infections); diabetes, depression, dysmenorrhea, and migraine. More important to the current research is that Burton et al. (2003) believed that the impact of pharmaceuticals on presenteeism is under-represented and calls for this inclusion in future research.

\section{Under-Treatment}

From an employer's perspective, although most large self-insured corporations have access to anonymous claims and pharmacy data through third-parties; data on untreated or under-treated health problems are usually nonexistent (Berger, et al., 2003b; Kessler \& Stang, 2006). This makes it impossible to evaluate the potential effects of expanded outreach and treatment programs for employers, or to identify workforce level health benefits or issues with provider norms in a community. Some health-related productivity researchers believe that under-treatment occurs and impacts productivity when employees stay on-the-job and do not receive full recommended treatment for health conditions (Kessler \& Stang, 2006). There could be number of complex reasons that patients continue to experience health problems after receiving what they and their health providers consider 'treatment.' Researchers who focus on compliance/adherence 
have found that employees are more likely to comply with treatment regimes if there is a good relationship with their health care provider, communications are two-way, they feel that they participate in decisions about their treatment plan, and they believe their health provider cares about whether they follow the plan (DiMatteo \& Haskard, 2006). Studies indicated that when patients experience a resolution of symptoms that led them to make the providers visit; they are more satisfied with their care and are likely to report they are more satisfied with the quality of care provided (Thiedke, 2007).

Patient compliance with treatment is frequently discussed when under-treatment is empirically examined. Estimates are that each year $\$ 1.5$ billion in workdays are lost and total costs of medication non-compliance are $\$ 100$ billion (the estimates do not differentiate that costs may be from presenteeism loss of work days or absenteeism loss of workdays) (Crown, 2000; Kravitz \& Melnikow, 2004).

Robin DiMatteo performed a meta-analysis of empirical studies published in the 50 years span of 1948 to 1998 and noted a few significant issues. Patient non-adherence leads to missed opportunities to prevent the onset and progression of health problems (DiMatteo \& Haskard, 2006). Although in the more recent years patient non-adherence increased somewhat, estimates are that there is approximately $25 \%$ non-adherence to recommended treatment across all types of treatment, including medication and lifestyle adherence. Adherence varied according to method used to assess it and the health condition being treated (e.g. adherence for HIV 88\%, for diabetes and sleep 66\%). Of particular note for the current study is that, although non-adherence was statistically significant for socioeconomic level; it was so modest that the researchers determined that all patients are essentially non-adherent (DiMatteo \& Haskard, 2006; Kravitz \& Melnikow, 2004). Pharmaceutical companies have identified that pharmacotherapy is of value when outcomes are based on adherence or compliance with pharmacotherapy (Kessler \& Stang, 2006). It was determined that approximately one-third of adults often or very often are non-compliant with taking medications as prescribed (Harris Interactive, 2005). Of those who were not compliant, $45 \%$ had concerns about the actual drugs prescribed and $43 \%$ felt the drugs were not necessary (Harris Interactive, 2005). Estimates were that one-third of patients took all their medications, one-third took only a portion, and one-third never filled or totally abandoned their prescriptions. Approximately $22 \%$ of patients did not fill a prescription in the previous 12 months to save money. Rates for the disabled were higher and rates for low income groups were twice as high as non-poor (Kinnaird, Cox, \& Wilson, 2003). The National Association of Chain Drug Stores (NADCDS) expected that by 2006, 4 billion prescriptions would be dispensed each year (Smith, 2006). As recent as August 2007 the NCPIE indicated that problems such as prescription medication compliance were "America's other drug problem" - a public health issue that has reached crisis proportions in the US and around the world as the number of prescriptions written has increased (National Council on Patient Information and Education, 2007).

Although health-related productivity literature rarely refers to healthcare providers when it discusses under-treatment, it seems relevant to this discussion. A review of literature indicates that under-treatment can also indicate a lack of health care 
provider compliance with treatment guidelines (Kravitz \& Melnikow, 2004). According to the Institute of Medicine, it takes providers approximately 17 years after research determines that there is a more effective treatment for it to be incorporated into routine patient care (Rhoads, Ferguson, \& Langford, 2006). Moreover, according to the New England Journal of Medicine, only $55 \%$ of patients currently receive recommended care (Rhoads, et al., 2006). Therefore, it follows that provider compliance could be factor in employee under-treatment. Kravitz et al. (2004) indicated that numerous studies have shown that physician compliance with clinical practices is far from optimal even when such guidelines have solid data on their benefit. Kravitz's interesting perspective is that, much like physicians have had a role in enhancing patient adherence to recommended therapies; patients could have a role as agents for improving quality of care through involved participation to modify physician behavior in ways that lead to improved treatment (Kravitz \& Melnikow, 2004).

Table 2-2 summarizes key presenteeism studies which were reviewed in this section on key determinants of presenteeism.

\section{Presenteeism and Costs}

\section{Contrast Medical, Pharmacy, Absenteeism and Presenteeism Costs}

Ronald Loeppke and associates (2007), of Matria Healthcare, sought to assess the magnitude of health-related absenteeism, presenteeism, and disability relative to medical and pharmacy costs. They wanted to differentiate how various health-related productivity issues impacted a population differently. They surveyed four employers totaling 57,000 employees and used the Health and Productivity Questionnaire (HPQ) tool. Their productivity cost results were integrated with medical and pharmacy claims costs to determine overall costs results. The costs of health benefits were collected to facilitate analysis of the health costs in a business context. Portions of their research required retrospective and naturalistic designs due to the fact that methods were adapted to accommodate each company's desires for the study and the characteristics of the companies. Loeppke et al. (2007) found that the ranking of highest-cost conditions varied by employer and those conditions differed in their contribution to medical, pharmacy and productivity costs. They determined that the full costs of poor health were driven by different health conditions than could be determined by examining costs of medical and pharmacy costs alone. As examples, conditions of depression, fatigue, anxiety and allergy were not included in the top ten costs for medical and pharmacy cost category; yet they were among the highest costs for health-related productivity costs and, ultimately, greatly influenced the overall health costs category (Loeppke, et al., 2007). Moreover, gastro esophageal reflex disease (GERD), diabetes, coronary heart disease, and cancer were identified in the top ten of pharmacy/medical costs, but were not in the top ten of the broader total health costs category. Overall, Loeppke et al. (2007) found that healthrelated productivity costs were more than four times greater than medical and pharmacy costs. 
Table 2-2. Summary of Key Presenteeism Studies: Determinants of Presenteeism

\begin{tabular}{|c|c|c|c|c|}
\hline Source & Objectives & Setting/Subjects & Design and Tool & Relevant Findings \\
\hline $\begin{array}{l}\text { Stewart W et al. } \\
\quad(2003 a)\end{array}$ & $\begin{array}{l}\text { To establish a } \\
\text { perspective on lost } \\
\text { productive time and to } \\
\text { quantify the impact of } \\
\text { health conditions on } \\
\text { work productivity. }\end{array}$ & $\begin{array}{l}\text { AdvancePCS Center for } \\
\text { Work and Health with } \\
\text { the Geisinger Health } \\
\text { Systems analyzed a } \\
\text { multi-national } \\
\text { workforce. } \mathrm{N}=28,902 \\
\text { employees }\end{array}$ & $\begin{array}{l}\text { Random sample } \\
\text { telephone survey. } \\
\text { Used the Work and } \\
\text { Health Interview } \\
\text { (WHI) portion of the } \\
\text { American Productivity } \\
\text { Audit (APA) }\end{array}$ & $\begin{array}{l}\text { Ratio of reduced performance or } \\
\text { presenteeism LPT (lost productive } \\
\text { time) to work absence LPT was } 2.4 \\
\text { to } 1 . \text { Presenteeism, on average, } \\
\text { composed } 71 \% \text { of all health-related } \\
\text { LPT. Average of } 38.3 \% \\
\text { unproductive time (presenteeism) } \\
\text { was lost as a result of a personal } \\
\text { health reason }\end{array}$ \\
\hline $\begin{array}{l}\text { Burton WN } \\
\text { et al. } 2005\end{array}$ & $\begin{array}{l}\text { To study the impact of } \\
\text { employee health risk } \\
\text { factors on self-reported } \\
\text { worker presenteeism. }\end{array}$ & $\begin{array}{l}\mathrm{N}=28,375 \text { employees of } \\
\text { national financial } \\
\text { company spanning } 25 \\
\text { states. }\end{array}$ & $\begin{array}{l}\text { Cross-sectional, } \\
\text { convenience sample. } \\
\text { Used Work Limitation } \\
\text { Questionnaire } \\
\text { incorporated into a } \\
\text { Health Risk Appraisal. }\end{array}$ & $\begin{array}{l}\text { Most prevalent risk factors: high } \\
\text { stress }(35 \%) \text {, physical inactivity } \\
(30 \%) \text {, life dissatisfaction }(39 \%) \text {, } \\
\text { and obesity }(28 \%) \text {. As risk factors } \\
\text { increase, scores on presenteeism } \\
\text { scale increased. Each additional risk } \\
\text { was associated with addition of } \\
2.4 \% \text { productivity loss. Medium and } \\
\text { high risk productivity decrements } \\
\text { were } 6.2 \% \text { and } 12.2 \% \text {. Annual cost } \\
\text { of lost productivity between } \$ 1392- \\
\$ 2592 \text { per employee. }\end{array}$ \\
\hline $\begin{array}{l}\text { Burton WN } \\
\text { et al. } 2006\end{array}$ & $\begin{array}{l}\text { To investigate the } \\
\text { association of } 12 \\
\text { specific health risks } \\
\text { medical conditions and } \\
\text { changes in } \\
\text { presenteeism. }\end{array}$ & $\begin{array}{l}7026 \text { employees of a } \\
\text { large financial services } \\
\text { corporation. }\end{array}$ & $\begin{array}{l}\text { Longitudinal, } \\
\text { comparison of results } \\
\text { from Health risk } \\
\text { assessment (HRA) and } \\
\text { a modified version of } \\
\text { the Work Limitation } \\
\text { Questionnaire (WLQ) } \\
\text { 2002, 2004, \& } 2006 .\end{array}$ & $\begin{array}{l}\text { Confirmed that a change in health } \\
\text { risks (positive or negative) produced } \\
\text { the same directional change in } \\
\text { presenteeism. }\end{array}$ \\
\hline
\end{tabular}


Table 2-2. (continued)

\begin{tabular}{|c|c|c|c|c|}
\hline Source & Objectives & Setting/Subjects & Design and Tool & Relevant Findings \\
\hline $\begin{array}{l}\text { Boles M et } \\
\text { al. } 2004\end{array}$ & $\begin{array}{l}\text { To determine relationship } \\
\text { between health risks status } \\
\text { and work productivity lost } \\
\text { via presenteeism and } \\
\text { absenteeism. }\end{array}$ & $\begin{array}{l}\text { Surveyed N=2264 } \\
\text { employees of a } \\
\text { national employer. }\end{array}$ & $\begin{array}{l}\text { Cross-sectional analysis. } \\
\text { Analysis of variance, } \\
\text { logistic and linear } \\
\text { multivariate analysis. Used } \\
\text { a } 20 \text { question health risk } \\
\text { assessment tool that } \\
\text { contained questions from } \\
\text { the Work Productivity and } \\
\text { Activity Impairment } \\
\text { Questionnaire-General } \\
\text { Health (WPAI-GH) tool } \\
\text { was used. }\end{array}$ & $\begin{array}{l}\text { As number of health risk increase } \\
\text { above one, risk of lost productivity } \\
\text { increased. Risks most prevalent: high } \\
\text { cholesterol }-47 \% \text {, physical inactivity } \\
-45 \% \text {, high stress }-29 \% \text {, and lack of } \\
\text { emotional fulfillment }-24 \% \text {. } \\
\text { Individuals who reported high stress } \\
\text { also reported anF average } 10 \% \\
\text { impairment compared with } 5 \% \\
\text { reported by individuals who did not } \\
\text { report stress. Mean prevalence range } \\
1.3 \% \text { presenteeism with zero risk -- } \\
25.9 \% \text { presenteeism with eight risks. } \\
\text { Presenteeism more associated with } \\
\text { poor diet, physical inactivity, high } \\
\text { stress and lack of emotional } \\
\text { fulfillment }(\mathrm{P}<0.05) \text {, with stress } \\
\text { highest. Different risks are associated } \\
\text { with absenteeism vs. presenteeism. }\end{array}$ \\
\hline $\begin{array}{c}\text { Wang P et } \\
\text { al. } 2003\end{array}$ & $\begin{array}{l}\text { To determine the } \\
\text { associations between } \\
\text { chronic conditions \& } \\
\text { absenteeism, } \\
\text { presenteeism, \& critical } \\
\text { incidents. Also between } \\
\text { chronic conditions \& } \\
\text { absenteeism, } \\
\text { presenteeism, \& critical } \\
\text { incidents. }\end{array}$ & $\begin{array}{l}\text { Employees of } 4 \\
\text { occupations: } 441 \\
\text { reservation agents } \\
505 \text { customer service } \\
\text { representatives, } 554 \\
\text { manufacturer } \\
\text { executives, and } 850 \\
\text { railroad engineers. }\end{array}$ & $\begin{array}{l}\text { Analysis of covariance to } \\
\text { estimate associations for } \\
\text { the purpose of calibration } \\
\text { of surveys. They used the } \\
\text { interviewer version of the } \\
\text { Health and Productivity } \\
\text { Questionnaire }\end{array}$ & $\begin{array}{l}\text { Prevalence of health conditions } \\
\text { associated with lost productivity } \\
\text { varied by occupation. Most common } \\
\text { health conditions across all } \\
\text { occupations were, in order: seasonal } \\
\text { allergies, chronic back/neck pain, } \\
\text { chronic headaches, hypertension, } \\
\text { arthritis, and depression. More work } \\
\text { performance was lost due to } \\
\text { presenteeism than absenteeism. }\end{array}$ \\
\hline
\end{tabular}


Table 2-3 was adapted from the work of Loeppke et al. (2007) and shows the rank order of top ten health conditions associated with medical, pharmacy, absenteeism, presenteeism and overall health cost burden.

\section{Cost Burden of Highly Prevalent Conditions}

The review of literature indicated that the following groups of health symptoms are highly associated with presenteeism and they are reviewed separately to highlight their significant impact and estimated cost burden.

Fatigue often co-occurs with other conditions and is associated with a threefold increase, on average, in the proportion of workers with condition-specific absenteeism and presenteeism (Ricci \& Chee, 2005). Additionally, fatigue is often associated with depression. Using the Current Population Survey, a study performed by Ricci et al. (2005) found that the prevalence of fatigue in the national workforce was $37.9 \%$ for a 2 week period. Of workers with fatigue, $65.7 \%$ reported health-related LPT compared with $26.4 \%$ for those workers who did not have fatigue. Workers with fatigue cost employers $\$ 136.4$ billion annually in health-related LPT, an excess of $\$ 101.0$ billion compared with workers without fatigue (Ricci \& Chee, 2005). Gail Galinsky's research found that nearly half of employees who felt overworked reported that their health was also poor (Galinsky, et al., 2005). According to Galinsky, employees who were likely to adopt behaviors that can put them in a position to succeed professionally - multitasking, quickly moving from one task to another, working long hours, handling frequent interruptions, etc.; are in a position to experience presenteeism.

Pain consisting of pain from arthritis, neck and back pain, migraine and headache pain are a significant source of discomfort related to presenteeism. Stewart, Ricci, Chee, Hahn, and Morganstein (2003b) studied lost productive time and cost due to common pain conditions, found that pain constituted $13 \%$ of the loss productive time during a 2 week period on the population of 28,902 . Headache was the most common $(5.4 \%)$, followed by back pain (3.2\%), arthritis pain (2.0\%), and other musculoskeletal pain $(2.0 \%)$. The average loss of time for all pain conditions was 4.6 hours per week. Lost productive time due to pain conditions is estimated at $\$ 61.2$ billion per year with most (76.6\%) lost due to presenteeism versus absenteeism (Stewart, et al., 2003b).

Migraines are the most common headache disorder, yet it remained underdiagnosed and under-treated (Warshaw \& Burton, 1998). According to Warshaw et al. (1998), the highest prevalence of migraine occurred in adults between 25 and 55 years of age. Women suffered from migraines three times more than men. Estimates are that migraine caused an average 3.2 days lost through absenteeism, and 4.9 days lost through presenteeism. Warshaw et al. (1998) found that those who suffered from migraines were most likely to stay at work with productivity decreased by $31 \%$. Moreover, only $9.4 \%$ of migraine sufferers stay home with a migraine and $9.2 \%$ of those who stay at work reported that their work level was reduced by greater than $50 \%$. In another study on 
Table 2-3. Rank Order of Top Ten Cost Driving Health Conditions from Four Employers

\begin{tabular}{|c|c|c|c|c|c|c|}
\hline $\begin{array}{l}\text { Medical } \\
\text { Claims* }\end{array}$ & Pharmacy Claims & $\begin{array}{l}\text { Total } \\
\text { Claims }\end{array}$ & Absenteeism & Presenteeism & $\begin{array}{l}\text { Total } \\
\text { Productivity* }\end{array}$ & $\begin{array}{l}\text { Overall Cost } \\
\text { Burden }\end{array}$ \\
\hline Other cancer & High cholesterol & Other cancer & $\begin{array}{l}\text { Other } \\
\text { Chronic Pain }\end{array}$ & Fatigue & Fatigue & $\begin{array}{l}\text { Back/neck } \\
\text { pain }\end{array}$ \\
\hline Back/neck pain & $\begin{array}{l}\text { Gastroesophageal } \\
\text { reflex disease }\end{array}$ & Back/neck pain & Hypertension & Depression & Depression & Depression \\
\hline $\begin{array}{l}\text { Other chronic } \\
\text { pain }\end{array}$ & Arthritis & $\begin{array}{l}\text { Coronary heart } \\
\text { disease }\end{array}$ & Fatigue & Back/neck pain & Back/neck pain & Fatigue \\
\hline $\begin{array}{l}\text { Coronary health } \\
\text { disease }\end{array}$ & Diabetes & $\begin{array}{l}\text { Other chronic } \\
\text { pain }\end{array}$ & Arthritis & Sleep Problem & Sleep Problem & $\begin{array}{l}\text { Other } \\
\text { chronic pain }\end{array}$ \\
\hline Sleep problem & Depression & High cholesterol & Obesity & Anxiety & $\begin{array}{l}\text { Other chronic } \\
\text { pain }\end{array}$ & $\begin{array}{l}\text { Sleep } \\
\text { problem }\end{array}$ \\
\hline $\begin{array}{l}\text { High } \\
\text { cholesterol }\end{array}$ & Hypertension & GERD & Depression & Arthritis & Arthritis & $\begin{array}{l}\text { High } \\
\text { cholesterol }\end{array}$ \\
\hline Hypertension & Asthma & Diabetes & $\begin{array}{l}\text { Back/Neck } \\
\text { Pain }\end{array}$ & Obesity & Hypertension & Arthritis \\
\hline Diabetes & Allergy & Sleep problem & $\begin{array}{l}\text { High } \\
\text { cholesterol }\end{array}$ & Chronic Pain & Obesity & Hypertension \\
\hline Headache & Anxiety & Hypertension & $\begin{array}{l}\text { Sleep } \\
\text { problem }\end{array}$ & $\begin{array}{l}\text { High } \\
\text { cholesterol }\end{array}$ & High cholesterol & Obesity \\
\hline Depression & $\begin{array}{l}\text { Coronary heart } \\
\text { disease }\end{array}$ & Arthritis & Anxiety & Hypertension & Anxiety & Anxiety \\
\hline
\end{tabular}

* Does not include disability and worker's compensation.

Source: Adapted with permission from Loeppke, R., Taitel, M., Richling, D., Parry, T., Kessler et al., R, Hymel, P, et al. (2007). Health and productivity as a business strategy. Journal of Occupational and Environmental Medicine, 49, $712-721$. 
headaches by Stewart, Wood, Razzaghi, Reed, and Lipton (2008), they found that the mean lost productive time per week was 1.8 hours for headache while all other health related causes caused 2.8 hours per week. Presenteeism comprised $76.5 \%$ of that time. Yet another study by Stewart, Lipton, and Liberman (1996) indicated that the prevalence of migraines was significantly less in races of African and Asian descent than for Caucasians and concluded that race-related differences in genetic vulnerability to migraine are more likely to predominate as an explanatory factor..

Ricci et al. (2005), again using the Current Population Survey determined the 2 week prevalence of back pain to be $15.1 \%$. Approximately $42 \%$ of workers with back pain experienced pain exacerbations. They found that back pain was reported by $42.6 \%$ of all workers. Back pain with exacerbations related to lost productive time $22.1 \%$ versus $13.0 \%$ without limitations $(\mathrm{P}=.0259)$. Back pain in workers 40 to 65 years of age cost employers an estimated $\$ 7.4$ billion/year. Workers with back pain exacerbations account for $71.6 \%$ of this cost (Ricci \& Chee, 2005).

The US National Arthritis Data Workgroup estimated that approximately $15 \%$ of Americans were living with some form of arthritis in 1995 (Muchmore, Lynch, Gardner, Williamson, \& Burkey, 2003). Ricci et al. (2005) found that the prevalence of arthritis in US workers ages $40-65$ years was $14.7 \%$ during a 2 -week period. Pain exacerbation occurred among $38 \%$ of participants with arthritis. Workers with pain exacerbations, versus those without, were significantly more likely to report arthritis-related LPT ( $24.4 \%$ versus $13.3 \% ; \mathrm{P}=0.0118$ ). In Ricci et al. (2005) study, among those with LPT the average LPT did not differ (4.1 hours per week) between persons with and without exacerbations. The estimated annual LPT cost from arthritis in the US workforce was $\$ 7.11$ billion, with $65.7 \%$ of this cost attributed to the $38 \%$ of workers with pain exacerbations (Ricci \& Chee, 2005).

Researchers have found mixed results about the relationship between presenteeism BMI, overweight, and obesity. Persons with a BMI $>30 \mathrm{~kg} / \mathrm{m}^{2}$ are classified as obese. According to the Agency for Healthcare Research and Quality (AHRQ) over $32 \%$ of adults age 20 and older in the US are obese and this puts them at increased risk of many chronic diseases such as hypertension, cancer, diabetes, and coronary health disease (Agency for Healthcare Research and Quality, 2006). A study performed by Burton, Chen, Schultz, and Edington (1998) showed an association between unhealthy weight, (BMI), and increased likelihood of absenteeism while the Burton, Conti, Chen, Schultz, and Edington (1999) study showed the association also existed with presenteeism. Pronk et al. found a relationship between severe obesity (BMI $40 \mathrm{~kg} / \mathrm{m}^{2}$ ) and absenteeism, but did not find a relationship with obesity and presenteeism (Pronk, et al., 2004). Likewise, in the population that Collins (2005) studied, there was no association attached to BMI when unattached to other chronic illnesses. However, Ricci et al. (2005) in a national study of US workforce, found that obese workers $(42.3 \%)$ were significantly $(\mathrm{P}<0.0001)$ more likely to report LPT in the previous 2 weeks than normalweight $(36.4 \%)$ or overweight workers $(34.7 \%)$. They found that obese workers cost an estimated $\$ 42.29$ billion in LPT with $67.8 \%$ of the cost caused by presenteeism. That 
total amount was $\$ 11.70$ billion more costly when compared with normal-weight workers (Ricci \& Chee, 2005).

Stewart et al. (2003a) projected that health related productivity loss (of which $71 \%$ was for presenteeism) cost employers $\$ 225.8$ billion/year or $\$ 1686 /$ per employee per year. According to Stewart et al. (2003a), these numbers should be compared to the employee rate of $\$ 2606$ per year for what employers spent on health insurance premiums for the average employee (not including dependents) the year of the study-2001. Consistent with these estimates, in a different population Burton et al. (2005) estimated that the annual cost of lost productivity in the company he studied to be between $\$ 1392$ and \$2592 per employee. Taking a different approach, Goetzel et al. (2004) estimated that the overall economic burden of illness for the average per eligible employee per year (based on average impairment and prevalence) was highest for hypertension (\$392), heart disease (\$368), depression and other mental illnesses (\$348), and arthritis (\$327). The research of Goetzel et al. included 5 employer groups, all of whom had 3,000 to 5,000 employees (Goetzel, et al., 2004). Lastly, in a pilot project Vielife, a US based Occupational Health and Wellbeing Company, determined that people with good health can be $20 \%$ more productive than their less healthy colleagues. This between-group difference was equivalent to one extra day of productivity.

Table 2-4 summarizes key presenteeism studies which were reviewed in this section on healthcare costs.

\section{Presenteeism and the Healthcare Workforce}

The healthcare industry and its healthcare workforce is one of the most important and impactful in the US economy (Bodenheimer \& Grumbach, 2008; Longest, 2006). There are more than 13 million healthcare workers in the US and the US Department of Labor's projects that between 2002 and 2012, nearly half of the twenty fastest growing occupations will be in the health care industry (Bureau of Labor Statistics, 2007; Longest, 2006). Moreover, the healthcare segment leads the list of all US industries in job creation. Estimates are that 16 percent of all new wage and salary jobs created between 2002 and 2012 will be in health services - 3.5 million jobs (Bureau of Labor Statistics, 2007; Longest, 2006). Nurses as the largest and pharmacists as the third largest group of health professionals compose the majority of professional health care providers who are employed within the healthcare industry. These professions have the potential to differentiate one health service or product from another, thus increasing or decreasing specific market segment's growth and profitability (Pilette, 2005). Therefore, it can be reasoned that the importance of nurses and pharmacist workforce becomes exponential given that they directly impact the ability of healthcare organizations to provide health care needed by other US workers who collectively must maintain the viability of our nation in a global economic community.

The Institutes of Medicine, American Hospital Association, Joint Commission on Accreditation of Healthcare Organizations, Pew Health Professions Commission, and etc. have all called for efforts to transform and reengineer the health system. This pressure is 
Table 2-4. Summary of Key Presenteeism Studies: Presenteeism and Costs

\begin{tabular}{|c|c|c|c|c|}
\hline Source & Objectives & Setting/Subjects & Design and Tool & Relevant Findings \\
\hline $\begin{array}{l}\text { Goetzel R et al. } \\
2004\end{array}$ & $\begin{array}{l}\text { To establish the total } \\
\text { cost of health, } \\
\text { absence, disability, } \\
\text { and presenteeism of } \\
10 \text { common health } \\
\text { conditions (physical } \\
\text { and mental) affecting } \\
\text { US employers. }\end{array}$ & $\begin{array}{l}\text { N=374,799 employees. } \\
\text { Medstat's MarketScan } \\
\text { Health and Productivity } \\
\text { Management database } \\
\text { was used to generate } \\
\text { metrics for health } \\
\text { administrative claims for } \\
\text { the period } 1997 \text { to } 1999 .\end{array}$ & $\begin{array}{l}\text { Meta analysis combining } \\
\text { data from administrative } \\
\text { records of medical } \\
\text { treatment, administrative } \\
\text { records of employee } \\
\text { absence, and disability } \\
\text { combined with published } \\
\text { productivity survey studies. }\end{array}$ & $\begin{array}{l}\text { Absenteeism }=>10 \text { days lost/year } \\
\text { and presenteeism = } 30 \text { days } \\
\text { lost/year. Top } 10 \text { chronic and acute } \\
\text { conditions with highest economic } \\
\text { burden based on the "average } \\
\text { impairment and prevalence } \\
\text { estimates" for US employees: } \\
\text { hypertension, } \\
\text { depression/sadness/mental illness, } \\
\text { heart disease, arthritis, asthma, } \\
\text { cancer, migraine/headache, } \\
\text { allergies, and respiratory infections. } \\
\text { Presenteeism costs were higher } \\
\text { than medical costs in most cases, } \\
\text { and represented } 18 \% \text { to } 60 \% \text { of all } \\
\text { costs for the top } 10 \text { conditions. }\end{array}$ \\
\hline $\begin{array}{l}\text { Collins J et al. } \\
2005\end{array}$ & $\begin{array}{l}\text { To determine the } \\
\text { prevalence and total } \\
\text { cost estimates for } \\
\text { chronic health } \\
\text { conditions in the US } \\
\text { workforce for five } \\
\text { locations of Dow } \\
\text { Chemical Company. }\end{array}$ & $\begin{array}{l}8000 \text { employees in five } \\
\text { Dow Chemical Company } \\
\text { locations. }\end{array}$ & $\begin{array}{l}\text { Survey using Stanford } \\
\text { Presenteeism Scale and } \\
\text { SF-36 to identify global } \\
\text { health was merged with } \\
\text { demographic, medical, and } \\
\text { pharmaceutical claims, } \\
\text { biometric health risk } \\
\text { factors, payroll records, } \\
\text { and job type. }\end{array}$ & $\begin{array}{l}\text { Presenteeism associated with } \\
\text { chronic conditions resulted in } 44.5 \\
\text { to } 91 \text { days/yr. versus absenteeism } \\
1.35 \text { to } 8.85 \text { days. Those with } \\
\text { depression, anxiety, or emotional } \\
\text { disorder experienced highest } \\
\text { presenteeism at } 64.4 \% \text {, the range } \\
\text { for productivity loss was } 17.8 \% \text { to } \\
36.4 \% \text {. Migraines, back or neck } \\
\text { pain, and breathing disorder were } \\
\text { predictors of presenteeism. Costs } \\
\text { associated with presenteeism } \\
\text { greatly exceeded the combined } \\
\text { costs of absenteeism and medical } \\
\text { treatment combined. }\end{array}$ \\
\hline
\end{tabular}


believed to be caused partly by the cost burden of healthcare in the US and partly because "the shortage of health care workers is becoming so critical that it threatens the quantity and quality of health care, including patient safety" (Sellers \& White, 2002). Nurses and pharmacist as healthcare professionals have similar professional challenges in the context of the U.S. sociopolitical environments. Various researchers (Agency for Healthcare Research and Quality, 2006; American Organization of Nurse Executives (AONE), n.d.; Knapp \& Cultice, 2007; Knott \& Moscovice, 2000; Pilette, 2005; Rhoads, et al., 2006; Simpson \& Bolton, 2007; Woods, 2007) have reported common issues.

The list below is a partial list of concerns mentioned in literature focused on both professions:

- $\quad$ Critical workforce manpower and staffing patterns shortages

- $\quad$ Expanded knowledge-based roles using increased cognitive services, while still expected to render more technical or procedural services

- Under-represented numbers of ethnic and racial minorities

- $\quad$ Changing workforce demographics in terms of age and/or gender

- Transformed or reengineered professional educational requirements

- $\quad$ Need to develop new skills to use rapid technological innovations

- Clinical practice changes due to biological, genetic, and ecological innovations

- $\quad$ Expanded responder requirements for natural and terrorist disaster realities

- Uncertainties in US health policies

- $\quad$ Ever evolving healthcare market place

Much of the literature about both professions indicates that there are concerns about manpower and staffing patterns in terms of high demand, turnover, technical support, and technology use (Mott, et al., 2005; Pilette, 2005). However, according to Chou and Johnson (2008), healthcare workforce studies have primarily focused on demand and supply of health professionals, while research examining the health of health care workers and the implications are limited. Although more was published about nurses, much of it fails to distinguish between varying levels of nurses and more empirical data outside of the US health system was found than inside the US. Additionally, information on the health of the profession of pharmacists was also scarce, with more data becoming available in the mid to late 90's after pharmacy extended its educational requirement to the doctorate level. Some of the limited data on each profession follows in the next sections. 


\section{Nurses}

Since World War II, hospitals in the US have had cyclical shortages of nurses (Longest, 2006). According to the Tennessee Hospital Association, Tennessee's vacancy rate in 2001 was $9.44 \%$ for nurses. However, the American Hospital Association reports a national nursing vacancy rate of over 20\% (Buerhaus, Auerbach, \& Staiger, 2007). Moreover, other recent reports indicate that the nursing short fall is projected to be $36 \%$ by 2020 (Agency for Healthcare Research and Quality, 2006). The following factors are believed to influence the nursing shortage: a diminished pipeline of new students, a shortage of faculty, a decline in RN earnings relative to other career options, low job satisfaction, burnout, poor working conditions, increased attrition rates, an aging patient population with more intense healthcare services needs, and an aging nursing workforce (Kaiser Family Foundation, 2004; Longest, 2006). While there are undoubtedly a complexity of these factors impacting the current nursing shortage, a primary factor is reportedly burnout levels among nurses (Aiken, Clark, Sloane, Sochalski, \& Silber, 2002; Buerhaus, et al., 2007; Pilette, 2005; Shamansky, 2002). Shirey (2006) indicates that understanding the impact of stress and health on nursing in a greatly re-engineered role is crucial to maintaining an adequate nursing workforce in the future.

Previous empirical studies about the nurse workforce have not taken a macro view of the profession and focused on the personal health of nurses. In most instances, a micro views of the profession from one employer type occurred and the studies focused on the external environment and implications for nurse management or healthcare employers in creating work environments and work schedules to meet business needs (Knapp \& Cultice, 2007; Pilette, 2005).

An exception to the above is a study by Letvak et al. (2008) that sought to identify how work productivity of the nurse workforce is affected in older age. The average age of a nurse in Tennessee is 44 years and one half of the RN workforce will reach retirement age in the next 15 years (Tennessee Hospital Association, n.d.-b). However nationally, approximately $40 \%$ of the nurse workforce are expected to be over age 50 by 2010 (Letvak \& Buck, 2008). An ageing workforce of nurses is upon us. Letvak et al. (2008) studied 323 RNs who were employed in direct care in three hospitals in a southern U.S. state. Using the Work Productivity and Activity Impairment Questionnaire: General Health (WPAI-GH) tool to measure work productivity in the form of absenteeism and presenteeism, they documented relationships between individual and workplace characteristics, decrements in work productivity, and intent to stay employed in direct patient care in the hospital setting (Letvak \& Buck, 2008). Their study consisted of RNs of whom $87 \%$ worked an average 12.41 hours per day on a 12-hour day, their mean BMI was 26.1, and over half were overweight. However, this number was lower than the average that is $66 \%$ of U.S. adults overweight. The nurses were also, on average, younger ( 40.2 years old) than the national average nurse at age (46.8 years old) as reported by HRSA for the 2004 Nurses study. The number of years a nurse worked as a nurse was associated with a decline in work productivity, the range of time worked was 4 months to 50 years, $\mathrm{SD}=10.2$. The mean numbers of patients taken care of were 4.5. Having a health problem or job injury was associated with lowered work productivity. The mean work activity impairment score was $12.71 \%$ (range $0-90 \%, \mathrm{SD}=18.56)$. On a 
presenteeism range of 1-8, nurses reported an average health score of $5.72(\mathrm{SD}=1.43)$; $22.4 \%$ reported having at least one health problem, and $24.8 \%$ had a job-related injury within the past 2 years. The most frequently reported health problems were headache at $23.8 \%$; back pain at $21.4 \%$; joint pain at $16.7 \%$, anxiety at experienced $15.8 \%$, stomach problems at $14.9 \%$, hypertension at $13.9 \%$; depression at $12.4 \%$; and insomnia at $12.1 \%$. Of note in this study is that $63.2 \%$ of nurses worried occasionally about job injury, with $12.1 \%$ worrying more regularly. The mean job stress score was 47.9 (range 16-85, $\mathrm{SD}=14.9$ ). Higher job stress was significantly associated with being female, working more hours in a day, working day shift, being worried about injury and feeling unable to meet the needs of patients. In this study approximately $25 \%$ of the nurses experienced back pain also experienced lowered work productivity. Other health problems associated with low work productivity were joint pain, depression, anxiety. Of the nurses in this study, $16 \%$ planned to leaving nursing for retirement reasons and $28 \%$ planned to leave hospital nursing because of job stress. Nurses felt they were unable to meet the needs of their patient on average $12.7 \%$ of time. Approximately $73 \%$ felt they provided excellent to very good care and most were either highly or generally satisfied with their jobs -$93 \%$. Inability to provide quality of care and poor job satisfaction were also associated with a lack of intent to stay in the nursing at the bedside for 5 the next years.

Letvak et al. (2008) concluded that individual characteristics (longer years in nursing); longer work hours and day shifts; job stress; and health (having had a job injury and having a health problem) are associated with decrements in work productivity and intent to no longer stay in nursing at the bedside. The study supported other empirical studies (2005) that report that high levels of job stress contribute to a decrease in perceived worker productivity. Letvak et al.(2008) concluded that improving the hospital workplace environment to decrease job stress, providing adequate staffing so quality of care can be provided will enhance job satisfaction and as a consequence may encourage nurses to stay at the bedside and delay older nurses' retirement. Letvak et al. surveys were collected at each worksite and, and even though the surveys were turned in anonymously, the impact of bias in sample selection and response is unknown. Additionally, in quantifying productivity loss, Letvak's study did not separately differentiate quantity of work loss through absenteeism versus presenteeism, as was allowable using the WPAI. Letvak et al. (2008) was a recent study and the only one known to be published that specifically analyzed health productivity outcomes and quantified the impact on work productivity of U.S. nurses. No other US studies were noted on this issue, however there were several related studies in other countries and a few related factors are reviewed as follows.

A 2005 National Survey of the Work and Health of Nurses in Canada was performed as part of a national health workforces study in Canada such that the health of nurse could be benchmarked against the health of other employees. The Canadian study found that a number of physical and mental health problems were more prevalent in nurses than in employed in the larger population of all Canadian workers. Back problems and arthritis at $25.1 \%$ among female nurses versus $19 \%$ in female Canadians. Additionally pain was much more significant for nurses in that $33 \%$ had pain serious enough to prevent them from carrying out their normal daily activities including work. 
Greater than $10 \%$ reported severe or unbearable pain and $25 \%$ said pain affected their nursing duties. Nurses were also more likely than the larger population to experience depression, $9 \%$ for male and female nurses versus only $7 \%$ for females and $4 \%$ males in the larger population. No significant differences were noted for men. The following were conditions and percentages for common health conditions experienced by nurses in Canada were as follows: arthritis $15.2 \%$, back problems $25.1 \%$, at least one musculoskeletal condition $33.5 \%$, allergies $31.2 \%$, asthma $10.2 \%$, migraine $17.7 \%$, cancer $1.8 \%$, stomach or intestinal ulcers $3.6 \%$, sleep disorder $8.4 \%$, bowel disorder $4.7 \%$, and thyroid condition $9.6 \%$. The average percentage of Canadian nurses who felt role overload was $12.1 \%$, with $27.8 \%$ having a high score, and $30.7 \%$ reporting high job strain. Self-reports of fair or poor general health among Canadian nurses were found to be statistically significantly related to work stress, job strain, low support, high job insecurity and high physical demands. Of particular consequence is that they found this to be true even though nurses were no more likely to be obese, were less likely to smoke, and more likely to live in households with high incomes (Canadian Institute for Health Information, 2006).

The average annual number of days absent for all nurses in Canada was 14.5 days and $33 \%$ stated that at least some time in the previous month that their physical health had made it difficult to handle their workload. Factors that contribute to burnout--high work stress, including high job strain, low support from their supervisor or coworkers, high job insecurity and high physical demands--were associated with fair or poor general health status in the national Canadian study of nurses (Canadian Institute for Health Information, 2006). Moreover, a study that included nurses among many other occupations in Sweden, found that members of occupational groups whose everyday responsibilities are to provide health care or welfare services, or educate, were also found to have a substantially higher risk of experiencing presenteeism (Aronsson, Gustafsson, \& Dallner, 2000).

The Canadian nurses' study finding were consistent with one important longitudinal study of US nurses who were in low-control and high demand jobs, that found that over a 4-year period, the health of nurses deteriorated more than would have been expected if they had smoked or led sedentary lives (Lynch, Mercer, \& Reidel, 2001). The Canadian as well as Lynch findings were all consistent with other findings in the U.S. that indicate that women, more than men in the US, are more likely to report having arthritis, asthma, and serious mental illness (Agency for Healthcare Research and Quality, 2006). Given the larger component of women nurses, since the Canadian study found that nurses had more such illness than other women in the Canadian workforce, this kept the gender issue in perspective when comparisons were made.

Unfortunately, even during workforce shortages in the past, nursing staffing levels and benefits were often decreased as a matter of cost cost-cutting strategies (Pilette, 2005). For example, between 1981 and 1993, total hospital employment grew steadily, while nursing personnel declined by $7.3 \%$ after case-mix controlled (Aiken, Sochalski, \& Anderson, 1996). Studies in the U.S. indicate that inadequate staffing has been associated with back injuries among nurses (Lipscomb, Trinkoff, Brady, \& Geiger-Brown, 2004). In 
a cross-sectional study of 1163 nursing, Lipscomb et al. (2004) found that the odds ratios for neck, shoulder, and back musculoskeletal disorders showed a consistent and increasing trend with the level of reported health care system change experienced by nurses. The specific health care system changes referenced were ones that, within the course of a year, resulted in $65 \%$ increase in patient loads and $68 \%$ increase in patient acuity. The result was a 3-fold increase in neck and back musculoskeletal disorders. Among nurses, the prevalence for these disorders were as follows neck $20 \%$, shoulder $17 \%$, and back musculoskeletal-disorders 29\% (Lipscomb, et al., 2004). Lipscomb et al. (2004) concluded that nurses experienced difficult work conditions that have an impact on their health over and above the psychological and physical job demands.

According to the 2002 General Social Survey of the National Opinion Research Center, $89.1 \%$ of all employed individuals in the U.S were moderately or extremely satisfied with their jobs. However, according to a US national survey of nurses, nurse job satisfaction numbers were lower than average employees at $76.4 \%$ for nurses (Health Resources and Services Administration, 2004). In March of 2004, approximately 16.8\% of licensed nurses were not employed in nursing. Most were older than the general population of nurse 54.1 versus 45.4 years of age (Health Resources and Services Administration, 2004). Of 19 reasons listed, the number one reason for $44.9 \%$ of the nurses to leave the profession was burnout/stressful work environment, next was scheduling/too many hours $41.4 \%$, inadequate scheduling $33.3 \%$ and illness $4.9 \%$ and disability $4.7 \%$ (some nurses indicated more than one reason). Of the reasons that nurses left a position for another nursing position with the past year, the number one reason was burnout/stressful environment at $46 \%$ and for scheduling/inconvenient hours $29.6 \%$.

\section{Pharmacists}

There are no known studies of presenteeism in the pharmacist workforce which exists to date. The Health Resources and Services Administration, Bureau of Health Professions indicated that the country may face a critical shortage of pharmacists unless educational production can be expanded or unless ways were found to further increase the productivity of pharmacists (Health Resources and Services Administration, 2004). Although this statement was used to emphasize need to eliminate environmental barriers so that the pharmacists are freed from direct dispensing roles; it can be reasoned that interventions to increase individual productivity or capacity-improvement would also be of benefit to the profession.

The American Hospital Association reports a national vacancy rate of over $10 \%$ for five key health professions, one that includes pharmacists at 7-13\% nationally (Manasse, 2003). Empirical data that described personal health problems that was related to productivity of pharmacists was sparse; however, empirical data that concluded that pharmacists' work affects the health of pharmacists was plentiful. The 2004 National Pharmacist Workforce Survey included a quality of work-life supplement and scholars have been able to take the results of those data and make inferences on its potential impact. Approximately 30\% of pharmacists reported feeling that their work impacted their mental or emotional health 'negatively' or 'very negatively.' When asked the effect 
of workload on their physical health, $27 \%$ felt physical health was impacted 'negatively' or 'very negatively.' Moreover, $48 \%$ of pharmacists felt that work negatively or very negatively impacted their opportunity to take adequate breaks. A 2007 Pharmacist Task Force reported that $86 \%$ of licensed pharmacists were actively practicing and $23 \%$ of those planned to leave their position within the year (American Society of Health System Pharmacists, 2007). Of those planning to leave their position, 35\% indicated the reason was related to stress. Pharmacists turnover rate was 11\% from 1980-1997, but the rate for those who planned to leave their job went up to $31 \%$ in 2000 before it went down to $23 \%$ in 2004 (Mott, et al., 2005). Nationally in 2004, women pharmacists had a higher annual turnover rate $15 \%$ than men at $9.7 \%$, and twice as many women pharmacist worked parttime compared to men. A report released in 2006 that commented on the 2004 National Pharmacist Workforce Survey predicted a worsening of the shortage of active pharmacists mainly related to the increasing number of women in the field and their desire to work part-time (Edwards \& Patry, 2006). The Pharmacist profession was described as increasingly female at $50 \%$ nationally in 2003 , and was projected to be $64 \%$ female by 2020 (Gershon, Cultice, \& Knapp, 2000). The average tenure of a pharmacist job was 6.8 per year in 2004 (Mott, et al., 2005). Pharmacist workloads increased from 2000 to 2004 with $47 \%$ of pharmacist reporting that their workload was 'high' or 'excessively high' in 2004 . Over $66 \%$ of pharmacists reported overall scores above midpoint for role overload (Health Resources and Services Administration, 2004). Approximately a third of all pharmacists rated as highly stressful the following: inadequate staffing, interruptions by patients or provider phone calls, dealing with difficult patients, and having more work than time at work. Pharmacists in community settings indicated that frequent interruptions are the norm and that such interruptions can have a significant effect on memory, loss of concentration or lead to medical errors (Malone, et al., 2007). Higher workloads were associated with higher rates of safety incidences of drug-drug interactions called DDIs (OR $=1.10 ; 95 \% \mathrm{CI} 1.09-1.11$ ) (Malone, et al., 2007). More women than men rated items as highly stressful with the exception of paperwork.

As mentioned above, $23 \%$ of pharmacist planned to leave the profession within the year and 35\% indicated is was due to stress, however an even larger number percent, $55 \%$, indicated it was because of work schedule (Health Resources and Services Administration, 2004). Pharmacists suffer chronic staffing shortages and a need to provide around-the-clock care that means they are working many extra shifts at undesirable times (Woods, 2007). As mentioned previously, according to the 2002 General Social Survey of the National Opinion Research Center, 89.1\% of all employed individuals in the U.S were moderately or extremely satisfied with their jobs. However, for pharmacists job satisfaction numbers 68\% (Health Resources and Services Administration, 2004). Within the Institute of Medicine's (IOM) "To Err is Human, Building a Safety Health System" (Koch, Corrigan, \& Donaldson, 2000), staffing and work assignment deficiencies were deemed to be major causes of a large number $(29 \%)$ and variety of medical errors that the health care system needed to implement systems to stem. 
As pharmacists transition away from of primary role of drug dispensing to multiservices recognized as cognitive health care services, pharmacists assumed responsibilities such as medication management, direct patient consultations, and routine materials and people management (Manasse, 2003). Academic preparation began in the 1990's for such changes that were designed to facilitate the role of pharmacist at the doctoral level degree: Pharm D. Pharmacists are expected to need more management, scientific, and clinical expertise as they provide more cognitive services while technicians take over dispensing (Manasse, 2003). Studies have shown pharmacists play a vital role in providing care that results in better quality, efficiency, and efficacy for primary roles in disease management, patient compliance, and assessing patient risk. Studies that are exemplars for such roles include disease management conducted in the Asheville Project, counseling at risk patients through the North Carolina project, the project Improve Persistence and Compliance with Therapy (IMPACT), and medication planning and patient education in the State of Mississippi Medicaid program. (Blumi, McKenney, \& Cziraky, 2000).

However, some pharmacists find themselves unable to relinquish traditional roles to the extent desired in order to function at higher levels reflective of their education and training. A 1999 survey of pharmacists working in an ambulatory setting found that pharmacists continued to serve both roles. In addition to traditional roles of patient and physician education about medications, pharmacists were monitoring patient compliance and conducting wellness and preventive health programs and approximately $50 \%$ of respondents also performed: pharmacoeconomic studies for formulary decisions, medication management programs, track adverse events, negotiate pharmaceutical contracting, perform pharmcoepidemiology decisions, and design pharmacy benefits. Pharmacists roles are expanding to the extent that "essentially every area of our health systems are requesting new pharmacy services" (Woods, 2007). Pharmacists indicate that the profession has the ability to influence every aspect of the medication use process - prescribing, dispensing, administration, and monitoring (Woods, 2007). There is evidence that involving pharmacists in roles such as medical rounds reduces medical errors by $66 \%$ and their involvement in counseling patients in community pharmacies can decrease errors by 28\% (Health Resources and Services Administration, 2004).

The parallels in the evolution of both the nursing and pharmacy profession to include doctoral preparation are numerous. However, as increased opportunities to value these professionals' human capital, may come increased challenges to maintain a healthy workforce. Unintended health consequences can impact the value of both professions if. such conditions are not mediated. The impact of stress and experience overload has been quantified in nursing and can be inferred among pharmacists.

Table 2-5 summarizes key presenteeism studies which were reviewed in this section on the healthcare workforce. 
Table 2-5. Summary of Key Presenteeism Related Studies: Presenteeism and Healthcare Workforce

\begin{tabular}{|c|c|c|c|c|}
\hline Source & Objectives & $\begin{array}{l}\text { Setting/ } \\
\text { Subjects }\end{array}$ & Design and Tool & Relevant Findings \\
\hline $\begin{array}{c}\text { Lerner D } \\
2004\end{array}$ & $\begin{array}{l}\text { To describe } \\
\text { the impact } \\
\text { of } \\
\text { depression's } \\
\text { negative } \\
\text { symptoms } \\
\text { on multiple } \\
\text { dimensions } \\
\text { of varied } \\
\text { types of job } \\
\text { components. }\end{array}$ & $\begin{array}{l}\text { They } \\
\text { recruited } \\
\text { patients from } \\
\text { primary care } \\
\text { physician } \\
\text { offices. }\end{array}$ & $\begin{array}{l}\text { Administered the Work } \\
\text { Limitations Questionnaire to } \\
\text { patients with depression } \\
\text { compared to a control group. }\end{array}$ & $\begin{array}{l}\text { When employees' occupations required } \\
\text { employees to have high client contact with the } \\
\text { public, the result was that the employees' health } \\
\text { problems were associated with larger losses in } \\
\text { ability to handle mental and interpersonal } \\
\text { demands as well as physical job demands. Two } \\
\text { groups of depression symptoms increased } \\
\text { employee productivity loss - difficulty } \\
\text { concentrating and distractibility. Those } \\
\text { employees having these two symptoms had } \\
\text { poorer presenteeism scale scores and more } \\
\text { presenteeism loss. }\end{array}$ \\
\hline $\begin{array}{c}\text { Letvak S } \\
2008\end{array}$ & $\begin{array}{l}\text { To identify } \\
\text { how work } \\
\text { productivity } \\
\text { of the nurse } \\
\text { workforce is } \\
\text { affected in } \\
\text { older age. }\end{array}$ & $\begin{array}{l}\text { Letvak et al. } \\
\text { studied } 323 \\
\text { RNs who } \\
\text { were } \\
\text { employed in } \\
\text { direct care in } \\
\text { three } \\
\text { hospitals in a } \\
\text { southern U.S. } \\
\text { state. }\end{array}$ & $\begin{array}{l}\text { Used the Work Productivity and } \\
\text { Activity Impairment (WPAI) } \\
\text { tool to measure work } \\
\text { productivity in the form of } \\
\text { absenteeism and presenteeism, } \\
\text { they documented relationships } \\
\text { between individual and } \\
\text { workplace characteristics, } \\
\text { decrements in work } \\
\text { productivity, and intent to stay } \\
\text { employed in direct patient care } \\
\text { in the hospital setting. }\end{array}$ & $\begin{array}{l}\text { Having a health problem/job injury was } \\
\text { associated with lowered work productivity. The } \\
\text { mean work activity impairment score was } 12.71 \% \\
\text { (range } 0-90 \%, \mathrm{SD}=18.56 \text { ). Conclusions were that } \\
\text { individual characteristics (longer years in } \\
\text { nursing); longer work hours and day shifts; job } \\
\text { stress; and health (having had a job injury and } \\
\text { having a health problem) were associated with } \\
\text { decrements in work productivity and intent to no } \\
\text { longer stay in nursing at the bedside. The study } \\
\text { did not separately differentiate quantity of work } \\
\text { loss through absenteeism versus presenteeism. }\end{array}$ \\
\hline
\end{tabular}




\section{Presenteeism and a Diverse Workforce}

There is a real vacuum in health-related productivity studies that empirically examine presenteeism and race/ethnicity. The studies that follow are noted here because they have several presenteeism predictors or related factors relevant to this study and these factors vary by race and ethnicity.

The National Health Interview Survey of 2002 examined the prevalence of limitations with activities of daily living (ADLs) and instrumental activities of daily living (IADLs) across racial ethnic groups (Laviest, 2005). Activities related to daily living such as personal care and bathing or showering, dressing, getting into or out of bed or a chair, using the toilet, and eating are considered ADLs. Activities of daily living were considered an important indicator of the health status of a population and were closely associated with several chronic health conditions (among those mentioned were arthritis, osteoporosis, and stroke) (Laviest, 2005). Activities related to independent living such as preparing meals, managing finances, shopping, housework, and using the telephone are considered IADLs (Laviest, 2005). Results of the national survey for ADLs were that African Americans and Hispanics (both 12\%) had the highest limitations, followed by Asians (9\%), and Whites (6\%), with no information available about American Indians/Alaskan Natives. For IADLs the findings were that more than $25 \%$ of American Indians/Alaskan Natives report at least one IADL, with African Americans (19\%), Hispanics (17\%), Asian (16\%) and Whites (12\%). In self-assessed health status, African-Americans have the highest percentage of persons reporting their health status is fair or poor health (15.4\%), American Indians (14\%) and Hispanics (13\%) were closely following. These rates were nearly double that of Asians and Whites at around $8 \%$.

One other study, performed by Lofland and Frick (2006) of the Johns Hopkins Bloomberg School of Public Health, also included a national workforce from the 19961999 Medical Expenditure Panel Survey (MEPS) of non-institutionalized US employees ages 18-65 years. It was a retrospective study of workplace absenteeism that examined the relationship between health insurance and absenteeism. They also wanted to determine how absence days may be modified by level of access to care and healthcare utilization. While MEPS did not capture presenteeism, it captured absenteeism when the work time lost was at least half a work day. Files of 25,676 individuals revealed that $54 \%$ reported missed work days. The mean annual number of missed workdays was 4.3 (Range, 0.0027-240 days; SE, 0.099). Eight-four percent of respondents were white and $16 \%$ non-white. The mean age was 38 years old. Fifty-three percent were greater than a high school education. Among employers that offer health benefits, the percentage of employees covered by their health plan decreased from $64 \%$ in 2001 to $61 \%$ in 2004 . For health status, $93 \%$ reported their health status as good to excellent and $97 \%$ reported their mental health status good to excellent. For medical conditions, $19 \%$ had 0 health conditions, $22 \%$ had 1 conditions, $19 \%$ had 2 conditions, and $14 \%$ had 3 medical conditions. Six percent reported experiencing a depressive condition. Noteworthy is that none of their findings revealed significant differences across race for insurance, health care utilization, or days absent (Lofland \& Frick, 2006). They found that being female, employed, having a depressive conditions and an increased number of medical conditions were significantly $(\mathrm{p}=0.000)$ associated with missing more workdays. They also found 
that having health insurance anytime over the previous year was significantly associated with the decreased likelihood and number of missed work days (Lofland \& Frick, 2006). However, in this investigation, having access to care did not change the relationship between health insurance and workplace absence. In retrospect, the authors came to believe that healthcare utilization should be considered an explanatory variable and found it to be a confounder for health insurance in their study. They hypothesized that having insurance has an effect on productivity, but that the greatest impact would be in workplace presenteeism - that was not part of their study. They recommended that employers offer health insurance to their employees to decrease days absent.

Chou and Johnson (2008) of the University of Minnesota examined whether health status and obesity prevalence differed by race/ethnicity in a healthcare workforce aged 20 to 64 between the years 1982 and 2004. They reviewed 49,216 US health care workers from the Integrated Heath Interview Series (a cross-sectional time series of harmonized National health Interview Survey (NHIS) public use files). Race was selfreported for Asian, non-Hispanic Black, Hispanic, and non-Hispanic Whites. Educational category was college degree or not. They divided the health occupations into 4 categories: health diagnosing occupations; health assessing and treating occupations; health technologists and technicians; and health service. Both registered nurses and pharmacists were in the Health assessing and treating occupational category that comprised about $38 \%$ of healthcare workers in the study. The participants were predominately women (87\%). Blacks made up $15 \%$ of the total workforce but were underrepresented in health diagnosing professions (MD, OD, etc.) at $4 \%$ and overrepresented in the health service work at 28\%. Johnson reported that disparities were apparent when stratifying health status and obesity by workforce category except for those professionals in the health diagnosing category. This category composed the higher income professions of physicians and other doctorally prepared clinicians. Overall Black, Hispanic and Asian health care workers were less likely to report excellent health than White healthcare workers. In terms of obesity, only Asian health workers were less likely to be obese than White workers across the categories of health care workforces. The authors admit that there were few Blacks and Hispanics in the health diagnosing professions allowing for limited power detection of significant differences.

Huang, Chung, Kroenke, \& Spitzer (2006) examined functional status scores, disability days, health care, and symptom related difficulties in 5,427 primary care patients who worked and also scored positive for depression $(n=3000)$. They found that African Americans and Latinos reported slightly lower functional impairment than nonHispanic whites at comparable levels of depression severity. Huang used number of disability days, health care use, and the Short-Form 20 (SF-20) tool to determine functional status.

Considering that empirical data consistently reports poorer physical health outcomes across ethnic racial minorities, it is noteworthy that the trend is not the same for mental health conditions. Researcher Joshua Breslau found that members of disadvantaged minority ethnic groups in the United States do not have an increased risk for psychiatric disorders. Instead, disadvantaged members displayed tendencies to have 
more persistent psychiatric disorders when such illnesses were present (Breslau, Kendler, $\mathrm{Su}$, Gaciola-Aguilar, \& Kessler, 2005). Specifically, where differences across minority ethnic groups were found in lifetime risk, socially disadvantaged groups had lower risk. Compared to Non-Hispanic Whites, Hispanics had lower lifetime risk of substance use disorder and Non-Hispanic Blacks had lower lifetime risk of mood, anxiety and substance use disorders. Where differences were found in persistence of disorders, disadvantaged groups had higher risk. Hispanics with mood disorders were more likely to be persistently ill as were Non-Hispanic Blacks with respect to both mood disorders and anxiety disorders. These differences were generally consistent across population subgroups (Breslau, et al., 2005). These findings by Breslau were based on examination of a nationally representative sample of individuals. He believed that such a widely representative sample of racial and ethnic minorities had not previously been studied for psychiatric disorders. Breslau's findings were consistent with findings from the National Comorbidity Survey (NCS) and Agency for Healthcare Research and Quality's (AHRQ) 2006 National Health Disparities Report that indicates that African Americans are also less likely than Whites to have major depression (11.6\% vs. $17.7 \%)$, panic disorder $(1.4 \%$ vs. 3.9\%), phobic disorder (19.2\% vs. $22.3 \%)$ and dysthymic disorder (5.4\% vs. $6.7 \%)$ (Agency for Healthcare Research and Quality, 2006; Laviest, 2005). Supporting Breslau's findings of greater persistence of psychiatric disorders, was the finding by AHRQ (2006) that of those who experienced problems, only 16\% of African Americans with a diagnosable mood disorder saw a mental health specialist, and less than one-third consulted a health care provider of any type. However, they implied that the disorders were there but not diagnosed and speculated that the finding was related to minorities having less access to mental health care and are less likely to receive needed services that may reflect, in part, variation in preferences and cultural attitudes toward mental health (Agency for Healthcare Research and Quality, 2006). According to Laveist (2005), more African Americans seek assistance for their mental health concerns from primary care providers and spiritual advisors than psychiatrist and other mental health practitioners (Laviest, 2005).

The effects of treatment of minorities versus non-minorities in a primary care setting have been examined and the findings indicated that guideline concordant depression care by a health provider is effective with both minority and non-minority patients (Miranda, et al., 2003). Miranda et al. (2003) examined not only the clinical status, but included the functional outcomes of depression care of 1,360 members of six managed care organizations. The sample consisted of 601 whites, 258 Latinos, 56 African Americans, and 24 Asian and Native Americans. Even though Mirando et al. (2003) found response to treatment was equally effective at 6 months post treatment, they concluded that minorities were less likely to have positive functional outcomes such as continued employment. Again, this information is relevant to the current presenteeism research in predicting which health conditions may impact differently across racial and ethnic groups of employees. There were no indications of whether job terminations were initiated by the employee or employer.

Certain health conditions have been found to be more prevalent across racial and ethnic populations and when they occur, have been treated differently for ethnic/racial 
minorities than for non-minorities. A brief exploration of those illness seemed fitting in order to be able to put in perspective prevalence of and presenteeism outcomes for illnesses found in the workforce being studied in this research.

Nicholson and colleagues (2006) performed a study of patients with migraines in a primary care setting. The patient population included African Americans and Caucasians and the rate of utilization, diagnosis, and treatment for both groups were low. They found that compared to Caucasians, African Americans were less likely to utilize the health-care setting for migraine treatment ( $46 \%$ to $72 \%)$, to have been given a headache diagnosis $(47 \%$ to $70 \%)$, and to have been prescribed acute migraine medications (14\% to $37 \%$ ). All results were significant at $\mathrm{P}<.001$ (Nicholson, et al., 2006). The study found that trust and communication were factors in these results and encouraged provider and patient improved education about the illness and increased culturally appropriate communications.

From the National Business Group on Health, the following data were prepared under contract for the Office of Minority Health under the Office of Public Health and Science for the US Department of Health and Human Services and those facts most relevant to the current research follow (Weinstock, 2003).

- $\quad$ More than one in ten Hispanics (12.9\%), and Blacks (14.6\%) compared to $7.9 \%$ Whites, rated their health as fair or poor (Agency for Healthcare Research and Quality, 2006).

- $\quad$ Timely delivery of appropriate care results in improved health care outcomes and reduced costs of health care. More than $52 \%$ of Black and $45 \%$ of Hispanics report having difficulty getting care because of their racial or ethnic backgrounds while only $21 \%$ of Whites reported such difficulty (Weinstock, 2003).

- $\quad$ Blacks and Hispanic adults aged 18 and older are more likely than whites to report chronic conditions such as high blood pressure, health disease, cancer, diabetes, asthma, anxiety, depression or obesity (Agency for Healthcare Research and Quality, 2006; Kaiser Family Foundation, 2002).

- $\quad$ Asthma can be appropriately monitored, treated, and managed in an outpatient setting. Blacks are more likely to be hospitalized for asthmarelated health conditions and less likely to be treated by an asthma specialist (Zoratti, et al., 1998).

Obesity and diabetes puts US workers at significantly more increased risk for heart disease (Commonwealth Fund, 1998).

- Mortality and morbidity rates of diabetes among Black, Hispanic, and American Indians/Alaska Natives are 50\% to $100 \%$ higher than among Whites. Insured racial and ethnic minorities are significantly less likely 
than Whites to receive diabetes education as well as the recommended standards of preventive and treatment care for diabetes (Agency for Healthcare Research and Quality, 2006).

- Rates of heart disease mortality have decreased the most for whites and the least for Blacks. Mortality rates for heart disease are $50 \%$ higher for Blacks than Whites (Agency for Healthcare Research and Quality, 2006).

- $\quad$ Blacks are two times more likely to have diabetes than whites (Agency for Healthcare Research and Quality, 2006).

- $\quad$ More than three-fourths (68) of 80 studies conducted between 1984 and 2001 found disparities in cardiac care for at least one racial and ethnic minority groups and of these 68 studies, 46 found difference in cardiac care treatment for at least one racial and ethnic minority group (Kaiser Family Foundation, 2002).

- $\quad$ Insured Blacks and Hispanics are significantly less likely than insured Whites to undergo angiography, heart bypass surgery, or cardiac catheterizations that are effective procedures used to diagnose and treat heart disease (Kaiser Family Foundation, 2002).

Approximately $40 \%$ of cancer cases occur in people between the ages of 18 and 64 that are in their prime working years (National Business Group on Health, 2003). Screening rates among equally insured racial and ethnic minorities are lower than among whites.

- $\quad$ Black women with breast cancer are significantly less likely than white women with breast cancer to receive radiation therapy in combination with mastectomy.

- $\quad$ Black women with breast cancer are significantly less likely to get a progesterone receptor assays that is an important prognostic test.

Research by George Rust, from Morehouse College, and Lisa Cooper, from Johns Hopkins, has included a review of promising strategies to increase the impact of research on eliminating health disparities in America. They discuss that the Veteran's Health Administration's systems of health services seems to have overcome disparate outcomes in populations that traditionally suffer from high rates of health disparities-low-income, uninsured, minority populations. They indicate that there is evidence that the system's practices proactively serve these populations and achieve lower disparities or near-equal care across strata of patients who traditionally have disproportionately lower health outcomes (Rust \& Cooper, 2007). The implication from their studies, that are consistent with the National Institute of Health's (2002) findings, are that clear policies and standards of practice to provide guidance based on practice based research is an important ingredient for the success achieved by that system for all patient populations 
across ethnic/racial groups (Rust \& Cooper, 2007). Therefore, congruent with the understanding of medical utilization patterns among racial ethnic minorities as advocated by White-Means (1995), researchers will need to seek to understand the circumstances that generate racial diversity in medical decisions and to incorporate their perspectives in refined models of medical utilization patterns. Applying this logic to health and productivity research, researchers would need to acknowledge and understand the circumstances that generate racial diversity in health-related work outcomes and to incorporate those perspectives in their recommended models of integrated benefits for employees across racial and ethnic groups.

Table 2-6 summarizes key presenteeism studies which were reviewed in this section on the diverse healthcare workforce.

\section{Summary of Literature Review}

A review of literature indicates that the study of presenteeism through healthrelated productivity research is a relatively new and emerging area of inquiry. It is a phenomena attributed to loss at the population level of a workforce. Thus far when examining various workforces, there has been no real distinction in describing presenteeism outcomes according to race and ethnicity. Over the last decade, presenteeism research has married inquiry into three areas: work productivity, cost of illness, and health outcomes. The field of health-related productivity has been challenged in that it has not yet developed a gold standard to measure and quantify presenteeism. And, from an economic perspective, there continues to be the quest to develop a consensus method to assign cost to having presenteeism and a cost-plus-quality benefit from diverting it. Research indicates that presenteeism is associated with about two dozen common physical and mental health conditions. These conditions vary in prevalence and amount of productivity decrements depending on the industry and occupations involved.

Overall, most often presenteeism caused the highest decrement in productivity when health conditions included at least one chronic physical health condition, included a mental health condition, and there was 1 health risk factor present. The most prevalent health conditions associated with presenteeism are acute or chronic conditions with acute episodes. The most cited conditions include: arthritis, allergies, back and neck pain, chronic pain, gastrointestinal problems, depression, sleep problems, depression, anxiety, musculoskeletal problems, and migraines/ severe headaches. The associated health risks are factors such as: dissatisfaction with life/life unfulfillment, physical inactivity, stress, high BMI, increased cholesterol, and poor diet. Mental health conditions of anxiety and depression were believed to cause exponential decrements in productivity when workers experienced them along with physical health conditions associated with presenteeism. Mental health conditions most interfered with cognitive skills, jobs that require proficiency, exercising judgment, and community exposure. Collectively, presenteeism studies indicated that conditions associated with 'perceptions' either of a physical nature (as in pain) or of an emotional nature as in (stress, depression, and anxiety) have 
Table 2-6. Summary of Key Presenteeism Related Studies: Presenteeism and Diverse Workforce

\begin{tabular}{lllll}
\hline Source & Objectives & Setting /Subjects & Design and Tool & Relevant Findings \\
\hline $\begin{array}{l}\text { Loeppke } 2007 \\
\text { To assess the } \\
\text { magnitude of } \\
\text { health-related } \\
\text { absenteeism, } \\
\text { presenteeism, and } \\
\text { disability relative } \\
\text { to medical and } \\
\text { pharmacy costs. }\end{array}$ & $\begin{array}{l}\text { Four employers } \\
\text { totaling 57,000 } \\
\text { employees and } \\
\text { used the Health } \\
\text { and Productivity }\end{array}$ & $\begin{array}{l}\text { Retrospective and } \\
\text { naturalistic designs to } \\
\text { allow methods to be } \\
\text { adapted to accommodate } \\
\text { each company's desires } \\
\text { (HPQ). }\end{array}$ & $\begin{array}{l}\text { Ranking of highest-cost condions varied } \\
\text { by employer and those conditions differed } \\
\text { in their contribution to medical, pharmacy } \\
\text { and productivity costs. Full costs of poor } \\
\text { health were driven by different health } \\
\text { conditions than by examining costs of } \\
\text { medical and pharmacy costs alone. Found } \\
\text { that health-related productivity costs were } \\
\text { more than four times greater than medical } \\
\text { and pharmacy costs. }\end{array}$ \\
\hline
\end{tabular}


demonstrated the highest decrements in productivity due to presenteeism. Stress doubles the impairment regardless of health condition (Boles, et al., 2004). The more health risks and more chronic conditions a person has the higher the presenteeism. Conversely, as a person decreases health risks, presenteeism follows directionally. Generally, it can be stated that presenteeism often is associated with acute episodic health conditions, while absenteeism and disability are more often associated with persistent chronic health conditions.

There are significant differences in indirect cost estimates as well as prevalence estimates of presenteeism. Most studies indicate that presenteeism often causes 2.4 to 3 times more decrements in loss productivity than absenteeism. Its prevalence in the studies reviewed ranged from $8 \%$ to $38.3 \%$ of a workforce (Stewart, et al., 2003a). Differences in the prevalence of presenteeism varied often based on two factors. One was whether archived administrative data are included in the analysis of health conditions. Secondly, the extent of mental health conditions examined in studies seems to be a source of significant variation seen in prevalence and impact of presenteeism.

Based on the literature, a demographic profile of those workforces most apt to experience presenteeism would most often consists of more women than men who have any combination of physical ailments that produced fluctuations or episodes of acute sickness. They would be an aging workforce with most between ages 50 to 65 of nonspecific racial and ethnic mix, composed of these who make salaries under $\$ 10,000$ or over $\$ 50,000$ annually, and have a large proportion working under 40 hours a week. Those workforces most impaired by presenteeism would have physical ailments compounded by mental conditions inclusive of depression and anxiety. They would be employed in services or personal care jobs or ones considered low demand/high control jobs. As the US moves to more service and knowledge-based jobs with an older population, this does not bode well for a national economy. Additionally, the influx of more racial and ethnic mix brings an unknown and under-researched dimension.

Among all studies reviewed, presenteeism reportedly resulted in more significant indirect cost burden than direct cost burden (Greenberg, et al., 2001; Stewart, et al., 2003a). In all cases the indirect costs of presenteeism were projected to be higher than direct costs of health care. Cost approximations have ranged from $18 \%$ to $60 \%$ of a company's health care costs to many figures in between those numbers. Cost estimates using the HCA model is the most commonly used and are very dependent on the salary levels of the workforce researched. This makes comparisons across varying levels of employees, industries, sizes of employers misleading. Most studies reviewed examined more than one level, industry and size of employer. Also, if a study included archival administrative data, there was increased likelihood that higher medical cost conditions would be included in the presenteeism assessment of costs. Use of the HCA model seems most appropriate for costs from an employer's perspective.

A number of medications have been purported to decrease the prevalence or length of presenteeism, however the FDA has not yet been convinced enough to allow pharmaceutical companies to make such claims. Aggressive research is occurring in 
clinical trials in order to improve the integrity of data in hopes that the industry is allowed to make claims about productivity.

Empirical studies on nurses and pharmacists indicate that part of the workforce shortage in both professions occurs because of high turnover, not only for specific jobs but in challenges in retaining employees in the field. While a slow bleed in each profession is occurring, what is not clear is what if anything will avert it. There is a dearth of research on impact of presenteeism for either field in the US. Studies have been conducted in Sweden and in Canada that imply greater impact of presenteeism on health and welfare workers than other workers. Implications from related research suggested that both professions would be negatively impacted by presenteeism as knowledge-based health professionals.

Excluded from the literature is the distinct examination of presenteeim in nurses, pharmacists, and employees of racial and ethnic minority status. Moreover, the literature on presenteeism has not examined whether treatment or none treatment by a provider or by pharmacotherapy is a significant factor in presenteeism. These gaps are why the current study is needed. 


\section{CHAPTER 3. METHODOLOGY}

This chapter explains methods to be used to answer research questions and test hypotheses developed to examine presenteeism and its cost burden among diverse nurses and pharmacists. The chapter elaborates on research methodology to include the research design, selection of subjects, settings, instruments, procedures, statistical analyses, and protection of human subjects for data collection.

\section{Research Design}

This study employs a non-experimental descriptive and analytical, cross-sectional, correlation research design. The descriptive research design was appropriate for this study since certain aspects of the phenomena of interest has not been previously described in published empirical literature (Polit \& Beck, 2004). Additionally, the study has an analytical design to test hypotheses about relationships among race/ethnicity and professional specialty variables. The cross-sectional design provides a single point in time 'snap shot' of the research subjects' previous four weeks of health related on-the-job productivity. A review of literature revealed that the four week time line was most frequently used for these type studies. Although a longitudinal design would provide a more extensive review of presenteeism over time; the cross-sectional design was determined to be more feasible from a time and cost perspective. Moreover, the crosssectional design was most frequently used in empirical studies of presenteeism to date. The design is correlational in that the research seeks to compare differences and establish whether there are relationships or associations between the categorical dependent variable, presenteeism, and a number of independent categorical variables. The independent variables of interest are:

- Health profession - nursing or pharmacy

- $\quad$ Race/ethnicity — minority or non-minority

- $\quad$ Health conditions - physical health conditions (ph conditions) or mental health conditions (mh conditions)

- $\quad$ Health symptoms - physical health symptoms (ph symptoms) or mental health symptoms (mh symptoms)

- Treatment by a provider for health condition - previous, current, or none

- Treatment by medication for health condition - previous, none, or current; and lastly,

- Work setting - 24-hour/direct care setting or not. 


\section{Sample and Setting}

This study utilized patient reported outcomes (PRO) obtained via a web-based survey distributed to a non-probability convenience sample of employed nurses and pharmacists in Tennessee. The survey was available electronically through Survey Monkey located at www.surveymonkey.com. Survey Monkey is an on-line secured website especially designed to host multiple responder surveys. Potential respondents were allowed access to the survey for 24 hours a day of the thirty-three weeks between November 17, 2007 and June 17, 2008.

In order to ensure that nurses, pharmacists and racial/ethnic minorities within each profession were in proportion to their representation in both professions, quota sampling techniques were used to target study participants. According to the Tennessee Department of Health's (TDH) website and its Health Status of Tennesseans Report, licensed nurses numbered approximately 43,841 and pharmacists numbered approximately 1200 in 2003 (Tennessee Department of Health, n.d.). Despite the state's higher number of nurses, equal numbers of pharmacists and nurses were targeted. This was done because less has been written about the health of pharmacists and it was important to this research to be able to speak to a combined healthcare workforce sample that composed enough data to adequately reflect both professions.

Tennessee's population proportions for racial/ethnic minorities in nursing and pharmacy were lower than national rates for minority populations. In 2006 , the national composition by race was White non-Hispanic 66\%, Hispanic 15\%, African American non-Hispanic 12\%, Asian 4\%, American Indian/Alaska Native 1\%, Native Hawaiian Pacific Island 0\%, and two or more races 1\% (Kaiser Family Foundation, 2007). In 2000, Tennessee was composed of White non-Hispanic 80.2\%, African American nonHispanic 16.4\%, Hispanics 2.2\% and other races 1.2\% (i.e., American Indian, Asian, mixed races) (Tennessee Department of Health, n.d.). Of note was the dramatic rise (214\%) in Hispanics between 1990 and 2000 in Tennessee. African Americans in nursing compose $9 \%$ nationally and in Tennessee compose $7.8 \%$. Hispanics comprise the largest ethnic group nationally, however consistent with overall population percentages in Tennessee, they comprise $2.2 \%$ of nurses in Tennessee. African American pharmacists comprise $5.1 \%$ nationally and estimated $3.2 \%$ in Tennessee using HRSA nationally reported statistics (Tennessee Hospital Association, n.d.-a).

\section{Recruitment}

The initial survey distribution plan included two recruitment avenues: state level professional organizations (Tennessee Center for Nursing and the Tennessee Pharmacists Association) and email distribution through the University of Tennessee Health Science Center's state-wide distribution lists for nurses and pharmacist. The alternative of hosting the survey on the web sites of both professional organizations was abandoned once the nursing organization did not grant approval to allow use of their organization's web site. Ultimately, emails were distributed through lists containing alumni, continuing education participants, faculty, and students affiliated with the University of Tennessee 
Health Science Center's Colleges of Nursing and Pharmacy. Approximately 1250 (600 pharmacists and 650 nurses) email invitations were distributed. The number of emails that were subsequently blocked or undelivered could not be determined; nor could it be determined how many respondents that were reached did not meet inclusion criteria and did not elect to take the survey. Each email contained a direct web-link to either a nurse or pharmacist profession specific informed consent and survey tool to complete on Survey Monkey. The survey introduction and the IRB approved informed consent were on the first web page accessed by each respondent. As encouragement to complete the survey by December 30,2007, potential respondents were offered a free copy of the executive summary. Each nurse and pharmacists in the UT database received between three and six emails. Although equal representation by professions was obtained without extra recruitment efforts, responses by profession indicated that numbers for minority race/ethnicity were not adequate, particularly for pharmacists. Therefore, targeted recruiting for racial and ethnic minorities was instituted. Three additional emails were sent to executives of four large health facilities with large numbers of minority health professionals (Arlington Developmental Center, the Regional Medical Center at Memphis, The Memphis Veterans Hospital, and Memphis Mental Health Institute). Also, a College of Pharmacist list-serve that specifically targeted Black pharmacists was re-sent. Moreover, increased recruitment of minority respondents through word of mouth, face to face at functions such as community projects, holiday gatherings, and continuing education workshops were done until representative sample percentages were exceeded for both professions.

\section{Inclusion and Exclusion Criteria}

The following were inclusion criteria for participation in the study. Respondents were allowed to be in included when they were:

1. Licensed as a pharmacist or nurse in the state of Tennessee

2. Actively employed as pharmacist or nurse in the workplace

3. Able to obtain access to technology, navigate the internet, and participate in the on-line web-based survey

4. Sufficiently able to comprehend written English to respond to the survey

Respondents were excluded from participating in the study if they were:

1. Not currently licensed in Tennessee as pharmacist or nurse

2. Retired or not actively working for pay

3. Out of work on disability or sick leave

4. Unable to comprehend and respond to the study questionnaires in English 


\section{Sample Size}

The minimum sample size necessary to adequately conduct this study with $95 \%$ confidence level and moderate effect $(\mathrm{r}=.30)$ size to detect statistical significance was determined to be a minimum of 192 subjects that was broken down to 96 subjects per profession. A published table of sample sizes (Israel, 2003) provided the basis for calculation of minimum sample size. Using the sample size table published under the name of PEOD-6 that is one of a series of the Agriculture Education and Communication Department at the University of Florida, the recommended minimum size corresponds to Equation 3-1 (Israel, 2003):

$$
\mathrm{n}=\frac{\mathrm{N}}{1+\mathrm{N}(\mathrm{e})^{2}}
$$

This formula assumes a $95 \%$ confidence level, $\mathrm{P}=.05, \mathrm{n}$ is the sample size, $\mathrm{N}$ is the population size, and e is the level of precision. In this case the available population for which email addresses were available was 1250, precision or sampling error $.05 \pm$ $5 \%$, with moderate effect size $(\mathrm{r}=.30)$, power .80 , and significance of 0.05 -level using 2 sided tests of significance.

This investigator's minimum sample size number was more than adequate to be consistent with the rule of thumb for sample size adequacy fitting a logistic regression analysis. This rule of thumb indicated a ratio of 10 observations for each 2 potentially predicting variables so that no group has an expected value $<1$ and $95 \%$ of predictors having an expected frequency of $>5$ (Dawson-Saunders, Feltovich, Coulson, \& Steward, 1990; Garson, 2008). In this case a minimum of 70 respondents each for nursing and for pharmacy for a total of 140 respondents would be need to be recruited to declare a sufficient sample based on 12 independent (predictor) variables. Because stratification by race (minority and non-minority) was desired, the larger sample minimum of 192 was sought in order to provide the best chance of obtaining enough numbers for minority representation, minimums of 10 minority nurses and 10 minority pharmacists.

\section{Instrumentation}

\section{Wellness-at-Work Survey}

This investigator chose to adapt or adopt the previously published tools to form a survey to measure presenteeism and other variables of interest. The primary tool adopted for use was the entire World Health Organization's (WHO's) Health and Work Performance Questionnaire (HPQ), referred to as HPQ. One presenteeism question from the Work Productivity and Activity Impairment Questionnaire (WPAI) instrument was added to the HPQ to compose the presenteeism, health conditions and treatment measures used by this investigator. Additionally, adapted questions from the NHIS provided access to care and demographic questions, while the Harris Poll provided the basis for medication use and compliance questions. A copy of the Wellness-at-Work tool is 
located in Appendix A. The investigator's Wellness-at-Work tool was pilot tested with 7 nurses and 2 pharmacists. The pilot test allowed this researcher to revise the informed consent, survey instructions, demographic categories, and profession specific categories of work to be applicable to the nursing and pharmacy professions. A chart that follows visually depicts the 'logic crosswalk.' The crosswalk depicts which Wellness-at-Work survey questions correspond to variables, research questions, and hypotheses for this research study (see Appendix B).

\section{The Health and Productivity Questionnaire}

Harvard researchers Dr. Ronald Kessler et al. developed the HPQ tool in 2003 for the WHO as part of the Global Burden of Disease Initiative. This tool was developed after a review of existing health-related productivity scales by the Harvard researchers that Kessler et al. (2003) led. Pilot interviews were performed and cognitive debriefing interviews were conducted to determine if there were ambiguous questions or wording. There are two versions of the HPQ, an employee version and a clinical trials version. The clinical trials version is shorter and since the goal is to only focus on an illness associated with work impairment, the chronic conditions checklist and healthcare utilization are not included. The employee web version was used for this study. The tool is available in both a web version and a paper version (Kessler, et al., 2003). Both the web and paper version of the tool are equivalent psychometric tests. The employee version contained 91 questions in three sections: health status in 59 items, nature of work and work performance in 24 items, and demographics in 8 items (C. Evans, 2006). The recall period for most questions was the past four weeks.

Developers of the HPQ were more interested in arriving at a broad work population perspective of the effects of health problems on work performance than in documenting effects on separate dimensions by individual workers. Therefore, the HPQ asked workers to provide a single global rating of their overall work performance, rather than to report difficulties in a number of separate domains of work functioning. This was done using a 0 -to- 10 global rating scale of overall work performance where 0 means the "worst possible work performance" a person could have on this job and 10 means "top work performance" on this job. The underlying assumption was that workers did a better job than researchers of implicitly reviewing the various dimensions of their work functioning in order to summarize their personal overall job performance (Kessler, et al., 2004).

The following features of the HPQ were most attractive for this research despite concerns about the length of the tool. No other tools were found to have separated series of questions about chronic and acute conditions as well as symptoms. Also, no other tool attempted to capture treatment or under-treatment. An under-treatment was believed to be important in research involving the health of minority populations who have historically had higher rates of 'never treated' and under-treatment. Moreover, this investigator believed it was important to examine the role of pharmacotherapy treatment separate from provider treatment, given that there has been increased use of pharmacotherapy. Emergence of personalized medicine, the vast choices of drug 
treatment due to more recent technological and genomic developments. This investigator added a pharmacotherapy treatment option to the survey.

The HPQ is one tool that had documented use with knowledge-based workers (Kessler \& Stang, 2006). Additionally, during development the HPQ had been compared to objective data on work performance to demonstrate face validity and to generate calibration rules. During development of the HPQ, there were four HPQ calibration surveys to ensure content validity. Each calibration survey was carried out in a separate corporation and focused on a single type of worker for whom archival data were available. Calibration studies demonstrated 'good concordance' with self-reports both with payroll records and archival supervisor and peer performance ratings. These results implied that any bias in the estimated effects of health conditions on work performance was probably minimal (Wang, et al., 2003). The HPQ was also considered to have criterion validity in that the four calibration surveys were conducted using both white and blue collar employees (specifically railroad engineers, customer service representatives, airline reservation agents, and executives). Even though the sample was likely to have been composed of racial and ethnic diverse employees, no distinctness of differences or similarities was highlighted. Data from these calibration surveys were compared to HPQ self-reported presenteeism and archival data collected through independent employer records of job performance. They were found to have statistically significant monotonic associations across the range of occupations and a variety of outcomes (e.g. work audits, supervisor ratings, peer ratings) (Wang, et al., 2003). Statistically significant associations were also found in logistic regression analyses between HPQ rating and the odds of low archival/ Experience Sample Method [ESM] performance in all occupations (Kessler, 2002). Specifically, blinded validation studies documented HPQ productivity reports were associated with supervisor assessments of job performance $(\mathrm{r}=0.52)$ and other administrative indicators of job performance ( $\mathrm{r}=0.58-0.72)$ (Kessler, et al., 2004; Kessler, et al., 2003).

\section{WPAI-GH Tool}

Consistent with the HPQ, the WPAI quantified the overall work productivity related to health using a 10 point scale. The WPAI is in the public domain and was developed by Reilly et al. to measure the effects of general health and symptom severity on work productivity and regular activities (C. Evans, 2006). There are several versions of WPAI's tools, the general health conditions version was used for this study. The versions of the tool which are disease specific, e.g. WPAI- Diabetes, were believed to be less relevant to this study because a broad range of acute and chronic conditions were of interest. The entire tool is six questions that ask about hours worked or missed, the impact of health problems on work productivity, and the impact on activities of daily living. The recall period can be seven days or 28 days and 28 days or 4 weeks was used to be consistent with the recall period for the HPQ.

The WPAI is reliable in that its results have been reproduced. Test results for comparison between scores at baseline and within-group correlations coefficients for a 
retest (self-administered or interviewer facilitated) sample were: 0.71 for overall work productivity related to health; 0.75 for overall work productivity related to symptoms; .77 for impairment of regular activities related to health; and 0.87 for impairment of regular activities related to symptoms.

As mentioned, to date there is no gold standard for measuring presenteeism (Kessler \& Stang, 2006). However, with two tools that measure the same phenomenon of presenteeism, there is opportunity to establish concurrent validity of the 2 presenteeism measurements. Concurrent validity is one of two types of criterion validity that refers to the extent that the survey measure predicts or agrees with some criterion of the 'true' value (usually the gold standard) for the measure (Aday \& Corneilus, 2006). Researchers established construct validity by comparing the WPAI measures to several Medical Outcomes Study 36-Item Short-From Health Survey (SF-36) concepts: general health perceptions, role limitations (physical), role limitations (emotional), and pain. The WPAI's quantitative work-productivity and regular-activity impairment measures were positively associated with SF36 dimensions and the symptom severity measures. The greatest differences in the SF-36 dimensions at baseline and retest in a self-administered group were between the correlations of general health perceptions $(0.52)$ and overall work productivity related to health $(0.34)$; and between general health perceptions $(0.49)$ and work productivity related to symptoms $(0.31)$. Correlations were between the quantitative measures and role function related to emotional factors versus physical/pain factors.

\section{WPAI and HPQ Concurrent Validity}

This researcher will determine whether the presenteeism scales in the WPAI (Wellness-at-Work B14) and HPQ (Wellness-at-Work B13) will demonstrate concurrent validity in that their Pearson Correlation Coefficients significantly correlates at the $\mathrm{p}<.05$ level. Additionally, the priming question for presenteeism in the HPQ tool (Wellness-atWork B10) will also be tested for concurrent validity with the B14 and B13.

\section{Data Collection Procedures}

The following data collection procedures lists the steps used to collect data for this study:

1. The study was initiated after permission was received from the University of Tennessee Health Science Center (UTHSC) Institutional Review Board (IRB) to conduct the study.

2. The survey was uploaded to the Survey Monkey web page. With the exception of a profession specific greeting, each profession had separate but identical survey links. This allowed monitoring of numbers of responses and race/ethnicity scales by profession. 
3. The tool was pilot tested and minor changes were made based on feedback received regarding readability and application to the targeted professions.

4. Email invitations were sent to university list serves of Tennessee pharmacist and nurses inviting them to participate in the survey. The email contained a single link to take them to the profession specific Survey Monkey collector for pharmacists or nurses.

5. A free executive summary incentive was offered to encourage early completion of the survey by the end of December, 2007.

6. The first page of the web-based survey was the informed consent where potential participants were informed of the purpose of the study and their rights as research participants. When a respondent was given a choice to move forward away from the informed consent page, they were informed that by proceeding forward they will have consented to voluntarily participate in the survey.

7. The responses from nurses and pharmacists were stratified according to the respondents answer on the minority and non-minority racial/ethnic demographic make-up question. The initial numbers for minority racial/ethnic composition proved too limited and therefore, shortages required over sampling by extending more email invitations to racially and ethnic minority pharmacists and nurses. Procedures described in the recruitment section were implemented.

\section{Consideration of Human Subjects}

The web-based surveys provided minimal risk to research subjects. The identity of respondents was anonymous and capture was designed to protect participant's confidentiality. Survey Monkey captured computer numbers of respondents but these numbers could not identify specific users. As mentioned, the informed consent for the study was the first page of the survey instrument and respondents were informed that they were providing consent if they progressed forward from the first page. The informed consent and the Wellness-at-Work survey tool were approved by the University of Tennessee Institutional Review Board (see Appendix C).

\section{Study Variables}

Following section contains the aims, research questions, and statistical analyses planned to answer each research question and test the hypotheses. Prior to discussing these, detailed explanations of data collected and key variables follow. 


\section{Presenteeism Measure}

Presenteeism is the dependent categorical variable, the categorical variable of interest of this study. As previously mentioned, the phenomenon of presenteeism becomes visible, though not easily measured, in the form of reduced quantity and quality of work production (Stewart, et al., 2003a). Determining presenteeism requires measurement of how a worker's present performance differs from his or her own usual performance and how their present performance contrasts with their peer's (Mattke, Balakrishnan, Bergamo, \& Newberry, 2007). Capture of work activities that encompassed common mental, physical, and interpersonal activities was desirable in capturing the impact of presenteeism.

This investigator reviewed published accounts of empirical studies on presenteeism done between 1995 and 2008 with the objective of identifying the best instrument appropriate for measuring presenteeism for the current study. Part of this review encompassed a few studies that had the primary purpose of analyzing healthrelated productivity tools (C. Evans, 2006; Institute for Health and Productivity Management., n.d.; Mattke, et al., 2007; Stang, et al., 2006). This investigator concluded that Mattke's (2007) recommendations should form the minimum criteria of a basis for deciding which tools to consider. Mattke et al. (2007) recommended that presenteeism measurement tools have the following characteristics:

1. Assess a worker's self-perceived impairment

2. Allow comparative productivity, performance, and efficiency with a worker's normative group and others

3. Estimate the worker's time at work when unproductive

Additionally, the following were desirable characteristics identified by this investigator based on a compilation of insights gained from previous studies:

1. Be appropriate for use with knowledge-based (or cognitive services) workers

2. Produce scores that allowed the ability to easily monetize or translate into money

3. Capture health conditions that encompassed both acute and non-acute illnesses and symptoms

4. Include mental and physical health conditions

5. Allow for expansion of the tool to include other major independent variables of interests without being too long (over 20 minutes) 
6. Use components of tools that are well recognized, reliable, and valid in empirical studies

7. Use components of tools that are known to be accepted by employers for its practical use

The entire HPQ tool and the presenteeism scale from the WPAI-GH together met requirements listed by Matkke et al. (2007) and this investigator. The WPAI-GH specifically asks the respondents to think about their health problems and then attribute lost productive time to health problems. The 6 question WPAI-GH productivity questionnaire includes the following end-points for functional outcomes:

- $\quad$ Percentage of missed work time due to health

- $\quad$ Percentage of work productivity impairment due to health

- $\quad$ Percentage of overall work impairment due to health

- $\quad$ Percentage of overall activity impairment due to health (IHPM, 2001)

The HPQ duplicates these measures without specifying 'due to health' and for those reasons had less face validity than WPAI questions. The end-points for functional outcomes for HPQ were identified as follows (Institute for Health and Productivity Management., n.d.):

- Worst to best job performance based on 'any worker' doing the job

- Usual job performance of 'most workers' doing the job

- $\quad$ Self-rating of workers 'personal-performance' doing the job

- $\quad$ Self-rating of the time personal productivity was lower/higher than expected

\section{Race/Ethnicity Measures}

Respondents self-identified into ethnic and racial categories of: White NonHispanic, Hispanic, African American non-Hispanic, Asian, American Indian/Alaska Native, and Native Hawaiian Pacific Island. This investigator grouped these categories into dichotomous race and ethnicity 1) racial and ethnic minorities, and 2) racial and ethnic non-minorities. Non-minorities were considered as White, Non-Hispanic race and ethnicity. Minorities were considered as any one of five groups to include: Hispanic, African American non-Hispanic, Asian, American Indian/Alaska Native, and Native Hawaiian Pacific Island. 


\section{Health Conditions and Symptoms Measures}

Measures of health are reflected in four variables that were composed of two types of illnesses referred to as conditions (mental health conditions and physical health conditions) and two types of symptoms (mental health and physical health symptoms). The HPQ assessment of conditions uses two standard symptom checklists, one for mental disorders and the other for physical disorders. There were 23 illnesses dichotomized into categories of physical health conditions or mental health conditions. Approximately 19 health symptoms were dichotomized into physical symptoms or mental health symptoms. All of the health condition measures were adopted from the HPQ tool. Mental disorders reflect the K6 symptom checklist of non-specific psychological distress (Kessler, et al., 2003; Kessler \& Stang, 2006). The K6 is a six question Likert scale that assesses symptom frequency over the past 30 days for common symptoms of anxiety and mood disorders. The K6 has excellent concordance with blind clinical evaluations of mental disorders. Physical conditions were assessed with items selected from the Patient Health Questionnaire 15 (PHQ-15), a 15-question scale of acute somatic symptom severity. The PHQ-15 captured over $90 \%$ of the presenting complaints for acute physical health problems seen in primary care settings and has strong monotonic relationships with independent measures of global perceived health and functioning (Kessler, et al., 2004). Chronic conditions contained in the HPQ tool were from the checklists modified from the National Health Interview Survey in order for the tool to possess construct validity. A number of methodological studies have found the self-reports obtained in these checklists to be valid for disorders brought to medical attention or that significantly limit activities when compared to that determined by the HPQ (Kessler, et al., 2004).

\section{Treatment Measures}

There are six treatment related variables, two that distinguish treatment provided through a health provider and/or through pharmacotherapy. Three more variables distinquish when treatment was provided - current, previous, or never. The HPQ was already designed to capture whether a respondent was being treated by a provider either currently, not at all, or previously. Only slight adaptation was needed to add the pharmacotherapy treatment option and options for when treatment with medications occurred either currently, not at all, or previously.

Under-treatment was defined by Kessler \& Stang (2006) as presently experiencing health-related work productivity decrements for a health condition that was 'previously treated,' but not currently treated. If any of these factors were found to be significant in nurses and pharmacists whose presenteeism outcome was linked to previous treatment, then under-treatment could be further described by secondary endpoints contained in the Wellness-at-Work survey. 


\section{Direct Care/24-Hour Facility Measure}

Predictability or the odds of likelihood of presenteeism intra-professionally, defined as among the same health profession but in different healthcare work settings, was of interest. It is well documented that presenteeism has varied by types of employment and occupations (C. J. Evans, 2004; Kessler \& Stang, 2006; Mattke, et al., 2007; Prasad, Wahlqvist, Shikiar, \& Shih, 2004). While this has been measured across professions, it has not been measured intra-professionally. Both nurses and pharmacists as employees are often required to continuously staff health service organizations that provide care to patients on a 24-hour basis. The review of literature indicated that these settings often required undesirable work-shifts and work conditions that are implicated in reasons for diminished job satisfaction and burnout among both nurse and pharmacists (Aiken, et al., 2002; Buerhaus, Donelan, Ulrich, Norman, \& Dittus, 2005; Canadian Institute for Health Information, 2006; Health Resources and Services Administration, 2004; Kaiser Family Foundation, 2004; Letvak \& Buck, 2008; Longest, 2006; Pilette, 2005; Shamansky, 2002; Woods, 2007). Therefore, the decision healthcare professionals who work in direct care 24-hour settings versus non-direct care 24-hour settings were predictors of presenteeism in this study. Such data was believed to add further value to the analytical data of this study.

\section{Monitizing Presenteeism and Calculating Cost Burden}

Partnerships among economists and health-productivity researchers are relatively new alliances (Kessler \& Stang, 2006). Therefore, there are few economic approaches and theories on which methods and measurements of the cost impact of 'less than full health' have been successfully applied to on-the-job productivity (Lopez, Mathers, Ezzati, Murray, \& Jamison, 2006; Murray, Nicholson, Pauly, \& Berger, 2006; Pauly, 2007; Whiteford, 2006). A review of literature was performed to determine the most appropriate cost model for the current study.

Empirical research on work performance has not traditionally been linked with medical outcomes that addresses cost of illness (Anderson, Oppler, \& Rose, 2006). Moreover, empirical studies of health-economic concerns are most often costeffectiveness studies that compare various clinical interventions for disorders being studied (Whiteford, 2006). According to Whiteford (2006) the calculation of the economic consequences of loss of productivity due to ill health captured by conventional economic or cost-of-illness, cost-benefit, and cost-effectiveness calculations have limitations for studying the phenomenon of presenteeism. This is believed to be the case because these methods have not traditionally provided both cost and benefit of interventions between different health disorders that impact on-the-job productivity (Berger, et al., 2003b; Whiteford, 2006).

There is no consensus on the best economic measures to use to quantify cost in presenteeism or benefit of presenteeism averted (Kessler \& Stang, 2006). The most popular methods of productivity cost estimation are the friction cost method and the human capital approach (HCA) (Berger, et al., 2003b; Kessler \& Stang, 2006; Murray, et 
al., 2006). The friction method also called Koopmanschap method, estimates only the actual lost production and is considered a method of estimating productivity cost in the absence of market prices (Berger, et al., 2003b). In calculating losses, this method assigns only the value of the individual's future earning until another worker from the unemployment pool replaces the ill worker or the ill worker returns to the job (Berger, et al., 2003b). It considers that losses may be partially compensated by greater effort, or unpaid overtime of the worker or other team members, as well as by new hires (Mattke, et al., 2007). The time period that it takes to replace an ill worker is referred to as the 'friction period.' Use of this method results in a low cost to the employer because it the cost value of lost production is only the cost in terms of what it takes to replace a worker during the friction period. Most researchers have not embraced this method as it is believed to be a rather complicated method to utilize in long term illness and does not seem appropriate for estimation of loss of on-the-job productivity due to illness (Berger, et al., 2003b; C. Evans, 2006).

Conversely, the alternative method, the Human Capital Approach (HCA), is grounded in economic theory and expresses work loss as the product of missed workdays multiplied by the worker's salary (Mattke, et al., 2007). HCA represents the most frequently used equation for estimating indirect costs, and is often called the loss wages method (Murray, et al., 2006). The HCA method assigns the whole value of an individual's future earning as the indirect cost, while the friction method only assigns the value of the individual's future earnings until a replacement is made (Berger, et al., 2003b). Using the HCA method, the key concepts involved in measuring indirect cost of productivity changes are:

Cost of illness $=[(\mathrm{W}+(\mathrm{X} * \mathrm{Y}) * \mathrm{Z}]$, where

$\mathrm{W}=$ numbers of work days missed over a given period (weeks, a month, or a year), $\mathrm{X}=$ number of work-cutback days (or shortened workdays) during this period, $\mathrm{Y}=1$-percent average productivity on work-cutback days, and $\mathrm{Z}=$ wage rate.

According to a neoclassical model of economics, wage rates are equal to the value of marginal revenue generated by an additional worker under full employment (Murray, 2006). Therefore, according to Murray (2006) indirect costs are quantified in terms of forgone earnings. Critics of the HCA model indicate that it matters the way the wage rates are calculated and this renders wide cost variations among research finding (Murray, 2006). This is because wage rates may be an all-industry average wage, minimum wage or the wage rate for a specific group. Such subjectivity is believed to account for wide variation in costs results (Murray, et al., 2006).

Other criticism of the HCA method is more substantial than method of calculating wages. Pauly, among others, have embraced what they consider a more comprehensive 'employer's view' of declines in output versus the worker's self-reported view (Murray, et al., 2006; Pauly, 2007). Pauly suggests that the actual loss to a company may greatly exceed the wages lost by a given employee when it is difficult or impossible to find the 
perfect substitute. They feel that there are consequences of time in postponement or idle assets, loss of input on team efforts and co-workers, non-wage costs, etc.

\section{Summary of Literature Review}

A review of literature indicates that the study of presenteeism through healthrelated productivity research is a relatively new and emerging area of inquiry. It is a phenomena attributed to loss at the population level of a workforce. Thus far when examining various workforces, there has been no real distinction in describing presenteeism outcomes according to race and ethnicity. Over the last decade, presenteeism research has married inquiry into three areas: work productivity, cost of illness, and health outcomes. The field of health-related productivity has been challenged (Murray, et al., 2006, p. 137; Pauly, 2007). They believe all these factors need to be considered and that the HCA method may be too simplistic (Pauly, 2007).

There is optimism among some economists that presenteeism will be considered in summary constructs that are generalizations of life expectancy and include disability free life expectancy (DALYs), or quality adjusted life year variants (QALYs). There are limited empirical works that explicitly include the phenomena of presenteeism when comparing cost and outcomes using economic summary constructs, such as QALYs or DALYs (Lopez, et al., 2006; Whiteford, 2006). There is belief that such measures hold the best hope for including presenteeism to the extent it needs to be considered. QALYs are a universal summary health outcome measure of gains or losses in both quantity of life (mortality) and quality of life (morbidity) (Berger, et al., 2003a). The health preferences for states of 'quality of life' range between 0 (states equivalent to death) through to 1 (full health) (Lopez, et al., 2006). DALYs were introduced in 1993 as a unit of measurement of the impact of disease in terms of both time lost due premature death (mortality) and time lived with disability (morbidity) (Berger, et al., 2003a). QALYs gained and DALYs averted through an intervention are calculated in very similar ways, and the main differences relate to the interpretation of the weights. Whereas the disability weights in the DALY quantify loss of health, the corresponding QALY weights are often interpreted in terms of well-being, quality of life, or utility (Lopez, et al., 2006). Some economists envision that these measures could apply to presenteeism as in DALYs averted by health gain (Lopez, et al., 2006; Murray, et al., 2006). DALYs seem more applicable to population health as a means to supplement or replace the more detailed reporting of data for specific aspects of health and mortality. They are envisioned to provide a metric that can be used to monitor trends and compare health across populations or for measuring health outcomes in cost-effectiveness analyses.

Still other researchers who believe that presenteeism, akin to what has occurred with absenteeism, could have a wage multiplier established for each employee's health condition that can be assigned to specific types of job functions, such that costs and benefit of productivity loss can be estimated. An example of a wage multiplier as used in absenteeism, is the work of Sean Nicholson, PhD, Associate Professor, Department of Policy Analysis and Management, Cornell University, Ithaca, New York, and colleagues (including Mark Pauly) to determine the cost associated with missed work. They found 
that cost varies across jobs according to the ease with that a manager can find a perfect replacement for the absent worker, the extent to that the worker functions as part of a team, and the time sensitivity of the worker's output (Nicholson, et al., 2006; Suh, 2006). Their work supported the view that the cost to the firm of missed work is often greater than the wage (Nicholson, et al., 2006). They looked at a wide range of 800 managers in 12 industries and estimated the mean absence multiplier as 1.61 (median absence multiplier as 1.28). An example of how job functions can be broken out are by abilities (including cognitive abilities), skills, or work styles as is currently done by the Department of Labor and assigned the appropriate multiplier based on population level research (Anderson, et al., 2006). There are a number of economic researchers seeking to quantify costs through use of such multipliers; however, most are in the early stages of conceptualization and research (Nicholson, et al., 2006; Pauly, 2007; Suh, 2006).

Monetizing lost productivity is typically performed using one of three main methods: 1) salary conversion, using survey responses plus salary information to estimate productivity loss; 2) introspective methods where managers estimate the impact of presenteeism on their workforces; and 3) firm-level methods that are a logical extension of the introspective methods and uses a hierarchal top down approach to assess firm-level information for cost estimates.

This researcher chose the HCA method because it is the most grounded in economic theory, supports the employer perspective and presents the least research burden to utilize (Lopez, et al., 2006). Even though presenteeism costs using HCA methods have been found to be higher than direct cost or indirect costs of absenteeism, the HCA method is believed to represent a lower bound for societal costs due to work loss than all methods (Berger, et al., 2003b; Murray, et al., 2006).

Both the HPQ and WPAI-GH tools used in this study utilize the HCA method of cost measurement. The current research study focused on results at the population level. The percentage of time missed and how much that cost an employer in indirect costs was of concern. As was customarily done using the human capital model with presenteeism, cost was calculated by multiplying the percent of self-reported unproductive hours by the amount of the annual average wages (Kessler \& Stang, 2006).

\section{Plan of Analysis}

\section{Specific Aim 1}

Specific aim 1 was to describe presenteeism, its prevalence, associated health conditions and treatment in employed nurses and pharmacists and indicate whether there are differences across racial/ethnic groups. The research question that was used to address aim 1 was 'what is the prevalence of presenteeism, its associated health conditions and extent of treatment among nurses and pharmacists; and, do these vary across racial/ethnic groups?' The following hypotheses predict the answers to this 
research question. The planned analysis to either accept or reject hypotheses are then listed sequentially.

- Hypothesis 1.1-There are no differences in presenteeism among nurses and pharmacists nor does it vary across racial/ethnic groups of both professions.

- Hypothesis 1.2-Health conditions characterized as physical health conditions are more associated with presenteeism among racial/ethnic minority groups versus non-minority groups of nurses and pharmacists.

- $\quad$ Hypothesis 1.3-Health conditions characterized as mental health conditions are more associated with presenteeism among non-minority versus minority racial/ethnic groups of nurses and pharmacists.

- $\quad$ Hypothesis 1.4-Under-treated health conditions are associated with presenteeism in both nurses and pharmacists and it varies across racial/ethnic groups.

- $\quad$ Hypothesis 1.5-Health conditions treated by providers are more associated with presenteeism than conditions treated by pharmacotherapy and this does not vary across profession or racial/ethnic groups.

'Prevalence' as used in this research will be consistent with its use according to the International Society for Pharmacoeconomics and Outcomes Research (ISPOR) in its Book of Terms (Berger, et al., 2003a). This book indicated that presenteeism was the amount of disease problem or its burden within a defined population at a given point in time. For this study, two-by-two contingency tables will be constructed in SAS ${ }^{\circledR}$ for each individual health condition, each symptom, each treatment option (by pharmacotherapy/provider), and timeline for treatment (current/never/previous) to determine either differences or association with presenteeism. This analysis will occur both among nurses and pharmacists and by race/ethnicity (minority and non-minority).

Methodological steps to determine differences and associations with presenteeism for each hypothesis follow. Steps to analyze Hypothesis 1.1 were:

1. An identified positive score on two 0-10 point likert presenteeism scales will be considered a positive score for presenteeism.

2. The best presenteeism measure among 2 possible measures in the survey tool will be chosen based on correlation coefficients.

3. Association and differences will be determined by correlation using ChiSquare. However, when there are low cell counts of less than 5 per respondents for less than $25 \%$ of cells, Fisher's Exact will be used to determine statistical significance of associations or differences. 
4. Conclusions will be discussed based on findings for each hypothesis.

Secondly, steps to analyze Hypothesis 1.2 for physical health conditions and 1.3 for mental health conditions will be introduced as follows:

5. Two-by-two contingency tables will be constructed in $\mathrm{SAS} \otimes$ for the variables divided into four categories: individual conditions, individual symptoms, grouped conditions, and grouped symptoms.

6. Analyses by profession and by race/ethnicity will occur to determine association with presenteeism.

7. Analysis will also be run to determine differences within and among professions as well as within and among race/ethnicity.

8. Each variable will have correlations determined by Chi-Square, however, when there are low cell counts of less than 5 per respondents for less than $25 \%$ of cells, Fisher's Exact will be used to determine of statistical significance of associations.

Next, steps to analyze Hypothesis 1.4 regarding undertreated health conditions, and Hypothesis 1.5 regarding type of treatment provided were as follows:

9. Two-by-two contingency tables will be constructed in $\mathrm{SAS} \circledast$ for the variables: previous provider treatment and previous pharmacotherapy treatment.

10. Analyses by profession and by race/ethnicity will occur to determine association with presenteeism.

11. Analysis will also be run to determine differences within and among professions as well as within and among race/ethnicity.

12. Each variable will have correlations determined by Chi-Square, however, when there are low cell counts of less than 5 per respondents for less than $25 \%$ of cells, Fisher's Exact will be used to determine of statistical significance of associations.

Lastly, a model of combined variables to predict presenteeism using regression analyses were planned. Steps in the ordered logistic regression will be used to determine the association of presenteeism and the entire group of 12 categorical predictors or independent variables of interest to address all hypothesis except 1.1. Ordered logistic regression analyses was an appropriate form of regression for this study because presenteeism is a dichotomous categorical variable and the relationship of this variable as the dependent response variable with a group of independent categorical variables is of interest (Allison, 1999). 
13. The presenteeism variable was to be ordered into 3 levels: $0=$ no presenteeism, $1=$ low levels of presenteeism, and $2=$ high presenteeism decrements.

14. The multiple logistic regression model was to be fitted with the previously selected 12 independent binary variables against this polytomous indicator response variable $\mathrm{Y}$ (presenteeim $=0$, presenteeism $=1$, or presenteeism $=2$ ).

15. Using the equation for the logit model this makes presenteeism the response variable with three outcomes: $\mathrm{E}(\mathrm{Y})=0,1$, or 2 .

16. The appropriateness of the logistic regression model was to be calculated by 'goodness-of-fit tests' in the form of likelihood ratio test and the Wald statistic to test significance of individual independent variables.

17. The impact of the independent or predictor variables was to be explained in terms of marginal effects.

18. Interaction affects of race and health professions was to be tested in logistic regression (Garson, 2008).

19. Diagnostic and goodness of fit statistics, residuals, and marginal effects were to be obtained from the final fitted logistic regression model. These values were to reflect how likely it is that the observed values of presenteeism were predicted from the observed values of the independents variables tested (Allison, 1999). In other words, the fitted model was then to be used to predict the probability of response by the 12 selected independent variables.

The model to be fitted is shown in Equation 3-2. Let $\mathrm{p}_{\mathrm{ij}}$ be the probability that individual $\mathrm{i}$ falls into category $\mathrm{j}$ of the dependent variable presenteeism. We assumed that the three categories of presesenteeism are ordered in the sequence $\mathrm{j}=1, \mathrm{j}=2, J$. Next we define cumulative probabilities:

$$
F_{\mathrm{ij}} \stackrel{\mathrm{j}}{=} \sum p_{\mathrm{m}=1}
$$

$F_{\mathrm{ij}}$ is the probability that individual $\mathrm{i}$ is in the $j$ th category or lower. Each Fij corresponds to a different dichotomization of the dependent variable. The model is then fitted to a model as a set of $J$-1 equations (Equation 3-3):

$$
\underset{j=1, \ldots, J-1}{\log /\left[F_{i j} / 1-F_{i j}\right]}=\alpha_{j}+\beta_{j} x_{i}
$$


where $\beta \mathrm{x}_{\mathrm{i}}=\beta_{1} \mathrm{x}_{\mathrm{i} 1+\ldots+} \beta_{\mathrm{k}} \mathrm{x}_{\mathrm{ik}}$. Although there is a single set of coefficients, there is a different intercept for each of the equations. The explanatory variables predict the probability of being in a lower category.

The above specified model was to be fitted using PROC LOGISTIC in SAS ${ }^{\circledR}$. ordered logistic regression was used to determine effects, maximum likelihood results.

20. Separate regression models were to be run with interactions of profession and race/ethnicity variables with mental and physical health conditions and symptoms.

21. Marginal effects for predicting presenteeism will be modeled for all variables found significant in the regression model. This will be done for both levels of presenteeism, lower and higher levels of presenteeism by the independent variables.

22. Tests for statistical significance were to be performed as two-tailed tests. A p-value of $<0.05$ was to be considered significant.

\section{Specific Aim 2}

Specific aim 2 was to quantify, from the employer's perspective, the indirect cost of presenteeism in nurses and pharmacists and determine whether the indirect costs vary across racial/ethnic groups. The research question that addressed this aim was "what is the indirect cost burden of presenteeism among nurses and pharmacists and does it vary across racial/ethnic groups?' The hypothesis that was predicted to address this question was 'there are no differences in the indirect cost burden of presenteeism among nurses and pharmacists across racial/ethnic groups of both professions.' In order to monetize the impact of presenteeism, a series of steps needed to occur as follows:

1. The income of respondents and costs to employer were to be determined using salary medians, averages, and modes. Modes were to be obtained from the Wellness-at-Work survey.

2. In order to be able to determine relationship between salary and profession for those with presenteeism, income was to be divided into high income, middle income and low income ranges. Median annual income $\$ 50,000-$ $\$ 90,000$ was considered medium income; $<\$ 50,000$ annually was considered low income; and $>\$ 90,000$ annually was considered high income for each profession. Chi-Square analyses were to be used to determine significance of correlation of mean income groups by profession.

3. Population level cost burden was to be estimated using the human capital approach. By translating mean productivity loss to hours and by multiplying the self-reported median annual salary information obtained 
from the Wellness-at-Work survey, the cost burden of presenteeism for employers of nurses and pharmacist was to be calculated.

4. Difference by profession and by race/ethnicity was to be determined by Ttest.

\section{Specific Aim 3}

Specific Aim 3 was to examine the cost burden and policy implications of presenteeism in a diverse healthcare workforce of nurses and pharmacist. This aim was reflected in the research question 'what are cost and health policy implications that could address key determinants of presenteeism among a diverse workforce of nurses and pharmacist?

An analysis of results from all questions was to be quantified so that results can be converted to dollars using the human capital approach. Data from all prior analyses was to be used to examine policy implications with the goal of either reducing or eliminating the cost burden of presesenteeism and increasing the health status of nurses and pharmacist from the health care employer's perspective. 


\section{CHAPTER 4. RESULTS}

This chapter describes the results of a study to determine the cost burden of presenteeism across a racially and ethnically diverse workforce of nurses and pharmacists. This study employed a non-experimental descriptive and analytical, crosssectional, correlation research design. Data were obtained from what was commonly referred to as a patient reported outcomes (PRO) tool that was self-administered. This investigator compiled questions from existing surveys into a web-based survey called the Wellness-at-Work Survey. Data were collected over a seven month period of time. Select summary statistics consisting of frequencies and percentages were obtained directly from the Survey Monkey data base and more rigorous analyses of data were obtained using SAS ${ }^{\circledR}$ Version 9. Statistical analyses through contingency tables, chisquare statistics, ordered logistic regression, and marginal effects were used. The details of these analyses are in the following sections.

\section{Sample Description}

Simple summary statistics were captured from the survey tool data base in Survey Monkey. Chi-square statistics derived from $2 \times 2$ contingency tables determined differences in nurses versus pharmacists and minorities versus non-minorities. Of the 263 health care professionals who started to complete the Wellness-at-Work Survey, approximately $85.93 \%$ (226) completed questions sufficiently enough for analysis of data for purposes of this study. Those who started the survey were approximately one-half nurses $(n=131)$ and one-half pharmacists $(n=132)$. Not all respondents of the surveys answered all questions and therefore there will be varying N's reflecting this in tables describing the sample.

\section{Nurse Respondents}

Approximately one-hundred eight (108) nurses self-classified into three major types of nurses: staff nurses $28.4 \%$, nurse educators $25 \%$, or nurse clinicians $20.68 \%$. The smaller remaining numbers classified themselves as either nurse supervisor/managers at $10.3 \%$, nurse executives at $7.8 \%$, and the lowest number comprised nurse researchers at $6.89 \%$.

- $\quad$ Gender-As would be expected, the respondants were composed of a majority of female nurses, $90.1 \%$, and the remaining males comprised $9.9 \%$.

- $\quad$ Age - Two-thirds $66.30 \%$ of the nurses participating in this survey were between the ages of 45-66. This percent includes $40.6 \%$ in the range of $45-54$ and $25.7 \%$ age range $55-66$. Lower numbers were in the younger ages with $10.9 \%$ in age range $24-34$, and $21.8 \%$ in age range 35 44. There was one person within the $65-74$ age range. 
- $\quad$ Race/ethnicity-The majority, 76.5\%, of nurse respondents classified themselves as White/European with the remaining two categories divided by Blacks at $22.4 \%$ and $1 \%$ Native Hawaiian/ Pacific Islander. There were no Hispanics or Asian nurse respondents.

- $\quad$ Family status-Most nurses participating in this study were married with 2 children. The marital status reported by most nurses was married/living with a partner at $77.8 \%$. The remaining consisted of $7.1 \%$ single $/$ never married, $12.1 \%$ were divorced, and $3.0 \%$ were separated or widowed. Seventeen percent of nurses had no children. The majority of nurses had children with $43.0 \%$ having 2 children, $14.0 \%$ having 1 child, $18.0 \%$ having 3 children, $8.0 \%$ having four or more.

- Geographic Locale-Nurses participating in the study were from across the three grand divisions of the state of Tennessee that encompassed both rural and urban areas. Most nurses, $87.36 \%$ (77 or 83 ) lived in West Tennessee spanning 4 counties with most from urban Shelby County. Nurses living in Middle Tennessee, $8.42 \%$, spanned 6 counties with urban Davidson County having 3 of the 8 from this grand division. There were $4.21 \%$ nurses from East Tennessee spanning two counties with 3 of the 4 nurses from urban Knox County.

- $\quad$ Education-Nurses were highly educated with $78.2 \%$ having a masters or higher degree. Most nurses, $40.6 \%$, had a master's in nursing and another $22.8 \%$ had a doctorate in nursing. The remaining consisted of $5.9 \%$ with non-nursing doctorates and $8.9 \%$ had non-nursing master's degrees. Approximately 13\% had bachelors' degrees that are inclusive of the $8.9 \%$ with nursing, and 5\% with non-nursing bachelors. The remaining $7.9 \%$ had Associates or Diplomas in Nursing.

- Work Setting - Nurses participating in this study were primarily from 2 work settings, $42.47 \%$ worked in a hospital or hospital system and $35.39 \%$ worked in educational/academic settings. A distant third and fourth respectively were from outpatient clinics $10.6 \%$ and private or independently owned practices $9.7 \%$. Far fewer, approximately $2.7 \%$ worked in long term care facilities and the remaining categories with only $.9 \%$ each in the following settings: pharmaceutical company, home health, disease management, non-academic related clinical research, and public health administration.

- Income-Most nurses in this study, $83 \%$, had annual incomes within the income range of $\$ 50,000-\$ 150,000$. Nurse's income categories in the median annual income of $\$ 50,000$ — $\$ 90,000$ was considered middle income; $<\$ 50,000$ annually was considered low income; and $>\$ 90,000$ annually was considered high income for each profession. 


\section{Pharmacist Respondents}

One-hundred twelve (112) pharmacists classified themselves in three primary categories of pharmacists: staff pharmacists at $31.7 \%$, supervisor/manager pharmacists at $25.8 \%$, and clinical and/or medication management pharmacists at $20.8 \%$. Smaller percentages were executive pharmacists at $11.7 \%$ and educator pharmacists $5.0 \%$. The remainders were at $.8 \%$ each for medical liaison, professional association work, retail, and part-time pharmacist positions.

- Gender-Consistent with national trends of increasing numbers of female, more than half, $56 \%$, of pharmacists were female and males comprised $44 \%$.

- $\quad$ Age-Approximately three-quarters of the pharmacists in this study fall between the age range of 24 and 54 . Specifically, there were $26.1 \%$ in age ranges $24-34,22.5 \%$ in ages $35-44$, and $26.1 \%$ in age ranges $45-54$. The remaining were $21.6 \%$ within age ranges $55-66$. The fewest numbers of pharmacists were among the ages 65-74 that composed 3.6\%.

- Race/Ethnicity—Race/ethnicity of the majority of pharmacy respondents were $80.7 \%$ White/European race with the remaining minorities divided by Blacks at $11.9 \%$, Asians at $4.5 \%$, and $.9 \%$ each for the 3 classifications of Hispanic, Native Hawaiian/ Pacific Island, and other.

- $\quad$ Family Status - The majority of pharmacists in this study were married with 2 children. Those that classified their marital status as married/living with a partner were at $80.2 \%$, with $9 \%$ single/never married, $7.2 \%$ divorced, and $1.8 \%$ each separated and widowed. The majority of pharmacists had children with $39.6 \%$ having 2 children, $13.5 \%$ with 1 child, $11.7 \%$ with 3 children, and $33.7 \%$ having no children.

- Geographic Locale - Pharmacists participating in the study were from across the state of Tennessee with the most concentrated in the larger urban areas of Memphis (Shelby County), Nashville (Davidson County) and Knoxville (Knox County). Most pharmacists, $42.10 \%$ lived in Middle Tennessee spanning 20 counties with most from 16 of 40 Davidson County. Pharmacists living in West Tennessee, 37.89\%, spanned 11 counties with Shelby County having most at 25 of 36 . There were $20.01 \%$ pharmacists from East Tennessee spanning 11 counties with most from Knox County.

- $\quad$ Education-A majority of pharmacists in this study had doctorate degrees. Those with a doctorate in pharmacy comprised $64 \%, 0.9 \%$ had nonpharmacy doctorates, and $0.9 \%$ had non-pharmacy master degrees. Approximately $30.6 \%$ had bachelors in pharmacy degrees and $2.7 \%$ had bachelors in non-pharmacy areas. 
- Work Setting-Three-quarters of pharmacists in this study practiced in primarily 2 types of settings. Most were in retail pharmacies at $46.84 \%$ and secondly in hospitals or hospital systems at $31.5 \%$. A distant third worked for pharmaceutical companies (including mail order and pharmacy benefits management) at $6.3 \%$. A fifth were educators at $4.5 \%$, those who worked in infusion/home health/hospice and palliative care were at $2.7 \%$. There were $1.8 \%$ each in military pharmacies, disease management, private or independently owned practices. Lastly, .9\% worked in nuclear pharmacy.

- Income-The incomes of pharmacists range from $\$ 25,000$ - $\$ 499,999$. The distribution of income levels within the profession are shown in categories listed in Table 4-1. Median annual income of $\$ 50,000$ $\$ 90,000$ was considered medium income; $<\$ 50,000$ annually was considered low income; and $>\$ 90,000$ annually was considered high income for each profession. Most pharmacists fell in the high income range with approximately $53.21 \%$, made $\$ 100,000-\$ 139,999$ and another group of $22.9 \%$ earned $\$ 75,000-\$ 99,999$. The differences in income categories between nurses and pharmacists, as well as by profession and race ethnicity, were highly statistically significant (professions chi-square value $42.5649, \mathrm{p}=<.0001$; non-minority professions chi-square value $33.8865, \mathrm{P}=<.0001$; and minority professions chi-square value 8.8034 , $\mathrm{p}=0.0123)$.

\section{Summary of Key Demographics}

Simple descriptive statistics revealed that survey respondents who completed the survey were nearly equally stratified by nurses $(\mathrm{N}=126)$ and pharmacists $(\mathrm{N}=128)$ and were a rather homogeneous socioeconomic. A review of major demographic characteristics of both professions revealed that only one of nine demographic categories differed to a statistically significant degree. Pharmacists and nursing salaries were strongly significantly different (chi-square value $42.5647, \mathrm{p}=<.0001$ ). Pharmacists' median annual incomes were higher with $83 \%$ clustered around $\$ 75,000-\$ 149,000$; while $83 \%$ of nurses clustered around $\$ 50,000-\$ 149,000$. Wages or salaries are an integral factor in determining cost burden of presenteeism and are important in this study.

However, even though the salaries differed between each specialty profession, salaries for nurses and pharmacists were above the median salaries nationally or state wide. The median salary of all workers in Tennessee is a salary of $\$ 36,000$ and the median national salary of all workers is a salary of $\$ 41,994$ (Tennessee, 2003).

The sample of racial and ethnic minorities who completed surveys exceeded the investigators targets for racial minority representativeness. Racial minorities collectively represented percentages larger than their composition across either profession nationally 
Table 4-1. Income Categories by Profession and Race/Ethnicity

\begin{tabular}{|c|c|c|c|c|c|c|c|}
\hline \multirow[b]{4}{*}{ Income Medians } & \multirow[b]{4}{*}{$\mathrm{N}^{3}$} & \multicolumn{2}{|c|}{ Healthcare Professions } & \multicolumn{2}{|c|}{ Non-Minority Race/Ethnicity ${ }^{1}$} & \multicolumn{2}{|c|}{ Minority Race/Ethnicity2 ${ }^{2}$} \\
\hline & & Nurses & Pharmacists & Nurses & Pharmacists & Nurses & Pharmacists \\
\hline & & $\mathrm{N}=100 *$ & $\mathrm{~N}=107$ & $\mathrm{~N}=78$ & $\mathrm{~N}=86$ & $\mathrm{~N}=22$ & $\mathrm{~N}=21$ \\
\hline & & $\%(n)$ & $\%(n)$ & $\%(n)$ & $\%(n)$ & $\%(n)$ & $\%(n)$ \\
\hline High $>\$ 90,000$ & 85 & $18.00(18)$ & $62.62(67)$ & $17.95(14)$ & $62.79(54)$ & $18.18(4)$ & $61.90(13)$ \\
\hline Med $\$ 50 \mathrm{k}-\$ 90 \mathrm{k}$ & 102 & $69.00(69)$ & $30.84(33)$ & $69.23(54)$ & $31.40(27)$ & $68.18(15)$ & $28.57(6)$ \\
\hline Low $<\$ 50,000$ & 20 & $13.00(13)$ & $6.54(7)$ & $12.82(10)$ & $5.81(5)$ & $13.64(3)$ & $9.52(2)$ \\
\hline
\end{tabular}

${ }^{1}$ Differences by profession and non-minority race ethnicity were highly statistically significant (chi-square value 33.8865 , $\mathrm{P}=<.0001)$.

${ }^{2}$ Differences by profession and minority race ethnicity were statistically significant (chi-square value $8.8034, \mathrm{p}=0.0123$ ).

${ }^{3}$ Differences by profession were highly statistically significant (chi-square value $42.5649, \mathrm{p}=<.0001$ ). 
and state wide. Minority nurses composed $23.5 \%$ of survey completers and this compared to $10 \%$ minorities in TN's population of nurses. However, survey representativeness for nurse ethnicity compared to national and state numbers indicated that Hispanics were under-represented in the sample. Minority pharmacists composed $19.3 \%$ of the survey respondents compared to a prevalence of $5.5 \%$ within the United States. Compared to national rates Tennessee pharmacists are over-represented in Asians and under-represented in African American minorities. Findings indicated that almost three-quarters of the total sample of professionals were female and this undoubtedly influenced the increased representation of females as pharmacists $(60 \%)$ along with the majority female nurses $(90 \%)$.

The hospital work setting was the most common setting for both professions. The second most common work settings differed by profession, with nurses in educational institutions and pharmacists in retail pharmacies. Overall, the hospital, educational institute, and retail pharmacies were the 3 most common work settings.

Other relevant demographic findings were that, compared to pharmacists, fewer nurses occupied younger age ranges of 24-34 and tended to be more heavily concentrated in the older age ranges of 44-54. Interestingly, a higher percentage of pharmacists than nurses were living with a spouse or partner and more pharmacist than nurses had no children, although the mode for both professions was 2 children.

Approximately $63.6 \%$ of Tennesseans live in urban areas surrounding the major cities: Memphis and Jackson in the West Grand Region, Nashville in the Central, Knoxville and Chattanooga in the East Grand Regions (National Center for Health Workforce Analysis, 2002). The geographic locale of the survey sample indicated that pharmacists were more widely dispersed across the 3 grand regions of Tennessee, while nurses were primarily from the west region of Tennessee. Both nurses and pharmacist were more concentrated in urban counties.

Collectively, the sample is very highly educated compared to state and national rates of those having a bachelors or higher degree at $19.6 \%$ of Tennesseans and $24.4 \%$ of the nation (National Center for Health Workforce Analysis, 2002). Almost half of the sample had doctorate degrees and the remainder was split between master's and bachelor's degrees. Twice as many pharmacists had doctorate degrees as nurses, while more nurses had master's degrees than did pharmacists had combined master's and bachelor's degrees. Key summary demographic statistics are summarized in Table 4-2.

\section{Health Conditions of Total Sample}

Table 4-3 and Table 4-4 contain frequencies and percentages of self-identified physical health conditions and mental health conditions respectively. Two by two contingency tables were constructed in $\mathrm{SAS} \otimes$ to identify the frequency, prevalence, and association of or difference between each health condition by profession (nurse or pharmacist) and by race/ethnicity (minority or non-minority). For the most part, chisquare analysis 
Table 4-2. Demographics Entire Sample of Nurse and Pharmacist Respondents

\begin{tabular}{|c|c|c|c|}
\hline Characteristic & $\begin{array}{c}\text { Nurses } \\
49.81 \% \quad \mathrm{~N}=131 * \\
\%(\mathrm{n})\end{array}$ & $\begin{array}{c}\text { Pharmacists } \\
50.19 \% \quad \mathrm{~N}=132 * \\
\%(\mathrm{n})\end{array}$ & $\begin{array}{c}\text { Total } \\
100 \% \mathrm{~N}=263 * \\
\%(\mathrm{n})\end{array}$ \\
\hline Gender & $\mathrm{N}=\mathbf{1 0 1}$ & $\mathrm{N}=109$ & $\mathrm{~N}=\mathbf{2 1 0}$ \\
\hline Female & $90.1(91)$ & $56.0(61)$ & $72.4(152)$ \\
\hline Male & $9.9(10)$ & $44.0(48)$ & $27.6 \quad(58)$ \\
\hline Age & $\mathrm{N}=\mathbf{1 0 1}$ & $\mathrm{N}=\mathbf{1 1 1}$ & $\mathrm{N}=\mathbf{2 1 2}$ \\
\hline 24-34 & $10.9(11)$ & $26.1(29)$ & $18.86(40)$ \\
\hline $35-44$ & $21.8(22)$ & $22.5(25)$ & $22.20(47)$ \\
\hline $44-54$ & $40.6(41)$ & $26.1(29)$ & $33.00(70)$ \\
\hline $55-64$ & $25.7(26)$ & $21.6(24)$ & $23.60(50)$ \\
\hline $65-74$ & $1.0(1)$ & $3.6 \quad(4)$ & $2.4 \quad(5)$ \\
\hline Race/ethnicity & $\mathbf{N}=98$ & $\mathrm{~N}=109$ & $\mathbf{N}=\mathbf{2 0 7}$ \\
\hline Asian & $0.0 \quad(0)$ & $4.6 \quad(5)$ & $2.4(5)$ \\
\hline Black & $22.4(22)$ & $11.9(13)$ & $16.9(35)$ \\
\hline Hispanic/Latino & $0.0 \quad(0)$ & $0.9 \quad(1)$ & $.5(1)$ \\
\hline Native Hawaiian or Pacific Island & $1.0 \quad(1)$ & $0.9 \quad(1)$ & $1.0(2)$ \\
\hline Total Minorities & $23.5(23)$ & $19.3(20)$ & $21.3(43)$ \\
\hline White/European & $76.5(75)$ & $80.7(88)$ & $78.7(163)$ \\
\hline Family Status & $\mathrm{N}=99 / \mathrm{N}=100$ & $\mathrm{~N}=111$ & $\mathrm{~N}=\mathbf{2 1 1}$ \\
\hline Married/Partner & $77.8(77)$ & $80.20(89)$ & $79.0(166)$ \\
\hline Divorced & $12.10(12)$ & $7.2(8)$ & $9.5(20)$ \\
\hline Single/Never married & $7.10(7)$ & $9.0(10)$ & $8.1(17)$ \\
\hline Separated & $2.00(2)$ & $1.8(2)$ & $1.9(4)$ \\
\hline Widowed & $1.00(1)$ & $1.8(2)$ & $1.4(3)$ \\
\hline No children & $17.00(17)$ & $33.3(37)$ & $25.6(54)$ \\
\hline
\end{tabular}


Table 4-2. (continued)

\begin{tabular}{|c|c|c|c|}
\hline Characteristic & $\begin{array}{c}\text { Nurses } \\
49.81 \mathrm{~N}=131^{*} \\
\%(\mathrm{n})\end{array}$ & $\begin{array}{c}\text { Pharmacists } \\
50.19 \mathrm{~N}=132 * \\
\% \text { (n) }\end{array}$ & $\begin{array}{c}\text { Total } \\
100 \% \mathrm{~N}=263 * \\
\%(\mathrm{n})\end{array}$ \\
\hline 1 child & $14.00(14)$ & $13.5(15)$ & $13.7(29)$ \\
\hline 2 children & $43.00(43)$ & $39.6(44)$ & $42.2(87)$ \\
\hline 3 children & $18.00(18)$ & $11.7(13)$ & $14.7(31)$ \\
\hline 4+children & $8.00(8)$ & $1.8(2)$ & $4.7(10)$ \\
\hline Geographic Locale & $\mathbf{N}=94$ & $\mathbf{N}=\mathbf{9 5}$ & $N=189$ \\
\hline West TN & $88.29(83)$ & $37.89(36)$ & $62.96(119)$ \\
\hline Middle TN & $8.50(8)$ & $42.10(40)$ & $25.39(48)$ \\
\hline East TN & $4.25(4)$ & $20.01(19)$ & $12.16(23)$ \\
\hline Highest Education & $\mathrm{N}=\mathbf{1 0 1}$ & $\mathrm{N}=111$ & $\mathrm{~N}=\mathbf{2 1 2}$ \\
\hline Associates/Diploma & $7.90(8)$ & $00.00(00)$ & $3.70 \quad(8)$ \\
\hline Bachelors & $13.90(14)$ & $33.30(37)$ & $24.00(51)$ \\
\hline Masters & $49.50(50)$ & $1.80(2)$ & $24.50(52)$ \\
\hline Doctorates & $28.70(29)$ & $64.90(72)$ & $47.60(101)$ \\
\hline Work Settings & $\mathrm{N}=\mathbf{1 1 1}$ & $\mathbf{N}=\mathbf{1 1 1}$ & $\mathrm{N}=\mathbf{2 2 2}$ \\
\hline Hospital or hospital system & $42.34(47)$ & $31.50(35)$ & $36.28(82)$ \\
\hline Educational institution & $32.44(36)$ & $4.5(5)$ & $18.14(41)$ \\
\hline Outpatient clinic/Retail pharmacy & $10.82(12)$ & $48.64(54)$ & $29.20(66)$ \\
\hline Pharmaceutical company & $0.90 \quad(1)$ & $6.30(7)$ & $3.53(8)$ \\
\hline $\begin{array}{l}\text { Home Health/Palliative/Long term } \\
\text { care }\end{array}$ & $3.60 \quad(4)$ & $2.70(3)$ & $3.09(7)$ \\
\hline Private/Independently owned & $9.90(11)$ & $1.80(1)$ & $5.30(12)$ \\
\hline Income $^{1}$ & $\mathbf{N}=100$ & $N=109$ & $\mathrm{~N}=\mathbf{2 0 9}$ \\
\hline Below $\$ 44,999$ & $10.00(10)$ & $5.50(6)$ & $7.65(16)$ \\
\hline$\$ 45,000-\$ 49,999$ & $4.00(4)$ & $0.00(0)$ & $1.90(4)$ \\
\hline$\$ 50,000-\$ 74,999$ & $37.00(37)$ & $7.33(8)$ & $21.50(45)$ \\
\hline
\end{tabular}


Table 4-2. (continued)

\begin{tabular}{|c|c|c|c|}
\hline Characteristic & $\begin{array}{c}\text { Nurses } \\
49.81(131)^{*} \\
\%(n)\end{array}$ & $\begin{array}{c}\text { Pharmacists } \\
50.19(132)^{*} \\
\%(n)\end{array}$ & $\begin{array}{c}\text { Total } \\
100(263)^{*} \\
\%(\mathrm{n})\end{array}$ \\
\hline$\$ 75,000-\$ 99,999$ & $32.00(32)$ & $22.90(25)$ & $27.30(57)$ \\
\hline$\$ 100,000-\$ 149,999$ & $14.00(14)$ & $53.21(58)$ & $34.40(72)$ \\
\hline$\$ 150,000-199,999$ & $2.00(2)$ & $6.42(7)$ & $4.30(9)$ \\
\hline$\$ 200,000-299,999$ & $0.00(0)$ & $2.80(3)$ & $1.40(3)$ \\
\hline$\$ 300,000-499,999$ & $1.00(1)$ & $1.83(2)$ & $1.40(3)$ \\
\hline Insurance & $N=100$ & $N=103$ & $\mathbf{N}=\mathbf{2 0 3}$ \\
\hline Private insurance & $96.00(96)$ & $96.10(99)$ & $96.70(195)$ \\
\hline No insurance & $1.00(1)$ & $0.00(0)$ & $0.50(1)$ \\
\hline Public/Private combo & $3.00(3)$ & $3.90(3)$ & $2.80(6)$ \\
\hline Public & $0.50 \quad(1)$ & $0.00(0)$ & $0.50(1)$ \\
\hline
\end{tabular}

*Ns vary because all respondents did not provide answers to all demographic questions in each category.

${ }^{1}$ Significant differences in income by professions (Chi-Square value 42.5649, $\mathrm{p}=<.0001$ ) 
Table 4-3. Rank Order Physical Health Conditions by Profession and Race/Ethnicity Entire Sample

\begin{tabular}{|c|c|c|c|c|c|c|c|c|c|}
\hline \multicolumn{2}{|c|}{$\begin{array}{c}\text { All } \\
\mathrm{N}=261 *\end{array}$} & \multicolumn{2}{|c|}{$\begin{array}{c}\text { Nurses } \\
\mathrm{N}=129 *\end{array}$} & \multicolumn{2}{|c|}{$\begin{array}{l}\text { Pharmacists } \\
\mathrm{N}=130^{*}\end{array}$} & \multicolumn{2}{|c|}{$\begin{array}{c}\text { Minorities } \\
\mathrm{N}=43^{*}\end{array}$} & \multicolumn{2}{|c|}{$\begin{array}{c}\text { Non-Minorities } \\
\mathrm{N}=213^{*}\end{array}$} \\
\hline $\begin{array}{l}\text { Physical } \\
\text { Condition }\end{array}$ & $\%(n)$ & $\begin{array}{l}\text { Physical } \\
\text { Condition }\end{array}$ & $\%(n)$ & $\begin{array}{l}\text { Physical } \\
\text { Condition }\end{array}$ & $\%(n)$ & $\begin{array}{l}\text { Physical } \\
\text { Condition }\end{array}$ & $\%(n)$ & $\begin{array}{l}\text { Physical } \\
\text { Condition }\end{array}$ & $\%(n)$ \\
\hline $\begin{array}{l}\text { Back or neck } \\
\text { pain }\end{array}$ & $45.6(115)$ & $\begin{array}{l}\text { Back or neck } \\
\text { pain }\end{array}$ & $50.8(64)$ & $\begin{array}{l}\text { Back or neck } \\
\text { pain }\end{array}$ & $40.0(51)$ & Allergies & $35.71(15)$ & $\begin{array}{l}\text { Back or neck } \\
\text { pain }\end{array}$ & $48.11(102)$ \\
\hline Allergies & $35.4(91)$ & Allergies & $36.2(46)$ & Allergies & $34.6(45)$ & $\begin{array}{l}\text { Back or neck } \\
\text { pain }\end{array}$ & $33.33(13)$ & Allergies & $35.51(76)$ \\
\hline $\begin{array}{l}\text { Sleep } \\
\text { problem }\end{array}$ & $25.1(64)$ & Hypertension & $36.2(46)$ & $\begin{array}{l}\text { High } \\
\text { cholesterol }\end{array}$ & $26.0(32)$ & Hypertension & $24.39(10)$ & Sleep problem & $26.76(57)$ \\
\hline Hypertension & $23.2(60)$ & Sleep problem & $26.0(33)$ & $\begin{array}{l}\text { Sleep } \\
\text { problem }\end{array}$ & $24.2(31)$ & $\begin{array}{l}\text { Chronic } \\
\text { fatigue/ } \\
\text { Low energy }\end{array}$ & $19.51(8)$ & Hypertension & $23.04(50)$ \\
\hline $\begin{array}{l}\text { High } \\
\text { cholesterol }\end{array}$ & $22.6(59)$ & Obesity & $24.0(31)$ & Hypertension & $23.7(31)$ & Obesity & $19.51(8)$ & High cholesterol & $24.77(53)$ \\
\hline Obesity & $22.0(56)$ & Arthritis & $24.0(31)$ & $\begin{array}{l}\text { Chronic } \\
\text { fatigue } \\
\text { /Low energy }\end{array}$ & $21.1(27)$ & $\begin{array}{l}\text { Sleep } \\
\text { problem }\end{array}$ & $17.07(7)$ & Obesity & $22.64(48)$ \\
\hline Arthritis & $21.3(54)$ & $\begin{array}{l}\text { Gastrointestinal } \\
\text { problem }\end{array}$ & $23.2(29)$ & Obesity & $19.2(25)$ & $\begin{array}{l}\text { Gastro- } \\
\text { intestinal } \\
\text { problem }\end{array}$ & $17.07(7)$ & Arthritis & $22.54(48)$ \\
\hline $\begin{array}{l}\text { Gastro- } \\
\text { intestinal } \\
\text { problem }\end{array}$ & $21.3(54)$ & High cholesterol & $21.3(27)$ & $\begin{array}{l}\text { Gastro- } \\
\text { intestinal } \\
\text { problem }\end{array}$ & $19.2(25)$ & $\begin{array}{l}\text { High } \\
\text { cholesterol }\end{array}$ & $14.63(6)$ & $\begin{array}{l}\text { Gastro-intestinal } \\
\text { problem }\end{array}$ & $22.27(47)$ \\
\hline $\begin{array}{l}\text { Chronic } \\
\text { fatigue/ Low } \\
\text { energy }\end{array}$ & $19.3(49)$ & $\begin{array}{l}\text { Migraine/Severe } \\
\text { headache }\end{array}$ & $20.8(26)$ & Arthritis & $18.0(23)$ & Arthritis & $12.5(5)$ & $\begin{array}{l}\text { Chronic fatigue/ } \\
\text { Low energy }\end{array}$ & $19.34(41)$ \\
\hline $\begin{array}{l}\text { Migraine/ } \\
\text { Severe } \\
\text { headache }\end{array}$ & $17.9(45)$ & $\begin{array}{l}\text { Chronic fatigue/ } \\
\text { Low energy }\end{array}$ & $17.5(22)$ & $\begin{array}{l}\text { Other } \\
\text { musculo- } \\
\text { skeletal }\end{array}$ & $15.6(20)$ & $\begin{array}{l}\text { Urinary/ } \\
\text { Bladder }\end{array}$ & $12.2(5)$ & $\begin{array}{l}\text { Migraine/ } \\
\text { Severe headache }\end{array}$ & $19.43(41)$ \\
\hline
\end{tabular}


Table 4-3. (continued)

\begin{tabular}{|c|c|c|c|c|c|c|c|c|c|}
\hline \multicolumn{2}{|c|}{$\begin{array}{c}\text { All } \\
\mathrm{N}=261 *\end{array}$} & \multicolumn{2}{|c|}{$\begin{array}{c}\text { Nurses } \\
\mathrm{N}=129 *\end{array}$} & \multicolumn{2}{|c|}{$\begin{array}{c}\text { Pharmacists } \\
\left.\mathrm{N}=130^{*}\right)\end{array}$} & \multicolumn{2}{|c|}{$\begin{array}{c}\text { Minorities } \\
\mathrm{N}=43^{*}\end{array}$} & \multicolumn{2}{|c|}{$\begin{array}{c}\text { Non-Minorities } \\
\mathrm{N}=213^{*}\end{array}$} \\
\hline $\begin{array}{l}\text { Physical } \\
\text { Condition }\end{array}$ & $\%(n)$ & $\begin{array}{l}\text { Physical } \\
\text { Condition }\end{array}$ & $\%(n)$ & $\begin{array}{l}\text { Physical } \\
\text { Condition }\end{array}$ & $\%(n)$ & $\begin{array}{l}\text { Physical } \\
\text { Condition }\end{array}$ & $\%(n)$ & $\begin{array}{l}\text { Physical } \\
\text { Condition }\end{array}$ & $\%(n)$ \\
\hline $\begin{array}{l}\text { Other } \\
\text { musculo- } \\
\text { skeletal }\end{array}$ & $15.0(38)$ & $\begin{array}{l}\text { Other } \\
\text { musculo- } \\
\text { skeletal }\end{array}$ & $14.3(18)$ & $\begin{array}{l}\text { Migraine/ } \\
\text { Severe } \\
\text { headache }\end{array}$ & $15.0(19)$ & $\begin{array}{l}\text { Migraine/ } \\
\text { Severe } \\
\text { headache }\end{array}$ & $10.0(4)$ & $\begin{array}{l}\text { Other } \\
\text { musculo- } \\
\text { skeletal }\end{array}$ & $16.51(35)$ \\
\hline $\begin{array}{l}\text { Chronic } \\
\text { pain }^{1}\end{array}$ & $11.4(29)$ & Chronic pain ${ }^{1}$ & $14.3(18)$ & $\begin{array}{l}\text { Urinary/ } \\
\text { bladder }\end{array}$ & $10.3(13)$ & $\begin{array}{l}\text { Stomach/ } \\
\text { intestinal } \\
\text { ulcer }\end{array}$ & $9.76(4)$ & Chronic pain ${ }^{1}$ & $13.21(28)$ \\
\hline $\begin{array}{l}\text { Urinary/ } \\
\text { Bladder }\end{array}$ & 11. (28) & $\begin{array}{l}\text { Urinary/ } \\
\text { Bladder }\end{array}$ & $11.9(15)$ & Chronic pain ${ }^{1}$ & $8.6(11)$ & Diabetes & 7.50 & $\begin{array}{l}\text { Urinary/ } \\
\text { bladder }\end{array}$ & $10.95(23)$ \\
\hline $\begin{array}{l}\text { Stomach/ } \\
\text { Intestinal } \\
\text { ulcer }\end{array}$ & 7. (18) & $\begin{array}{l}\text { Stomach/ } \\
\text { Intestinal } \\
\text { ulcer }\end{array}$ & $6.20(8)$ & $\begin{array}{l}\text { Stomach/ } \\
\text { Intestinal } \\
\text { ulcer }\end{array}$ & $7.69(10)$ & $\begin{array}{l}\text { Other } \\
\text { muculo- } \\
\text { skeletal }\end{array}$ & $7.32(3)$ & $\begin{array}{l}\text { Stomach/ } \\
\text { intestinal } \\
\text { ulcer }\end{array}$ & $6.60(14)$ \\
\hline Asthma $^{2}$ & $7.1(18)$ & Asthma $^{2}$ & $10.52(14)$ & Cancer $^{3}$ & $6.92(9)$ & $\begin{array}{l}\text { Chronic } \\
\text { pain }^{1}\end{array}$ & $2.44(1)$ & Asthma $^{2}$ & $7.98(17)$ \\
\hline Cancer $^{3}$ & $6.3(16)$ & Cancer $^{4}$ & $5.42(7)$ & $\begin{array}{l}\text { Health } \\
\text { disease }\end{array}$ & $3.84(5)$ & $\begin{array}{l}\text { Health } \\
\text { disease }\end{array}$ & $2.44(1)$ & Cancer $^{3}$ & $7.51(16)$ \\
\hline Diabetes & $4.3(11)$ & Diabetes & $6.20(8)$ & Asthma $^{2}$ & $3.07(4)$ & Asthma ${ }^{2}$ & $2.44(1)$ & Diabetes & $3.77(8)$ \\
\hline Heart disease & $3.5(9)$ & Heart disease & 3.32 (3) & Diabetes & 3.07 (4) & $\begin{array}{l}\text { Other } \\
\text { respiratory/ } \\
\text { lung }\end{array}$ & $2.44(1)$ & Heart disease & $3.77(8)$ \\
\hline $\begin{array}{l}\text { Other } \\
\text { respiratory/ } \\
\text { lung }\end{array}$ & $3.1(8)$ & $\begin{array}{l}\text { Other } \\
\text { respiratory/ } \\
\text { lung }\end{array}$ & $3.10(4)$ & $\begin{array}{l}\text { Other } \\
\text { respiratory/ } \\
\text { lung }\end{array}$ & $2.3(3)$ & Cancer $^{3}$ & $0000(0)$ & $\begin{array}{l}\text { Other } \\
\text { respiratory/ } \\
\text { lung }\end{array}$ & $3.30(7)$ \\
\hline
\end{tabular}


Table 4-4. Rank Order Mental Health Conditions by Profession and Race/Ethnicity Total Sample

\begin{tabular}{|c|c|c|c|c|c|c|c|c|c|}
\hline \multicolumn{2}{|c|}{$\begin{array}{l}\text { All in Sample } \\
\quad \mathrm{N}=261^{*}\end{array}$} & \multicolumn{2}{|c|}{$\begin{array}{l}\text { Nurses } \\
\mathrm{N}=129 *\end{array}$} & \multicolumn{2}{|c|}{$\begin{array}{l}\text { Pharmacists } \\
\mathrm{N}=130^{*}\end{array}$} & \multicolumn{2}{|c|}{$\begin{array}{c}\text { Minorities } \\
\mathrm{N}=43^{*}\end{array}$} & \multicolumn{2}{|c|}{$\begin{array}{c}\text { Non-Minorities } \\
\mathrm{N}=213^{*}\end{array}$} \\
\hline Mental & & Mental & & Mental & & Mental & & Mental & \\
\hline Health & & Health & & Health & & Health & & Health & \\
\hline Condition & $\%(n)$ & Condition & $\%(n)$ & Condition & $\%(n)$ & Condition & $\%(n)$ & Condition & $\%(n)$ \\
\hline Depression & $22.30(57)$ & Depression & $22.7(29)$ & Depression & $23.7(31)$ & Depression & $17.07(7)$ & Depression & $23.36(50)$ \\
\hline Anxiety & $16.90(43)$ & Anxiety & $17.5(22)$ & Anxiety & $16.4(21)$ & Anxiety & $17.07(7)$ & Anxiety & $16.98(36)$ \\
\hline $\begin{array}{l}\text { Substance } \\
\text { use } \\
\text { problem }\end{array}$ & $4.00(10)$ & $\begin{array}{l}\text { Substance } \\
\text { use } \\
\text { problem }\end{array}$ & $3.32(3)$ & $\begin{array}{l}\text { Substance } \\
\text { use } \\
\text { problem }\end{array}$ & $5.38(7)$ & $\begin{array}{l}\text { Substance } \\
\text { use } \\
\text { problem }\end{array}$ & $5.26(2)$ & $\begin{array}{l}\text { Substance } \\
\text { use } \\
\text { problem }\end{array}$ & $3.81(8)$ \\
\hline $\begin{array}{l}\text { Other } \\
\text { emotional } \\
\text { problem }\end{array}$ & $3.20(8)$ & $\begin{array}{l}\text { Other } \\
\text { emotional } \\
\text { problem }\end{array}$ & 3.10 & $\begin{array}{l}\text { Other } \\
\text { emotional } \\
\text { problem }\end{array}$ & $3.84(5)$ & $\begin{array}{l}\text { Other } \\
\text { emotional } \\
\text { problem }\end{array}$ & $2.50(1)$ & $\begin{array}{l}\text { Other } \\
\text { emotional } \\
\text { problem }\end{array}$ & $3.30(7)$ \\
\hline
\end{tabular}

*All survey respondents did not answer all questions, frequencies and percents based on number of respondents per question. 
for significance of associations were used. However, when $25 \%$ of the frequencies of cells were under 5, Fisher's Exact Tests were used to capture significance of associations for the smaller frequencies.

Physical Health

As expected, similar to what has been found in previous empirical studies of working professionals, the prevalence of acute episodic conditions were more prevalent than chronic conditions in the general healthcare workforce. Specifically, as can be seen in Table 4-3, acute episodic conditions such as back and neck pain, allergies, sleep problems, and GI problems were often more prevalent (above 20\%) than the more persistent chronic conditions such as asthma, cancer, diabetes, heart disease, and lung disease (under $8 \%$ ). Most conditions appear similarly prevalent across both nurses and pharmacists. For the entire sample, chi-square analyses of association of health conditions by professions showed that there was the only one of 23 health physical conditions which was significantly more prevalent by profession and only one of 23 that was significantly more prevalent by race/ethnicity. Asthma was more prevalent in nurses (5.51\%) than in pharmacists $(1.57 \%)$. The difference was statically significant at chisquare $\mathrm{p}=.0131$. Chronic pain was more prevalent in non-minorities than minorities $(11.07 \%, 0.40 \%$ respectively) and the difference was statistically significant (chi-square $\mathrm{p}=0.0476)$. Also, there was near statistical significant difference in cancer by race $(2.3 \%$ non-minority, $0 \%$ minority; chi-square value 3.2075 , $p=.0733$ and Fisher's exact $\mathrm{p}=.0580$ ).

Mental Health

Table 4-4 shows that mental health conditions were also comparably prevalent across both professions. As expected, due to the prevalence of depression and anxiety in the general population, these illnesses were also the most predominant behavioral health conditions for both professions (Agency for Healthcare Research and Quality, 2006). More non-minorities experienced both depression and anxiety conditions than minorities, however, the differences were not statistically significant for either condition (depression $\mathrm{p}=.3757$; anxiety $\mathrm{p}=0.9885$ ). Rates in the general population nationally for substance abuse disorders were estimated at be $4 \%$, the prevalence of mental health disorders collectively was estimated at $26 \%$, rates of depression at $10 \%$, and anxiety $(18 \%)$ (Agency for Healthcare Research and Quality, 2006). The entire sample reported rates of substance use problems at $4.0 \%$, other emotional problem $3.2 \%$, depression at $22.30 \%$, and anxiety at $16.9 \%$. These results indicated that substance use and anxiety of the sample was as expected based on national norms, but that depression was higher than national norms. Given the work of Burton (2005) and Boles (2004) with impact of perception-level health risk factors, this indicated that this investigator needed to be alert to whether these health patterns changed or were factors in those who also experienced presenteeism. 


\section{Results of Analysis}

The results in this chapter are organized by each of three aims. Each aim, research question, hypotheses and corresponding results were presented together. For ease of interpretation of hypothesis, findings and a separate conclusions section are summarized at the end of each specific hypothesis.

\section{Specific Aim 1}

Specific aim 1 was to describe presenteeism, its prevalence, associated health conditions and treatment in employed nurses and pharmacists and indicate whether there are differences across racial/ethnic groups. The research question that was used to address this aim was 'what is the prevalence of presenteeism, its associated health conditions and extent of treatment among nurses and pharmacists; and, do these vary across racial/ethnic groups?' The first steps prior to reporting results of hypotheses under aim 1 were to determine presenteeism and to determine its prevalence.

The Wellness-at-Work survey tool was used to determine the presenteeism measure. Contained within the Wellness-at-Work survey were three scales that measured presenteeism -- B14 presenteeism scale from the WPAI-GH scale, B-13 presenteeism scale from the HPQ scale, and B-10 a presenteeism priming question from the HPQ. Concurrent validity among the three scales was established using analysis of Pearson Correlation Coefficients. Question B14 was found to be highly correlated with B13 $(-0.47597, \mathrm{p}<.0001)$ (see Table 4-5). Also, B14 was highly correlated with B10, the presenteeism priming question from the HPQ survey tool $(0.53393, \mathrm{p}<.0001)$ (see Table 4-6). Therefore, the WPAI-GH scale (B14) was adopted as the presenteeism measure for use in analysis for this study. When a respondent rated their productivity decrement between 1 and 10 versus 0 on the Wellness-at-Work question B14, they were considered to be positive for presenteeism. For example a score of 1, 2, 3...represented 10\%, 20\% and $30 \%$ increments respectively in a presenteeism score.

'Prevalence,' consistent with its definition according to the International Society for Pharmacoeconomics and Outcomes Research (ISPOR) Book of Terms (Berger, Bingfors, 2003a), indicates that presenteeism is the amount of disease problem or its burden within a defined population at a given point in time. Applied to this study, presenteeism was considered a disease burden examined through a survey of patient reported outcomes (PRO) for nurses and pharmacists for the defined time of the 'previous 28 days.'

Hypothesis 1.1: Results

Hypothesis 1.1 states there are no differences in prevalence of presenteeism among nurses and pharmacists, nor across racial/ethnic groups of both professions. Survey presenteeism scales were scored for a total of 226 nurses and pharmacists. Table 4-7 show results of contingency table analysis for differences in rates of presenteeism 
Table 4-5. WPAI B14 and HPQ B13 Presenteeism Scales Correlation

\begin{tabular}{lllll}
\hline Question & N & Mean & SD & $\begin{array}{l}\text { Pearson Correlation Coefficients } \\
\text { Pr }>|r| \text { under HO: Rho }=0\end{array}$ \\
\hline B -13 (HPQ) & 221 & 8.47 & 1.25256 & 0.47597 \\
B-14 (WPAI) & 226 & 1.27 & 1.94796 & $<0.0001$ \\
\hline
\end{tabular}

Table 4-6. WPAI B14 Scale and HPQ B10 Priming Question Correlation

\begin{tabular}{lcccl}
\hline Question & $\mathrm{N}$ & Mean & SD & $\begin{array}{l}\text { Pearson Correlation Coefficients } \\
\operatorname{Pr}>|\mathrm{r}| \text { under HO: Rho }=0\end{array}$ \\
\hline B -10 (HPQ) & 223 & 1.32 & 0.64760 & $0.53393<0.0001$ \\
\hline
\end{tabular}


Table 4-7. Differences in Presenteeism by Profession across Race/Ethnicity

\begin{tabular}{|c|c|c|c|c|c|c|c|c|c|}
\hline & & Each & rofession $^{1}$ & $\mathrm{Mi}$ & 1orities $^{2}$ & Non-N & Minorities $^{3}$ & Combined & Professions 6 \\
\hline Presenteesim & $\begin{array}{c}\text { Total } \\
\mathrm{N}=226 \\
\% \\
\text { (n) }\end{array}$ & $\begin{array}{c}\text { Nurses } \\
\mathrm{N}=112 \\
\% \\
\text { (n) }\end{array}$ & $\begin{array}{c}\text { Pharmacists } \\
\mathrm{N}=114 \\
\% \\
\text { (n) }\end{array}$ & $\begin{array}{c}\text { Nurses } \\
\mathrm{N}=22 \\
\% \\
(\mathrm{n})\end{array}$ & $\begin{array}{c}\text { Pharmacists } \\
\qquad \mathrm{N}=21 \\
\%(\mathrm{n})\end{array}$ & $\begin{array}{c}\text { Nurses }^{4} \\
\mathrm{~N}=90 \\
\% \\
\text { (n) }\end{array}$ & $\begin{array}{c}\text { Pharmacist }^{5} \\
\mathrm{~N}=93 \\
\% \\
\text { (n) }\end{array}$ & $\begin{array}{c}\text { Minorities } \\
\mathrm{N}=42 \\
\% \\
\text { (n) }\end{array}$ & $\begin{array}{c}\text { Non- } \\
\text { Minorities } \\
\mathrm{N}=183 \\
\% \\
\text { (n) }\end{array}$ \\
\hline Yes & $\begin{array}{l}52.65 \\
(119)\end{array}$ & $\begin{array}{c}50.00 \\
(56)\end{array}$ & $\begin{array}{c}55.26 \\
(63)\end{array}$ & $\begin{array}{c}40.91 \\
(9)\end{array}$ & $\begin{array}{c}57.14 \\
(12)\end{array}$ & $\begin{array}{c}52.22 \\
(47)\end{array}$ & $\begin{array}{c}54.84 \\
(51)\end{array}$ & $\begin{array}{c}48.84 \\
(21)\end{array}$ & $\begin{array}{c}53.55 \\
(98)\end{array}$ \\
\hline No & $\begin{array}{l}47.35 \\
(107)\end{array}$ & $\begin{array}{c}50.00 \\
(56)\end{array}$ & $\begin{array}{c}44.74 \\
(51)\end{array}$ & $\begin{array}{c}54.09 \\
(13)\end{array}$ & $\begin{array}{c}42.86 \\
(9)\end{array}$ & $\begin{array}{c}47.78 \\
(43)\end{array}$ & $\begin{array}{c}45.16 \\
(42)\end{array}$ & $\begin{array}{c}51.16 \\
(22)\end{array}$ & $\begin{array}{c}46.45 \\
(85)\end{array}$ \\
\hline
\end{tabular}

${ }^{1}$ No statistically significant differences in presenteeism for nurses versus pharmacists (chi-square value 0.6278 , $\mathrm{p}=0.4282$ ).

${ }^{2}$ No statistically significant differences in presenteeism for racial/ethnic minority nurses versus pharmacist (Chi-square value $1.1332, \mathrm{p}=0.2871$ ).

${ }^{3}$ No statistically significant differences in presenteeism for racial/ethnic non-minority nurses versus pharmacist (chisquare value $0.1259, \mathrm{p}=0.7227$ ).

${ }^{4}$ No statistically significant differences in presenteeism for nurses who are racial/ethnic minorities versus nonminorities (chi- square value $0.9051, \mathrm{p}=0.3414$ ).

${ }^{5}$ No statistically significant differences in presenteeism for pharmacists who are racial/ethnic minorities versus nonminorities (chi-square value $0.0368, \mathrm{p}=0.8479$ ).

${ }^{6}$ No statistically significant differences in presenteeism for combined professions when divided by racial/ethnic minorities versus non-minorities (chi-square value $0.3105, \mathrm{p}=0.5774$ ). 
by profession, and by race/ethnicity. Findings were that $52.65 \%$ (119) professionals reported presenteeism and the remaining $47.35 \%$ (107) reported no presenteeism. Of the 119 professionals who reported presenteeism, there were larger percentages of pharmacists $55.26 \%$ than nurses $50.00 \%$, however, these differences were not statistically significant (chi-square value $0.6278, \mathrm{p}=0.4282$ ). The tendency for higher rates of presenteeism for pharmacists also existed when data were reviewed according to race/ethnicity. Minority pharmacists' rates of presenteeism, 57.14\%, were higher than minority nurses rates, $40.91 \%$. Non-minority pharmacists also experienced higher rates of presenteeism than non-minority nurses, $54.84 \%$ versus $52.22 \%$ respectively. However, all differences between these professions were not statistically significant (minorities chi-square value $1.1332, \mathrm{p}=0.2871$; non-minorities chi-square value 0.1259 , $p=0.7227$ respectively).

The pictures within each profession stratified by race/ethnicity also revealed differences, but were not statistically significant ones. Rates of presenteeism for nonminority nurses at $52.22 \%$ were higher than minority nurses' rate at $40.91 \%$ (chi-square value $0.9051, \mathrm{p}=0.3414$ ). The rate of presenteeism for minority pharmacist, $57.14 \%$, was higher versus non-minority pharmacists, $54.83 \%$ (chi-square value 0.0368 , $\mathrm{P}=0.8479$ ). Although there was no statistical significance, this one instance of rates for minority racial/ethnic pharmacists was not strong enough to influence the presenteeism rate of the overall sample which indicated that minorities had lower rates, $48.84 \%$, than non-minorities, $53.55 \%$. The differences by race/ethnicity were not statistically significant (Chi-square value $0.3105, \mathrm{P}=0.5774$ ). Table 4-7 shows the data for these results. The next section addresses results of presenteeism divided into two levels of lower and higher ranges of presenteeism.

Table 4-8 shows data from respondents when presenteeism was divided into two levels. Based on a review of previous empirical studies of the presenteeism phenomena, this study defines low level presenteeism as $10 \%-30 \%$ decrements in work productivity. Higher levels were defined as $40 \%$ or more decrements in work productivity (Stewart et al., 2003a).

As can be seen from Table 4-8, 119 nurses and pharmacists with presenteeism at lower levels composed $41.15 \%$ (93) of the sample and those with higher levels composed $11.50 \%$ (26). The prevalence of presenteeism at lower levels for pharmacists was $79.37 \%$ (50) and this was only slightly more than for nurse at 76.78\% (43). Presenteeism at higher levels was slightly more for nurses at $23.21 \%$ (13), than for pharmacists at $20.63 \%$ (13). (Note: the N's for the cells counts were coincidentally the same). There were no statistical differences in presenteeism for both professions by levels (chi-square value $0.1155, \mathrm{P}=0.7339$ ).

The variation in levels of presenteeism within professions across racial/ethnic groups was also quite similar. Table 4-8 shows nurses who reported lower levels of presenteeism composed $76.60 \%$ non-minorities and this was slightly lower than rates for racial/ethnic minority nurses at $77.78 \%$. Nurses reporting higher levels of presenteeism include $23.40 \%$ racial/ethnic non-minorities which was only slightly higher than $22.22 \%$ 
Table 4-8. Levels of Presenteeism by Profession and Race/Ethnicity

\begin{tabular}{|c|c|c|c|}
\hline Groups & $\begin{array}{c}\text { Presenteeism } \\
\text { Lower Level } \\
\%(\mathrm{n}) \\
\end{array}$ & $\begin{array}{c}\text { Presenteeism } \\
\text { Higher Levels } \\
\%(\mathrm{n})\end{array}$ & $\begin{array}{c}\text { Total Presenteeism } \\
\text { Two Levels } \\
\%(\mathrm{n})\end{array}$ \\
\hline \multicolumn{4}{|l|}{ Nurses } \\
\hline Minorities & 77.78 (7) & $22.22(2)$ & $40.91 \quad(9)$ \\
\hline $\begin{array}{l}\text { Non- } \\
\text { minorities }\end{array}$ & $76.60(36)$ & $23.40(11)$ & $52.22(47)$ \\
\hline Total nurses & $76.79(43)$ & $23.21(13)$ & $50.00(56)$ \\
\hline \multicolumn{4}{|l|}{ Pharmacists } \\
\hline Minorities & $83.33(10)$ & $16.67(2)$ & $57.14(12)$ \\
\hline $\begin{array}{l}\text { Non- } \\
\text { minorities }\end{array}$ & $78.43(40)$ & $21.57(11)$ & $54.84(51)$ \\
\hline $\begin{array}{l}\text { Total } \\
\text { pharmacists }\end{array}$ & $79.37(50)$ & $20.63(13)$ & $55.26(63)$ \\
\hline $\begin{array}{l}\text { Both Professions } \\
\text { with } \\
\text { Presenteeism }\end{array}$ & $78.15(93)$ & $21.85(26)$ & $100(119)$ \\
\hline Total Sample & $41.15(93)$ & $11.50(26)$ & $100(226)$ \\
\hline
\end{tabular}


minorities. Differences within the nurse profession of presenteeism levels were not statistically significant by race/ethnicity (chi-square $0.0059, \mathrm{P}=0.9387$ ).

The trend of no significant differences followed with pharmacists. Pharmacists who reported lower levels of presenteeism were composed of $78.43 \%$ non-minorities and $83.33 \%$, minorities. Pharmacists who reported higher levels of presenteeism included more racial/ethnic non-minorities, $21.57 \%$, and $16.67 \%$ minorities. These differences by levels of presenteeism within the pharmacy profession were not statistically significant by race/ethnicity (chi-square $0.1425, \mathrm{P}=0.7058$ ).

Hypothesis 1.1: Conclusions

These findings suggest that over half, $52.65 \%$, of pharmacists and nurses experienced presenteeism. Both Tables 4-7 and 4-8 show data that supports the decision to fail to reject Hypothesis 1.1. Data indicates that there are no statistically significant differences in prevalence of presenteeism among nurses $(50 \%)$ and pharmacists (55.26\%). Even though rates were higher for non-minorities (53.55\%) than minorities $(48.84 \%)$, there were no statistically significantly differences within or across racial/ethnic groups of both professions. These results remain true even when data were examined for both lower and higher levels of presenteeism.

Hypothesis 1.2: Results

Hypothesis 1.2 indicated that health conditions characterized as physical health conditions are more associated with presenteeism among racial/ethnic minority groups versus non-minority groups of nurses and pharmacists. Physical health (ph) data collected from the survey were divided into four categories: individual ph conditions, individual $\mathrm{ph}$ symptoms, combined ph conditions, and combined ph symptoms. Nurses and pharmacist chose from among 19 individual physical health conditions to identify ones that impacted them. Table 4-9 contained data from contingency tables constructed in SAS ${ }^{\circledR}$ that summarized the conditions experienced by nurses and pharmacists who reported presenteeism. Ten of 19 individual physical health conditions were found to be significantly associated with presenteeism in nurses and pharmacists:

1. Back and neck pain

2. Allergies

3. Sleep problems

4. Hypertension 
Table 4-9. Prevalence of Individual Physical Health Conditions in Nurses and Pharmacists with Presenteeism

\begin{tabular}{|c|c|c|c|c|c|c|c|}
\hline $\begin{array}{l}\text { Individual Health } \\
\text { Conditions }\end{array}$ & $\begin{array}{l}\text { Whole } \\
\text { Sample } \\
\mathrm{N}=261 \\
\%(\mathrm{n})\end{array}$ & $\begin{array}{c}\text { All } \\
\mathrm{n}=119 \\
\%(\mathrm{n})\end{array}$ & $\begin{array}{l}\text { Chi-Sq (P- } \\
\text { value) }\end{array}$ & $\begin{array}{c}\text { Non- } \\
\text { Minorities } \\
\mathrm{n}=96 \\
\%(\mathrm{n})\end{array}$ & $\begin{array}{c}\text { Minorities } \\
\mathrm{n}=21 \\
\%(\mathrm{n})\end{array}$ & $\begin{array}{c}\text { Nurses } \\
n=54 \\
\%(n)\end{array}$ & $\begin{array}{c}\text { Pharmacists } \\
n=60 \\
\%(n)\end{array}$ \\
\hline Back/neck pain*1,4 & $45.6(115)$ & $54.87(62)$ & $4.2852(0384)$ & $58.95(56)$ & $33.30(6)$ & $64.81(35)$ & $45.76(27)$ \\
\hline Allergies* & $35.4(91)$ & $42.37(50)$ & $4.3881(.0362)$ & $42.24(40)$ & $47.62(10)$ & $43.64(24)$ & $41.27(26)$ \\
\hline Sleep problem ${ }^{*} 6$ & $25.1(64)$ & $33.62(39)$ & $7.6018(.0058)$ & $37.50(36)$ & $15.00(3)$ & $32.74(18)$ & $34.43(21)$ \\
\hline Hypertension* & $23.2(60)$ & $29.31(34)$ & $7.4001(.0065)$ & $24.17(28)$ & $30.00(6)$ & $33.33(18)$ & $25.81(16)$ \\
\hline High cholestero $^{1 *}$ & $22.6(59)$ & $30.17(35)$ & $.8455(.0029)$ & $32.29(31)$ & $20.00(4)$ & $27.78(15)$ & $32.26(20)$ \\
\hline Obesity & $22.0(56)$ & $26.96(31)$ & $2.9274(.0871)$ & $27.37(26)$ & $25.00(5)$ & $34.55(19)$ & $20.00(12)$ \\
\hline Arthritis $^{2}$ & $21.3(54)$ & $21.93(25)$ & $0.5006(.4792)$ & $23.16(22)$ & $15.79(3)$ & $29.63(16)$ & $15.00(9)$ \\
\hline Gastrointestinal* & 21.3.(54) & $29.57(34)$ & $14.8852(.0001)$ & $31.58(30)$ & $20.00(4)$ & $27.78(15)$ & 31.15 (19) \\
\hline Chronic fatigue* & $19.3(49)$ & $33.91(39)$ & $26.4959(.0001)$ & $32.63(31)$ & $40.00(8)$ & $29.63(16)$ & $37.70(23)$ \\
\hline Migraine/headache $*^{5}$ & $17.9(45)$ & $25.44(29)$ & $4.7792(.0288)$ & $30.53(29)$ & $0000(0)$ & $22.22(12)$ & $28.33(17)$ \\
\hline Musculoskeletal & $15.0(38)$ & $18.26(21)$ & $3.3592(.0668)$ & $18.95(18)$ & $15.001(3)$ & $14.81(8)$ & $21.31(13)$ \\
\hline Chronic pain $*^{3}$ & $11.4(29)$ & $17.39(20)$ & $8.5515(.0035)$ & $20.00(19)$ & $5.00(1)$ & $25.93(14)$ & $9.84(6)$ \\
\hline Urinary/bladder* & $11.1(28)$ & $14.04(16)$ & $4.0033(.0454)$ & $14.89(14)$ & $10.00(2)$ & $16.67(9)$ & $11.67(7)$ \\
\hline Stomach/intestinal & $7.1(18)$ & $7.83(9)$ & $.3671(.5473)$ & $7.37(7)$ & $10.00(2)$ & $5.56(3)$ & $9.84(6)$ \\
\hline Asthma & $7.1(18)$ & $6.96(8)$ & $.0073(.9321)$ & $8.42(8)$ & $0000(0)$ & $11.11(6)$ & $3.28(2)$ \\
\hline Cancer & $6.3(16)$ & $7.83(9)$ & $2.5218(.1123)$ & $9.38(9)$ & $0000(0)$ & $9.09(5)$ & $6.67(4)$ \\
\hline
\end{tabular}


Table 4-9. (continued)

\begin{tabular}{|c|c|c|c|c|c|c|c|}
\hline $\begin{array}{l}\text { Individual Health } \\
\text { Conditions }\end{array}$ & $\begin{array}{c}\text { Whole } \\
\text { Sample } \\
\text { N=261 } \\
\%(n)\end{array}$ & $\begin{array}{c}\text { All } \\
N=119 \\
\%(n)\end{array}$ & $\begin{array}{l}\text { Chi-Sq }(\mathrm{P}- \\
\text { value }) \\
\end{array}$ & $\begin{array}{c}\text { Non- } \\
\text { Minorities } \\
\mathrm{N}=96 \\
\%(\mathrm{n}) \\
\end{array}$ & $\begin{array}{c}\text { Minorities } \\
\mathrm{N}=21 \\
\%(\mathrm{n}) \\
\end{array}$ & $\begin{array}{l}\text { Nurses } \\
\mathrm{N}=54 \\
\%(\mathrm{n})\end{array}$ & $\begin{array}{l}\text { Pharmacists } \\
\qquad \begin{array}{c}\mathrm{N}=60 \\
\%(\mathrm{n})\end{array}\end{array}$ \\
\hline Asthma & $7.1(18)$ & $6.96(8)$ & $.0073(.9321)$ & $8.42(8)$ & $0000(0)$ & $11.11(6)$ & $3.28(2)$ \\
\hline Cancer & $6.3(16)$ & $7.83(9)$ & $2.5218(.1123)$ & $9.38(9)$ & $0000(0)$ & $9.09(5)$ & $6.67(4)$ \\
\hline Diabetes & $4.3(11)$ & $6.09(7)$ & $2.3588(.1246)$ & $4.21(4)$ & $15.00(3)$ & $2.70(2)$ & $8.20(5)$ \\
\hline Heart disease & $3.5(9)$ & $3.48(4)$ & $.0210(.8848)$ & $4.21(4)$ & $0000(0)$ & $3.70(2)$ & $3.28(2)$ \\
\hline Respiratory/lung & $3.1(8)$ & $3.48(4)$ & $.4957(.4814)$ & $3.16(3)$ & $5.00(1)$ & $3.70(2)$ & $3.28(2)$ \\
\hline $\begin{array}{l}{ }^{1} \text { Significantly diffe } \\
{ }^{2} \text { Approached signi } \\
\text { and NOT statistica } \\
{ }^{3} \text { Significantly diffe } \\
{ }^{4} \text { Significantly diffe } \\
{ }^{5} \text { Significantly diffe } \\
\text { Fisher's Exact } \mathrm{P}=0 \\
{ }^{6} \text { Significantly diffe } \\
\text { *Significantly asso }\end{array}$ & $\begin{array}{l}\text { y profes } \\
\text { differenc } \\
\text { nificant } \\
y \text { profes } \\
y \text { race/et } \\
y \text { race/et } \\
\text { ). } \\
\text { by race/e } \\
\text { with pr }\end{array}$ & $\begin{array}{l}\text { higher i } \\
\text { y professi } \\
\text { oresentee } \\
\text { higher i } \\
\text { ity, high } \\
\text { ity, high } \\
\text { city, high }\end{array}$ & $\begin{array}{l}\text { urses versus pha } \\
\text {, higher in nurse } \\
\text { n. } \\
\text { lurses versus pha } \\
\text { in non-minorities } \\
\text { in non-minorities } \\
\text { in non-minoritie }\end{array}$ & $\begin{array}{l}\text { acist (chi- } \\
\text { ersus pharn } \\
\text { lacists (chi } \\
\text { ersus mino } \\
\text { ersus mino } \\
\text { yersus min }\end{array}$ & $\begin{array}{l}\text { luare value } \\
\text { cists (chi-s } \\
\text { quare value } \\
\text { ties (chi-sq } \\
\text { ties (chi-sq } \\
\text { ities (chi-sc }\end{array}$ & $\begin{array}{l}1328, \mathrm{P}= \\
\text { are value } \\
1615, \mathrm{P}= \\
\text { e value } 4 \\
\text { e value } 7 \\
\text { re } 3.7546\end{array}$ & $\begin{array}{l}\text { 421). } \\
529, \mathrm{P}=0.0594) \\
231) . \\
93, \mathrm{P}=0.0452) \\
88, \mathrm{P}=0.0053 ; \\
=0.0527)\end{array}$ \\
\hline
\end{tabular}


5. High cholesterol

6. Gastrointestinal problems

7. Chronic fatigue

8. Migraine and other severe headaches

9. Chronic pain

10. Urinary/bladder problems

Four of these 10 conditions associated with presenteeism did not differ significantly by profession or by race/ethnicity.

This next section describes the 6 conditions where differences were found. Table 4-9 identified statistically significant differences in physical health conditions by profession. Results were that of the 10 physical health conditions associated with presenteeism, there were statistically significant different by profession for 2 conditions:

- $\quad$ Back or neck pain was first in prevalence for both nurses and pharmacists and it was significantly associated with presenteeism $(4.2852, \mathrm{p}=.0384)$. Of those with presenteeism, there was almost a $20 \%$ difference in the prevalence of back pain between the professions. Consistent with their work responsibilities, more nurses than pharmacists $(64.81 \%$ and $45.76 \%$ respectively) reported experiencing back or neck pain. The differences between nurses and pharmacists were statistically significant at chi-square value $4.1328, \mathrm{P}=.0421$.

- $\quad$ Chronic pain ranked $12^{\text {th }}$ among nurses and $13^{\text {th }}$ among pharmacists and is associated with presenteeism $(8.5515, \mathrm{p}=.0035)$. The percentage of nurses was almost 2.5 times that of pharmacists, $25.93 \%$ versus $9.84 \%$. The differences between nurses and pharmacists were statistically significant with a chi-square value $5.1615, \mathrm{P}=0.0231$.

One other condition approached statistical significant difference but was not significantly associated with presenteeism for nurses and pharmacists as a single workforce group. Arthritis is mentioned here even though it was not significantly associated with presenteeism because it followed a trend of seemingly pain related conditions that were more prevalent in nurses: Arthritis ranked $6^{\text {th }}$ among nurses, $9^{\text {th }}$ among pharmacists and was NOT significantly associated with presenteeism $(0.5006$, $\mathrm{p}=.4792$ ) for the professions as a group. Approximately $15 \%$ of pharmacists reported arthritis but nearly twice as many nurses, $29.63 \%$, reported arthritis (chi-square value $3.5529, \mathrm{p}=.0594)$. 
In order to determine differences in individual physical health 'conditions' by race/ethnicity, contingency tables constructed in SAS ${ }^{\circledR}$. These tables summarized the data on 19 physical health conditions by race/ethnicity (minority and non-minority) and is shown in Table 4-9. The table indicates that most physical health conditions, 13 $(68.42 \%)$, were more prevalent in racial/ethnic non-minorities than minorities 6 (31.57\%). Of the total 19 physical health conditions reported by respondents having presenteeism, three conditions were significantly different by race/ethnicity at the .05 level:

- $\quad$ As mentioned earlier and as shown in Table 4-9, back and neck pain were highest in prevalence for racial/ethnic non-minorities and was third highest for racial/ethnic minorities. It was significantly associated with presenteeism (4.2852, $\mathrm{p}=.0384$ ). Approximately $58.95 \%$ of non-minorities with presenteeism reported back and neck pain, while only $33.33 \%$ of minorities leaving the differences by race/ethnicity statistically significant (Chi-Square value 4.0093, $\mathrm{P}=0.0452$ ).

- $\quad$ Migraines, severe or frequent headaches were seventh in prevalence for non-minorities, $30.53 \%$, and tied for last place with minorities in that no minority reported this condition in either profession. Migraines showed statistically significant association with presenteeism $(4.7792, \mathrm{p}=.0288)$. The difference by race/ethnicity was statistically significant (Chi-Square criteria not met due to low cell counts with $25 \%<5$ with Chi-Square value 7.7788, $\mathrm{P}=0.0053$ and therefore the Fisher's Exact $\mathrm{P}=0.0031$ is considered valid). These results were consistent with conclusions of Stewart et al. (1996) that there may be a genetic race component responsible for lower levels of migraine in people of African and Asian descent versus Caucasians.

- $\quad$ Sleep Problems were third highest in prevalence in non-minorities and was tied for tenth place with minorities. It was significantly association with presenteeism (7.6018, $\mathrm{p}=.0058)$. Approximately $37.50 \%$ of non-minorities with presenteeism reported sleep problems, while only $15 \%$ of minorities with presenteeism reported this health condition. The differences in sleep problems by race/ethnicity were statistically significant (Chi-Square value 3.7546, $\mathrm{P}=0.0527)$.

Racial/ethnic minorities reported a higher prevalence of three of ten conditions association with presenteeism -- chronic fatigue, hypertension, and allergies. The differences between the prevalence of these conditions for minorities versus nonminorities were not statistically significant.

Nurses and pharmacist chose from among 11 common physical health 'symptoms' to identify ones that impacted them. Table 4-10 shows the symptoms and prevalence identified by race/ethnicity and by profession. Findings were that all 11 
Table 4-10. Presenteeism and Physical Health Symptoms: Differences by Profession and Race/Ethnicity

\begin{tabular}{|c|c|c|c|c|c|c|c|}
\hline $\begin{array}{l}\text { Pysical } \\
\text { Health } \\
\text { Symptoms }\end{array}$ & $\begin{array}{c}\text { All without } \\
\text { Presenteeism } \\
\mathrm{N}^{*}=107 \\
\%(\mathrm{n})\end{array}$ & $\begin{array}{c}\text { All with } \\
\text { Presenteeism } \\
\mathrm{N}^{*}=119 \\
\%(\mathrm{n})\end{array}$ & $\begin{array}{c}\text { All with } \\
\text { Presenteeism } \\
\text { Chi-Sq } \\
\text { (P-value) }\end{array}$ & $\begin{array}{c}\text { Non-Minorities } \\
\text { with } \\
\text { Presenteeism } \\
N^{*}=96 \\
\%(n) \\
\end{array}$ & $\begin{array}{c}\text { Minorities } \\
\text { with } \\
\text { Presenteeism } \\
\mathrm{N}^{*}=21 \\
\%(\mathrm{n}) \\
\end{array}$ & $\begin{array}{c}\text { Nurses } \\
\text { with } \\
\text { Presenteeism } \\
\mathrm{N}^{*}=54 \\
\%(\mathrm{n}) \\
\end{array}$ & $\begin{array}{c}\text { Pharmacists } \\
\text { with } \\
\text { Presenteeism } \\
\mathrm{N}=60 \\
\%(\mathrm{n})\end{array}$ \\
\hline $\begin{array}{l}\text { Feeling tired } \\
\text { or having } \\
\text { low energy* }\end{array}$ & $18.69(20)$ & $56.30(67)$ & $\begin{array}{l}33.6615 \\
(<.0001)\end{array}$ & $58.16(57)$ & $47.62(10)$ & $57.14(32)$ & $55.56(35)$ \\
\hline $\begin{array}{l}\text { Trouble } \\
\text { sleeping* }\end{array}$ & $19.63(21)$ & 36.97 (44) & $\begin{array}{l}8.2762 \\
(.0040)\end{array}$ & $39.80(39)$ & $23.81(5)$ & $41.07(23)$ & $33.33(21)$ \\
\hline Headaches* & $5.61(6)$ & $23.53(28)$ & $\begin{array}{l}14.1589 \\
(.0002)\end{array}$ & $26.53(26)$ & $9.52(2)$ & $21.43(12)$ & $25.40(16)$ \\
\hline $\begin{array}{l}\text { Back or neck } \\
\text { pain* } 1\end{array}$ & $15.89(17)$ & $40.34(48)$ & $\begin{array}{l}16.4360 \\
(<.0001)\end{array}$ & $45.92(45)$ & $14.29(3)$ & $50.00(28)$ & $31.75(20)$ \\
\hline $\begin{array}{l}\text { Pain in arms, } \\
\text { legs, joints } \\
\text { (knees, hips, } \\
\text { etc.)* }\end{array}$ & $8.49(9)$ & $35.29(35)$ & $\begin{array}{l}23.3015 \\
(<.0001)\end{array}$ & $35.71(35)$ & $33.33(7)$ & 33.93 (19) & $36.51(23)$ \\
\hline $\begin{array}{l}\text { Muscle } \\
\text { soreness* }\end{array}$ & $7.48(8)$ & 24.37 (29) & $\begin{array}{l}11.7434 \\
(.0006)\end{array}$ & $26.53(26)$ & $14.29(3)$ & $26.79(15)$ & $22.22(14)$ \\
\hline $\begin{array}{l}\text { Watery eyes, } \\
\text { runny nose, } \\
\text { or stuffy } \\
\text { head* }\end{array}$ & $9.35(10)$ & $31.93(38)$ & $\begin{array}{l}17.1826 \\
(<.0001)\end{array}$ & $34.69(34)$ & $19.05(4)$ & 33.93 (19) & $30.16(19)$ \\
\hline $\begin{array}{l}\text { Cough or } \\
\text { sore throat* }\end{array}$ & $6.54(7)$ & $16.81(20)$ & $\begin{array}{l}5.6430 \\
(.0175)\end{array}$ & $13.27(13)$ & $19.05(4)$ & $17.89(10)$ & $33.33(21)$ \\
\hline $\begin{array}{l}\text { Fever, chills, } \\
\text { other cold/flu } \\
\text { symptoms }\end{array}$ & $1.87(2)$ & $12.61(15)$ & $\begin{array}{l}9.3351 \\
(.0022)\end{array}$ & $13.27(13)$ & $9.52(2)$ & $17.86(10)$ & $7.94(5)$ \\
\hline
\end{tabular}


Table 4-10. (continued)

\begin{tabular}{|c|c|c|c|c|c|c|c|}
\hline $\begin{array}{l}\text { Physical } \\
\text { Health } \\
\text { Symptoms }\end{array}$ & $\begin{array}{c}\text { All without } \\
\text { Presenteeism } \\
\mathrm{N}^{*}=107 \\
\%(\mathrm{n})\end{array}$ & $\begin{array}{c}\text { All with } \\
\text { Presenteeism } \\
N^{*}=119 \\
\%(n)\end{array}$ & $\begin{array}{c}\text { All with } \\
\text { Presenteeism } \\
\text { Chi-Sq } \\
\text { (P-value) }\end{array}$ & $\begin{array}{c}\text { Non-Minorities } \\
\text { with } \\
\text { Presenteeism } \\
N^{*}=96 \\
\%(n)\end{array}$ & $\begin{array}{c}\text { Minorities } \\
\text { with } \\
\text { Presenteeism } \\
\mathrm{N}^{*}=21 \\
\%(\mathrm{n})\end{array}$ & $\begin{array}{c}\text { Nurses } \\
\text { with } \\
\text { Presenteeism } \\
\mathrm{N}^{*}=54 \\
\%(\mathrm{n})\end{array}$ & $\begin{array}{c}\text { Pharmacists } \\
\text { with } \\
\text { Presenteeism } \\
\mathrm{N}=60 \\
\%(\mathrm{n})\end{array}$ \\
\hline $\begin{array}{l}\text { Constipation, } \\
\text { loose } \\
\text { bowels, or } \\
\text { diarrhea* }^{3}\end{array}$ & $4.67(5)$ & $21.01(25)$ & $\begin{array}{l}13.0595 \\
(.0003)\end{array}$ & $25.51(25)$ & 0000 & $17.89(10)$ & $23.81(15)$ \\
\hline $\begin{array}{l}\text { Nausea, gas, } \\
\text { or } \\
\text { indigestion* }\end{array}$ & $8.41(9)$ & $20.17(24)$ & $\begin{array}{l}6.2453 \\
(.0125)\end{array}$ & $20.41(20)$ & $19.05(4)$ & $21.43(12)$ & $19.05(12)$ \\
\hline
\end{tabular}

*Symptom is significantly associated with presenteeism.

${ }^{1}$ Significantly higher in nurses versus pharmacist $(4.148, \mathrm{p}=.0428)$ and significantly higher non-minorities versus minorities (7.1906, $\mathrm{p}=.0073)$.

${ }^{2}$ Approached significant difference by profession, higher in nurses versus pharmacists (2.6487, $p=.0605$ Fisher's Exact).

${ }^{3}$ Significantly higher in non-minorities versus minorities (6.7819, $p=.0041$ Fisher's Exact). 
symptoms identified were highly associated with presenteeism in nurses and pharmacists. The ones strongly associated at the $\mathrm{p}<.0001$ level were the following four:

1. Feeling tired or having no energy

2. Back or neck pain

3. Pain in arms, legs, joints (knee, hips, etc.)

4. Watery eyes, runny nose, or stuffy head

The remaining seven individual physical health symptoms were associated with significantly associated with presenteeism at the .05 level:

1. Trouble sleeping

2. Headaches

3. Muscle soreness

4. Cough or sore throat

5. Fever, chills, or other cold/flu

6. Constipation, loose bowels, or diarrhea

7. Nausea, gas, or indigestion

Table 4-10 shows that racial/ethnic non-minorities reported physical health symptoms at a rate higher than minorities for 10 of 11 physical health symptoms. Symptoms of cough/sore throat were the only ones more prevalent in minorities. The table also shows that only one symptom was significantly different by race/ethnicityback pain and neck pain: Non-minorities reported back and neck pain by three times as much as minorities, $45.92 \%$ versus $14.29 \%$ (chi-square $7.1906, \mathrm{p}=0.0073$ ).

Nurses reported physical health symptoms at a rate more often than pharmacists for 7 of 11 physical health symptoms, however; only one symptom was significantly different by profession. Back and neck pain symptoms significantly different by profession in that nurses reported this symptom $50 \%$, versus pharmacists, $31.75 \%$ (chisquare $7.1906, \mathrm{p}=0.0073$ ).

One symptom approached significant differences by profession: Fever, chills, or other cold/flu symptoms were more prevalent in nurses, $17.86 \%$, versus pharmacists 7.94\% (chi-square 2.6487, $\mathrm{p}=0.0605$ ). Analysis of differences in grouped physical health conditions and symptoms by profession were determined. Table 4-11 shows outcome of analyses of data from contingency tables across both specialty health professions. When analyzed separately, physical health 'conditions' were not associated with presenteeism 
Table 4-11. Grouped Physical Health Conditions and Symptoms Associated with Presenteeism by Profession and Race/Ethnicity

\begin{tabular}{llllc}
\hline Health Factors & Variable & Rate (n) & Chi-Square & P-Value \\
\hline $\begin{array}{l}\text { Physical health } \\
\text { conditions }\end{array}$ & & & \\
& & & & \\
& Pharmacists & $92.86(52)$ & 1.4933 & 0.2217 \\
& Nurse & $98.41(62)$ & 9.0836 & $0.0049^{*}$ \\
& Non-minorities & $96.94(95)$ & 8.5373 & 0.0035 \\
& Minorities & $90.48(19)$ & 0.6708 & $0.6640^{*}$ \\
Physical health & & & \\
symptoms & & & \\
& Pharmacists & $85.71(48)$ & 17.7989 & $<0.0001$ \\
& Nurse & $80.95(51)$ & 17.5001 & $<0.0001$ \\
& Non-minorities & $86.73(85)$ & 29.8577 & $<0.0001$ \\
& Minorities & $66.67(14)$ & 5.2220 & 0.0223 \\
\hline
\end{tabular}

*Chi-Square defaults to Fisher's Exact test for low cell count. 
in the manner for pharmacists and nurses. Presenteeism was not significantly associated with physical health 'conditions' in pharmacists (chi-square value 1.4933, $\mathrm{P}=.2217$ ). However, presenteeism was strongly associated with physical health 'conditions' (chisquare value 9.0836, $\mathrm{p}=0.0026$ ) in nurses. The picture was different for physical health 'symptoms.' For both professions separately, nurses (chi-square value 17.5001, $\mathrm{P}=<.0001$ ) and pharmacists (chi-square value $17.7989, \mathrm{P}=<.0001$ ), physical health 'symptoms' were highly significantly associated with presenteeism (see Table 4-11).

Analysis of differences in grouped physical health conditions and symptoms by race and ethnicity were determined. Table 4-11 also shows contingency tables results using chi-square in most cases, however, when $50 \%$ of the cell counts were less than 5 , the Fisher's Exact test was considered valid. Results were that presenteeism in racial/ethnic non-minorities was associated with physical health 'conditions' (chi-square value $8.5373, \mathrm{P}=0.0035$ ). Presenteeism was not associated with physical health 'conditions' in racial/ethnic minorities (Chi-square 0.6708, $\mathrm{P}=.4128$; Fishers Exact $\mathrm{P}=0.6640$ ). Presenteeism was highly significantly associated with physical health 'symptoms' in both non-minorities (Chi-square value 29.8577, $\mathrm{P}=<.0001$ ) and minorities (Chi-square value 5.2220, $\mathrm{P}=0.0223$ ).

Hypothesis 1.2: Conclusions

Data from Table 4-9, Table 4-10, and Table 4-11 indicate that we reject the hypothesis that states that health conditions characterized as physical health conditions are more associated with presenteeism among racial/ethnic minority groups versus nonminority groups of nurses and pharmacists. Despite associated individual health conditions and symptoms differing on a few occasions, results were that physical health 'conditions' as a group were not associated with presenteeism in racial ethnic minority nurses and pharmacists. Compared to non-minorities, minorities had lower rates of most individual health 'conditions' associated with presenteeism, but the differences were not statistically significant. Data showed strong significant association between physical health 'symptoms' and presenteeism across professions and race/ethnicity.

Hypothesis 1.3: Results.

Mental health ( $\mathrm{mh})$ data collected from the survey were divided into four categories: individual mh conditions, individual mh symptoms, combined mh conditions, and combined mh symptoms. Hypothesis 1.3 indicated that health conditions characterized as mental health conditions are more associated with presenteeism among non-minority versus minority racial/ethnic groups of nurses and pharmacists.

Nurses and pharmacists chose from among four mental health conditions to identify the condition that applied to them. Table 4-12 shows prevalence of individual mental health conditions across both nurses and pharmacists, as well as across racial/ethnic groups. Three of 4 individual mental conditions - anxiety, depression, and 
Table 4-12. Prevalence of Mental Health Conditions in Nurses and Pharmacists with Presenteeism

\begin{tabular}{|c|c|c|c|c|c|c|c|}
\hline Mental Health & $\begin{array}{l}\text { Whole } \\
\text { Sample } \\
\mathrm{N}=261\end{array}$ & $\begin{array}{c}\text { All with } \\
\text { Presenteeisr } \\
\mathrm{N}=119\end{array}$ & $\begin{array}{l}\text { All with } \\
\text { Presenteeism }\end{array}$ & $\begin{array}{c}\text { Non- } \\
\text { Minorities } \\
\text { with } \\
\text { Presenteeism } \\
\text { N=96 }\end{array}$ & $\begin{array}{c}\text { Minorities } \\
\text { with } \\
\text { Presenteeism } \\
\mathrm{N}=21\end{array}$ & $\begin{array}{c}\text { Nurses } \\
\text { with } \\
\text { Presenteeism } \\
N=54\end{array}$ & $\begin{array}{c}\text { Pharmacists } \\
\text { with } \\
\text { Presenteeism } \\
\mathrm{N}=60\end{array}$ \\
\hline $\begin{array}{l}\text { Mental Health } \\
\text { Condtions }\end{array}$ & $\%(\mathrm{n})$ & $\%(\mathrm{n})$ & Chi-Sq, P-value & $\%(\mathrm{n})$ & $\%(n)$ & $\%(n)$ & $\begin{array}{l}N=60 \\
\%(n)\end{array}$ \\
\hline Anxiety*1 & $16.9(43)$ & $24.35(28)$ & $.95801,(0020)$ & $24.21(23)$ & $25.00(5)$ & $24.07(13)$ & $24.59(15)$ \\
\hline Depression*1 ${ }^{1}$ & $22.3(57)$ & $32.76(38)$ & $18.9660(<.0001)$ & $34.38(33)$ & $25.00(5)$ & $36.36(20)$ & $29.51(18)$ \\
\hline Other Eemotional ${ }^{* 1}$ & $3.2(8)$ & $4.35(5)$ & $4.5834(.0323)$ & $4.21(4)$ & $5.00(1)$ & $3.70(2)$ & $4.92(3)$ \\
\hline Substance use & $4.0(10)$ & $5.36(6)$ & $.2627(.6082)$ & $5.32(5)$ & $5.56(1)$ & $1.96(1)$ & $8.20(5)$ \\
\hline
\end{tabular}

*Significantly associated with presenteeism.

${ }^{1}$ No statistically significant differences by profession or by race/ethnicity. 
other emotional problems - were significantly associated with presenteeism. Of those mental health conditions, depression had the highest prevalence and strongest association $(\mathrm{p}<.0001)$ with presenteeism. Reported depression was higher in nurses $(36.36 \%)$ than pharmacists $(29.51 \%)$, but not statistically significantly different by profession $(\mathrm{p}=0.4321)$. Depression was also higher in non-minorities $(34.38 \%)$, than minorities $(25.00 \%)$, however, again the differences were not statistically significant $(\mathrm{p}=0.4164)$. Anxiety was similarly prevalent in nurses and pharmacists experiencing presenteeism and slightly higher for racial/ethnic minorities. The differences between the professions were not statistically significant ( $p=0.9404)$. The prevalence of 'other emotional problems,' was significantly association with presenteeism by race/ethnicity. It was higher in minorities than in non-minorities, although the difference was not statistically significant (5.00\% minorities versus $4.21 \%$ non-minorities).

Analyses of differences in individual mental health symptoms were performed. Data from $2 \mathrm{X} 2$ contingency tables were analyzed in SAS ${ }^{\circledR}$ for association by either chisquare of Fisher's Exact. Individual mental health symptoms were similar across professions and race/ethnicity as shown in Table 4-13. For nurses and pharmacists as a workforce, the table shows that presenteeism was significantly associated at the .05 level with the following 4 mental health symptoms:

- $\quad$ Restless or fidgety $(\mathrm{p}=.0470)$

- $\quad$ Hopeless $(\mathrm{p}=.0165)$

- $\quad$ Easily irritated $(\mathrm{p}<.0001)$

- $\quad$ Anger, aggressive $(\mathrm{p}=.0014)$

For all 4 symptoms associated with presenteeism, minorities had higher prevalence rates than non-minorities, although there were not statistically significant differences by race/ethnicity (see Table 4-13). Among professions, mental health symptoms (with the exception of "easily irritated") associated with presenteeism were more prevalent in pharmacists than nurses, but none were statistically significantly different by profession.

Analysis of differences in grouped mental health conditions and symptoms by profession were performed. Table 4-14 shows data results from analysis of $2 \mathrm{X} 2$ contingency tables that indicates presenteeism was significantly associated with mental health 'conditions' in nurses and pharmacists separately (nurses chi-square value 13.9210, $\mathrm{P}=0.0002$; pharmacists chi-square value 7.2605, $\mathrm{P}=0.0070$ ). Presenteeism was also significantly associated with mental health 'symptoms' in nurses and pharmacists separately (nurses chi-square $10.2185, \mathrm{P}=0.0014$; pharmacists chi-square value 5.3904, $\mathrm{P}=0.0202$ ). Analysis of differences in grouped mental health conditions and symptoms by race/ethnicity were performed. Table 4-14 shows that presenteeism was significantly associated with mental health 'symptoms' in non-minorities of both professions (Chisquare value 13.9058, $\mathrm{P}=0.0002$ ). However for racial/ethnic minorities, mental health 'symptoms' were clearly not associated with presenteeism across both professions (Chi- 
Table 4-13. Presenteeism and Individual Mental Health Symptoms: Differences by Profession and Race/Ethnicity

\begin{tabular}{|c|c|c|c|c|c|c|c|}
\hline & $\begin{array}{l}\text { All without } \\
\text { Presenteeism }\end{array}$ & $\begin{array}{c}\text { All } \\
\text { with } \\
\text { Presenteeism }\end{array}$ & $\begin{array}{c}\text { Symptom \& } \\
\text { Presenteeism }\end{array}$ & $\begin{array}{c}\text { Non- } \\
\text { Minorities } \\
\text { with } \\
\text { Presenteeism }\end{array}$ & $\begin{array}{c}\text { Minorities } \\
\text { with } \\
\text { Presenteeism }\end{array}$ & $\begin{array}{c}\text { Nurses } \\
\text { with } \\
\text { Presenteeism }\end{array}$ & $\begin{array}{l}\text { Pharmacists } \\
\text { with } \\
\text { Presenteeism }\end{array}$ \\
\hline Mental Health & $\mathrm{N}=107$ & $\mathrm{~N}=119$ & Chi-Sq (P- & $\mathrm{N}=96$ & $\mathrm{~N}=21$ & $\mathrm{~N}=54$ & $\mathrm{~N}=60$ \\
\hline Symptoms & $\%(\mathrm{n})$ & $\%(n)$ & Value) & $\%(n)$ & $\%(n)$ & $\%(n)$ & $\%(n)$ \\
\hline $\begin{array}{l}\text {...so sad nothing } \\
\text { could cheer you } \\
\text { up? }\end{array}$ & $6.54(7)$ & $13.45(16)$ & $2.9372(.0866)$ & $12.24(12)$ & $19.05(4)$ & $10.71(6)$ & $15.87(10)$ \\
\hline ...nervous? & $14.02(15)$ & $21.85(26)$ & $2.3260(.1272)$ & $22.45(22)$ & $19.05(4)$ & $17.86(10)$ & $25.40(16)$ \\
\hline $\begin{array}{l}\text {...restless or } \\
\text { fidgety?* }\end{array}$ & $11.21(12)$ & $21.01(25)$ & $3.9468(.0470)$ & $19.39(19)$ & $28.57(6)$ & $17.86(10)$ & $23.81(15)$ \\
\hline ...hopeless?* & $3.74(4)$ & $12.61(15)$ & $5.7523(.0165)$ & $13.64(3)$ & $19.05(4)$ & $10.71(6)$ & $14.29(9)$ \\
\hline $\begin{array}{l}\text {...that } \\
\text { everything was } \\
\text { an effort? }^{1}\end{array}$ & $13.08(14)$ & $22.69(27)$ & $3.5001(.0614)$ & $25.51(25)$ & $9.52(2)$ & $25.00(14)$ & $20.6313)$ \\
\hline ...worthless? & $2.80(3)$ & $5.04(6)$ & $.7382(.3902$ & $5.10(5)$ & $4.76(1)$ & $3.57(2)$ & $5.04(6)$ \\
\hline $\begin{array}{l}\text {...easily } \\
\text { irritated?* }\end{array}$ & $14.02(15)$ & $37.82(45)$ & $16.3608(<.0001)$ & $37.76(37)$ & $38.10(8)$ & $41.07(23)$ & $34.92(22)$ \\
\hline $\begin{array}{l}\text {...anger, } \\
\text { aggressive?* }\end{array}$ & $4.67(5)$ & $18.49(22)$ & $10.2210(.0014)$ & $18.37(18)$ & $19.05(4)$ & $17.86(10)$ & $19.05(12)$ \\
\hline
\end{tabular}


Table 4-14. Grouped Mental Health Conditions and Symptoms Associated with Presenteeism by Profession and Race/Ethnicity

\begin{tabular}{lllll}
\hline Health Factor & Variable & Rate $(\mathrm{n})$ & Chi-Square & P-Value \\
\hline MH Symptoms & & & & \\
& Pharmacists & $50.00 \%(28)$ & 5.3904 & 0.0202 \\
& Nurses & $46.30 \%(29)$ & 5.3904 & 0.0024 \\
& Non-minorities & $48.98 \%(48)$ & 13.9058 & 0.0002 \\
MHealth & Minorities & $33.33 \%(7)$ & 1.1488 & 0.2838 \\
Conditions & & & \\
& & & & \\
& Pharmacists & $41.07 \%(23)$ & 7.2605 & 0.0070 \\
& Nurses & $38.10 \%(24)$ & 13.9210 & 0.0002 \\
& Non-minorities & $40.82 \%(40)$ & 15.9515 & $<0.0001$ \\
& Minorities & $33.33 \%(7)$ & 3.8154 & $0.0689^{*}$ \\
\hline
\end{tabular}

*Chi-Square defaults to Fisher's Exact test for low cell count. 
square value $1.1488, \mathrm{P}=0.2838)$. Results of analyses of contingency tables using chisquare tests were that presenteeism in racial/ethnic non-minority nurses and pharmacists was associated with mental health 'conditions' (chi-square value 15.9515, $\mathrm{p}=<.0001$ ). Presenteeism in racial/ethnic minority nurses and pharmacists approached significance in association with mental health 'conditions,' but did not make it (Chi-square 3.8154, $\mathrm{P}=.0508$; Fishers Exact $\mathrm{P}=0.0689$ ). Because $50 \%$ of the cell counts were less than 5, the Fisher's Exact test is considered valid.

Hypothesis 1.3: Conclusions

Table 4-14 indicates assumptions of Hypothesis 1.3 that mental health conditions were more associated with presenteeism among non-minorities versus minorities could not be rejected. Grouped mental health conditions $(p=.0002)$ and grouped mental health symptoms $(\mathrm{p}=<.0001)$ were strongly associated with presenteeism in non-minorities. Mental health conditions approached significance $(p=.0689)$ in minorities. Moreover, grouped mental health 'symptoms' were clearly not significantly associated with presenteeism in minorities ( $\mathrm{p}=.2838$ ). However, pharmacists, nurses, and non-minorities were more likely to report mental health conditions and mental health symptoms, if they experienced presenteeism. Although there were differences in the prevalence of individual conditions and individual symptoms, differences by race/ethnicity or profession were not statistically significant for individual level conditions and symptoms.

Hypotheses 1.4 and 1.5: Results

- Hypothesis 1.4 stated that under-treated health conditions are associated with presenteeism in both nurses and pharmacists and it varies across racial/ethnic groups. Under-treated occurred when a worker continued to experience presenteeism associated with health conditions that were previously treated (Kessler \& Stang, 2006).

- Hypothesis 1.5 stated that health conditions treated by providers are more associated with presenteeism than conditions treated by pharmacotherapy and this does not vary across profession or racial/ethnic groups. To test these hypotheses required determining if previous treatment was associated with presenteeism, and then determining the provider.

Table 4-15 shows results of $2 \mathrm{X} 2$ contingency table analysis to determine if there were indications that conditions previously treated were associated with presenteeism and could thereby be considered under-treatment. Also, Table 4-15 indicates whether presenteeism was associated with previous treatment performed by provider versus pharmacotherapy. Findings in Table 4-15 indicated $21.43 \%$ of nurses and $17.5 \%$ of pharmacists who experienced presenteeism were under-treated by a provider. Also, $39.13 \%$ of nurses and $47.37 \%$ pharmacists who experienced presenteeism were undertreated with pharmacotherapy. The results indicated that among nurses and pharmacists 
Table 4-15. Presenteeism Associated with Provision of Treatment of Health Conditions

\begin{tabular}{lccc}
\hline Variable & Rate (n) & Chi-Square & Pr \\
\hline Under-Treated by & & & \\
Provider & & & \\
$\quad$ Nurse - N=56 & $21.43 \%(12)$ & 2.1856 & 0.1393 \\
Pharmacist - N=63 & $17.49 \%(11)$ & 1.6431 & 0.1999 \\
Non-minority - N=98 & $20.41 \%(20)$ & 2.5068 & 0.1134 \\
Minority - N=21 & $14.29 \%(3)$ & 1.805 & $0.2806^{*}$ \\
Under-Treated by & & & \\
Pharmacotherapy & & & \\
Nurse - N=56 & $39.13 \%(9)$ & 1.3679 & 0.2422 \\
Pharmacist - N=63 & $47.37 \%(9)$ & 0.5748 & 0.4484 \\
Non-minority - N=98 & $44.74 \%(17)$ & 1.4982 & 0.2209 \\
Minority - N=21 & $25.00 \%(1)$ & 1.0029 & $0.6069 *$ \\
\hline *Chi-Square defaults to Fisher's Exact test for low cell count. &
\end{tabular}

*Chi-Square defaults to Fisher's Exact test for low cell count. 
combined, neither under-treatment by a provider versus pharmacotherapy was statistically significantly associated with presenteeism, although it approached significance by provider $(\mathrm{p}=.0806)$ and not by pharmacotherapy $(\mathrm{p}=0.1587)$. Results were no different when nurses separate from pharmacists were analyzed $(\mathrm{P}=0.1393$; pharmacists $\mathrm{P}=0.1999)$. Results were similarly not found to be significant across race/ethnicity.

Hypotheses 1.4 and 1.5: Conclusions

We reject both hypotheses 1.4 and 1.5 and found that under-treatment is not significantly associated with presenteeism in nurses and pharmacists nor does it differ significantly by race/ethnicity. There were no statistical differences in presenteeism found to be associated with previous treatment by either provider or by pharmacotherapy.

Regression: Results

By modeling the determinants of presenteeism, this next section addresses aim one and research question. Research Question 1 asks 'what is the prevalence of presenteeism, its associated health conditions and extent of treatment among nurses and pharmacists; and, do these vary across racial/ethnic groups?' With the exception of the prevalence hypothesis, all other hypotheses under research question 1 as indicated below were addressed:

- $\quad$ Hypothesis 1.2-Health conditions characterized as physical health conditions are more associated with presenteeism among racial/ethnic minority groups versus non-minority groups of nurses and pharmacists.

- $\quad$ Hypothesis 1.3-Health conditions characterized as mental health conditions are more associated with presenteeism among non-minority versus minority racial/ethnic groups of nurses and pharmacists.

- $\quad$ Hypothesis 1.4-Under-treated health conditions are associated with presenteeism in both nurses and pharmacists and it varies across racial/ethnic groups.

- $\quad$ Hypothesis 1.5-Health conditions treated by providers are more associated with presenteeism than conditions treated by pharmacotherapy and this does not vary across profession or racial/ethnic groups.

Use of multiple logistic regression, PROC Logistic in SAS ${ }^{\circledR}$, facilitated the best fitting model to describe the relationship between the dependent dichotomous categorical variable, presenteeism, and set of 12 independent predicting variables. Using survey question B14 at 3 levels to represent ordered levels of presenteeism, the ordered logistic 
regression model was found to be the best model fit. Twelve independent variables of interest were entered into the model and they are identified as:

- $\quad$ Physical health conditions

- $\quad$ Mental health conditions

- $\quad$ Physical health symptoms

- $\quad$ Mental health symptoms

- $\quad$ Previously treated by pharmacotherapy

- $\quad$ Previously treated by provider

- $\quad$ Never treated by pharmacotherapy

- $\quad$ Never treated by provider

- $\quad$ Non-minority (White/European) or minority (Asian, Black/African Americans; Hispanic/Latino, Native Hawaiian/Pacific Island)

- $\quad$ Nurse professional specialty or Pharmacist professional specialty

- 24-hour/direct care or not

(The reference variables were currently treated by provider and currently treated by pharmacotherapy).

The type of logistic regression used was the cumulative logit model for ordered data. Data were read from 263 observations and 226 observations were used in the analysis. Table 4-16 shows the response profile of the model obtained from SAS. It indicates the descending order of the dependent variables such that when the ordered logit regression coefficients were estimated, a positive coefficient corresponds to a positive relationship for presenteeism and a negative coefficient has a negative relationship with presenteeism. Table 4-16 also shows the frequency distribution of the subjects in the dependent variable.

The model fit diagnostic statistics of the logistic regression model predicts presenteeism very well. Convergence was satisfied at the default criterion of relative gradient convergence (GCONV) with the default precision $10^{-8}$. Additionally, the "Score Test for the Proportional Odds Assumption" (chi-square 6.5166, $\mathrm{p}=.8368$ ) was a high p-value which indicated the model's ability to test the ordinal restrictions were valid. Table 4-17 shows the "Model Fit Statistics" were also good in that the intercept and covariates were smaller than the intercept only column for each fit criterion-AIC (Akaike Information Criterion), SC (Schwarz Criterion), and -2 Log L. 
Table 4-16. Ordered Logistic Regression: Response Profile

\begin{tabular}{lccc}
\hline $\begin{array}{l}\text { Ordered } \\
\text { Value }\end{array}$ & $\begin{array}{c}\text { Presenteeism } \\
\text { Level }\end{array}$ & $\begin{array}{c}\text { Survey Score } \\
\%\end{array}$ & Total Frequency \\
\hline 1 & 2 Higher Level & $<40$ & 26 \\
2 & 1 Lower Level & $10-30$ & 93 \\
3 & 0 & none & 107 \\
\hline
\end{tabular}

Table 4-17. Ordered Logistic Regression: Model Fit Statistics

\begin{tabular}{lcc}
\hline Criterion & Intercept Only & Intercept and Covariates \\
\hline AIC & 441.612 & 391.511 \\
SC & 448.453 & 435.978 \\
-2 Log L & 437.612 & 365.511 \\
\hline
\end{tabular}

NOTE: $R$-square value $=0.2731$ and max-rescaled $r$-square $=0.3192$. 
The results of the regression model's three tests (Likelihood Ratio, Score, and Wald) of the null hypothesis that all the predictors' regression coefficient are equal to zero are shown in Table 4-18. The highly significant $p$-values from all three tests lead to the conclusion that at least one of the regression coefficients in the model is not equal to zero. The association of predicted probabilities and observed responses for the regression model are shown in Table 4-19. The table indicates the model is $76 \%$ concordant. The ' $c$ ' value indicating model sensitivity (the ability to predict an event correctly) and specificity (the ability to predict a non-event correctly) was $77.20 \%$. All 4 indices of rank correlation assessing predictive ability of the model (Somer's D, Gamma, C, and Tau-a) were good and values are shown in Table 4-19. Also Table 4-19 shows maxrescaled R-Square which is the likelihood ratio chi-square testing the null hypothesis that all coefficients are ' 0 .' It indicates the percent variation in the likelihood of presenteeism that is explained by the regression model for this study is $32 \%$. This is considered good for a cross-sectional study.

Independent variables were entered into the ordered logistic regression model for analyses and results are in Table 4-20. Results indicate that estimated probability of presenteeism in diverse nurses and pharmacists across Tennessee was more likely when mental health 'conditions' and physical health 'symptoms' were present.

Moreover, presenteeism was less likely when nurses and pharmacists were previously treated with pharmacotherapy or had conditions for that which they were 'never treated' by pharmacotherapy. Mental health 'symptoms' approached significance as a predictor of presenteeism in the regression model (chi-square value 3.3926, $\mathrm{P}=.0655$ ). Neither profession (nurse versus pharmacist), nor race/ethnicity (minority versus non-minority), nor treatment by a provider (current, previous, never), nor work in a 24-hour direct care setting demonstrated statistical significance.

Separate regression models were run with interactions of profession and race/ethnicity variables with mental and physical health conditions and symptoms (see Tables 4-21 and 4-22). The interactions of nurse specialty and physical health conditions approached significance with a negative estimate (chi-square value $1.4107, p=0.0639$ ) indicating that nurses with physical health conditions were less likely to experience presenteeism than pharmacists who had physical health conditions (see Table 4-22). Interaction of profession and race variables revealed marginal significance. Minorities with mental health conditions were more likely to experience presenteeism than nonminorities with mental health conditions.

Table 4-23 and Table 4-24 report the marginal effects for predicting presenteeism. The models make comparatively stronger prediction for presenteeism at lower levels than it does for presenteeism at higher levels. For those health professionals with mental health conditions were more likely to experience presenteeism than nonminorities with mental health conditions.with mental health 'conditions,' this model predicts they have $22.5 \%$ increased chance of experiencing lower level presenteeism and a $2.7 \%$ increased chance of experiencing higher level presenteeism. Lastly, those nurses and pharmacists with physical health symptoms also have a $22.4 \%$ increased chance of 
Table 4-18. Ordered Logistic Regression: Testing Global Null Hypothesis: BETA=0

\begin{tabular}{lccc}
\hline Test & Chi-Square & DF & Pr $>$ Chi-Square \\
\hline Likelihood Ratio & 72.1010 & 11 & $<.0001$ \\
Score & 64.4959 & 11 & $<.0001$ \\
Wald & 55.8570 & 11 & $<.0001$ \\
\hline
\end{tabular}

Table 4-19. Logistic Model Predictive Probabilities \& Observed Responses

\begin{tabular}{lccc}
\hline Category & Observe Responses & Category & Observed Responses \\
\hline Percent concordant & 76.0 & Somers' D & 0.543 \\
Percent discordant & 21.7 & Gamma & 0.556 \\
Percent tied & 2.3 & Tau-a & 0.324 \\
Pairs & 15151 & $\mathrm{c}$ & 0.772 \\
\hline
\end{tabular}


Table 4-20. Logistic Regression: Maximum Likelihood Estimates of Independent Variables Predicting Presenteeism

\begin{tabular}{|c|c|c|c|c|c|}
\hline Variable & FREQ & $\%$ & Estimate & $\mathrm{SE}$ & $\begin{array}{c}\text { Pr }>\text { Chi- } \\
\text { Square }\end{array}$ \\
\hline Mental health condition & 74 & 28.14 & \multirow[t]{2}{*}{1.1476} & \multirow[t]{2}{*}{0.3339} & \multirow[t]{2}{*}{$0.0006^{*}$} \\
\hline (No mental health condition) & 189 & 71.86 & & & \\
\hline Mental health symptom & 96 & 36.50 & \multirow[t]{2}{*}{0.5888} & \multirow[t]{2}{*}{0.397} & \multirow[t]{2}{*}{$0.0655 \dagger$} \\
\hline (No mental health symptom) & 167 & 63.50 & & & \\
\hline Physical health condition & 168 & 63.88 & \multirow[t]{2}{*}{0.1974} & \multirow[t]{2}{*}{0.6499} & \multirow[t]{2}{*}{0.7614} \\
\hline (No physical health condition) & 95 & 36.12 & & & \\
\hline Physical health symptom & 234 & 88.97 & \multirow[t]{2}{*}{1.1451} & \multirow[t]{2}{*}{0.3683} & \multirow[t]{2}{*}{$0.0019^{*}$} \\
\hline (No physical health symptom) & 29 & 11.03 & & & \\
\hline Provider treatment never & 59 & 22.43 & \multirow[t]{2}{*}{0.7702} & \multirow[t]{2}{*}{0.8841} & \multirow[t]{2}{*}{0.3837} \\
\hline (Provider treatment current) & 204 & 77.57 & & & \\
\hline Provider treatment previous & 64 & 24.33 & \multirow[t]{2}{*}{0.4828} & \multirow[t]{2}{*}{0.6774} & \multirow[t]{2}{*}{0.4760} \\
\hline (Provider treatment current) & 199 & 75.67 & & & \\
\hline Medication treatment never & 80 & 30.42 & \multirow[t]{2}{*}{-1.7422} & \multirow[t]{2}{*}{0.7858} & \multirow[t]{2}{*}{$0.0266^{*}$} \\
\hline (Medication treatment current) & 183 & 69.58 & & & \\
\hline Medication treatment previous & 45 & 17.11 & \multirow[t]{2}{*}{-1.4795} & \multirow[t]{2}{*}{0.7204} & \multirow[t]{2}{*}{$0.0400 *$} \\
\hline (Medication treatment current) & 218 & 82.89 & & & \\
\hline Minority & 43 & 16.36 & \multirow[t]{2}{*}{0.2214} & \multirow[t]{2}{*}{0.3733} & \multirow[t]{2}{*}{0.5530} \\
\hline (Non-minority) & 220 & 83.65 & & & \\
\hline 24-hour direct care aetting & 106 & 40.30 & \multirow[t]{2}{*}{-0.00212} & \multirow[t]{2}{*}{0.2918} & \multirow[t]{2}{*}{0.9942} \\
\hline (Non-24hr/direct care) & 157 & 59.70 & & & \\
\hline Nurse & 131 & 49.81 & \multirow[t]{2}{*}{-0.2358} & \multirow[t]{2}{*}{0.2830} & \multirow[t]{2}{*}{0.4047} \\
\hline (Pharmacist) & 132 & 50.19 & & & \\
\hline
\end{tabular}


Table 4-21. Health Factors Interacting with Race/Ethnicity

\begin{tabular}{lccc}
\hline & \multicolumn{2}{c}{ Maximum Likelihood Estimates } & \\
\cline { 2 - 3 } Variables & Estimate & SE & Pr $>$ Chi-Square \\
\hline Minority*Mhealth conditions & 1.1424 & 0.8687 & 0.1040 \\
Minority*Mhealth symptoms & -0.1380 & 0.8332 & 0.8685 \\
Minority*Phealth conditions & 0.0182 & 1.3066 & 0.9889 \\
Minority*Phealth symptoms & -0.1590 & 0.8342 & 0.8488 \\
\hline
\end{tabular}

Table 4-22. Health Factors Interacting with Specialty Profession

\begin{tabular}{lccc}
\hline & \multicolumn{2}{c}{ Maximum Likelihood Estimates } & \\
\cline { 2 - 3 } Variables & Estimate & SE & Pr $>$ Chi-Square \\
\hline Specialty*Mhealth conditions & -0.6631 & 0.6456 & 0.3044 \\
Specialty*Mhealth symptoms & -0.5330 & 0.6489 & 0.4115 \\
Specialty*Phealth conditions & -2.6134 & 1.4107 & 0.0639 \\
Specialty*Phealth symptoms & 0.7942 & 0.7438 & 0.2856 \\
\hline
\end{tabular}


Table 4-23. Marginal Effects of Model for Predictor Variables on Presenteeism at Lower Levels

\begin{tabular}{|c|c|c|c|c|c|c|}
\hline Variable & Freq & $\%$ & Estimate & SE & $\begin{array}{c}\text { Marginals } \\
\text { Signt Xi }\end{array}$ & $\operatorname{Pr}>$ Chi-Square \\
\hline Mental health condition & 74 & 28.14 & 1.1476 & 0.3339 & .225259 & $0.0006^{*}$ \\
\hline (No mental health condition & 189 & 71.86 & & & & \\
\hline Mental health symptom & 96 & 36.50 & 0.5888 & 0.397 & .115574 & 0.0655 \\
\hline (No mental health symptom & 167 & 63.50 & & & & \\
\hline Physical health symptom & 234 & 88.97 & 1.1451 & 0.3683 & .224769 & $0.0019 *$ \\
\hline (No physical health symptom) & 29 & 11.03 & & & & \\
\hline Medication treatment never & 80 & 30.42 & -1.7422 & 0.7858 & -0.341972 & $0.0266^{*}$ \\
\hline (Medication treatment current) & 183 & 69.58 & & & & \\
\hline Medication treatment previous & 45 & 17.11 & -1.4795 & 0.7204 & -0.290407 & $0.0400 *$ \\
\hline (Medication treatment current) & 218 & 82.89 & & & & \\
\hline
\end{tabular}

*Chi-Square defaults to Fisher's Exact test for low cell count. 
Table 4-24. Marginal Effects of Model for Predictor Variables on Presenteeism at Higher Levels

\begin{tabular}{|c|c|c|c|c|c|c|}
\hline Variable & Freq & $\%$ & Estimate & SE & $\begin{array}{c}\text { Marginals } \\
\text { Signt Xi }\end{array}$ & $\operatorname{Pr}>$ Chi-Square \\
\hline Mental health condition & 74 & 28.14 & 1.1476 & 0.3339 & .027031 & $0.0006^{*}$ \\
\hline (No mental health condition & 189 & 71.86 & & & & \\
\hline Mental health symptom & 96 & 36.50 & 0.5888 & 0.397 & .013869 & 0.0655 \\
\hline (No mental health symptom & 167 & 63.50 & & & & \\
\hline Physical health symptom (No & 234 & 88.97 & 1.1451 & 0.3683 & .026972 & $0.0019^{*}$ \\
\hline Physical health symptom) & 29 & 11.03 & & & & \\
\hline Medication treatment never & 80 & 30.42 & -1.7422 & 0.7858 & -0.03485 & $0.0266^{*}$ \\
\hline (Medication treatment current) & 183 & 69.58 & & & & \\
\hline Medication treatment previous & 45 & 17.11 & -1.4795 & 0.7204 & -0.04104 & $0.0400 *$ \\
\hline (Medication treatment current) & 218 & 82.89 & & & & \\
\hline
\end{tabular}

*Chi-Square defaults to Fisher's Exact test for low cell count. 
experiencing presenteeism at lower levels and a $2.6 \%$ increased chance of experiencing it at higher levels.

The model predicts decreased odds of presenteeism consistent with the regression model as well. Those health professionals who were 'never' treated with pharmacotherapy and those who were 'previously' treated with pharmacotherapy have decreased odds of experiencing presenteeism. Specifically, those 'never' treated were $34 \%$ less likely to experience presenteeism at lower levels and 3.4\% less likely to experience presenteeism at higher levels. Those who were 'previously' treated were $29 \%$ less likely to experience presenteeism at lower levels and $4.1 \%$ less likely to experience presenteeism at higher levels. Clearly these data confirms the impressions obtained from the contingency tables and regression analyses which indicated that under-treatment, identified as 'previously' treated, is not a problem for nurses and pharmacists in this research study.

\section{Regression: Conclusions}

Results in this section support previous conclusions that we reject Hypothesis 1.2a that physical health conditions are more associated with racial ethnic minorities. Results in this section does not support our previous conclusion that we could not reject Hypothesis $1.2 \mathrm{~b}$ that mental health conditions are more associated with racial ethnic nonminorities. However, the data in this section, though not strong, supports that we can reject Hypothesis $1.2 \mathrm{~b}(\mathrm{p}=.1040)$. Data supporting conclusions of both hypotheses can be seen in Table 4-21 which shows the physical health condition variable interacting with race/ethnicity variables the mental health condition variable interacting with race/ethnicity. Separating results by profession, results were marginally significant indicating that physical health conditions were less a predictor of presenteeism for nurses versus pharmacists. The regression model predicts that there is no statistically significant interaction of mental health conditions or physical health and presenteeism according to race/ethnicity.

As predicators of presenteeism, among choices of mental health (conditions or symptoms) and physical health (conditions or symptoms); mental health 'conditions' and physical health 'symptoms' were predictors of presenteeism for nurses and pharmacists as a combined workforce, see Table 4-20. This was consistent with what was shown with marginal effects see, Tables 4-23 and 4-24. The marginal effects predictions were that nurses and pharmacists chances of experiencing lower level presenteeism were increased $22.5 \%$ when they report mental health 'symptoms' and $22.4 \%$ when they reported physical health symptoms. Chances of higher level presenteeism were increased $2.7 \%$ for mental health conditions and $2.6 \%$ for physical health symptoms. Marginal effects more strongly predicted presenteeism at lower levels than at higher levels.

Other variables were less significant. Mental health 'symptoms' approached significance as a predictor and physical health 'conditions' were not a significant factor (see Tables 4-21 and 4-22). 
The model showed less likely predictors of presenteeism as well. Data from the regression model, Table 4-20, as well as a previous table, Table 4-15, supported the conclusions to reject Hypotheses 1.3a and 1.3b. Choosing from among previous, currently, or never treated by a provider or pharmacotherapy; previously treated by pharmacotherapy or 'never treated' by pharmacotherapy were less likely predictors of presenteeism in nurses and pharmacists. Treatment by a provider (past, currently or never treated) was not reported as a significant predictor variable. Similarly, we saw earlier under-treatment versus current treatment was not significantly associated with presenteeism (see Table 4-15) and in the regression model we then saw that undertreatment, versus current treatment, was less likely a predictor variable with either treatment by provider or pharmacotherapy (see Table 4-20 and with marginal effects (see Tables 4-23 and 4-24).

\section{Specific Aim 2}

Specific aim 2 was to quantify, from the employer's perspective, the indirect cost of presenteeism in nurses and pharmacists and whether the indirect costs vary across racial/ethnic groups. Research Question 2 was 'what is the indirect cost burden of presenteeism among nurses and pharmacists and does it vary across racial/ethnic groups?' Hypothesis 2.0 corresponding to this section was that 'there are no differences in the indirect cost burden of presenteeism among nurses and pharmacists across racial/ethnic groups of both professions.

Hypothesis 2.0: Results

As shown in Table 4-25, nurses and pharmacists reported presenteeism that amounted to a cost burden of over $\$ 2.6$ million annually $(\$ 2,621,835)$. The median per person cost burden across the workforce of nurses and pharmacists (226) in this study averaged $\$ 12,605$ annually. However, if we only considered those (119) nurses and pharmacists with presenteeism, the cost per employee with presenteeism was $\$ 22,237$. The workforce sample reported a mean decrement of $13.20 \%$ in productivity. Such costs of presenteeism were impacted by what is considered a relatively high median annual salary of $\$ 97,584$ for this workforce of nurses and pharmacists.

Wages are important in the study of presenteeism because they largely determine the cost burden when there are productivity decrements due to presenteeism. Total wages of nurses and pharmacists were $\$ 20,047,287$. Lost labor costs were estimated using the human capital approach by translating mean decrements (using the survey tool) of lost productive time (mean score of $1.32=13.20 \%$ ) into lost dollars (see Table 4-6 for mean scores). Lost dollars from the employer perspective were valued as equal to wages paid to employees and not earned. More specifically, consider that formula indicated that to determine presenteeism cost burden $\left(\mathrm{P}_{\$}\right)$ one must first determine the lost productive time. Lost productive time (LPT) was a percent that was equal the presenteeism score $\left(\mathrm{P}_{\mathrm{sc}}\right)$ on the Wellness-at-Work survey question B14 times 100 . On a scale of $0-10$, the $\mathrm{B} 14$ score was the reported number that nurses and pharmacists chose to correspond to 
Table 4-25. Workforce Presenteeism and Cost Burden for Nurse and Pharmacist Workforce

\begin{tabular}{|c|c|c|c|c|c|}
\hline $\begin{array}{c}\text { Total Wages } \\
\mathrm{N}=226\end{array}$ & $\begin{array}{c}\text { Mean } \\
\text { Wages Per } \\
\text { Employee } \\
\mathrm{N}=226\end{array}$ & $\begin{array}{c}\text { Mean } \\
\text { Presenteeism } \\
\text { Decrement } \\
\mathrm{N}=226\end{array}$ & $\begin{array}{c}\text { Mean } \\
\text { Cost/Employee } \\
\text { w/Presenteeism } \\
\mathrm{N}=119\end{array}$ & $\begin{array}{c}\text { Mean Cost/Employee } \\
\text { Workforce } \\
\mathrm{N}=226\end{array}$ & $\begin{array}{c}\text { Annual } \\
\text { Pharm/Nursing } \\
\text { Workforce Cost } \\
\text { Burden } \\
\mathrm{N}=226 \\
\end{array}$ \\
\hline$\$ 20,047,287$ & $\$ 97,584$ & $13.20 \%$ & $\$ 22,237$ & $\$ 12,605$ & $\$ 2,646,242$ \\
\hline
\end{tabular}


the amount of their productivity decrement due to health reasons. Presenteeism cost burden $\left(\mathrm{P}_{\$}\right)$ was equal to lost productive time multiplied by wages $(\mathrm{W})$.

$$
\begin{aligned}
& \text { Wellness-at-Work B14= } \mathrm{P}_{\mathrm{sc}} \\
& \text { LPT }=\text { Psc x } 100 \\
& \mathrm{P}_{\$}=\text { LPT x W }
\end{aligned}
$$

This formula was also used to compare differences in presenteeism according to high, middle and low income nurses and pharmacists. Wages were obtained from dividing wage ranges reported by each nurse and pharmacist into medians of high, middle and low income. The annual income $<\$ 50,000$ was considered low income; $\$ 50,000$ $\$ 90,000$ was considered medium income; and $>\$ 90,000$ annually was considered high income. Chi-square analyses indicated that the per person annual cost burden for pharmacists with presenteeism in the lower income level was $\$ 20,849$, for the middle income $\$ 27,578$, and for higher income $\$ 34,306$. The mean for nurses with presenteeism in the lower income level was $\$ 14,775$, for middle income $\$ 20,000$ and for higher income $\$ 25,392$.

The Pooled T-Test that determined statistical significance of differences in mean cost burden by profession did not reflect that mean cost burden were statistically different in nurses versus pharmacists, although it approached significance ( $\mathrm{t}$-value 1.68, $\mathrm{p}=0.0956$ ). Moreover, differences by professions between minorities and non-minorities in each profession were not significantly different (pharmacists t value $0.85, p=0.3995$; nurses $t$ value $0.54, p=.5918$ ). Combining professions and viewing by race/ethnicity, similarly revealed results were not significantly different ( $t$ value $1.04, p=.3006$ ). The finding of no significantly different cost burden is quite consistent with results from contingency tables which indicated no statistical differences in the rate of presenteeism across professions of nurses and pharmacists (chi-square value .6278, $\mathrm{P}=0.4282$ ).

Hypothesis 2.0: Conclusions

While the cost burden was substantial for the workforce, nurses and pharmacists, data supports that we fail to reject Hypothesis 2.0 which states there are no differences in presenteeism cost burden across professions and race/ethnicity. Data from Table 4-26 confirm t-test results indicating that there were no statistical differences in cost burden by race/ethnicity or profession.

\section{Specific Aim 3}

Specific Aim 3 was to examine the cost burden and policy implications of presenteeism in a diverse healthcare workforce of nurses and pharmacists. Research question 3 was 'what are cost and health policy implications that could address key determinants of presenteeism among a diverse workforce of nurses and pharmacist?' 
Table 4-26. Comparison of Cost Means across Professions and Race/Ethnicity

\begin{tabular}{|c|c|c|c|c|c|c|}
\hline Profession & $\mathrm{N}$ & Mean $(\$)$ & Conf Limits & SE & T Value & $\operatorname{Pr}>|t|$ \\
\hline Nurse & 48 & 20,083 & $\begin{array}{l}\$ 14,775- \\
\$ 25,392\end{array}$ & 2638.70 & 2.68 & 0.0956 \\
\hline Pharmacist & 61 & 27,578 & $\begin{array}{l}\$ 20,849- \\
\$ 34,306\end{array}$ & 3363.70 & & \\
\hline \multicolumn{7}{|l|}{ Race/Ethnicity } \\
\hline Minority & 22 & 19,443 & $\begin{array}{l}\$ 13,401- \\
\$ 25,485\end{array}$ & 2640.2 & 1.04 & 0.3006 \\
\hline Non-minority & 89 & 25,180 & $\begin{array}{l}\$ 19,933- \\
\$ 30,427\end{array}$ & 2905.2 & & \\
\hline \multicolumn{7}{|l|}{$\begin{array}{l}\text { Nurses by } \\
\text { Race/Ethnicity }\end{array}$} \\
\hline Minority & 10 & 17,400 & $\begin{array}{l}\$ 8,713- \\
\$ 26,087\end{array}$ & 3840.1 & 0.54 & 0.5918 \\
\hline Non-minority & 37 & 20,980 & $\begin{array}{l}\$ 14,349- \\
\$ 27,611\end{array}$ & 3269.6 & & \\
\hline \multicolumn{7}{|l|}{$\begin{array}{l}\text { Pharmacists by } \\
\text { Race/Ethnicity }\end{array}$} \\
\hline Minority & 11 & 21,477 & $\begin{array}{l}\$ 10,895- \\
\$ 32,059\end{array}$ & 4749.3 & 0.85 & 0.3995 \\
\hline Non-minority & 50 & 28,920 & $\begin{array}{l}\$ 20,961- \\
\$ 36,879\end{array}$ & 3960.5 & & \\
\hline $\begin{array}{l}\text { All with } \\
\text { Presenteeism }\end{array}$ & & 22,237 & & & & \\
\hline
\end{tabular}


Analysis: Results

From the healthcare employer's perspective, this study indicates that nurses and pharmacists were drivers of lost productivity valued at $\$ 22,237$ per person (see Table 4-24). That amount reflected lower and higher levels of presenteeism (see Tables 4-23 and 4-24). According to regression and marginal effects modeling, the key determinants that drove presenteeism for 119 nurses and pharmacists were physical health symptoms and mental health conditions. Producing projections from the marginal effects analyses(see Table 4-23); this researcher determined that per person costs for lower and higher level presenteeism were increased $25 \%$ or $\$ 5559$ per person due to physical health symptoms and increased by $25.2 \%$ or $\$ 5604$ per person due to mental health conditions. A review of all health symptoms and conditions in Table 4-10 and Table 4-11 reveals that care can be divided into 5 areas to support reducing these costs of presenteeism:

1. Treatment of perceptions of pain (back or neck pain; pain in arms, legs, joints, knees, hips, etc.; headaches; muscle soreness)

2. Treatment for perceptions of tiredness and sleeplessness (feeling tired or having low energy; trouble sleeping)

3. Treatment for allergy and cold/flu (watery eyes, runny nose, or stuffy head; cough or sore throat; fever, chills, or other cold/flu)

4. Treatment of gastrointestinal discomforts (constipation, loose bowels, or diarrhea; nausea, gas, or indigestion)

5. Treatment of mental health conditions (anxiety and depression)

The 2 key determinants of mental health conditions and/or physical health symptoms, when divided into the above 5 categories, could reduce the 2.6 million in costs by a range $25 \%$ to $50 \%$ depending on whether both mental health 'conditions' and physical health 'symptoms' were involved.

Moreover, the data analyses indicated that the per-person employer's costs could decrease further by $37.4 \%$ or $\$ 8317$ per person if health conditions presumably did not require pharmacotherapy treatment. Or, costs could decrease $33.1 \%$ or $\$ 7360$ per person if nurses and pharmacists that previously received (and not currently receiving) appropriate treatment through pharmacotherapy, no longer needed it. Addressing these factors could reduce the 2.6 million cost burden in saving valued at either $33.1 \%$ or $37.4 \%$ depending on the factor targeted for reduction.

Lastly, even though the regression and marginal effects modeling did not show that grouped mental health symptoms were statistically significant, $(p=.0655$, see Table 4-23), mental health 'symptoms' approached statistical significance as a key determinant. The data indicated that an additional cost burden of $13 \%$ or $\$ 2890$ per person could be avoided (see Tables 4-23 and 4-24) if these symptoms were included. Moreover, in 
addition to grouped mental health 'symptoms' that approached significance in the regression model, there were 3 individual physical health 'conditions'(see Table 4-9) that were associated with presenteeism and were not considered key determinants but highly prevalent in some groups: cholesterol, hypertension, and kidney/bladder (see Table 4-9). While from a statistical perspective these data were not significant in the regression model, from a clinical perspective they were considered important and can be of value in guiding an employer to impact presenteeism's cost and disease burden.

Based on these cost projections, employers could reduce the cost burden of presenteeism from $25 \%$ to a $64 \%$ by appropriately health factors associated with presenteeism. An additional 13\% can be saved if other associated conditions are also addressed. More specifically, given that the workforce cost burden of presenteeism for this study was 2.6 million dollars, it is reasonable to project that the 2.6 million could be decreased by minimum of $25 \%$ or $25.2 \%$ for addressing the main health determinants of mental health or physical health symptoms respectively, and $37.4 \%$ or $33.1 \%$ savings if they received care such that they did not need pharmacotherapy or when they previously received pharmacotherapy it was effective such that they currently did not receive it respectively, and by decreasing costs of $13 \%$ by addressing mental health symptoms. This combined cost saving effort ranged $25 \%$ at minimum to $64 \%(\$ 661,560$ to $\$ 1,693,594)$ to address key determinants. Moreover, the potential from $25 \%$ to a maximum up to $75 \%(\$ 661,560$ to $\$ 1,984,681)$ if other factors individually associated with presenteeism were addressed appropriately by supporting nurses and pharmacist in getting care needed.

The policy implications of this study were that employers needed to be intentional about endorsing work place and benefits policies which were consistent with creating work environments and paying for treatment that work to reduce the impact of presenteeism. In order for employers to facilitate that, they needed to change the focus of a variety of policies that provided incentive to be sick to policies that endorse prevention of 'conditions' and early symptomatic reduction of 'symptoms.' The recommendation was for employers to become involved in examining a host of policies to include: internal worksite operational policies, policies which govern contractors who service employees, integrated health insurance and benefits management policies, policies guiding treatment providers who service employees, human resource development policies, and national/state/governmental policies which impacted how employees pay for care for their employees. As was advocated by the Institute of Medicine's 2001 report, "Crossing the Quality Chasm: A New Health System for the 21st Century." this investigator considered that workplace policies that supported decreased presenteeism for nurses and pharmacists would need to support IOM's STEEP principals (Koch, et al., 2000). More specifically, policies would support care that was safe, timely, efficient, effective and patient/employee centered (STEEP) (Koch, et al., 2000) by the most appropriate provider in the most conveniently accessible venue. An assessment of change implications from a business of health systems as well as the provider of clinical treatment perspective was recommended to provide the individual employer with a roadmap for specific changes needed in their organization. 
Designing appropriate policies to support a clinical models that specifically addressed clinical needs of nurses, pharmacists, minorities and non-minorities, required only a few differences by profession or race/ethnicity. Based on the data from this study, models of care which provide certain features were recommended divided by profession and race/ethnicity. focused on:

Data indicated nurses required treatment related policies that supported care that

1. Perceptions of pain (includes chronic pain)

2. Tiredness and sleeplessness

3. Allergies and cold/flu

4. Gastrointestinal disorders

5. Mental health (includes feeling easily irritated) (see Table 4-12)

6. $\quad$ Urinary/ bladder (see Table 4-9)

7. Hypertension

Data indicated treatment for pharmacists required policies that supported care that focused on:

1. Perceptions of pain (include migraine)

2. Tiredness and sleeplessness (include chronic fatigue)

3. Allergies and cold/flu as above

4. Gastrointestinal disorders as above

5. Mental health (includes restless or fidgety, hopeless, feelings of easily irritated, and anger and aggressiveness)

6. High cholesterol

Data indicated that treatment for racial/ethnic minorities required policies that supported care that focused on:

1. Perceptions of pain (does not include headaches/migraines)

2. Tiredness and sleeplessness (does not include chronic fatigue condition) 
3. Allergies and cold/flu as above

4. Gastrointestinal disorders (does not include constipation, loose bowels, or diarrhea symptoms)

5. Mental health (include restless or fidgety, hopeless, feelings of easily irritated, and anger and aggressiveness)

6. Hypertension

In addition to the conditions and symptoms of the key determinants specifically identified above, data indicated non-minorities required policies that supported treatment or care that focused on:

1. Perceptions of pain (include migraine, add chronic pain)

2. Tiredness and sleeplessness (include chronic fatigue)

3. Allergies and cold/flu as above

4. Gastrointestinal disorders as above

5. Mental health (include restless or fidgety, hopeless, feelings of easily irritated, and anger and aggressiveness)

6. High cholesterol

7. Urinary/bladder conditions

Analysis: Conclusions

Based on the data from this study, costs and policy implications indicated that, given specific workplace and healthcare policy focus on the part of employers, the 2.6 million employer cost burden of presenteeism could be addressed. As a start, the focus on decreasing either of the 2 key determinants of physical health symptoms and mental health conditions would reduce cost approximately $25 \%$ each. However, cost reductions for employers can range from a total of $25 \%$ to $62 \%$ ( 0.6 million to 1.7 million), and depending on what is targeted beyond key determinants, the data indicates the range can be up to $75 \%$ ( 0.6 million to 2 million). For maximum results policy targets would need to have sought to decrease all symptoms and conditions associated with presenteeism in this study and they would have needed to implement policies that enabled employees to receive preventive and symptomatic care easily. 
Conclusions and Implications

The results of this analytical study formulated the basis for several heretoforeunreported perspectives on the presenteeism outcome in a diverse workforce of nurses and pharmacists. This last chapter discussed insights, both expected and unexpected, into the determinants of presenteeism and the un-explored distinctness of presenteeism among racial/ethnic groups across nurses and pharmacist. Finally, given the findings of the study, suggestions for strategies to mediate the cost burden of presenteeism by influencing practice models and health policies from an employer's perspective were summarized.

\section{Presenteeism and Determinants}

More than half, 52.65\% (119), of the 226 workforce of nurses and pharmacists participating in this study reported presenteeism (see Table 4-7). Divided among professions, $47.06 \%$ of nurses and $52.94 \%$ of pharmacists reported presenteeism. Rates of presenteeism among nurses and pharmacists were not found to be significantly different $(\mathrm{p}=0.4282)$. Moreover, rates of presenteeism between racial and ethnic nonminority and minority groups were also not found to be significantly different $(p=.5774)$. Presenteeism was reported at two levels of productivity decrements, lower levels $(\leq 30 \%)$ composed of $41.15 \%(93)$ of the sample and higher levels $(\geq 40 \%)$ that composed $11.50 \%$ (26) of those with presenteeism. Among those with presenteeism, the prevalence of presenteeism at lower levels for pharmacists was 79.37\% (50) and this was only slightly more than for nurse at $76.78 \%$ (43). Presenteeism at higher levels was slightly more for nurses at $23.21 \%$ (13), than for pharmacists at $20.63 \%$ (13).

The key determinants of presenteeism reported by nurses and pharmacists across race and ethnicity were physical health symptoms, mental health conditions, previously treated by pharmacotherapy, and never treated by pharmacotherapy (see Table 4-24). Specifically, among a majority of nurses and pharmacists $(52.65 \%)$, the likelihood of presenteeism increased $22.4 \%$ if nurses and pharmacists suffered physical health symptoms, increased $22.5 \%$ if they suffered mental health conditions, decreased $34 \%$ if their health conditions were never treated by pharmacotherapy, and decreased $29 \%$ if they were previously treated by pharmacotherapy (but not currently treated). Consistent with previous empirical studies, this presenteeism study indicated that conditions associated with 'perceptions' either of a physical nature (as in pain) or of an emotional nature as in (stress, depression, and anxiety) have demonstrated the highest decrements in productivity due to presenteeism (Boles, 2004; Burton, 2005). Stewart et al. (2003a) also found that more episodic conditions versus more chronic health conditions were associated with presenteeism.

Nurses and pharmacists who were 'never' treated with pharmacotherapy and those who were 'previously' treated with pharmacotherapy (but not currently treated) had decreased odds of experiencing presenteeism. Specifically, those 'never' treated were $34 \%$ less likely to experience presenteeism at lower levels and 3.4\% less likely to experience presenteeism at higher levels. Those who were 'previously' treated were 29\% 
less likely to experience presenteeism at lower levels and $4.1 \%$ less likely to experience presenteeism at higher levels.

Clearly these data confirm that for this sample of nurses and pharmacists in Tennessee, there were no differences in presenteeism across profession or by racial/ethnic group. Also, analyses indicated that under-treatment, identified as 'previously' treated, is not a problem regardless of whether treatment was through pharmacotherapy or through a healthcare provider.

\section{Distinctness of Presenteeism among Racial/Ethnic Groups}

This empirical study purposefully sought data distinctions across race and ethnicity, not as mere demographic or descriptive note, but to provide insight into implications that might be prescriptive in addressing historically poor health outcomes in racial and ethnic minorities. Survey respondents self-identified their race and ethnicity and the result was 43 racial ethnic minorities and 163 non-minorities. Across this diverse group, prevalence of presenteeism as a functional health outcome was not significantly different when stratified by race and ethnicity. Moreover, presenteeism was comparatively less in racial/ethnic minorities than in non-minorities $(51.65 \%$ vs. $53.55 \%$ respectively, $\mathrm{P}=0.2871$ ) in this workforce see Table 4-7.

Despite there being a relatively fair prevalence of chronic conditions among minorities (diabetes, respiratory/lung, and stomach/intestinal condition (see Table 4-9), these chronic conditions were not associated with presenteeism. This possibly helped explain the relatively lower level presenteeism among racial and ethnic minorities than non-minorities. Similarly, the prevalence of 3 out of the 4 mental health conditions were higher in minorities than non-minorities -- anxiety, other emotional problems, and substance abuse (see Table 4-11). However, only 2 of the 3 conditions were associated with presenteeism (anxiety and other emotional problems). Therefore, despite these findings, racial ethnic minorities did not report statistically significant higher mental health conditions associated with presenteeism.

Although the positive findings that racial and ethnic minorities had lower levels of presenteeism than non-minorities can be explained as indicated above; the explanation does not exclude another possibility. Consistent with the "Presenteeism as a Health Driven Economic Engine" theoretical framework, resilience to the impact of health conditions on productivity could also occur in racial and ethnic minorities in nursing and pharmacy fields. Nurses and pharmacists bring positive health determinants to the workforce such as higher socioeconomic status, health literacy, healthcare access, educational rigor of higher education, and survival of training as healthcare profession, which could presumably position nurses and pharmacists to have better health outcomes than are historically attributed to racial/ethnic minorities. Additionally, the process of pursuing higher education could 'weed-out' those who have less resilience and it could have directly impacted their ability to complete the rigors of education or training. 
The point is not to belabor the positive finding, but to point out that better quantifying how, if, and when any factors might impact racial and ethnic minorities to produce more positive results in workforces than has been historically reported about such groups can enrich both disparities research as well as health-related productivity research. More race and ethnic distinct data about health-related productivity outcomes provides the best chance of determining where impacting the course of health outcomes occurs in other diverse populations more broadly.

\section{Cost Burden}

This study indicated that presenteeism was the driver of 2.6 million dollars employer cost burden (see Tables 4-24 and 4-25). If key determinants of presenteeism were addressed, this study indicated that a combined cost saving could range between $25 \%$ to $64 \%$ ( $\$ 661,560$ to $\$ 1,693,594)$. Moreover, the potential of up to a maximum up $75 \%(\$ 661,560$ to $\$ 1,984,681)$ could occur if other factors individually associated with presenteeism were also addressed appropriately. These cost savings were based on the human capital approach where presenteeism averaged $13.2 \%$ lost productivity valued at $\$ 12,700$ per nurse or pharmacist in a 226 person healthcare workforce with median wages of $\$ 97,584$.

The prevalence of presenteeism averaged 52.65\% across the workforce of nurses and pharmacists. Based on reviews of empirical studies of employees across multiple types of employment, including knowledge-based employees, amounts of fewer than $39 \%$ were expected across a workforce (Boles, et al., 2004; Burton, et al., 2005; Collins, et al., 2005; Stewart, et al., 2003a).

According to Loeppke et al. (2007) whose group studied 4 large companies using the HPQ tool, the recommendation for presenteeism research is to "not compare dollars reported as point estimates, but rather as markers to observe the relative magnitude of the health condition and relative contribution of each cost component" (Loeppke, et al., 2007). Researchers have advised this because there is currently no standard for monetizing presenteeism and there is wide variation in monetizing presenteeism from study to study and employer to employer (Kessler \& Stang, 2006; Loeppke, et al., 2007; Nicholson, et al., 2006; Pauly, 2007). "No single monetizing formula will be accurate for all employers or for workers of all types within a single workforce due to financial value varying as a function of type of work and industry" (Loeppke, et al., 2007). For example, the study that Burton et al. (2005) performed estimated that the annual cost of lost productivity was between $\$ 1392$ and $\$ 2592$ per employee. Stewart et al. (2003a) projected that health related productivity loss (of which $71 \%$ was for presenteeism) cost employers \$225.8 billion/year or \$1686/per employee per year. However, Goetzel (2004) estimated that absenteeism caused greater than 10 days lost/year and that presenteeism cost 30 days lost/year. Using Goetzel's formula for value of 30 days lost wages and comparing a nursing and pharmacist workforce whose average earnings are approximately $100 \mathrm{~K}$ a year, the results were approximately $\$ 8291.00$ a year in expected losses for the employer. The take-away message is that studies seem to indicate that the nurse and pharmacist workforce experienced higher cost burden than some other 
workforces. Based on the results of this research, the differences are believed to be related to two factors. One is that higher than US population norms for perception related or cognitively related conditions seem to imply that these conditions have "pathogenic effects' resulting in impaired performance. Specifically conditions of depression, anxiety, pain, tiredness, and sleep deprivation are believed to impact knowledge workers the more their work is dependent on use of such cognitions. The notion that health professionals and employees in service jobs experience higher levels of presenteeism than other jobs has been documented in other studies, ironically in other countries of Sweden and Canada (Aronsson, et al., 2000; Canadian Institute for Health Information, 2006).

For the current study, the estimate of $\$ 2.6$ million for 226 healthcare professionals, which amounts to $\$ 12,700$ per nurse and pharmacist, is higher than most per employee estimates in a general workforce. However, these amounts calculated based on percentage of lost wages, can be considerable an under-estimate of employer cost burden if non-wage economic barometers are used. For health care employers whose product sold is a 'human service,' there are other potential costs of presenteeism. A few economists (Berger, et al., 2003b; Nicholson, et al., 2006; Pauly, 2007) have implied that costs higher than lost wages would be estimated if a replacement or supplemental worker is needed, if the person's work impacts a team, or if a manager had to predict the cost burden. While all these may be reasons that additional costs of presenteeism could apply to a nurse and pharmacist workforce; there may be other even larger cost to healthcare employers.

Healthcare employers also may lose more money when nurses and pharmacists fail to generate reimbursable services. Moreover, if the nurse or pharmacist's actions are related to medical errors and increased malpractice risks, the costs can take on tentacles and apply to other providers and the entire institution. Given that impaired 'thought' processes can impact error rates of healthcare practitioners the notion that these healthcare employees function with higher than expected rates of 'thought and perception' related health problem (anxiety, depression, pain, and fatigue); there are compounded reasons for healthcare employers to be concerned about presenteeism. If these factors are linked with healthcare service payments for performance, quality, and medical error free services; healthcare employers may have more potential loss of revenue than other types of employers. Costing presenteeism is one of the major challenges in the field of health-related productivity research. However, starting to collect the data from those healthcare employees who experience it is a necessary first step in what will likely be a process that gathers greater sophistication. The connection with the possibility of increased costs and increased returns can be determined. For now, employers might want to ask themselves why they have such a need for supplemental and on-call employees, why medical errors are not decreasing even though greater resources have been put into addressing such errors. 


\section{Unexpected Findings and Recommendaton for Future Research}

There were several unexpected findings. The finding that presenteeism in this sample was highly associated with physical health 'symptoms' versus actual physical health 'conditions' or illnesses was a surprising one. All empirical studies reviewed by this investigator identified presenteeism associated with diagnosable physical health conditions. In fact, this investigator examined the top ten health conditions associated with presenteeism in the nurse and pharmacist workforces (see Table 4-9) and compared them with prevalence of the same health conditions frequently reported in the literature associated with presenteeism (see Table 2-1). The comparison indicated that the prevalence of the top ten health conditions for nurses and pharmacists were up to five times higher for some health conditions compared to previous studies as indicated in Table 4-27.

Unfortunately, previous empirical studies of presenteeism did not separately report prevalence of health 'symptoms' in order to compare the findings in this current study. The finding that 'symptoms' were significant and 'conditions' were not significant predictors of presenteeism among pharmacists and nurses was quite unexpected. Because nurses and pharmacists are health literate and quite capable of discerning when they are impacted by an actual disease versus symptoms; speaks to whether examining physical health symptoms creates a gap in the research on presenteeism. Moreover, since most presenteeism studies have not been performed on an entire group of knowledge-based professions, this also could speak to a distinct finding more attributable to knowledge based versus other professions. Exploring the association with knowledge based professionals versus others is an opportunity for further research. Moreover, exploring the association of mental health conditions with all physical health symptoms in those with presenteeism is also another opportunity for future research.

Based on a review of literature about both professions, this investigator also expected that nurses had more physical health conditions than pharmacists. This was attributed to the sometimes physical nature of the work of nurses and the more direct hands on contact with sick patients. Indeed nurses reported $20 \%$ more back and neck pain, 2 times the prevalence of arthritis, and two and 2.5 times more of chronic pain than pharmacists. However, in the final analysis, the model found very strong significant association of reported physical health symptoms (not conditions) and presenteeism in both nurses and pharmacists (see Table 4-10). Moreover, interactions in the regression model between the nurse variable and physical health conditions approached significance with a negative estimate. This indicated that the physical health conditions variable approached significance for the pharmacists' profession (see Table 4-22). This suggests that healthcare employers need to further evaluate the impact of health of nurses and pharmacists. This is an area for future research.

The extent of mental health problems was also unexpected. The expectation was that nurses and pharmacists would endorse mental health symptoms rather than actual diagnosable mental health conditions. Collectively they reported anxiety $(24 \%)$ and depression (33\%). These conditions, along with self-reported sleep problems (34\%) and chronic fatigue (34\%) among nurses and pharmacists indicate a need for employer 
Table 4-27. Top 10 Conditions Associated with Presenteeism: Previous Research Compared to Current Study

\begin{tabular}{lccc}
\hline & $\begin{array}{c}\text { Sample of } \\
\text { Nurses and } \\
\text { Pharmacists } \\
\%\end{array}$ & $\begin{array}{c}\text { Previous } \\
\text { Studies } \\
\%\end{array}$ & \\
\hline Health Condition & 54.87 & 25.1 & Goetzel, 2004 \\
Migraines, severe/frequent headaches & 25.44 & 17.7 & Goetzel, 2004 \\
Hypertension & 29.31 & 14.9 & Wang, 2003 \\
High cholesterol & 30.17 & 20.0 & Kessler, 2008 \\
Other gastrointestinal problems & 29.57 & 8.1 & Kessler, 2008 \\
Allergies & 42.37 & 31.2 & Goetzel, 2004 \\
Sleep problem & 33.62 & 8.6 & Kessler, 2008 \\
Chronic fatigue/low energy & 33.91 & 6.4 & Kessler, 2008 \\
Anxiety & 24.35 & 5.6 & Kessler, 2008 \\
Depression & 32.76 & 9.4 & Goetzel, 2004 \\
\hline
\end{tabular}


concern about cognitive health in knowledge based professions (see Tables 4-9 and 4-11). To highlight this point, consider that the prevalence of these conditions was higher than fever, chills, or other cold/flu symptoms 12.61\% (see Table 4-10).

The mental health findings had several implications to this researcher. It suggested there is reason to be concerned about the high prevalence of mental health conditions coupled with the particular physical health conditions of sleeplessness and fatigue as was indicated in the review of literature, very often mental health concerns compound the impact of physical health problems on a worker's presenteeism. Given the extent of physical health symptoms in this study, the strength of associations of mental health conditions and the physical health symptoms versus physical health condition is an interesting question for future research.

\section{Practice Models and Policy Strategies to Address Key Determinants}

\section{Assumptions}

When considering the findings of this study, a number of assumptions were made about self-reported health conditions in order to determine potential practice and policy implications to address:

1. The implication from an employer's perspective regarding policies for ease of accessing, referring to, and seeking mental health care and symptomatic treatment of physical health symptoms for nurses and pharmacists in each workplace needs to be assessed in light of the findings of this study.

2. Nurses and pharmacists experienced physical health symptoms and either did not feel such symptoms warranted time off work, or they felt their alternative consequences related to addressing the symptoms were more undesirable than staying at work with lowered productivity.

3. When mental health conditions are self diagnosed and yet treatment is not sought, it is often due to the stigma of seeking and acknowledging need for treatment, or not being familiar with options for seeking such help. Given the knowledge base of these professional, reasons of stigma are a logical conclusion.

4. When nurses and pharmacists suffered health conditions and symptoms that did not warrant them seeking medications to treat the conditions, the health conditions and symptoms were also not severe enough to impact work productivity. 


\section{Policy Recommendations}

Given the results of this study, policy strategies that minimized costs and addressed determinants of presenteeism in nurses and pharmacists were identified. These suggestions were from an employer's perspective and are listed below:

Transform Employee Assistance Programs (EAPs)

Transformation of EAPs can rather easily include a model of practice to provide short term acute mental health and symptomatic physical health concerns. When such programs are conceptually re-engineered, the costs of such services need not be more than current costs. The difference would be the venue where services are provided not the payment structure. To address presenteeism associated with mental health conditions, the EAP can be expanded to include brief limited pharmacotherapy. EAPs generally are contracted services staffed primarily by mid-level therapist for counseling. The EAP concept can be expanded to provide mid-level providers who can also provide psychopharmacotherapy as well as pharmacotherapy to address symptomatic relief of acute episodic conditions. EAP models do not seem to be hampered by the stigma of psychiatric treatment. For example the employers could contract to add similar to convenience care or retail clinics (Hansen-Turton, 2007) to the EAP services. The costs of such clinic services average about $\$ 50$ or $\$ 60$ per visit and could be paid as an employee would normally pay them if they accessed them in a Walgreens or CVS.

Revisit Benefits Financing Strategies

Reducing the burden of co-pays, co-insurance and insurance deductible can take the disincentive of obtaining preventive care and addressing symptomatic relief from low cost acute care. Higher employee burden financing strategies were aimed at reducing moral hazard, however, they can have the unintended impact of reducing low or no cost early intervention and preventive care which could save money longer term and address presenteeism related physical health symptoms. Alternatively, supplying employer sponsored services such as in suggestion II above, have ingrained provider moral hazard protections in that the providers will have scope of practice limitations that limit the amount of services which can be supplied. Employee moral hazard can be controlled in the way it occurs with EAPs currently, with caps on number of visits per episode. Referrals to medical homes or other benefits could occur as usual.

Provide Worksite Based Ergonomics and Rehabilitative Services

Worksite based ergonomics and rehabilitative services, whether contracted through an external entity, or staffed by the health facility should be provided. These services are recommended for ease of convenient use by nurses and pharmacists. Ergonomically appropriate chairs, stools, desks to work and standing podiums could 
address the most common physical musculoskeletal and pain symptoms. Additionally, an adequate supply of equipment that facilitates lifting and turning patients are indicated for nurses. Provide lounges with massage chairs or hydro-massage equipment to decrease back and neck strain. Consider employee distressing rooms and allow modified work assignments when employees have less than full health times, etc. Monitored use can be instituted and justified for mandatory referrals for more intense treatment.

\section{Revise Worksite Time-Off Policies}

Many employers have 'paid time off' and no longer provide separate sick and vacations days. Many employees choose to save vacation days and come to work when they have physical health symptoms. The result can be prolonged recovery and spread of contagious infections to others (Levin-Epstein, 2005). Alternatives time off policies can send the message that when workers are at work, they are expected to be fully productive and that recovery from ill feelings is an acceptable reason to stay home. Employers can implement this reallocation of days without increasing the number of paid days off.

Include Presenteeism Measures in Employee Wellness Assessments

Regular employee wellness assessments can identify health problems that are known to impact workforce productivity. The addition of presenteeism and other productivity measures can also assist in determining effectiveness of benefit pricing and other program components institute to impact employee health and productivity.

\section{Strengths and Limitations of the Study}

The strengths of this study were that it provided complete anonymity in collecting candid responses, on personal and sensitive data from nurses and pharmacists about their workforce performance. Lack of interviewer bias as the collection of data from the web is a neutral event. This study used a sample of respondents who were relatively homogenous in terms of socioeconomic status and the outcomes of treatment or lack thereof on productivity are less likely to be confounded by these variables across race and ethnicity. Results are stratified and analyzed by race and ethnicity and this approach was heretofore lacking in empirical research on presenteeism. That health related factors of treatment through pharmacotherapy and providers introduced new unique insights for further empirical study. Also, separation of physical health symptoms from physical health conditions in determining presenteeism was a strength and unique to this study.

The limitations of this study were that it was based on cross-sectional versus a longitudinal study and therefore may have come to different conclusions had workers been followed for a period of time to determine health related productivity decrements. Another limitation is the generalizability of results to all nurse and pharmacist professionals or to all areas of the country is limited due to the sample being a 
convenience sample of professionals available on from one university's distribution list of professionals across the state.

As mentioned earlier, another limitation of this study is that it did not capture 'health risks' as has been more prominently noted in presenteeism in more recent research - inactivity, smoking, stress, etc. Collecting that data could have allowed richer comments from a clinical perspective about the levels of practice models that might facilitate prevention or 'salutogenic effects' in regards to the symptoms and conditions reported.

Another limitation of this study is that it did not capture all treatment modes to include self-medication or self treatment, use of over the counter medications, home remedies, and alternative medicines. Whether these factors figured into presenteeism results or the perceptions reported by nurses or pharmacists were not considered. Additionally, since the study examined only the two modes of treatment (pharmacotherapy and provider therapy), but only in reference to one versus the other, consideration of how both combined might impact presenteeism was not captured.

\section{Healthcare Employer's Imperative}

Nurses as the largest and pharmacists as the third largest providers of healthcare report presenteeism loss of considerable financial value from a healthcare employer perspective. Health care employers are in the business of healthcare and they have the opportunity to proactively make changes in practice models they support and policies they enact which have ramifications that can reach farther than their individual bottom lines. This analytical study hopefully provides some insight into the healthcare needed for the healthcare givers. Changes in one healthcare workplace are not likely to address the presenteeism issue with nurses and pharmacists, but the advocacy and market support of each workplace can have a profound effect on the US healthcare system. 


\section{LIST OF REFERENCES}

Aday, L., Begley, C. E., Lairson, D. R., \& Balkrishman, R. (2004). Evaluating the healthcare system: Efficiency and equity (3rd ed.). Chicago, IL: Health Administration Press, Academy Health.

Aday, L., \& Corneilus, L. (2006). Designing and conducting health surveys: A comprehensive guide (3rd ed.). San Francisco: Jossey-Bass.

Agency for Healthcare Research and Quality (2004). National healthcare disparities report. Retrieved March 19, 2008, from http://www.ahrq.gov/qual/nhdr04/fullreport/Index.htm

Agency for Healthcare Research and Quality (2006). National healthcare disparities report. Retrieved May 20, 2008, from http://www.ahrq.gov/qual/nhdr06/nhdr06report.pdf

Aiken, L. H., Clark, S. P., Sloane, D. M., Sochalski, J., \& Silber, J. H. (2002). Hospital nurse staffing and patient mortality, nurse burnout, and job dissatisfaction. JAMA, 288(16), 1987-1993.

Aiken, L. H., Sochalski, J., \& Anderson, G. F. (1996). Downsizing the hospital nursing workforce. Health Affairs, 15(4), 88-92.

American Organization of Nurse Executives (AONE) (n.d.). AONE position statement on diversity. Retrieved July 10, 2005, from http://www.aone.org/aone/advocacy/statement_on_diversity.html

American Society of Health System Pharmacists (2007). Report on the ASHP Task Force on pharmacy's changing demographics. American Journal of Health System Pharmacists, 64, 1311-1319.

Anderson, L., Oppler, S., \& Rose, A. (2006). Estimating the dollar costs of productivity losses due to illness: An application of the O*Net In R. Kessler \& P. Stang (Eds.), Health and productivity work: Making the business case for quality health care (pp. 120-141). Chicago: University of Chicago Press.

Antonovsky, A. (1990). Studying health vs. studying disease. Lecture at the Congress for Clinical Psychology and Psychotherapy, Universidade Nova de Lisboa, Berlin. Retrieved March 6, 2009, from http://www.ensp.unl.pt/saboga/soc/pulic/soc_AAconference_berlim_91.pdf

Aronsson, G., Gustafsson, K., \& Dallner, M. (2000). Sick but yet at work. An empricial study of sickness presenteeism. Journal of Epidemilogy and Community Health, 54(7), 502-509. 
Bahrs, O., Heim, S. V., Matthiessen, P. F., \& Müller, H. (2003). Salutogenesis in general practice. Abstract obtained from 2nd Conference on Making Sense of Health Illness and Disease, 2003. Oxford: St. Hilda's College.

Baldwin, D. (2003, June 12, 2008). Disparities in health and health care: Focusing efforts to eliminate unequal burdens Retrieved June 12, 2008, from http://www.nursingworld.org/MainMenuCategories/ANAMarketplace/ANAPerio dicals/OJIN/TableofContents/Volume82003/No1Jan2003/DisparitiesinHealthand HealthCare.aspx

Berger, M. L., Bingelors, K., Hedblom, E. C., Pashos, C. I., \& Torrance, G. W. (Eds.). (2003a). 'Prevalence.' In Health care costs, quality and outcomes: ISPOR book of terms. Lawrenceville, NJ: International Society for Pharmacoeconomics and Outcomes Research.

Berger, M. L., Howell, R., Nicholson, S., \& Shardra, C. (2003b). Investing in healthy human capital. Journal of Occupational and Environmental Medicine, 45(12), 1213-1225.

Blumi, B. M., McKenney, J. M., \& Cziraky, M. J. (2000). Pharmaceutical care services and results in project ImPACT: Hyperlipidemia. Journal of the American Pharmaceutical Association, 402, 157-165.

Bodenheimer, T., \& Grumbach, K. (2008). Understanding health policy (5th ed.). New York: McGraw-Hill.

Boles, M., Pelletier, B., \& Lynch, W. (2004). The relationship between health risks and work productivity. Journal of Occupational \& Environmental Medicine, 46(7), 737-745.

Brach, C., \& Fraser, I. (2002). Reducing disparities through culturally competent health care: an analysis of the business case. Quality Management in Health Care, 10(4), $15-28$.

Brandt-Rauf, P., Burton, W. N., \& McCunney, R. J. (2001). Health, productivity, and occupational medicine. Journal of Occupational \& Environmental Medicine, $43(1), 1$.

Breslau, J., Kendler, K., Su, M., Gaciola-Aguilar, S., \& Kessler, R. (2005). Lifetime risk and persistence of psychiatric disorders across ethnic groups in the United States. Psychological Medicine, 35(3), 317-327.

Buerhaus, P. I., Auerbach, D. I., \& Staiger, D. O. (2007). Recent trends in the registered nurse market in the U.S.: Short-run swings on top of long-term trends. Nursing Economics, 25(2), 59-66. 
Buerhaus, P. I., Donelan, K., Ulrich, B. T., Norman, L., \& Dittus, R. (2005). Is the shortage of hospital registered nurses getting better or worse? Findings from two recent national survey of RNs. Nursing Economics, 23(2), 61-96.

Bureau of Labor Statistics (2007). National census of fatal occupational injuries in 2007. Retrieved May 18, 2008, from http://www.bls.gov/news.release/pdf/cfoi.pdf

Burton, W. N., Chen, C. Y., Schultz, A. B., Conti, D. J., Pransky, G., Edington, D. W., et al. (2006). Worker productivity loss associated with arthritis. Disease Management, 9(3), 131-143.

Burton, W. N., Chen, C. Y., Schultz, A. B., \& Edington, D. W. (1998). The economic costs associated with body mass index in a workplace. Journal of Occupational \& Environmental Medicine, 40(9), 786-792.

Burton, W. N., Conti, D. J., Chen, C. Y., Schultz, A. B., \& Edington, D. W. (1999). The role of health risk factors and disease on worker productivity. Journal of Occupational \& Environmental Medicine, 41(10), 863-877.

Burton, W. N., McCalister, K. T., Chen, C. Y., \& Edington, D. W. (2005). The association of health status, worksite fitness center participation, and two measures of productivity. Journal of Occupational \& Environmental Medicine, 47(4), 343-351.

Burton, W. N., Morrison, A., \& Wertheimer, A. I. (2003). Pharmaceuticals and worker productivity loss: A critical review of the literature. Journal of Occupational \& Environmental Medicine, 45(6), 610-621.

Burton, W. N., Pransky, G., Conti, D. J., Chen, C. Y., \& Edington, D. W. (2004). The association of medical conditions and presenteeism. Journal of Occupational \& Environmental Medicine, 46(6 Suppl), S38-45.

Canadian Institute for Health Information (2006). Findings from the 2005 national survey of the work and health of nurses. Retrieved May 3, 2007, from http://secure.cihi.ca/cihiweb/products/NHSRep06_ENG.pdf

Chou, C. F., \& Johnson, P. J. (2008). Health disparities among America's health care providers: Evidence from the Integrated Health Interview Series, 1982 to 2004. Journal of Occupational \& Environmental Medicine, 50(6), 696-704.

Clark, R. T. (2006). The value proposition in healthcare. American Journal of Managed Care, 12(11), 645-646.

Collins, J. J., Baase, C. M., Sharda, C. E., Ozminkowski, R. J., Nicholson, S., Billotti, G. M., et al. (2005). The assessment of chronic health conditions on work performance, absence, and total economic impact for employers. Journal of Occupational \& Environmental Medicine, 47(6), 547-557. 
Commonwealth Fund (1998). International health policy survey. Retrieved August 8, 2007, from http://www.commonwealthfund.org/Content/Surveys/1998/1998International-Health-Policy-Survey.aspx

Crown, W. H. (2000). Productivity measurement in pharmaceutical studies. Drug Benefit Trends, 12(2), 5-8.

Davies, P. G. (2007). Between health and illness. Perspectives in Biology \& Medicine, 50(3), 444-452.

Dawson-Saunders, B., Feltovich, P. J., Coulson, R. L., \& Steward, D. E. (1990). A survey of medical school teachers to identify basic biomedical concepts medical students should understand. Academic Medicine, 65(7), 448-454.

DiMatteo, M. R., \& Haskard, K. B. (2006). Further challenges in adherence research: measurements, methodologies, and mental health care. Medical Care, 44(4), 297 299.

Edwards, J. M., \& Patry, R. A. (2006). Pharmacy's changiong demographics. American Journal of Health System Pharmacy, 63(18), 1691.

Ericksson, M., \& Lindstrom, B. (2006). Antonovsky's sense of coherence and the relationship with health: A systematic review. Journal of Epidemiology and Community Health, 60, 376-381.

Ericksson, M., \& Lindstrom, B. (2007). Antonovsky's sense of coherence and its relationship with quality of life: A systematic review. Journal of Epidemiology and Community Health, 60, 938-944.

Evans, C. (2006). The pharmaceutical industry and productivity research. In R. Kessler \& P. Stang (Eds.), Health and productivity work: Making the business case for quality health care. (pp. 224-241). Chicago: University of Chicago Press.

Evans, C. J. (2004). Health and work productivity assessment: State of the art or state of flux? Journal of Occupational \& Environmental Medicine, 46(6 Suppl), S3-11.

Galinsky, E., Bond, J. T., Kim, K. S., Backon, L., Brownfield, E., \& Sakai, K. (2005). Overwork in America: When the way we work becomes too much. Executive Summary of [2004]. Retrieved July 20, 2007, from http://familiesandwork.org/site/research/summary/overwork2005summ.pdf

Garson, G. D. (2008). Logistic regression: Statnotes. Retrieved October 4, 2008, from http://faculty.chass.ncsu.edu/garson/PA765/logistic.htm

Gershon, S. K., Cultice, J. H., \& Knapp, K. K. (2000). How many pharmacists are in our future? The Bureau of Health Professions projects supply to 2020. Journal of the American Pharmaceutical Association, 40(6), 757-764. 
Goetzel, R. Z., Long, S. R., Ozminkowski, R. J., Hawkins, K., Wang, S., Lynch, W., et al. (2004). Health, absence, disability, and presenteeism cost estimates of certain physical and mental health conditions affecting U.S. employers. Journal of Occupational \& Environmental Medicine, 46(4), 398-412.

Greenberg, P. E., \& Binbaum, H. (2006). Linking administrative claim data with archival productivity measurers to inform employer decision-making. In R. Kessler \& P. Stang (Eds.), Health and productivity work: Making the business case for quality health care (pp. 29-53). Chicago: University of Chicago Press.

Greenberg, P. E., Birnbaum, H. G., Kessler, R., Morgan, M., \& Stang, P. (2001). Impact of illness and its treatment on workplace costs: Regulatory and measurement issues. Journal of Occupational \& Environmental Medicine, 43(1), 56-63.

Grossman, H., \& Banaji, J. (1992). The law of accumulations and breakdown of the capitalist system: Being also a theory of crises. London: Pluto Press.

Harris Interactive (2005). Prescription drug compliance a significant challenge for many patients, according to new national survey. Retrieved May 18, 2008, from http://www.harrisi.org/news/allnewsbydate.asp?NewsID=904

Health Enhancement Research Organization (HERO) (n.d.). About HERO. Retrieved June 4, 2008, from http://www.the-hero.org/about_hero.htm

Health Resources and Services Administration (2004). State health workforce profiles (2000) Retrieved June 6, 2008, from http://bhpr.hrsa.gov/healthworkforce/reports/profiles/

Hemp, P. (2004). Presenteeism: At work--but out of it. Harvard Business Review, 82(10), 49-58.

Holland, J., \& Holland, C. (2001). Impact of the workplace environment on worker health and productivity. Scottsdale, AZ: The Institute for Health and Productivity Management.

Huang, F. Y., Chung, H., Kroenke, K., \& Spitzer, R. (2006). Racial ethnic differences in the relationship between depression severity and functional status. Psychiatric Service, 57, 498-503.

Institute for Health and Productivity Management. (n.d.). Our origins; organization, staffing management brief Retrieved June 4, 2008, from http://www.ihpm.org/info/background.php\#origins

Integrated Benefits Institute (n.d.). About IBI Retrieved June 4, 2008, from http://ibiusa.com/aboutus.htm 
Israel, G. (2003). Determining sample size in sampling the evidence of extension program impact (PEOD-6). Retrieved November 27, 2007, from http://edis.ifas.ufl.edu/PD006

Kaiser Family Foundation (2002). Key facts: Race, ethnicity, and medicale care. Retrieved October 7, 2007, from http://www.kff.org/content/factsheets.cfm

Kaiser Family Foundation (2004). Key facts: Race, ethnicity and medical care. Retrieved October 7, 2007, from http://www.kff.org/content/factsheets.cfm

Kaiser Family Foundation (2007). Key facts: Race, ethnicity and medical care. Retrieved January 7, 2008, from http://www.kff.org/content/factsheets.cfm

Kerr, S. (1995). On the folly of rewarding A, while hoping for B. The Academy of Management Executive, 9(1), 7-8.

Kessler, R. (2002). Background information, letter dated 1/1/2002. Retrieved August 15, 2005, from http://www.hcp.med.harvard.edu/hpq/ftpdir/hpq1_background.pdf

Kessler, R., Ames, M., Hymel, P. A., Loeppke, R., McKenas, D. K., Richling, D. E., et al. (2004). Using the World Health Organization Health and Work Performance Questionnaire (HPQ) to evaluate the indirect workplace costs of illness. Journal of Occupational \& Environmental Medicine, 46 (6 Suppl), S23-37.

Kessler, R., Barber, C., Beck, A., Berguldn, P., Cleary, P. D., \& McKenas, D. (2003). The World Health Organization Health and Work Performance Questionnaire (HPQ). Journal of Occupational \& Environmental Medicine, 45(2), 156-174.

Kessler, R., \& Stang, P. (2006). Intersecting issues in the evaluations of health and work productivity. In R. Kessler \& P. Stange (Eds.), Health and productivity work: Making the business case for quality health care (pp. 1-26). Chicago: University of Chicago Press.

Kinnaird, D., Cox, T., \& Wilson, J. P. (2003). Unclaimed prescriptions in a clinic with computerized prescriber order entry. American Journal of Health-System Pharmacy, 60(14), 1468-1470.

Knapp, K. K., \& Cultice, J. M. (2007). New pharmacist supply projections: Lower separation rates and increased graduates boost supply estimates. Journal of the American Pharmacists Association, 47(4), 463-470.

Knott, A., \& Moscovice, I. (2000). The practice of rural primary care - A national survey [Abstract]. Paper presented at the Academy for Health Services Research and Health Policy Meeting, Rural Health Research Center, University of Minnesota, Minneapolis, MN.

Koch, L. T., Corrigan, J. M., \& Donaldson, M. S. (Eds.). (2000). To err is human: Building a safer health system. Washington, DC: The National Academies Press. 
Kravitz, R. L., \& Melnikow, J. (2004). Medical adherence research: Time for a change in direction. Medical Care, 42(3), 197-199.

Laviest, T. A. (2005). Minority populations and health: An introduction to health disparities in the United States. San Francisco: A Wiley Imprint.

Lerner, D., Adler, D. A., Chang, H., Lapitscky, L., Hood, M. Y., Perissinotto, C., et al. (2004). Unemployment, job retention, and productivity loss among employees with depression. Psychiatric Services, 55(12), 1371-1378.

Lerner, D., \& Henke, R. M. (2008). What does research tell us about depression, job performance, and work productivity? Occupational and Environmental Medicine, $50,401-410$.

Letvak, S., \& Buck, R. (2008). Factors influencing work productivity and intent to stay in nursing. Nursing Economics, 26(3), 159-165.

Levin-Epstein, J. (2005). Presenteeism and paid sick days. Retrieved August 25, 3008, from http://www.clasp.org/publications/presenteeism.pdf

Lipscomb, J., Trinkoff, A., Brady, B., \& Geiger-Brown, J. (2004). Health care system changes and reported musculoskeletal disorders among registered nurses. American Journal of Public Health, 94(8), 1431-1435.

Loeppke, R., Taitel, M., Richling, D., Parry, T., Kessler, R., Hymel, P., et al. (2007). Health and productivity as a business strategy. Journal of Occupational \& Environmental Medicine, 49(7), 712-721.

Lofland, J. H., \& Frick, K. D. (2006). Effect of health insurance on workplace absenteeism in the U.S. workforce. Journal of Occupational \& Environmental Medicine, 48(1), 13-21.

Longest, B. B. (2006). Health policymaking in the United States (4th ed.). Chicago: Health Administration Press.

Lopez, A. D., Mathers, C. D., Ezzati, M., Murray, C. J. L., \& Jamison, D. T. (2006). Global burden of disease and risk factors. New York: Oxford University Press.

Lowe, G. (2002). Here in body, absent in producitivity: Presenteeism hurts output, quality of work-life and employee health. Retrieved February 3, 2005, from http://www.grahamlowe.ca/documents/26/2002-12-02-Lowe.pdf

Lynch, W. D., Mercer, W. M., \& Reidel, J. E. (Eds.). (2001). Measuring employee productivity. 2001: A guide to self-assessment tools. Scottsdale, AZ: Institute for Health and Productivity Management. 
Malone, D. C., Abarca, J., Skrepnek, G. H., Murphy, J. E., Armstrong, E. P., Grizzele, A. J., et al. (2007). Pharmacist workload and pharmacy characteristics associated with the dispensing of potentially clinically important drug-drug interactions. Medical Care, 2007(45), 5.

Manasse, H. R., Jr. (2003). Health in a hand basket? Pursuing your profession through a challenging, changing landscape. American Journal of Health-System Pharmacy, 60(23), 2484-2490.

Mattke, S., Balakrishnan, A., Bergamo, G., \& Newberry, S. J. (2007). A review of methods to measure health-related productivity loss. American Journal of Managed Care, 13(4), 211-217.

McGinnis, J. M., Williams-Russo, P., \& Knickman, J. R. (2002). The case for more active policy attention to health promotion. Health Affairs, 21(2), 78-93.

Miranda, J., Duan, N., Sherbourne, C., Schoenbaum, M., Lagomasino, I., Jackson-Triche, M., et al. (2003). Improving care for minorities: Can quality improvement interventions improve care and outcomes for depressed minorities? Results of a randomized, controlled trial. Health Services Research, 38(2), 613-630.

Moody, R. C. (2004). Nurse productivity measures for the 21st century. Health Care Management Review, 29(2), 98-106.

Mott, D. A., Doucette, W., Gaither, C., Cline, R., Kreling, D., Schommer, J., et al. (2005). Final report of the national sample survey of the pharmacist workforce to determine contemporary demographic and practice characteristics. Alexandria, VA: Pharmacy Manpower Project, Inc.

Muchmore, L., Lynch, W. D., Gardner, H. H., Williamson, T., \& Burkey, T. (2003). Prevalence of arthirits and associated joint disorders in an employed population and the associated healthcare, sick leave, disability, and workers' compensation benefits cost and productivity loss of employers. Journal of Occupational and Environmental Medicine, 45, 369-378.

Murray, J. F., Nicholson, S., Pauly, M., \& Berger, M. (2006). Investing in health to boost employee productivity: The employer's perspective. In R. Kessler \& P. Stang (Eds.), Health and work productivity: Making the business case for quality health care (pp. 185-205). Chicago: University of Chicago Press.

National Business Group on Health (2003). Why companies are making health disparities their business: The business case and practical strategies. Retrieved April 24, 2005, from http://www.omhrc.gov/assets/pdf/checked/business_case.pdf

National Center for Health Workforce Analysis (2002). The health care workforce In eight states: Education, practice, and policy. Retrieved December 4, 2005, from http://bhpr.hrsa.gov/healthworkforce/reports/states02/default.htm 
National Council on Patient Information and Education (2007). Enhancing prescription medicine adherence: A national action plan. Retrieved August 12, 2007, from http://www.talkaboutrx.org/documents/enhancing_prescription_medicine_adhere nce.pdf

National Institutes of Health (2002). Women of color health data book (No. 02-4247). Bethesda, MD: Office of Research on Women's Health.

Nicholson, S., Pauly, M. V., Polsky, D., Sharda, C., Szrek, H., Berger, M. L., et al. (2006). Measuring the effects of work loss on productivity with team production. Health Economics, 15(2), 111-123.

Pauly, M. (2007). Valuing reductions in on-the-job illness: "Presenteeism" from managerial and economic perspectives. Unpublished manuscript.

Pilette, P. C. (2005). Presenteeism in nursing: a clear and present danger to productivity. Journal of Nursing Administration, 35(6), 300-303.

Polit, D. F., \& Beck, C. T. (2004). Nursing research: Principles and methods (7th ed.). Philadelphia: Lippincott, Williams \& Wilkins.

Prasad, M., Wahlqvist, P., Shikiar, R., \& Shih, Y. C. (2004). A review of self-report instruments measuring health-related work productivity: a patient-reported outcomes perspective. Pharmacoeconomics, 22(4), 225-244.

Pronk, N. P., Martinson, B., Kessler, R., Beck, A. L., Simon, G. E., \& Wang, P. (2004). The association between work performance and physical activity, cardiorespiratory fitness, and obesity. Journal of Occupational \& Environmental Medicine, 46(1), 19-25.

Rabin, S., Mataloni, A., Maoz, B., \& Shiben, A. (2005). Keeping doctors healthy: A salutogenic perspective. Families, Systems, and Health, 23(1), 94-102.

Rhoads, J., Ferguson, L. A., \& Langford, C. A. (2006). Measuring nurse practioner productivity. Dermatology Nursing, 18(1), 32-38.

Ricci, J. A., \& Chee, E. (2005). Lost productive time associated with excess weight in the U.S. workforce Journal of Occupational and Environmental Medicine, 47, 12271234.

Rust, G., \& Cooper, L. A. (2007). How can practice-based research contribute to the elimination of health disparities? Journal of the American Board of Family Medicine, 20(2), 105-114.

Santerre, R. E., \& Neun, S. P. (2004). Health economics: Theories, insights, and industry studies (3rd ed.). Mason, OH: South-Wester. 
Sellers, J. A., \& White, S. J. (2002). Finding more pharmacists. American Journal of Health-System Pharmacy, 59(9), 831.

Shamansky, S. L. (2002). Presenteeism... or when being there is not being there. Public Health Nursing, 19(2), 79-80.

Shirey, M. R. (2006). Stress and coping in nurse managers: Two decades of research. Nursing Economics, 24(4), 193-203.

Simpson, R. L., \& Bolton, L. B. (2007). Roundup: perspectives on a perfect storm. Nursing Administration Quarterly, 31(2), 99-104.

Smedley, B. D., Stitch, A. Y., \& Nelson, A. R. (2003). Unequal treatment: Confronting racial and ethnic disparities in health care. Retrieved December 13, 2005, from http://www.nap.edu/openbook.php?isbn=030908265X

Smith, A. D. (1904). An inquiry into the nature and causes of the wealth of nations. Retrieved April 7, 2007, from http://www.econlib.org/library/Smith/smWN.html

Smith, A. D. (2006). Barriers to accepting e-prescribing in the U.S.A. International Journal of Health Care Quality Assurance Incorporating Leadership in Health Services, 19(2-3), 158-180.

Stang, P., Greenberg, P. E., Birnbaum, H. G., Kessler, R., Hoffman, L., \& Duh, M. S. (2006). A regulatory perspective on productivity claims: Implications for future productivity research. In R. Kessler \& P. Stang (Eds.), Health and productivity work: Making the business case for quality health care (pp. 242-261). Chicago: University of Chicago Press.

Stewart, W. F., Lipton, R. B., \& Liberman, J. (1996). Variation in migraine prevalence by race. Neurology, 47(1), 52-59.

Stewart, W. F., Ricci, J. A., Chee, E., Hahn, S. R., \& Morganstein, D. (2003b). Cost of lost productive work time among US workers with depression. JAMA, 289(23), 3135-3144.

Stewart, W. F., Ricci, J. A., Chee, E., \& Morganstein, D. (2003a). Lost productive work time costs from health conditions in the United States: Results from the American Productivity Audit. Journal of Occupational \& Environmental Medicine, 45(12), 1234-1246.

Stewart, W. F., Wood, G. C., Razzaghi, H., Reed, M. L., \& Lipton, R. B. (2008). Work impact of migraine headaches. Journal of Occupational \& Environmental Medicine, 50(7), 736-745.

Suh, R. (2006). An aging workforce: Health-related productivity and the economic value of health promotion. Retrieved September 11, 2007, from http://cme.medscape.com/viewarticle/543680 
Tennessee Department of Health (n.d.). Health professionals licensing. Retrieved August 26, 2008, from http://health.state.tn.us/Licensurereports/

Tennessee Hospital Association (n.d.-a). The center for health workforce development in Tennessee. Retrieved December 31, 2007, from http://www.healthworkforce.org/

Tennessee Hospital Association (n.d.-b). Tennessee Nursing Profiles. Retrieved December 31, 2007, from http://www.healthworkforce.org/data/TennesseeNursing-Profiles.pdf

Thiedke, C. C. (2007). What do we really know about patient satisfaction? Family Practice Management, 14(1), 33-36.

Wang, P. S., Beck, A., Berglund, P., Leutzinger, J. A., Pronk, N., Richling, D., et al. (2003). Chronic medical conditions and work performance in the health and work performance questionnaire calibration surveys. Journal of Occupational \& Environmental Medicine, 45(12), 1303-1311.

Warshaw, L., \& Burton, W. (1998). Cutting the costs of migraine: Role of the employee health unit. Journal of Occupational and Environmental Medicine, 40, 943-953.

Weinstock, B. (2003). Reducing health disparities: Why and how companies are making it their business. Retrieved April 24, 2005, from http://www.businessgrouphealth.org/pdfs/business_case_issuebrief.pdf

Wellness Councils of America (2003). A WELCOA expert interview: Formula for sucess - David Hunnicutt and Bill Whitner. Retrieved January 4, 2009, from http://www.davidhunnicutt.com/pdf/Whitmer_INTERVIEW.pdf

White-Means, S. I. (1995). Conceptualizing race in economic models of medical utilization: A case study of community-based elders and the emergency room. Health Services Research, 30(1 Pt 2), 207-223.

Whiteford, H. (2006). Investing in health to promote human capitol in developing countries: The importance of productivity and health to the World Bank. In R. Kessler \& P. Stang (Eds.), Health and productivity work: Making the business case for quality health care (pp. 253-267). Chicago: University of Chicago Press.

Woods, T. M. (2007). No ordinary time. American Journal of Health-System Pharmacy, 64(8), 859-862.

World Health Organization (2001). The international classification of functioning, disability and health - ICF. Retrieved December 1, 2007, from http://www.who.int/classifications/icf/en/ 
Zoratti, E. M., Havstad, S., Rodriguez, J., Robens-Paradise, Y., Lafata, J. E., \& McCarthy, B. (1998). Health service use by African Americans and Caucasians with asthma in a managed care setting. American Journal of Respiratory and Critical Care Medicine, 158(2), 371-377. 


\section{APPENDIX A. WELLNESS-AT-WORK SURVEY}

\section{A. YOUR HEALTH STATUS}

Section I: The first section asks about your personal health and whether you have had treatment.

Click one circle to select your answer to each question.

A1. In general, how would you rate your overall health now?

Click the down arrows to select your answer to the next series of questions. (Note: Professional treatment is defined as any treatment supervised by a health professional).

A3. Do you have any of the following conditions? If your answer is YES, select whether you currently, previously, or never received professional treatment AND if treatment included prescription medications.

(1) Do you have this condition?

a. Arthritis?

b. Hypertension

c. Heart Condition?

d. Asthma?

e. Diabetes?

f. Obesity?

g. Cancer?

h. Back/Neck Pain?

I. Urinary or bladder problems

j. Migraine, frequent or severe headaches?

k. Gastrointestinal problems?

I. Sleep problems?

m. Depression?

$\mathrm{n}$. Anxiety disorder?

o. Musculoskeletal problems?

p. Other (specify below)

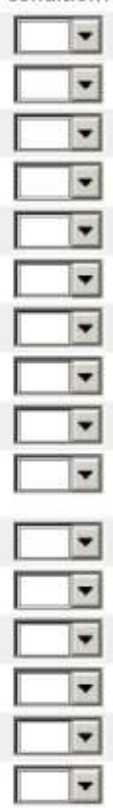

(2) If yes, recieved professional treatment?

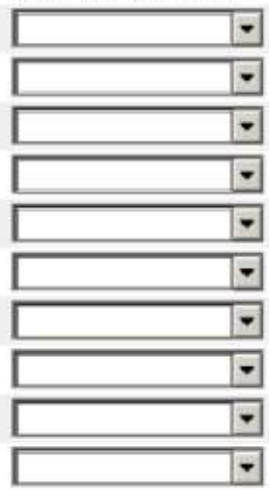

(3) If treated, medications included?

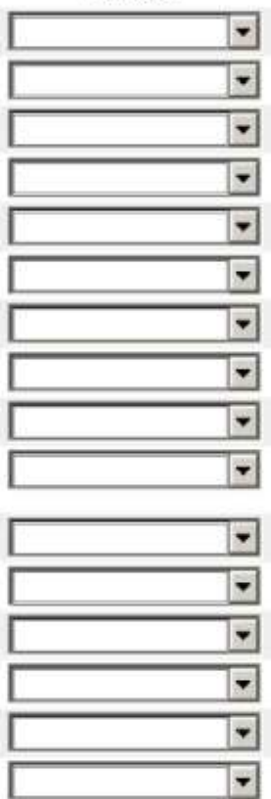




\section{INTRODUCTION}

\section{PARTICIPANT INFORMATION \& CONSENT}

Welcome to the Wellness-At-Work Survey for the HealthCare Workforce. You are invited to participate in this study if you are:

1. A licensed Nurse or Pharmacist in the State of Tennessee.

2. Currently working for pay in healthcare.

3. Not currently on leave from work.

Participation in this survey involves supplying information about your health, work, health care, and general status. This survey takes approximately 15-20 minutes to complete.

You will be asked demographic information, but neither your name nor other individually identifiable information will be asked. Your informed consent is given by choosing to proceed to the next screen and respond to the survey questions.

PURPOSE:

The purpose of the research is to examine how health care costs and professional productivity are impacted when a healthcare workforce remains on the job while experiencing certain health conditions. Findings are expected to have implications for healthcare employers/payers, professional associations, practice models, policies and health systems.

VOLUNTARY and CONFIDENTIAL:

You are not required to participate in this research. You may stop at any time. This research is not part of any group or specific employer-related effort. Your answers will only be reported as group information. This on-line survey is on a secured website.

RISKS and BENEFITS:

There are no anticipated risks to participating in this study. No portions of the survey should cause distress.

Personal and professional gratification are benefits to participating in the survey. The survey offers nurses and pharmacist opportunities to contribute data which lends itself to understanding factors which impacts health at the personal, professional, organizational levels.

CONTACT INFORMATION:

The findings from this research will be reported as part of a dissertation study. Questions about the study can be directed to:

Carol Warren-Blakemore, APRN-BC, MBA, PhD Candidate

College of Graduate Health Sciences

Health Outcomes and Policy Research (HOPR)Program

cwarren2@utmem.edu

(901) 448-3932

or

Dr. Shelley White-Means, Phd

Professor \& Vice Chair, Dept of Pharmaceutical Sciences

Chair, Health Outcomes and Policy Research (HOPR)

swhiteme@utmem.edu

(901) $448-7666$

This study is approved through the

University of Tennessee Health Science Center

Institutional Review Board

Approval date _October 11, 2007

Click "Next" if you agree to participate and want to get started. If you'd like to leave the survey at any time, just click "Exit this survey". 


\section{Health Conditions}

A4. During the past 4 weeks ( 28 days), how much were you bothered by each of the following conditions?
a. Feeling tired or having low energy
b. Trouble sleeping?
c. Headaches?
d. Back or neck pain?
e. Pain in your arms, legs, or joints (knees, hips,
etc.)?
f. Muscle soreness?
g. Water eyes, runny nose, or stuffy head?
h. Cough or sore throat?
i. Fever, chills, or other cold/flu symptoms?
j. Constipation, loose bowels, or diarrhea?
k. Nausea, gas, or indigestion?

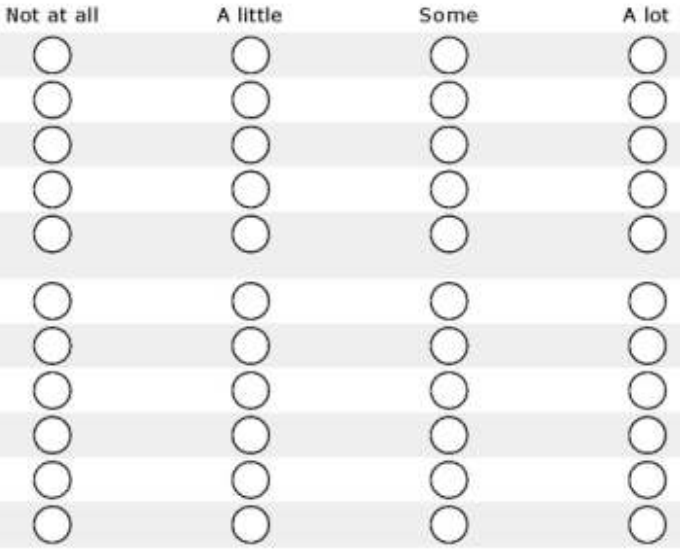

A5. During the past 4 weeks ( 28 days), how much of the time did you feel...

a. ...so sad nothing could cheer you up?
b. ...nervous?
c. ....restless or fidgety?
d. ...hopeless?
e. ...that everything was an effort?
f.....worthless?
g....quick to anger, more irritable or
agressive?

For the question which follows, click on the choice closest to the way you feel about the statement.

A6. As a healthcare professional, staying healthy is very important for me to be successful in my career.

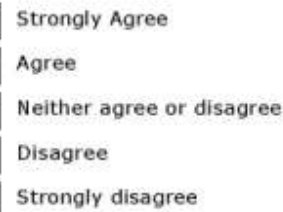




\section{B. YOUR WORK}

Part II: This section is about your work and your productivity while at work.

B1. What is your profession?

A. Nurse

B. Pharmacist

Licensed Professional
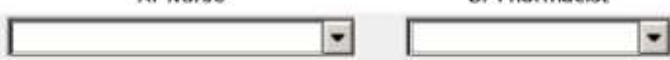

B2. Are you currently working for pay in your profession?

a. Yes

b. No

If No, please end the survey by clicking "Exit this survey." The remainder of the survey only applies to currently working healthcare providers. Thank you for your interest. You may comment below.

B3. Do you perform the following kinds of work? Please use the drop down arrow to respond 'Yes' or 'No". For each 'Yes' response, estimate the number of hours you typically spend doing this kind of work each week. If it varies, estimate the average.

a. Caregiver for adults/parents?

b. Caregiver for your child(ren)?

c. Working in a full-time paying job?

d. Working a part-time paying job?

e. Self-employed?

f. Volunteer work?

g. Full-time student?

h. Part-time student?

i. Housework/home maintenance?

Response

Average Number of Hours each Week

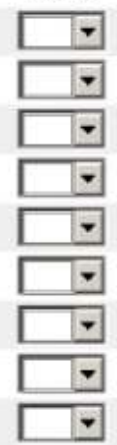


40 hours per week for 4 weeks $=160$ hours

35 hours per week for 4 weeks $=140$ hours

40 hours per week for 4 weeks with 28 -hour days missed $=144$ hours

40 hours per week for 4 weeks with 34 -hour partial days missed $=148$ hours

35 hours per week for 4 weeks with 2 8-hour days missed and 34 -hour partial days missed = 112 hours

\section{Work Quality}

B9. Did you have any of the following experiences at work in the past 4 weeks ( 28 days)?

b. Any special work failure?

c. An accident that caused either damage, work delay, a

near miss, or a safety risk?

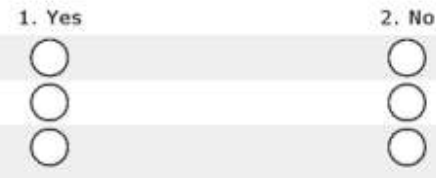

B9(1) If you answered "Yes" to any of the questions B6a, B6b, or B6c, please describe what happened.

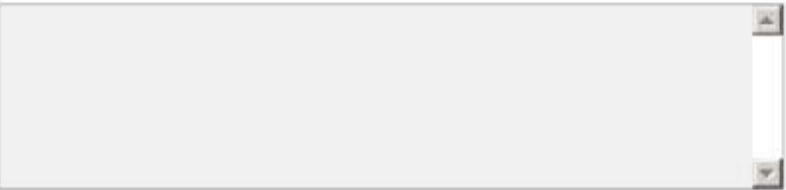

B10. The next questions are about your experiences during your work hours over the past 4 weeks ( 28 days). Select the one response for each question that comes closest to your experience.

a. How often was your performance higher than
most workers on your job?
b. How often was your performance lower than
most workers on your job?
c. How often did you do no work at times when
you were supposed to be working?
d. How often did you find yourself not working
as carefully as you should?
e. How often was the guality of your work lower
than it should have been?
f. How often did you not concentrate enough
on your work?
g. How often did health problems limit the kind
or amount of work you could do?




\section{Work Quantity}

B4. Please choose the category that best describes your main nursing or pharmacist job function. If none of the categories fits you exactly, please respond with the closest category to your experience. (Select only one.)

a. Executive (e.g., administrator or senior manager)

b. Supervisor/Manager

c. Staff

e. Researcher

f. Educator

g. Adminstrative Services (e.g.,quality, sales, marketing, development)

h. Compounding

i. Clinical

j. Medication Therapy Management

k. Other (please specify)

B5. What type of organization/facility is your main work place?

Place of Work

Kind of Healthcare Organizations

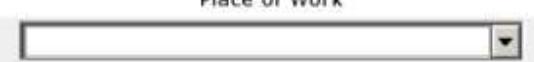

j. Other (please specify)

B6. About how many hours altogether did you work in the past 7 days? (If more than 97, enter 97.)

$\$$ of hours (00-97)

B7. How many hours does your employer expect you to work in a typical 7-day week? (If it varies, estimate the average. If more than 97, enter 97.)

* of hours (00-97)

B8. About how many hours altogether did you work in the past 4 weeks ( 28 days)? (See examples below.)

* of hours in the past 4

weeks ( 28 days) 


\section{Work Productivity}

The following questions ask you to rate working or performance ability under various specific circumstances.

B11. On a scale from $\mathbf{0}$ to $\mathbf{1 0}$ where $\mathbf{0}$ is the worst job performance anyone could have at your job and $\mathbf{1 0}$ is the performance of a top worker, how would you rate the usual performance of most workers in a job similar to yours?

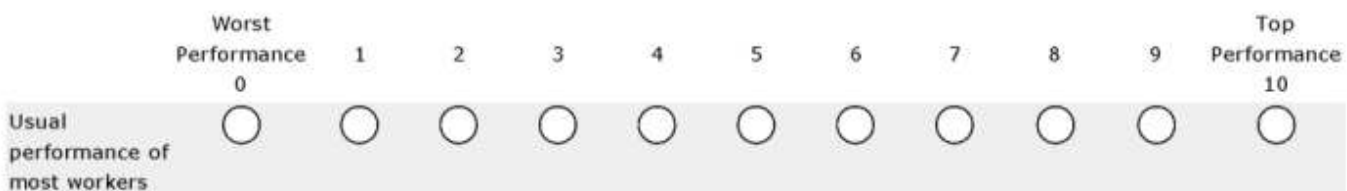

most workers

B12. Using the same 0-to-10 scale, how would you rate your usual job performance over the past year or two?

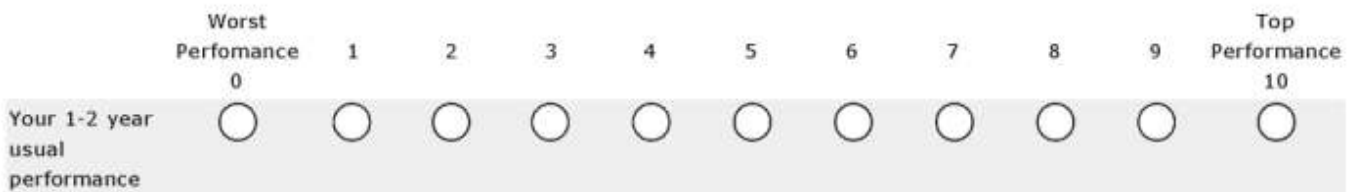

B13. Using the same 0-to-10 scale, how would you rate your overall job performance on the days you worked during the past 4 weeks ( 28 days)?

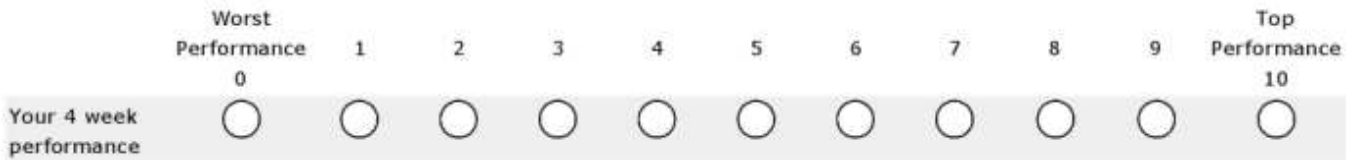




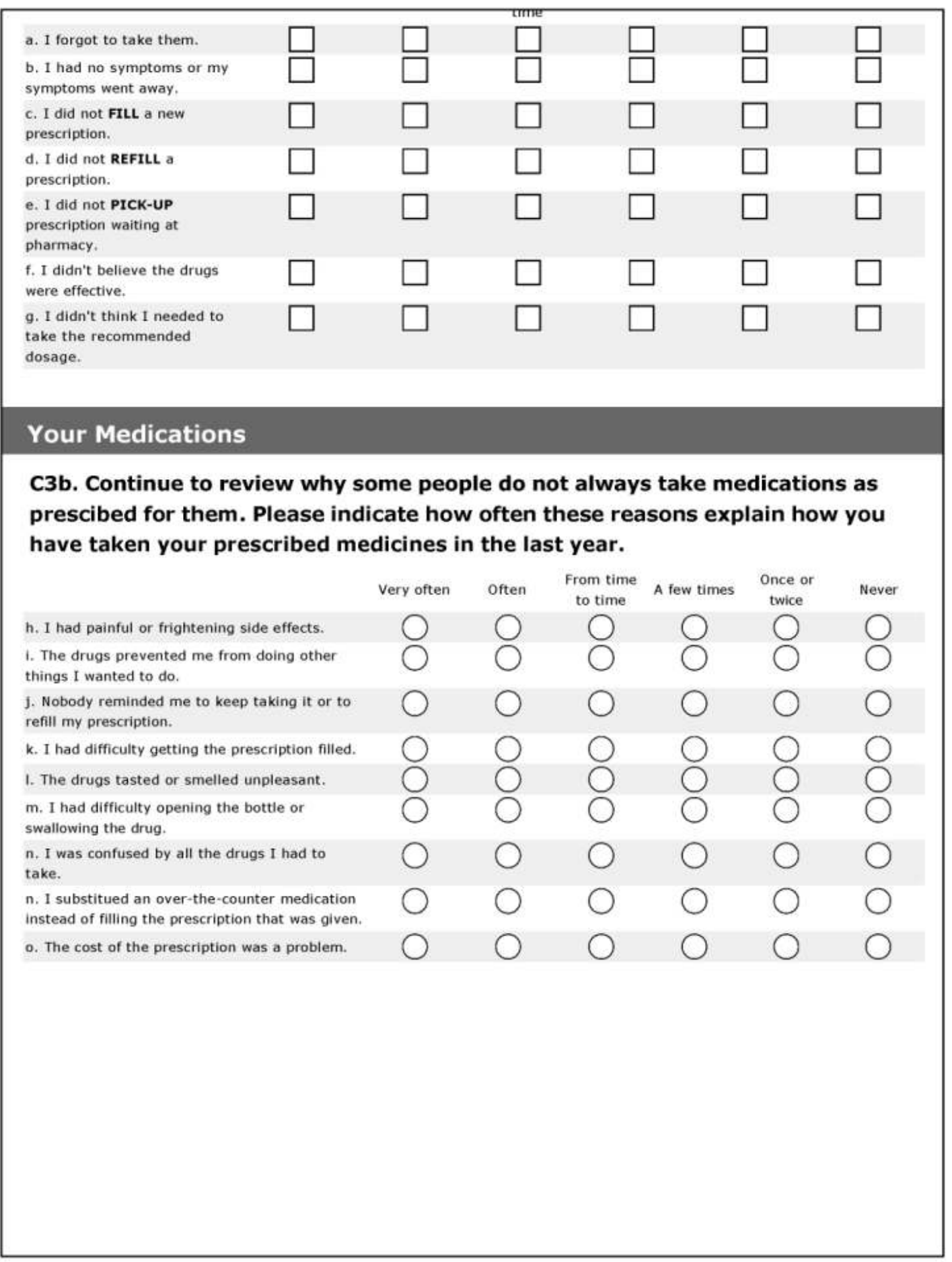




\section{Health Impact on Work}

The following question is about the effect of health conditions on your ability to work and perform. By health conditions we mean any ill physical or emotional conditions or symptoms.

Consider only how much health conditions affected productivity while you were working. Think about whether there were days you were limited in the amount or kind of work you could do, days you accomplished less than you would like, or days you could not do your work as carefully as usual.

B14. How much did your health conditions affect your productivity while you were working during the past 4 weeks ( 28 days)? If health conditions affected your work only a little, chose a low number. Choose a high number if health conditions affect your work a great deal.

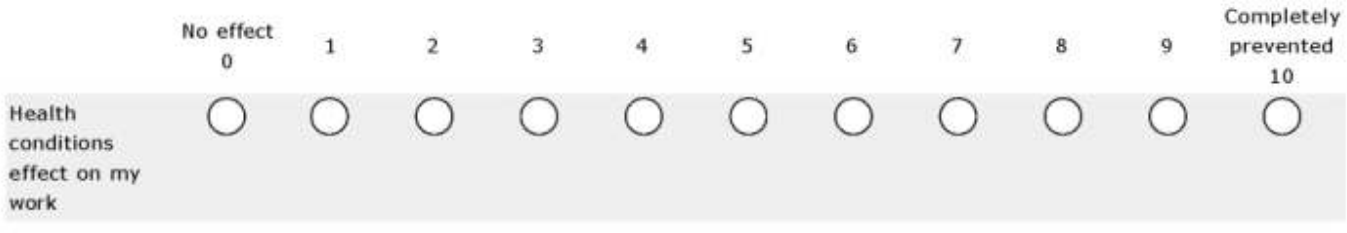

\section{YOUR PERSONAL HEALTH CARE}

Part III: This section is about the personal health care you recieve.

C1. During the past 12 months, have you been prescribed medications that you are to take on a regular basis?

a. Yes

b. No (Skip to question C4)

c. Not sure/can't remember (Skip to question C4)

C2. How many different prescribed medications do you take on a regular basis?
a. $1-2$
b. $3-5$
c. $\geq 6$

C3a. Please review this list of why some people do not always take medications as prescibed for them. Please indicate how often these reasons explain how you have taken your prescribed medicines in the last year. 


\section{Your Personal Providers}

\section{C4. Who is your regular health care provider?}

Do not have one (Skip to question C7)

Family practitioner

Internist

OB/GYN or gynecologist

$\bigcirc$ other medical specialist

Physician assistant

Nurse practitioner

Don't know

\section{C5. Is your regular health care provider a man or woman?}

1. Man

2. Woman

3. Don't know

\section{C6. What is your regular provider's racial or ethnic background?}

a. American Indian \& Alaskan Native

b. Asian

c. Black/African American

d. Hispanic/Latino (all races)

e. Native Hawaiin and Pacific Island

f. White/European American

g. Other (please specify) 


\section{Your Use of Services}

For the following questions, include only visits regarding your own health, not visits when you took someone else to be examined.

C7. During the past 12 months, how many times did you see a health professional, hospital, or clinic for a routine physical check-up or gynecological exam (not counting pregnancy related care)?

* of times $(000-365)$

C8. During the past 12 months, how many times did you see a dentist or hygienist for a routine dental check-up or exam?

* of times(000-395)

C9. During the past 12 months, how many times did you see a health professional, emergency room, or clinic for urgent care treatment (for example, because of new symptoms, an accident, or something else unexpected)?

\# of times (000-365)

C10. During the past 12 months, how many times did you see a nurse practitioner or physician assistant in a convenience clinic, retail based mini-clinic, or other outpatient office/clinic for treatment of minor acute episodic health conditions.

* of times (000-365)

C11. During the past 12 months, how many times did you see a psychiatrist, psychologist, clinical social worker, psychiatric nurse, counselor, or other mental health professional?

* of times (000-365)

C12. During the past 12 months, how many times did you see a pharmacists about your medications to ask questions or express concerns about dosage, side effects, uses, substitutions, etc.?

$t$ of times $(000-365)$ 


\section{Your Available Services}

C13. In the last 12 months, have you left a provider's office and not remembered or understood some of the information given to you?

1. Yes

2. No

3. Do not know

C14. In the last 12 months, when seeing a health care provider, did the provider usually take the time to answer all of your questions?

1. Yes

2. No

3. Don't know

C15. In the last 12 months, was there ever a time when any of the circumstances below applied to you? When you...

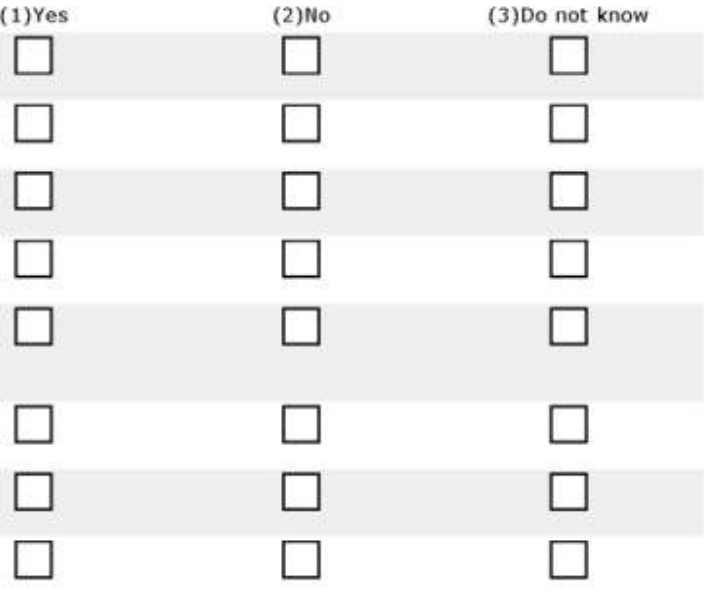

a....had a health condition and needed to see a provider but did not see one.

b....were not able to see a specialist when you thought you needed one.

c...felt you did not have enough personal contro over decisions affecting your own health care.

d. ...had concerns about the quality of care you received.

e. ...had difficulty getting care because there were

not enough providers or clinics located

conveniently.

f. ...tried to see a new provider but could not because the provider was not taking new patients.

g. ....wanted to see a provider but couldn't easily take time off work.

h. ... didn't see a provider because you couldn't afford to pay your portion of costs for the visit.

C16. During the past 12 months, what kind of place have you USUALLY gone to when you needed routine or PREVENTIVE CARE, such as a physical examination or check-up?

a. Clinic or health center

b. Health provider's office or HMO

c. Hospital emergency room

d. Hospital outpatient department

e. Urgent Care clinic or minor medical center 


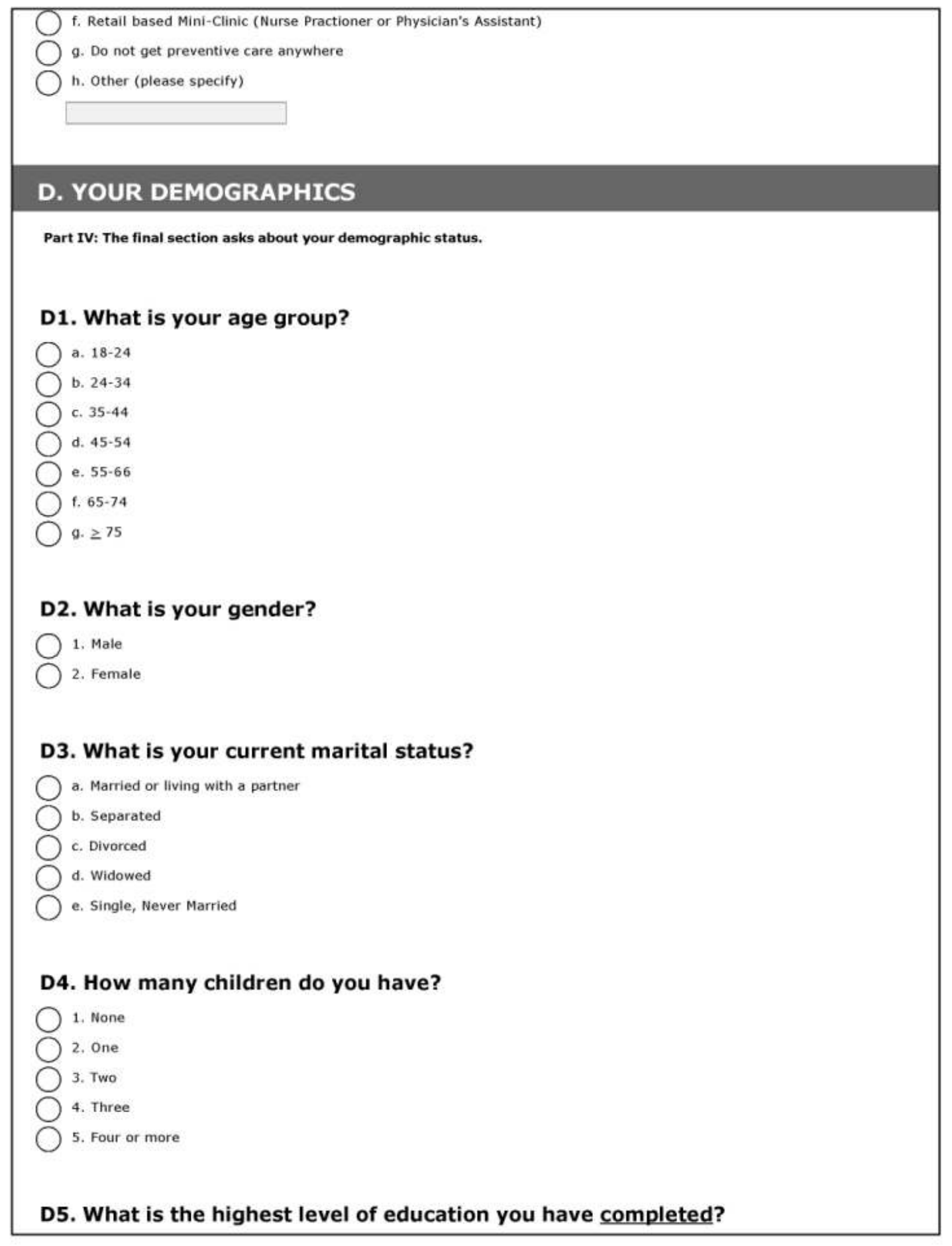




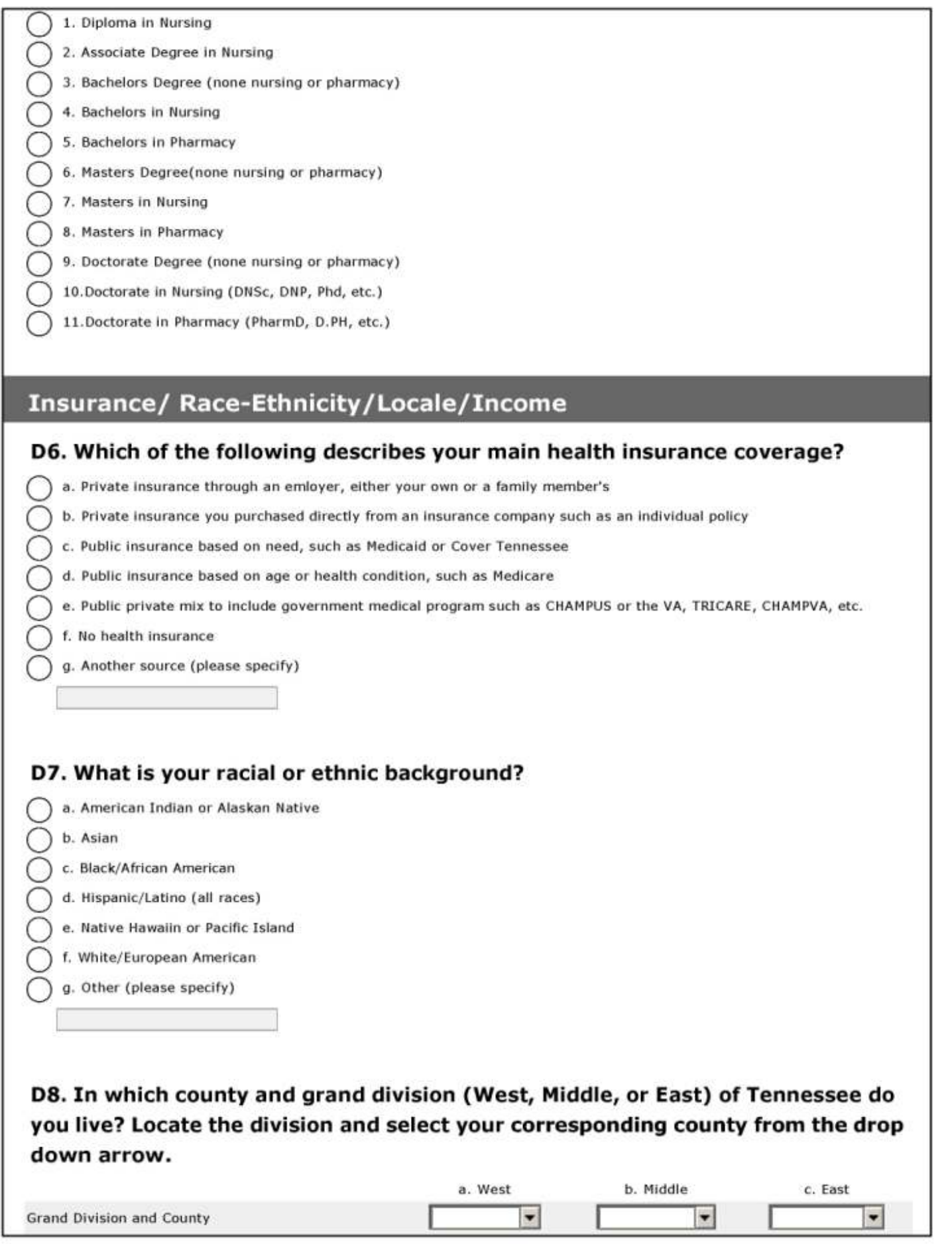


D9. What is your annual income from your main job, before taxes? (Reminder: this information cannot be linked to you as an individual and this income detail is essential for calculating the impact of health conditions on costs).

Income from Main Job

Annual Income Before Taxes

\section{End}

THE ENDI You have just completed the Wellness-At-Work Survey for the HeaithCare Workforce. We appreciate your interest and participation in the study. Thank you for your time and patience. 


\section{INTRODUCTION}

\section{PARTICIPANT INFORMATION \& CONSENT}

Welcome to the Wellness-At-Work Survey for the HealthCare Workforce. You are invited to participate in this study if you are:

1. A licensed Nurse or Pharmacist in the State of Tennessee.

2. Currently working for pay in healthcare.

3. Not currently on leave from work.

Participation in this survey involves supplying information about your health, work, health care, and general status. This survey takes approximately 15-20 minutes to complete.

You will be asked demographic information, but neither your name nor other individually identifiable information will be asked. Your informed consent is given by choosing to proceed to the next screen and respond to the survey questions.

PURPOSE:

The purpose of the research is to examine how health care costs and professional productivity are impacted when a healthcare workforce remains on the job while experiencing certain health conditions. Findings are expected to have implications for healthcare employers/payers, professional associations, practice models, policies and health systems.

VOLUNTARY and CONFIDENTIAL:

You are not required to participate in this research. You may stop at any time. This research is not part of any group or specific employer-related effort. Your answers will only be reported as group information. This on-line survey is on a secured website.

RISKS and BENEFITS:

There are no anticipated risks to participating in this study. No portions of the survey should cause distress.

Personal and professional gratification are benefits to participating in the survey. The survey offers nurses and pharmacist opportunities to contribute data which lends itself to understanding factors which impacts health at the personal, professional, organizational levels.

CONTACT INFORMATION:

The findings from this research will be reported as part of a dissertation study. Questions about the study can be directed to:

Carol Warren-Blakemore, APRN-BC, MBA, PhD Candidate

College of Graduate Health Sciences

Health Outcomes and Policy Research (HOPR)Program

cwarren2@utmem.edu

(901) 448-3932

or

Dr. Shelley White-Means, Phd

Professor \& Vice Chair, Dept of Pharmaceutical Sciences

Chair, Health Outcomes and Policy Research (HOPR)

swhiteme@utmem.edu

(901) 448-7666

This study is approved through the

University of Tennessee Health Science Center

Institutional Review Board

Approval date __october 11, 2007

Click "Next" if you agree to participate and want to get started. If you'd like to leave the survey at any time, just click "Exit this survey". 


\section{APPENDIX B. SURVEY TOOL LOGIC CROSSWALK}

Table B-1 Survey Tool Logic Crosswalk

\begin{tabular}{|c|c|c|c|c|}
\hline Нур & otheses & Key Variables ${ }^{1}$ & $\begin{array}{l}\text { Questions from Published } \\
\text { Surveys }^{2}\end{array}$ & $\begin{array}{l}\text { Corresponding } \\
\text { Wellness-at-Work } \\
\text { Survey Questions }\end{array}$ \\
\hline \multirow{10}{*}{1.1} & Primary & Dependent & Presenteeism & B10 Presenteeism \\
\hline & There are no & - Presenteeism & $\mathrm{B} 10-\mathrm{HPQ}^{3}$ & priming question \\
\hline & prevalence of & Independent & $\mathrm{B} 11-\mathrm{HPQ}^{3}$ & B13 ( Presenteeism \\
\hline & presenteeism among & - Profession/Occupation & & measure \#1) \\
\hline & nurses and & ○ nurse & 5 - WPAI-GH ${ }^{4} *$ & \\
\hline & $\begin{array}{l}\text { pharmacists nor does } \\
\text { it vary across }\end{array}$ & ○ pharmacist & & $\begin{array}{l}\text { B14 (Presenteeism } \\
\text { measure \#2) }\end{array}$ \\
\hline & racial/ethnic groups & - Race/ethnicity & & \\
\hline & of both professions. & o Minority & Profession/Occupation & $\mathrm{B} 1, \mathrm{~B} 4, \mathrm{~B} 5, \mathrm{D} 5$ \\
\hline & & ○ Non-minority & $\mathrm{B} 1-\mathrm{HPQ} \dagger$ & \\
\hline & & & $\begin{array}{l}\text { Race/Ethnicity } \\
\text { C9 - HPQ }\end{array}$ & D7 \\
\hline \multirow[t]{7}{*}{2.1} & There are no & Dependent & $\operatorname{Costs}^{6}$ & D9, B13 \\
\hline & differences in & - Costs burden & $\mathrm{C} 8, \mathrm{~B} 11-\mathrm{HPQ}^{\ddagger}$ & (Costs, consistent \\
\hline & indirect cost burden & ○ Median salary & & with HPQ, \\
\hline & of presenteeism & ○ By race & & determined using \\
\hline & among nurses and & $\circ$ By profession & & human capital \\
\hline & $\begin{array}{l}\text { pharmacists across } \\
\text { racial/ethnic groups }\end{array}$ & - Level of presenteeism & & approach -HCA ) \\
\hline & of professions. & & & D9, B14 \\
\hline
\end{tabular}


Table B-1. (continued)

\begin{tabular}{|c|c|c|c|}
\hline Hypotheses & Key Variables ${ }^{1}$ & $\begin{array}{l}\text { Questions from Published } \\
\text { Surveys }^{2}\end{array}$ & $\begin{array}{l}\text { Corresponding } \\
\text { Wellness-at-Work } \\
\text { Survey Questions } \\
\end{array}$ \\
\hline 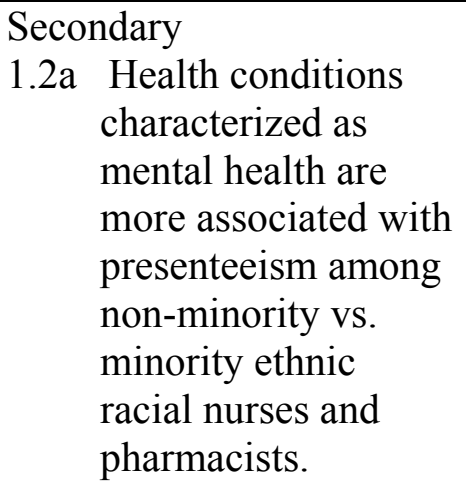 & $\begin{array}{l}\text { Independent } \\
-\quad \text { Health conditions } \\
\circ \text { mental health } \\
-\quad \text { conditions } \\
-\quad \text { symptoms }\end{array}$ & $\begin{array}{l}\text { Conditions } \\
\text { A3-A6 - HPQ }\end{array}$ & $\begin{array}{l}\mathrm{A} 3(1), \mathrm{A} 4, \\
\mathrm{~A} 5\end{array}$ \\
\hline $\begin{array}{c}\text { 1.2b Health conditions } \\
\text { characterized as } \\
\text { physical health are } \\
\text { more associated with } \\
\text { presenteeism among } \\
\text { minority versus non- } \\
\text { minority } \\
\text { racial/ethnic nurses } \\
\text { and pharmacists. }\end{array}$ & $\begin{array}{l}\text { Independent } \\
-\quad \text { Health conditions } \\
\circ \text { mental health } \\
\text { - } \text { conditions } \\
- \text { symptoms }\end{array}$ & $\begin{array}{l}\text { Conditions } \\
\text { A3-A6 - HPQ }\end{array}$ & $\begin{array}{l}\mathrm{A} 3(1), \mathrm{A} 4, \\
\mathrm{~A} 5\end{array}$ \\
\hline $\begin{array}{l}\text { 1.3a Under-treated health } \\
\text { conditions associated } \\
\text { with presenteeism in } \\
\text { both nurses and } \\
\text { pharmacists. }\end{array}$ & $\begin{array}{l}\text { - Previous treatment } \\
\quad 0 \text { professional treatment } \\
\circ \text { pharmacotherapy } \\
\text { treatment }\end{array}$ & $\begin{array}{l}\text { Treatment } \\
\text { A3-A6 - HPQ }\end{array}$ & $\mathrm{A} 3(2), \mathrm{A} 3(3)$ \\
\hline
\end{tabular}




\begin{tabular}{|c|c|c|c|}
\hline Hypotheses & Key Variables ${ }^{1}$ & $\begin{array}{l}\text { Questions from Published } \\
\text { Surveys }^{2}\end{array}$ & $\begin{array}{l}\text { Corresponding } \\
\text { Wellness-at-Work } \\
\text { Survey Questions }\end{array}$ \\
\hline $\begin{array}{l}\text { varies across racial/ethnic } \\
\text { groups } \\
\text { 1.3b Health conditions } \\
\text { treated by providers } \\
\text { are more associated } \\
\text { with presenteeism } \\
\text { than conditions } \\
\text { treated by pharma- } \\
\text { cotherapy; this does } \\
\text { not vary across } \\
\text { professions or } \\
\text { racial/ethnic groups. }\end{array}$ & $\begin{array}{l}\text { Under-treatment } \\
-\quad \text { Previous Treatment }\end{array}$ & $\begin{array}{l}\text { Under-treatment }^{6} \\
\text { A3 - A6 }\end{array}$ & $\begin{array}{l}\text { A3a-k previous } \\
\text { professional and } \\
\text { pharmacotherapy } \\
\text { treatment } \\
\text { C1-yes }\end{array}$ \\
\hline $\begin{array}{cc}* & \text { Changed order of senter } \\
\dagger & \text { Adapted and added so tl } \\
& \text { WPAI-GH does not hav } \\
\S & \text { added pharmacotherapy } \\
1 & \text { Only key variables are } \\
2 & \text { Presenteeism scales fro } \\
\text { the other from the Wor } \\
\text { from a Harris Interactiv } \\
\text { adapted from the Adult } \\
\text { The HPQ presenteeism } \\
\text { scale. For both measure } \\
\text { norm. Presenteeism is } \\
\text { and WPAI presenteeisn }\end{array}$ & $\begin{array}{l}\text { ces in instructions and terr } \\
\text { at items applied to a healtl } \\
\text { a cost or monetizing com } \\
\text { s a treatment option } \\
\text { dentified. All confounders } \\
\text { a two different surveys are } \\
\text { Productivity and Activity } \\
\text { On-line Survey. General } \\
\text { Access to Health Care \& I } \\
\text { neasure is a } 10 \text { point ratin } \\
\text {, we will consider each pc } \\
\text { global measure, therefore }\end{array}$ & $\begin{array}{l}\text { oblem' to 'health conditions } \\
\text { orce } \\
\text { ariables were be fully specif } \\
\text { from Health and Productivi } \\
\text { t-General Health (WAPI-GH } \\
\text { ic and quality of care questic } \\
\text { todules of the National Heal } \\
\text { e WPAI-GH presenteeism } 1 \\
0 \text { scales equal to a } 10 \% \text { decr } \\
\text { eeism will be reported as HI }\end{array}$ & $\begin{array}{l}\text { Methods chapter. } \\
\text { tionnaire (HPQ) and } \\
\text { lication compliance is } \\
\text { key variables) are } \\
\text { view Survey (NHIS). } \\
\text { is a } 10 \text { point rating } \\
\text { n productivity from the } \\
\text { enteeism measure-1 }\end{array}$ \\
\hline
\end{tabular}


Table B-1. (continued)

5 The human capital approach is used to in estimating cost or monetizing presenteeism. The most common monetizing approach is the HCA or human capital approach. It states loss is the product of self-reported productivity decrements multiplied by salaries (sometimes actual salaries of the respondents or mean salaries of a corporation, or mean salaries). Consistent with economic theory that assumes perfectly competitive labor markets) that wages reflect worker's marginalcontribution to a firm's output, salaries should reflect a worker's marginal contribution to a firm's output. HCAprovides a least a lower-bound estimate for the true cost of lost productivity. There is consensus that HCA provides a lower bound estimate of a firms true cost production (Kessler et al., 2005; Mattke, 2007).

6 Under-treatment occurs when a person continues to experience ill health and decrements in work productivity even after undergoing treatment (Kessler \& Stang, 2006).

7 National Council on Patient Information and Education's (NCPIE) acknowledged confusion over 'common terms': compliance, adherence, persistence, and concordance - all used to define the act of seeking medical attention, filling prescriptions and taking medicines appropriately (NCPIE, 2007). 


\section{APPENDIX C. INSTITUTIONAL REVIEW BOARD APPROVAL}

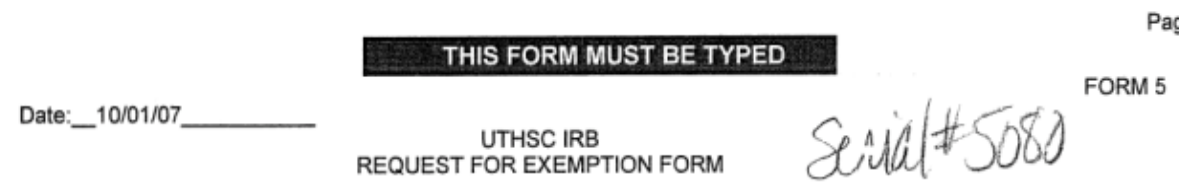

PROPOSAL TITLE: _Cost Burden of Presenteeism in a Diverse Healthcare Workforce: Practice, Health System and Policy Implications

INVESTIGATOR:__Carol Warren-Blakemore

DEPARTMENT \& SCHOOL:_Graduate Health Sciences, Health Outcomes and Policy Research _tELEPHONE \#:_901 448-3932_faX\#__901 448-4121

ADDRESS: 877 Madison, Suite 633 E-MAIL:_cwarren2@utmem.edu

FUNDING SOURCE (SPONSOR):

STUDY SITE(S): University of Tennessee Health Science Center

(Answer all items, attach separate sheets as necessary)

1. PURPOSE OF THE STUDY:

The purpose of the research is to examine the prevalence and impact of certain heath conditions on employer cost burden and employee work productivity in a diverse healthcare workforce. Findings are expected to have implications for healthcare employers, health professional associations, health policies and systems, and health practice models.

2. DESCRIPTION OF SUBJECT POPULATION AND METHOD(S) OF SUBJECT RECRUITMENT:

(Include an explanation how recruitment of subjects is intended to satisfy NIH or FDA requirements for the inclusion of women, racial/ethnic groups and children in human subjects research).

This is an on-line survey of approximately 70,000 total population of licensed pharmacists and nurses in Tennessee. A combination of mailing and online distribution of the survey link will be performed until a representative sample of a diversity of participants have responded to the survey. Announcement of the survey will be distributed on-line through the Tennessee Nurses Association (TNA) or the Tennessee Pharmacy Association (TPA) as the first option. In addition to a mailing, if needed, professionals may voluntarily access a special link to a secured website Survey Monkey in order to complete the survey.

3. DESCRIPTION OF PROCEDURES:

(Attach copies of surveys, questionnaires, etc.)

1. Mailing lists of TNA and TPA are obtained.

2. An announcement describing the purpose of the research is distributed to the professional associations.

3. TNA and TPA are asked to publish the survey announcement and the survey tool link.

4. When participants access the survey tool web site, they are supplied information to consent to the survey and asked to complete the survey.

5. Survey results will be compiled for statistical analyses.

6. Implications of the findings will be reported.

4. RATIONALE FOR EXEMPT STATUS: Explain why the study as described falls under a specific exemption category as outlined in the instructions for Form 5.

This study qualifies under $\mathrm{C} 2$ because the research involves the use of survey procedures, interview procedures or observation of public behavior and does not involve the following: (i) the information obtained is recorded in such a manner that human subjects can be identified, directly or indirectly through identifiers 
linked to the subjects; AND (ii) any disclosure of the human subjects' responses outside the research could reasonably place the subjects at risk of criminal or civil liability or be damaging to the subjects' financial standing, employability, or reputation.

a. The study does not involve "research" as defined in the regulations.

b. The study does not use "human subjects" as defined in the regulations.

(i) All data or specimens are from deceased persons.

(ii) No data or specimens can be linked to identifiable individuals.

c. The study qualifies for exempt status under 45CFR46.101(b).

(Indicate category (b)(1) or (b)(2), etc.)

$-\sqrt{ }(b)(2)$

6. INFORMED CONSENT: Informed consent is generally required for an exempt study unless it cannot practicably be carried out without a waiver of consent. Please check the appropriate box.

a. The study cannot practicably be carried out without a waiver of consent.

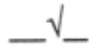

b. The study can be undertaken even if informed consent is required.

If line (a) is checked, briefly explain below why the study cannot practicably be carried out without a waiver of consent. If the study involves the use of protected health information, also complete Form 8 to request the use of protected health information without subject authorization.

The study is a survey distributed electronically. Once a participant accesses the survey and starts the survey, consent is assumed to be given.

If line (b) is checked, briefly describe below the plan to secure and document the informed consent of subjects. Attach the informed consent document to the application.

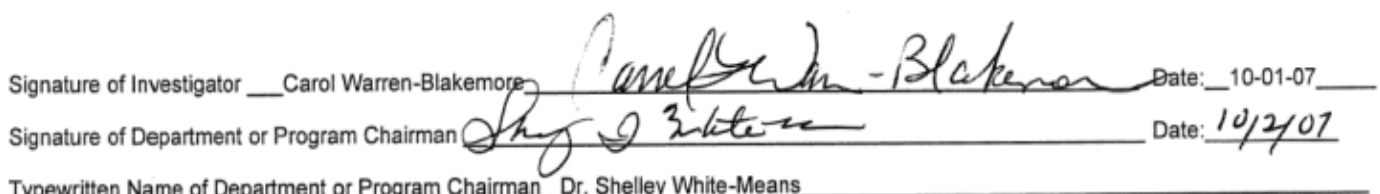

Typewritten Name of Department or Program Chairman_Dr. Shelley White-Means

(The IRB reserves the right to request the investigator to provide additional information concerning the proposal.)

Submission requires original and 2 copies.

DO NOT WRITE BELOW THIS LINE

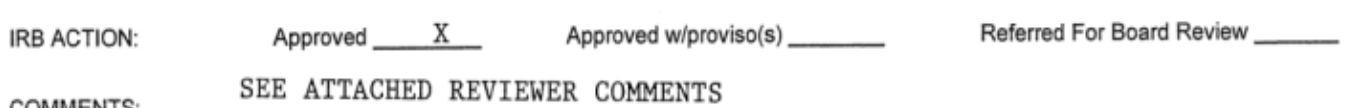

COMMENTS

SEE ATTACHED REVIEWER COMMENTS

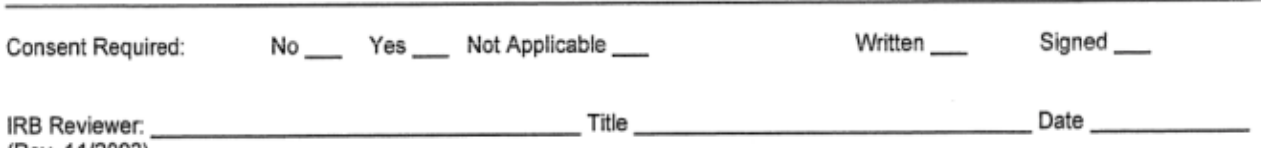


$\begin{array}{ll}\text { Principal Investigator: } & \text { Carol Warren-Blakemore } \\ \text { Brief Project Title: } & \text { Cost Burden of Presenteeism in a Diverse Healthcare Workforce: Practice, } \\ \text { Health System and Policy Implications }\end{array}$

IRB ACTION: $\quad$ Approved __ _ _ Approved w/proviso(s) _ _ Referred For Board Review

COMMENTS: This study qualifies for exempt status under 45CFR46.101(b)(2). In accord with 45CFR46.116(d), informed consent may be altered with the consent cover statement used in lieu of a consent interview. The requirement to secure a signed consent form is waived under 45CFR46.117(c)(2).

Consent Required: No: * Yes: Not Applicable: Written

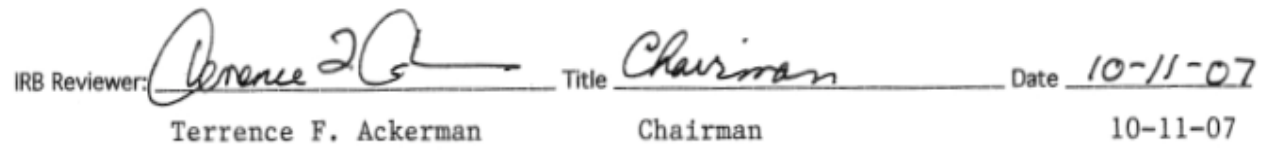




\section{VITA}

Carol L. Warren was born in Memphis, Tennessee on January 19, 1953. She was awarded a Bachelor of Science degree in Medical-Social Welfare in 1976 and a Master of Science in Social Work from the University of Tennessee in 1978, both in Knoxville, Tennessee. In 1985, she earned an Associate in Nursing from Shelby State Community College (now Southwest Community College), and in 2002 she was awarded a Masters in Business Administration from Belhaven College, also both in Memphis, TN. Carol earned a Doctor of Philosophy in Health Outcomes and Policy Research from The University of Tennessee Health Science Center in May 2009. 